\title{
Capital Humano como fuente de ventajas competitivas. Algunas reflexiones y experiencias
}





\section{Capital Humano como fuente de ventajas competitivas. Algunas reflexiones y experiencias}

Ma Ángeles López Cabarcos - Antonio Grandío Dopico (Coords.) 
CAPITAL HUMANO COMO FUENTE DE VENTAJAS COMPETITIVAS. ALGUNAS REFLEXIONES Y EXPERIENCIAS

No está permitida la reproducción total o parcial de este libro, ni su tratamiento informático, ni la transmisión de ninguna forma o por cualquier medio, ya sea electrónico, mecánico, por fotocopia, por registro u otros métodos, sin el permiso previo y por escrito de los titulares del Copyright.

DERECHOS RESERVADOS 2005, respecto a la primera edición en español, por

(C) Netbiblo

ISBN: 84-9745-119-8

Depósito Legal: C-2485-2005

Editor: Carlos Iglesias

Producción Editorial: Gesbiblo, S.L.

Impreso en España-Printed in Spain. 


\section{Contenido}

Prólogo

1 Los Recursos Humanos en la empresa. ¿Cómo llegar a la persona? ................... 1

1. La estrategia y el valor de la empresa.................................................................. 3

2. La importancia de gestionar el valor que no se ve.............................................. 3

3. La dirección por valores................................................................................... 5

3.1.Actitud apasionada ....................................................................................... 8

3.1.1. Motivación y empresa.................................................................... 9

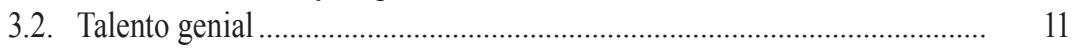

3.2.1. El valor de la creatividad ................................................................ 13

3.3. Patrón de valores ................................................................................... 16

3.3.1. La gestión ética en la empresa...................................................... 17

3.3.2. Normalización en el campo de la ética.......................................... 20

3.3.3. La Norma SA8000: Certificación de la gestión ética .................... 23

4. Conclusiones ................................................................................................ 24

Bibliografía ...................................................................................................... 24

2 Capital Humano: Medición y gestión …………………………………………... 29

1. Introducción .................................................................................................... 31

2. Capital Intelectual ..................................................................................... 31

2.1.Cuadro de Mando Integral ....................................................................... 36

2.2. Modelo Technology Broker...................................................................... 39

2.2.1. Activos de infraestructura ............................................................. 42

2.3. Intelectual assets monitor......................................................................... 42

2.4. Modelo Intelect ..................................................................................... 50

2.4.1. Elementos componentes del modelo y estructuración ................... $\quad 52$

2.5. Navigator Skandia .................................................................................... 55

3. Capital Humano …............................................................................................. $\quad 59$

4. Conclusiones …......................................................................................... 64

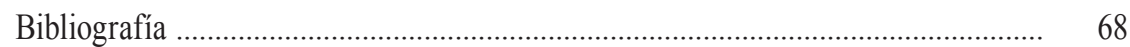

Anexo. Indicadores de Unión Fenosa...................................................................... 73

3 La dirección por implicación (DPI): Cómo implantar el cambio estratégico en la empresa para competir en base al Capital Humano .................................. 75

1. El reto estratégico de las organizaciones del siglo XXI: Adecuarse para competir en base al talento

1.1. Las empresas deberán de adaptarse a la Sociedad del Conocimiento, que es algo más que la Sociedad de la Información 
1.2. Los nuevos tiempos demandan un nuevo concepto de estrategia:

Integración y cambio.

1.2.1. La estrategia como integración de futurización y planificación

1.2.2. Integración de la estrategia intencional y de lo emergente.

1.2.3. La estrategia como integración de lo técnico y de lo humano

1.2.4. Para muchas empresas, una función clave de la dirección estratégica debe ser dirigir el cambio estratégico.

2. Una tipología de empresas en base a su capacidad para liberar,

desarrollar y aplicar el talento de sus empleados

2.1. La empresa como una combinación de personas y tecnologías:

La matriz T-H de estilos de dirección.

2.2. Características de los tipos de empresa de referencia

3. Hacia la DPI: La ruta ideal del cambio estratégico

3.1. La DPI como vía de creación de ventajas competitivas

sostenibles basadas en el Capital Intelectual

3.2. La ruta ideal del cambio estratégico

4. El ¿qué? del cambio: Un modelo explícito para los procesos de profesionalización y de renovación de la empresa

4.1. Los modelos explícitos como herramienta para determinar el contenido del cambio.

4.2. Contenido del cambio (el ¿qué?): El Trípode

del cambio estratégico.

4.2.1. La mejora de la competitividad como objetivo del cambio estratégico

4.2.2. Identificación de los grandes grupos de factores que causan la competitividad: El "Trípode del cambio estratégico"

5. El cómo del cambio: Los mapas del cambio estratégico .

5.1. La estructura organizativa para el cambio estratégico:

Los equipos de mejora y la espiral de aprendizaje

5.2. Hacia la empresa inteligente: El concepto de mejorable

y su papel en la mejora sistemática

5.3. Los mapas del cambio estratégico

5.3.1. El contenido del mapa del cambio estratégico:

Conocimiento sobre el análisis de la situación actual

5.3.2. El contenido del mapa del cambio estratégico:

Conocimiento sobre las acciones de mejora. 
6. El proceso de implantación de la DPI

6.1. El modelo del cambio estratégico en seis etapas ........................................ 117

6.1.1. Fase 1. Avance de la declaración de la visión................................... 118

6.1.2. Fase 2. Análisis y prediseño .......................................................... 118

6.1.3. Fase 3. Declaración de la visión y diseño ....................................... 119

6.1.4. Fase 4. Comunicación ..................................................................... 120

6.1.5. Fase 5. Elaboración .................................................................... 120

6.1.6. Fase 6. Implantación ...................................................................... 121

6.2. Cómo la metodología propuesta garantiza el funcionamiento de la espiral personas-equipos-organización durante el proceso de implantación del cambio

6.2.1. Iniciación del proceso: Partir del CTP ........................................... 123

6.2.2. Creación de conocimiento explícito personal.................................. 123

6.2.3. Creación de conocimiento explícito organizativo ............................ 123

6.2.4. Creación de conocimiento tácito organizativo ................................. 123

Bibliografía.

4 La adopción de la perspectiva de los recursos ( $R B V)$ como enfoque dominante en la Economía de la Empresa ............................................................ 127

1. Introducción ............................................................................................... 129

2. De los recursos, capacidades y competencias .................................................. 129

3. La adopción del enfoque RBV como perspectiva dominante en la Economía de la Empresa ........................................................................... 131

4. Conclusiones …................................................................................................. 137

Bibliografía................................................................................................ 138

5 Una apuesta por la creación de Capital Intelectual:

La Escuela de Negocios Caixanova ....................................................................... 145

1. Introducción ............................................................................................... 147

2. Los antecedentes .......................................................................................... 147

3. Capital Intelectual y desarrollo empresarial...................................................... 148

4. La puesta en marcha del proyecto....................................................................... 151

5. Una escuela pionera en la formación de directivos .............................................. 151

6. Las distintas áreas de actividad ........................................................................ 152

6.1. La formación de Postgrado ......................................................................... 152

6.2. Formación de grado: El BBA .................................................................. 153

6.3. Formación de directivos.......................................................................... 154

6.4. La Escuela para las Administraciones Públicas ........................................ 156

6.5. La actividad investigadora ................................................................. 156

6.6. El proceso de internacionalización .......................................................... 157 
7. Los rasgos de una estrategia marcada por el compromiso .................................. 158

7.1. Escuelas de Negocios y Negocios de Escuela............................................. 158

7.2. Formación para la acción: Un centro de entrenamiento de directivos

7.3. Una formación para cada etapa en la vida de un directivo.......................... 159

7.4. Una estrategia "glocalizada": La mejor escuela de negocios del mundo para Galicia .......................................................................... 160

7.5. Las clases son la consecuencia.................................................................. 161

7.6. Orientación al valor: Integración con las empresas e instituciones.............................................. 161

7.7. Un modelo comprometido: Mucho más que acercar formación de primer nivel a Galicia, crear conocimiento desde y para Galicia............... 161

7.8. La apuesta por el Capital Humano: "Todos somos tripulación”................. 162

Anexo 1. Principales hitos en la historia de la Escuela de Negocios Caixanova.

Anexo 2. Información general de la Escuela de

Negocios Caixanova

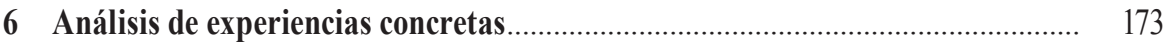

1. A modo de prólogo ........................................................................................ 175

2. Gobierno de la empresa ....................................................................................... 175

3. Ejemplo de estrategias bien concebidas................................................................ 178

4. Un posible método de análisis y alguna consideración final................................ 181 


\section{PRÓLOGO}

Es la primera vez que tengo el honor de prologar un libro y lo afronto con sumo agrado porque me va a permitir-desde mi libertad-reflexionar sobre lo que considero justifica la mayor parte -sino todos- los éxitos o fracasos de las organizaciones empresariales. Han sido años y años los dedicados a idear las máquinas más sofisticadas, a diseñar los procesos menos costosos, o a crear los productos más novedosos... y ¡no ha sido suficiente! Es ahora cuando algunos se han dado cuenta (muchos no lo harán jamás) de que es en las personas donde reside la posibilidad de triunfar o de fracasar.

Ha sido (y aunque sigue siéndolo, yo prefiero expresarlo en pasado) muy habitual que las organizaciones fijasen como objetivo principal la consecución de beneficios, lo que ha llevado a considerar determinados comportamientos como meros instrumentos para la consecución del mismo. Con un planteamiento así se corre el riesgo, y así ha ocurrido, de conculcar los derechos, no sólo de las personas, sino de otras organizaciones. Cualquier empresa está obligada a respetar los derechos de sus miembros y no puede atropellarlos aduciendo que su meta es lograr un beneficio económico expresado en la cifra de resultados. La organización ha de obtener legitimidad social. Para ello, a la vez que produce los bienes o servicios que se esperan de ella, debe respetar los derechos reconocidos por la sociedad en la que vive, así como los valores que esa sociedad comparte.

$\mathrm{Al}$ introducir argumentaciones de tipo social se inicia un debate muy interesante y necesario, aunque tremendamente complicado de resolver. Nadie duda de que los valores imperantes en la sociedad actual han cambiado. Si es así, ¿es este el hecho que ha posibilitado cambios en el comportamiento demostrado por las empresas? o ¿son los valores sociales los que se han visto afectados como consecuencia del injustificado y generalizado cinismo económico? Lo cierto es que la sociedad que hemos ido creando entre todos invita al culto al ego y valora como más importante el dinero, el éxito y la posición, premia sobremanera a los que por una u otra razón, de una u otra forma, "alcanzan el éxito"; y castiga, también de forma desmesurada, a los que se "quedan atrás" o fracasan, pudiendo suceder ambas cosas en un margen de tiempo asombrosamente breve. El éxito de uno supone el fracaso de otro. Reina una especie de "hipocresía cotidiana" a la que hemos aprendido a acomodarnos todos. No existen problemas de conciencia, perfectamente puede pensarse de una manera, argumentarse de otra y actuar de otra completamente distinta. Sin ánimo de dramatizar, en un contexto como el descrito la persona en su condición de tal queda diluida y su consideración histórica de "recurso" se mantiene y engrandece. ¿Dónde quedan entonces las argumentaciones sobre promoción del desarrollo humano o crecimiento profesional y personal? 
La obsesión desmesurada por el resultado conduce a las organizaciones a que se centren en cuestiones que poco o nada tienen que ver con la persona, con su componente emotivo o afectivo. Muy al contrario de la creencia generalizada, aquellas organizaciones que se preocupan por el bienestar, la salud y la felicidad de sus miembros obtienen mejores resultados y tienen menos conflictos que aquellas otras que gestionan a las personas en base a la amenaza, el "ordeno y mando" o la presión. La lealtad no se compra, la lealtad, como otros de los muchos valores importantes de la vida, se gana. El valor de una organización que consigue ganarse la lealtad de sus miembros puede ser incalculable... ; y los estados contables o el mercado sin saberlo, sin percatarse siquiera de ello!

La actividad empresarial debe contemplar un análisis reflexivo desde el punto de vista de los valores humanos y de los comportamientos justos. Afortunadamente, se avanza aunque de forma muy lenta hacia un concepto de organización que sabe combinar su fuerza en el mercado con la sensibilidad ante las necesidades de sus Recursos Humanos. Flexible pero altamente competitiva, capaz girar en redondo si la ocasión así lo exige y cuyo fin último sea la promoción del desarrollo humano. Una organización donde todos se sientan cómodos y que forman parte de ella. Cualquier alteración u omisión conduciría a una situación de la que, desgraciadamente, la humanidad tiene demasiadas experiencias.

Las organizaciones empresariales han asumido, y así debe ser, el reto de liderar el proceso de crear el entorno, facilitando que los profesionales pongan en juego sus talentos individuales como forma de crear el talento organizativo. Aumentar los márgenes de libertad de actuación y proponer retos ambiciosos, deben ser principios básicos del modus operandi de las organizaciones. ¿Cuántos jefes piensan que sus profesionales no tienen talento, cuando nunca les han dado la oportunidad de demostrarlo? "Lo fácil aburre, lo difícil es un reto".

Relacionado inexcusablemente con esto, está la posibilidad de errar, y, sobre todo, tolerar la posibilidad de hacerlo. Las empresas saben que pocas veces se logra el éxito a la primera, en ocasiones ni se logra. Con cada historia de éxito, conviven diez de fracasos y errores. Por tanto, penalizar el error es poco "rentable" (y este concepto es fácilmente entendible por la mayoría), porque genera un clima de miedo en el equipo que ahoga cualquier intento de ingenio o genialidad. "Mejor pedir perdón que pedir permiso".

Las organizaciones deben ser creadoras de entornos, los mismos entornos en los cuales van a tener que actuar después. Crear, crear y crear... la rutina es autodestructiva desde el momento en que las personas pierden el control de sus capacidades, habilidades y esfuerzos. Es difícil encontrar personas talentosas, no tanto por la falta de conocimientos o por la falta de este don natural, sino por la sorprendente estupidez de las organizaciones y de quienes las dirigen, que se han obcecado a lo largo del tiempo en entender el control por el control como la función administrativa principal, y el error como una pesada carga que hay que evitar a toda costa. 
Es necesario avanzar iy hacerlo rápido! en la concienciación sobre la importancia de la persona en la sociedad en general y en las organizaciones empresariales en particular. Sin personas nada tiene sentido, todo el "poder" está en sus cerebros, en sus cabezas, en sus capacidades, sin eso nada tiene sentido porque nada se puede hacer. Son las personas las que mueven el mundo. Entre todos urge decidir cómo queremos que lo hagan, en base a qué patrones, en base a qué referentes y mientras lo decidimos... resulta sorprendente la asombrosa despreocupación de muchas organizaciones por sus personas.

Que sirvan estas líneas de grito desgarrado para convencer a las organizaciones y a quienes las dirigen, de que deben creer en la persona, creer en su dignidad, creer en sus valores, creer en su ilusión, creer en su felicidad, creer en la vida. "Es mucho lo que está en juego, mucho lo que se puede ganar y mucho lo que se puede perder".

Me gustaría seguir reflexionando sobre estas y otras cuestiones sin embargo, acabo ya, no sin antes expresar mi satisfacción personal porque este libro sea por fin una realidad, por haber podido trabajar con grandes profesionales, además de maravillosas personas y amigos, y porque, independientemente del éxito o fracaso de este trabajo (da igual, ise puede errar!), cinco personas han dedicado su tiempo a intentar mejorar el mundo. ¡Ojalá, además, resulte de interés! 



\section{Los Recursos Humanos} en la empresa. ¿Cómo llegar a la persona?

M. Ángeles López Cabarcos Profesora Titular de Organización de Empresas Universidad de Santiago de Compostela 



\section{La estrategia y el valor de la empresa}

La aplicación del enfoque del valor a la gestión de la empresa ha sido un proceso largo y complejo. Normalmente se identifica empresa creadora de valor con accionariado satisfecho, es más, se ha establecido como objetivo principal de la empresa el de maximizar el valor para sus accionistas, por ser éstos los únicos que viendo maximizado su valor garantizan que se maximice el valor de toda la empresa en su conjunto. No cuestionamos la definición del objetivo, sin embargo sí criticamos la forma que utilizan algunas empresas de entenderlo y de llevarlo a la práctica. Su obsesiva preocupación por el valor del accionista las ha hecho obviar (o siquiera identificar) aspectos de enorme importancia dentro del enfoque del valor.

Este planteamiento del análisis del valor es válido y necesario, sin embargo queda incompleto si no se incluyen otros aspectos menos cuantificables y relacionados con la estrategia o con los sistemas de gestión de la empresa. El valor es un concepto abstracto y con una enorme carga de subjetividad, por lo que limitar su análisis a cálculos exclusivamente cuantitativos resulta, cuando menos, insuficiente.

Se trata de hacer coherente el enfoque del valor con la estrategia elegida por la empresa. Para ello, la empresa ha de ayudarse de un sistema de gestión que integre los deseos y las relaciones que se establezcan entre los accionistas, los empleados, los clientes, los proveedores y la comunidad en general. Este planteamiento significa llevar a cabo cambios importantes en la organización y, a buen seguro, una revisión en profundidad de su modo de funcionamiento.

Se pueden encontrar muchos ejemplos en los que los sistemas de gestión constituyen un auténtico escollo para crear valor añadido, por estar más pensados para la vigilancia del coste, del beneficio o del grado de desempeño de cada miembro de la organización, que para la generación de valor. En este caso, a la dificultad que supone el tratamiento del valor, se le suma el hecho de que la mentalidad de muchos directivos no se ha adaptado al nuevo entorno empresarial.

Que estrategia y valor están íntimamente relacionados no plantea ningún tipo de duda. De ahí, que los métodos que se centran exclusivamente en el análisis del valor del accionista, sin lograr una completa comprensión de las alternativas estratégicas, cuenten con una cada vez más larga lista de detractores. Las razones argumentadas van desde la facilidad de manipulación de los datos manejados en el análisis, hasta la obsesiva preocupación por los resultados, que puede sofocar ideas estratégicas innovadoras susceptibles de generar gran número de posibilidades. Este enfoque puede inducir a error a los directivos que, centrados exclusivamente en los resultados, pueden tomar decisiones equivocadas por infravalorar, sobrevalorar o, en casos incluso, olvidar alternativas estratégicas válidas.

\section{La importancia de gestionar el valor que no se ve}

Existe una diferencia, en casos muy grande, entre el valor real de una empresa y el valor que se deduce de su cotización o de la información contenida en sus 
estados financieros. Diferencia que variará en función de la razón que justifique la determinación del valor, y que expresa el valor extra (o, en su caso, la diferencia negativa de valor) que el mercado estima para la empresa. La identificación, la valoración y la potenciación de los factores que provocan dicho valor extra se convierte en un aspecto de enorme importancia para la supervivencia y el futuro de la empresa. Implícitamente dicha diferencia representa el valor extra en el que el mercado sitúa el "valor intelectual y de servicio" de la empresa o, dicho de otro modo, la cantidad que los potenciales compradores estarían dispuestos a pagar por poseer dichas partidas intangibles. Si bien no figuran en los estados financieros y de cuentas que habitualmente maneja la empresa, se configuran como fuentes de valor, no sólo importantes, sino fundamentales para su funcionamiento.

La mayor parte de las empresas son capaces de identificar como partidas activas de su patrimonio las naves, los terrenos, el mobiliario, la maquinaria, las patentes, los derechos de reproducción o las marcas registradas. Suelen estar contabilizadas por su precio de coste y no por su valor de mercado, pero al menos figuran en el patrimonio empresarial. Lo que ya no aparece reflejado en dichos estados es el conjunto de valores que hemos definido como intelectuales. La gravedad del hecho está no tanto en su ignorancia a nivel contable, sino en que en la mayoría de los casos la empresa no se ha percatado, siquiera, de su existencia. En casos, las prácticas contables no sólo han sido inadecuadas, sino que además han ejercido una significativa influencia negativa. En lugar de considerar como inversiones a medio o largo plazo las cantidades aportadas a las partidas que integran el conjunto de valores intelectuales, las han considerado como gastos que deben ser minimizados y luego amortizados lo antes posible.

Determinar el valor de algunas partidas de naturaleza intangible no resulta difícil porque, precisamente, su consideración como activo de la empresa hace posible su reflejo en los distintos estados contables, y con ello su cuantificación de una u otra forma. Son otro tipo de partidas intangibles las que realmente plantean problemas, teniendo que empezar por determinar las circunstancias en las cuales deben ser tratadas como activos y en cuales no.

Son muchos los puntos de vista que existen en relación a la consideración y tratamiento de las partidas intangibles. En este sentido, merece la pena considerar los análisis realizados por Miller, que utiliza la línea de producción de la empresa y la entidad física para la consideración de los activos; Gauthier, que admite la gran dificultad de valorar los intangibles sencillamente porque su valor fluctúa continuamente; Betriou y De Montille, que plantean el problema de cómo amortizar las partidas intangibles, cuestionándose, incluso, si deben ser o no amortizadas; o Hendriksen, que sostiene que el principal problema para valorar determinadas partidas intangibles es el alto grado de incertidumbre que existe en relación a la estimación de los futuros beneficios que deberán servir de base a ese valor.

Para analizar el valor de aquellos activos que no figuran en el balance, pero que contribuyen en buena medida a crear valor para la empresa, Lusch y Harvey 
proponen una metodología interesante. Parten de que los instrumentos de control cuantitativos y financieros tradicionales son válidos para las partidas que figuran en los estados contables de la empresa, sin embargo demandan otro tipo de instrumentos cuando, y utilizando sus mismas palabras, el gestor financiero ha de centrarse en campos más "blandos" y más "cualitativos". Como ejemplo estos autores proponen la evaluación del Consejo de Administración de la empresa.

Se han utilizado técnicas de todo tipo para llegar a cuantificar el valor de dichas partidas, algunas de ellas simples formulismos matemáticos exentos de todo contenido económico, pero que, sin embargo, han permitido tomar en consideración la existencia de unas fuentes de valor reales, positivas y fundamentales. Aunque no figuren en los estados de cuentas de lo que no hay duda es de que, independientemente de su valor, juegan un papel principal en cuanto al funcionamiento de la empresa y, como no, a la hora de determinar su valor.

La empresa debe empezar por hacer valoraciones que irán ganando en exactitud a medida que avance el tiempo. A pesar de las imprecisiones en las valoraciones iniciales, lo realmente importante es que la empresa habrá tenido que iniciar un proceso de identificación, catalogación y posterior valoración de unas partidas que, en otro caso, pasarían desapercibidas.

El punto de partida en la aplicación de los modelos de medición está, lógicamente, en identificar el valor intelectual de la empresa (sistemas de información, bases de datos, paquetes de software que codifican y almacenan el conocimiento de la empresa, modelos de conocimiento compartidos, relaciones del personal, calidad de las relaciones, clima de trabajo, mentes y cerebros de investigadores, especialistas, directivos o de cualquier persona que participe en mayor o menor grado en la generación de valor empresarial). Éste último es uno de los valores menos tangible pero más importante para cualquier empresa: “...todo el valor de esta empresa está en su gente. Si ardieran todas nuestra fábricas, y sólo quedara nuestro personal y nuestros archivos de información, pronto seríamos tan fuertes como siempre. Llévense a nuestro personal y podríamos no recuperarnos nunca...” Tom Watson Jr., de IBM.

\section{La dirección por valores}

La gestión de la empresa en base al valor supone hacer coherentes las aspiraciones de la empresa con los procesos de gestión, enfocando las decisiones de gestión sobre los actuadores clave de valor. Implica jugar con el corto y con el largo plazo, involucra a todos los niveles de la empresa y supone tomar decisiones fundamentadas siempre en el valor.

Es en el contexto de la gestión en base al valor, donde adquiere sentido como forma de gestión empresarial la Dirección por Valores.

La Dirección por valores $(\mathrm{DpV})$ es una herramienta de gestión que, desde la óptica del valor, pretende orientar el desarrollo estratégico de la empresa. En la 
Figura 1.1. se puede ver cual ha sido la evolución en el tiempo del enfoque sobre la forma de dirigir empresas.

Según Anzizu la palabra valor tiene en castellano tres acepciones que en conjunto explican la filosofía de la DpV:

“...el valor de tener valor para dirigir mediante valores (...) Valor significa valía (dimensión económica), arrojo (dimensión psicológica) y, sobre todo, elección preferencial entre algo y su opuesto para orientar la conducta..."

\section{Figura 1.1. Continuidad evolutiva de tres formas de dirigir empresas: por instrucciones, por objetivos y por valores.}

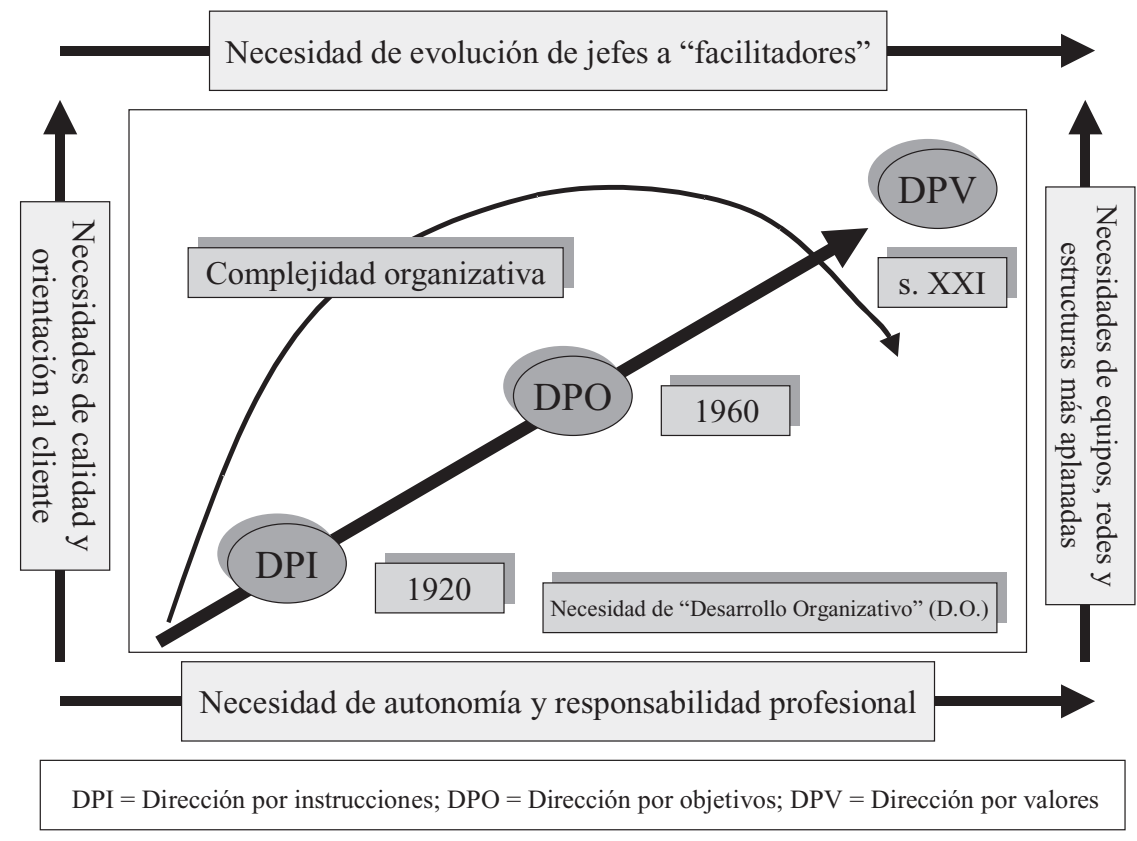

Fuente: Anzizu Fuest, J.; García Sánchez, S., 1997.

La DpV exige adoptar una cultura empresarial en la que el valor ha de guiar los objetivos y cualquier acción tendente a posibilitar su logro. Este enfoque centrado en el valor afecta a los dos aspectos a través de los cuales la empresa interactúa con su entorno: el económico y el social. Esto es, el valor debe justificar cualquier decisión tomada en relación al objetivo de la empresa, las relaciones con el mercado y con el medio ambiente, las relaciones con sus empleados y la forma de trabajo de éstos, la asignación de recursos y la forma de obtenerlos, los procesos productivos, su calidad y su adecuación al mercado, etc. 
Lograr explicar todas las decisiones relacionadas con los aspectos anteriores desde una perspectiva comprendida y compartida por todos, el valor, resulta inmensamente más potente, para encauzar el esfuerzo y desarrollo estratégico de la empresa, que el más completo y sofisticado manual de procedimientos.

Un buen ejemplo de empresas que han sabido dar respuestas adaptadas al entorno en el que desarrollan su actividad son las Learning Organizations (LO), que concretan su forma de actuar en tres aspectos básicos: frente a la variedad: unificación; frente al cambio: capacidad de aprendizaje; frente a la necesidad de conseguir mayor calidad: trabajo en equipo.

$\mathrm{Su}$ significado es que trabajar en una misma dirección y en equipo es una de las piezas clave para asegurar el éxito empresarial. Los mercados, cada vez más abiertos, provocan una diversidad de casuísticas difíciles de gestionar si no se desarrolla la capacidad de estar aprendiendo continuamente y se trabaja tomando como referencia el mismo "norte". En las LO se habla de valores compartidos y por tal se entiende, precisamente, la definición de ese norte que define a la organización y habrá de orientar a todos sus miembros.

Resulta muy adecuado el ejemplo de la Estrella Polar formulado por Hinterhuber y Popp, porque el norte al que nosotros nos referimos es comparable a la Estrella Polar de su ejemplo. El guía de una caravana en el desierto, donde las tormentas de arena alteran el paisaje constantemente, mira la disposición de las estrellas en el cielo para no perderse. Las estrellas no son el destino, sin embargo proporcionan una orientación fiable cualquiera que sea la procedencia de la caravana, de lo bien equipada que esté, o de lo abrupto del terreno. Por supuesto, las estrellas señalan el camino, pero cualquier beduino que intente llegar al siguiente oasis a salvo, debe saber observar igualmente el terreno, evitando las arenas movedizas o cualquier alteración del mismo, y confiando en el sentido de orientación del guía de su caravana.

La identificación, la implantación, el conocimiento y la revisión de la "estrella" de la empresa por todos sus miembros, asegura el alineamiento de intereses en una misma dirección. La DpV propone que la estrella sea el valor. Lo que resta ahora es contar con el "valor" necesario para adoptar el enfoque. Entendemos necesarios tres pilares fundamentales: motivación = actitud apasionada; creativi$\mathrm{dad}=$ talento genial; $\mathrm{y}$ ética $=$ patrón de valores de comportamiento. Todos ellos residen en las personas, por tanto éstas se colocan como punta de lanza para la consecución de cualquier tipo de logro. En este sentido, nada ha cambiado en relación al pasado, excepto la consideración de una variable, la persona, que ya era importante y fundamental desde siempre, pero ahora, además, se la reconoce y valora como tal. La necesidad de comprender el comportamiento humano en las organizaciones, así como el comportamiento de la propia organización, ha animado el desarrollo de la idea de empresa como "grupo humano".

Esto significa redefinir las políticas organizacionales orientadas al factor humano hacia una nueva modalidad que se encuadra en asistir, asesorar, orientar, 
acompañar y ayudar a la persona en su actividad laboral, profesional o técnica, consiguiendo, al mismo tiempo, desarrollar e integrar sus necesidades y responsabilidades profesionales, con sus necesidades y responsabilidades personales.

Este planteamiento implica un cambio de paradigma organizacional, definido a través de una política orientada hacia la responsabilidad social de la organización. Dos factores básicos y necesarios: osadía, esto es, valentía, atrevimiento...; y coraje, esto es, fuerza, intrepidez...

En las empresas las personas que las integran ponen su cuerpo y mente a disposición del trabajo diario, lo que no es suficiente para asegurar la continuidad o supervivencia de la empresa en un entorno fuertemente cambiante e incierto. En un contexto como éste, es fundamental implicar, involucrar y, sobre todo, comprometer a las personas. Para ello, se necesita algo más que cuerpo y mente, se necesita alma y corazón y eso, afortunadamente, no es modelizable, transferible o canjeable con nada se consigue o no se consigue. Es patrimonio de quién, además de poseerlo, lo sabe utilizar adecuadamente.

A través de un proceso integrador se genera congruencia entre cuerpo-almamente-corazón, generándose un conocimiento individual, grupal y organizacional capaz de transformar la complejidad de los escenarios cambiantes y de convertir las paradojas en ventajas. Eso sí, es decisivo conseguir la confianza y el compromiso necesarios de una variable, "la humana", más importante y decisiva que nada y que nunca.

\subsection{Actitud apasionada}

Todas las organizaciones persiguen alcanzar unos resultados. Los directivos son los responsables de su consecución, que no será posible sin los esfuerzos y la colaboración de sus subordinados. En ellos se concreta el conocimiento, arma fundamental de competencia, y son el auténtico motor de la empresa, haciendo que adquieran sentido los planes, los procedimientos, los programas o los objetivos. Si esto es así, el directivo tiene que pensar en cómo imbuir en el personal el deseo de conseguir resultados, contagiándoles un espíritu de trabajo positivo y lleno de pasión capaz de superar los escollos que puedan ir surgiendo.

El proceso motivacional del individuo se inicia porque éste experimenta necesidades o deseos que pretende satisfacer, para lo que desarrollará una serie de actuaciones o comportamientos cuyos resultados decidirán si concluir el proceso o reactivarlo mediante la generación de nuevas necesidades o deseos. Aunque dicho proceso parece sencillo, en la práctica no lo es tanto, y de hecho han surgido gran cantidad de teorías que han tratado de dar una solución al problema de como motivar al personal. Todas ellas tienen limitaciones y son criticables por lo que no deben ser utilizadas aisladamente, sin embargo el conocimiento de los principios básicos que las fundamentan puede servir como guía de actuación en la mayoría de los casos.

Si hay algo importante de la función de dirección es la posibilidad de relacionarse con otras personas, tratándolas en función de sus motivaciones. Es necesario 
alcanzar el "equilibrio motivacional" que consiste en conseguir que se produzca una correspondencia entre lo que un individuo desea y lo que hace realmente. En el ámbito empresarial el problema se produce porque puede ser fácil saber lo que desea un individuo, sin embargo no es tan fácil saber que es lo que desea o motiva a cada grupo, equipo o a todo el conjunto. El equilibrio se consigue cuando los tres tipos de motivación se mueven en el mismo sentido y la maximización de una de ellas maximiza las otras dos.

\subsubsection{Motivación y empresa}

La motivación hace referencia a toda clase de impulsos, aspiraciones, necesidades, deseos y fuerzas que inducen a actuar a los individuos y los motivadores son los instrumentos a través de los cuales es posible conciliar las necesidades en conflicto o destacar una como prioritaria. Es por ello que en cualquier empresa organizada los directivos deben preocuparse por identificar y entender aquellos factores que sean motivadores, demostrando un "uso" ingenioso de los mismos, a la vez que son la manera que tiene la empresa de que los subordinados desempeñen su trabajo eficazmente.

Si bien en muchas ocasiones se han identificado como sinónimos los conceptos de motivación y satisfacción, lo cierto es que, aunque relacionados, motivación y satisfacción hacen referencia a conceptos distintos. Así, mientras la satisfacción hace referencia al placer experimentado cuando se satisface un deseo, la motivación se refiere al impulso y esfuerzo por satisfacer un deseo o meta. Esto es, la motivación implica un impulso hacia un resultado y la satisfacción es el resultado experimentado.

La manera más adecuada de entender la motivación es concebirla como una reacción en cadena que empieza con la detección de las necesidades, consecuencia de lo cual se provocan tensiones y conflictos que acabarán por desencadenar aquellas acciones que han de posibilitar la satisfacción de las primeras. La explicación de la cadena es compleja, ya que salvo las necesidades fisiológicas, el resto dependen del entorno o circunstancias, estimulando éste muchas de ellas.

Las características del entorno, la enorme competitividad entre las empresas y las exigencias que plantean, obligan a fijar la mirada cada vez más sobre el rol de los Recursos Humanos y fundamentalmente sobre las relaciones que se establecen entre los integrantes de la organización. En este sentido, la aportación de la psicología es fundamental para facilitar y contribuir a un proceso sobre el que influyen necesariamente múltiples actuantes. Por ello, se hace necesario conocer y, lo que es más importante, comprender la psicología de la empresa, lo que exige:

- Establecer con claridad los roles de cada miembro de la organización, así como las relaciones entre ellos;

- Fortalecer el sentido de pertenencia al proyecto empresa;

- Incentivar el despliegue de iniciativas personales coherentes con la organización como un todo; 
- Favorecer la creatividad buscando el aporte múltiple de cada uno de sus integrantes;

- Buscar el equilibrio entre la estructura de la empresa y el desarrollo personal de cada uno de sus miembros.

El primer paso del proceso motivacional consiste en analizar los factores que influyen el trabajo de las personas y la manera en que lo hacen. En este sentido, lo primero que se viene a la cabeza es que la gente trabaja con más entusiasmo en la medida en que se incrementa su remuneración. De hecho, la gente trabaja porque se les ofrece dinero a cambio, surgiendo problemas en el caso de que la relación retribución-trabajo no resulte ajustada. Sin restarle importancia a la remuneración como aspecto motivacional, lo cierto es que actualmente su importancia es discutible por la existencia de otros factores motivacionales que han pasado a cobrar una mayor importancia. Así, hacer bien el trabajo y ver el resultado del mismo, sentirse parte de un equipo, disponer de información, tener cierto nivel de control y de responsabilidad sobre el trabajo, recibir las alabanzas de un superior, la participación activa, la calidad de vida laboral, la comunicación interna, la autonomía, el apoyo social, la visión gerencial, la formación o el poder, son algunos de los factores que resultan claramente motivadores.

Numerosos estudios realizados al efecto permiten concretar tres condiciones necesarias para motivar al personal de cualquier nivel de la empresa:

- La competencia interpersonal.

- La oportunidad de trabajar con unos objetivos claros y significativos.

- La existencia de unos sistemas de dirección adecuados.

La competencia interpersonal hace referencia a un estilo de dirección motivador que persigue la autorrealización y la creatividad positiva. Es necesario determinar los elementos capaces de describir el estilo de supervisión de los superiores en términos de capacidad para estimular el entusiasmo, el nivel y coherencia de sus expectativas, su reconocimiento del éxito, su accesibilidad y receptividad de nuevas ideas, su actitud ante el riesgo y los errores, o su sensibilidad hacia los sentimientos de los demás.

Determinar unos objetivos significativos constituye una forma de orientar las motivaciones positivas, a través de aquellos objetivos que permitan alcanzar los deseos particulares de los subordinados, eliminando los obstáculos de la burocracia, el protocolo y las metas o fines irrelevantes.

Los sistemas de dirección constituyen la vía para ayudar a las personas motivadas positivamente a alcanzar los objetivos de la organización, reforzando y perpetuando, de este modo, su propia motivación. Es decir, se podría decir que los sistemas de dirección concretan el esfuerzo de la organización para alcanzar sus fines. Estos sistemas son una "prolongación” de quienes los dirigen, por lo que producen igual (o mayor) efecto de motivación, insatisfacción, apoyo o amenaza, que los mismos directivos. Las personas son los medios a través de los cuales funcionan los sistemas, aspecto a tener en cuenta a la hora de diseñarlos e implantarlos. 
En definitiva, los esquemas sólidos de motivación deben partir de la cúspide, estando estrechamente relacionada la motivación de un empleado con el estilo de supervisión de su jefe inmediato. Controlando con madurez la motivación institucional del poder, ésta no engendrará una expansión egoísta y agresiva. Los hombres y las naciones que disfrutan de este perfil motivacional están en disposición de construir enormes imperios, de crear una moral muy alta y de potenciar a las organizaciones que dirigen.

\subsection{Talento genial}

La creatividad no tiene nada que ver con musas, conspiraciones, ni con extrañas características de la personalidad. Si hubiera algo determinante, serían la constancia, la motivación y la voluntad. Es un concepto difícil de definir, tanto que puede hacer referencia a fenómenos o aspectos de muy diferente naturaleza, una capacidad, una habilidad, una disciplina, un proceso, una característica sobresaliente. Hace referencia a un concepto tan "confuso" que si definirlo resulta difícil, todavía lo es más detectarlo.

Cada autor realiza su propia interpretación acerca de lo que se puede entender por creatividad (véase la Figura 1.2.). Una de las definiciones de creatividad más ajustada, aunque general, es la que propone Juan Rodrigo (2002) que la entiende como "una capacidad con una base innata que se desarrolla en mayor o menor medida en función de la aparición y expresión de múltiples factores, algunos de los cuales están identificados y definidos". La creatividad, por tanto, es la capacidad de encontrar, imaginar y definir lo nuevo; una capacidad que se fundamenta en procesos mentales divergentes, que implican formas de pensar donde el alejamiento de lo conocido y la suspensión del juicio -la valoración diferida-son elementos centrales.

Introducir la filosofía de la creatividad en las organizaciones provoca en éstas cambios muy importantes, también de filosofía y, sobre todo, en la forma o modo de funcionar. Cervantes, Da Vinci, Miguel Ángel eran unos creativos. Cuando hablamos de la creatividad que requieren las empresas para competir y avanzar, no nos referimos a este tipo de talento genial.

Aunque en general se haga referencia a la creatividad como una capacidad o cualidad individual, como de hecho es así, es importante no perder de vista el potencial creativo que necesita una organización en su conjunto para desarrollarse plenamente, y que va más allá de la inteligencia o del talento natural. Las personas creativas no son sólo los extraordinarios, como Ronaldo o Von Karajan, sino todos aq uellos que contribuyeron a que Brasil ganara el mundial de fútbol, o que la Orquesta Philarmónica de Viena alcanzara límites increíbles. "Eso es lo que define a los profesionales y a las organizaciones con talento. Los primeros alcanzan resultados o colaboran en su consecución; las organizaciones facilitan que el talento de las personas que las constituyen se libere, aporten el máximo valor posible y colaboren en generar talento organizativo" (Jericó, 2000). 
Figura 1.2. Concepto de creatividad.

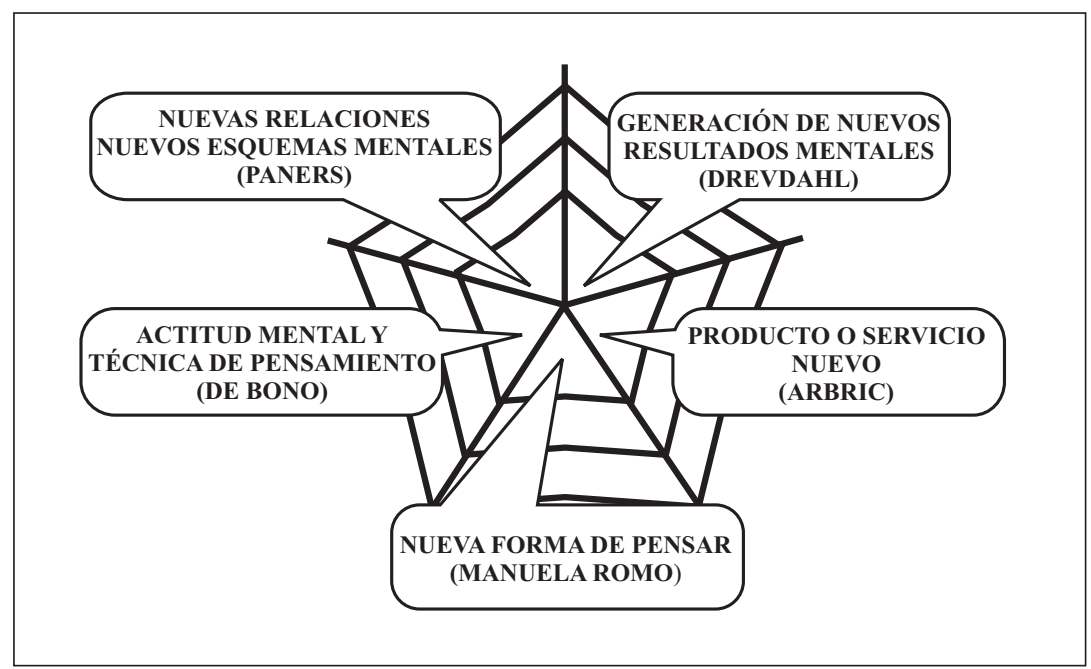

La "osadía" de ser un creador y además emprendedor e innovador presenta dos problemas o, mejor dicho, dos escollos a salvar. El primero es que es necesario estar ubicado en un tipo de organización con unas características determinadas, es decir, el talento creativo no funciona bien en organizaciones jerarquizadas, con estructuras muy rígidas, donde se impide cuestionar siquiera lo establecido.

Los creativos se caracterizan por su inconformismo, por su talante crítico y por sus enormes exigencias para realizar su trabajo. Al mismo tiempo, son los que más pueden aportar "...si no fuera así, tampoco tendrían ese tipo de talento..." (García Serena, Presidente de Grey Trace, 2000).

El segundo es que no existen alicientes claros que inciten a las personas a demostrar su potencial creativo. Es más, existe una escasez enorme de talento creativo. A la dificultad de ser innovador, se une la propia idiosincrasia de nuestro país. Tal y como apunta Esther Dyson, Presidenta de ICANN (Corporación de Internet para la Asignación de Nombres y Números de dominio), "el principal motivo de retraso de España en el ciberespacio se debe al miedo a arriesgar y que salga mal el negocio. En España existe una mayor conciencia del fracaso personal, si una iniciativa no tiene éxito. En EEUU no es así, si un proyecto falla se empieza otro sin que la persona quede marcada como un fracasado..." Con este panorama, ¿cómo se va a pedir, además, que las personas den rienda suelta a su ingenio o a su potencial creativo?

Cuando se habla de creatividad en el contexto de las organizaciones, normalmente se hace referencia al clima de la organización; a que las personas y los equipos resulten creativos, a la gestión de las ocurrencias que redunden en mejoras para la empresa; a la forma de resolución de problemas, o a la gestión del 
conocimiento. Es necesario crear el ambiente organizativo propicio para generar ideas, proporcionando las técnicas y herramientas adecuadas dentro de cada equipo de trabajo o puesto, y orientando los resultados obtenidos a la aplicación práctica en la empresa. Es inútil propiciar la creatividad, la novedad, el cambio, la genialidad en la empresa para, una vez lograda, constreñirla de forma que no pueda ponerse en práctica.

Algunos de los aspectos que caracterizan el ambiente que se respira en las empresas creativas son el Reto o grado de participación y esfuerzo exigido a los empleados; la Libertad o margen que tienen las personas para definir y desarrollar su trabajo; el Dinamismo o grado de actividad de la empresa; la Confianza y Disposición... la seguridad personal; el Tiempo para Imaginar.... dedicado a nuevas ideas; la Alegría y Humor como expresión de la espontaneidad y comodidad; los Conflictos generados entre los empleados; el Apoyo a las Ideas... cómo se reciben y se cuidan; los Debates como expresión de libertad para cuestionar en minoría; la Asunción de Riesgos... como forma de tolerar la ambigüedad.

Sin ninguna duda se pueden concretar en tres los ingredientes básicos del talento creativo: la capacidad, que hace referencia a los conocimientos, habilidades o competencias para desarrollar algo nuevo e impactante; el compromiso, que es la fuerza que hace posible que las personas estén ilusionadas, entusiasmadas e implicadas con los nuevos proyectos y, en definitiva, con las organizaciones; y la acción, que en el escenario económico actual significa velocidad o no dejarse llevar por lo que Cubeiro denomina "síndrome de la almohada asesina". Son necesarios los tres ingredientes para poder hablar de talento creativo. La intensidad de cada uno de ellos puede variar en función de las circunstancias particulares, pero de lo que no hay duda es de que si no existe alguno de los tres, no se alcanzarán los resultados esperados.

La condición más clara a cumplir para contar con una organización que pueda ser considerada creativa es disponer de expertos bien cualificados en la investigación y desarrollo de la creatividad humana, tanto personal como profesional. Expertos que sean capaces de liderar equipos o unidades, y llevar a cabo con eficacia una gestión avanzada de la creatividad, del conocimiento y de los talentos, de la innovación y la inventiva. El reto es realmente ambicioso porque hasta el momento las empresas no se han preocupado en formar en creatividad a sus jefes, a sus empleados, volviéndolos más flexibles, activos, dinámicos e imaginativos.

\subsubsection{El valor de la creatividad}

Son muchas las empresas que sostienen que el talento creativo es su principal recurso estratégico. Tanto es así, que las 500 empresas más admiradas del mundo según la revista Fortune consideran que la "variable que más correlaciona con el éxito empresarial es precisamente la capacidad de atraer, retener y desarrollar 
el talento, más que la solidez financiera, la innovación o la calidad de productos y servicios".

La competencia, la desregulación, el mercado en sí, han convertido a las personas en agentes libres, exigentes y con capacidad para escoger. Si las empresas pretenden atraerlos y retenerlos, han de crear valor para ellos. El deseo de crear valor a los profesionales no es de ningún modo filantrópico, es un interés puramente económico. La organización quiere crear valor al profesional para que alcance resultados superiores, para que cree. Si lo hace así, está creando valor para el cliente, para el accionista, para ella y para toda la sociedad en su conjunto.

La cadena de creación de valor ha invertido su sentido. El presente (cada vez más pasado) pasa por la obtención de resultados financieros y por la satisfacción del cliente; el futuro por la gestión del conocimiento, por la promoción del talento creativo y por la creación de valor para toda la sociedad. Cuando John Chambers predica que Cisco Systems "cambiará la forma en que el mundo trabaja, vive y actúa” no busca sólo crear una imagen de marca en el mercado (que también), sino atraer a los mejores, motivar a sus profesionales para que se identifiquen con el mensaje y se sientan orgullosos de participar en ese propósito.

Uno de los retos que deben afrontar las empresas es liderar el proceso de crear el entorno, facilitando que los profesionales pongan en juego sus talentos individuales como forma de crear el talento organizativo. Aumentar los márgenes de libertad de actuación y proponer retos ambiciosos, deben ser principios básicos del modus operandi de las organizaciones. ¿Cuántos jefes piensan que sus profesionales no tienen talento cuando nunca les han dado la oportunidad de demostrarlo? "Lo fácil aburre, lo difícil es un reto".

Otro principio básico de actuación es que el líder ha de facilitar la excelencia de los miembros del equipo, personalizando sus actuaciones en función de las motivaciones de cada uno y de sus aportaciones. Además, no debe perderse de vista la posibilidad de errar, desarrollando un sentimiento de tolerancia hacia el mismo. Las empresas que pretenden ser creativas saben que pocas veces se logra el éxito a la primera ¡en ocasiones ni se logra! Con cada historia de éxito, conviven diez de fracasos y errores. Penalizar el error es poco rentable, porque genera un clima de miedo en el equipo que ahoga cualquier intento de creatividad. "Mejor pedir perdón que pedir permiso".

Por último, reforzar el compromiso de todos los miembros en un objetivo común -crear- es un principio fundamental para conducir a la organización y a sus personas al éxito. Resulta muy acertada e ilustrativa la reflexión de Sun Tzu, “...en general, la regla de la guerra al penetrar en territorio enemigo es que las tropas tienden a unirse cuando penetras profundamente, mientras que tienden a dispersarse cuando se hace una penetración ligera.” En la Figura 1.3. se pueden observar las diferencias en el aspecto creativo entre las empresas menos creativas y las más creativas. 


\section{Figura 1.3. Organizaciones conservadoras y organizaciones creativas.}

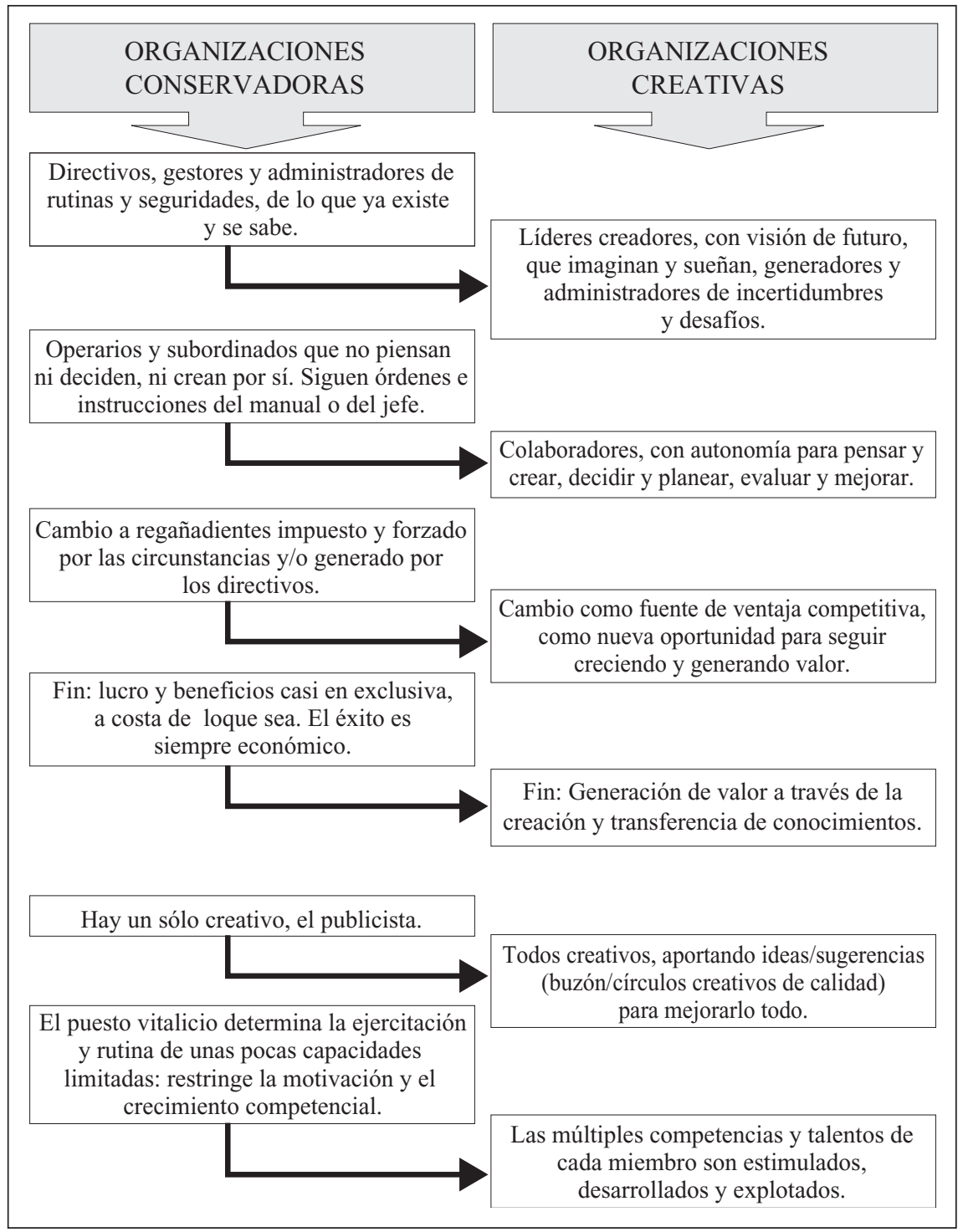

Una última reflexión, en este caso personal, las organizaciones deben ser creadoras de entornos, los mismos entornos en los cuales van a tener que actuar después. Crear, crear y crear... la rutina es autodestructiva desde el momento en que las personas pierden el control de sus capacidades, habilidades y esfuerzos. Es difícil encontrar personas creativas, no tanto por la falta de conocimientos o por la falta de este don natural, sino por la sorprendente estupidez de las organizaciones 
y de quienes las dirigen, que se han obcecado a lo largo del tiempo en entender el control por el control como la función administrativa principal, y el error como una pesada carga que hay que evitar a toda costa.

La originalidad, el talento, el ingenio (y también el genio) son patrimonio de las personas. Son ellas -las personas- las que cuentan, tanto que las cifras de resultados se limitan a cuantificar la actitud, la capacidad o el talento de aquellos que integran la organización. Es la materia prima del talento organizativo. En definitiva, no es imprescindible gente especialmente talentosa, sino gente entusiasmada, apasionada, comprometida y, sobre todo, feliz. Por decirlo de forma contundente: lo importante es contar con un grupo de personas no extraordinarias que produzcan resultados extraordinarios.

\subsection{Patrón de valores}

El análisis comparativo más simple nos descubre que vivimos en la época histórica en que más preocupación social y personal existe por las cuestiones morales; y la única en que se castiga legal o socialmente a las empresas que incurren en conductas desviadas del deseo popular. ¿Por qué entonces ese lento avance hacia estándares morales más elevados? ¿Por qué ese trato mayoritariamente frío e inhumano a los trabajadores? ¿Por qué siguen siendo rentables las actitudes empresariales despreciativas con la responsabilidad social?

El concepto de ética empresarial tiene asociadas una serie de connotaciones básicas que ayudan a delimitar, y también a dificultar, su alcance. Algunas de ellas son que los directivos quieren tener la capacidad de distinguir entre lo bueno y lo malo, entre lo que deben y no deben hacer; que muchos hechos económicos son ambiguos, en unos aspectos son buenos, $\mathrm{y}$ en otros malos; que hay muchos tipos de ética, porque las personas no son iguales; que las leyes van siempre por detrás de los acontecimientos; que los directivos siempre tienen una capacidad de acción, pueden elegir a favor de la ética, y negarse a ejecutar órdenes inmorales; o que los conflictos entre la ética y las decisiones comerciales son universales y permanentes. Además, la ética tiene una componente individual, esto es, cada persona, por su educación, por sus experiencias, por su situación económica y familiar, modifica sus actitudes que nunca podrán ser exactamente iguales a las de otro individuo.

La diversidad imperante conlleva enfrentarse simultáneamente a culturas, legislaciones y hábitos diversos que influyen gran parte de las actividades productivas y comerciales. Además de la relatividad ética, las políticas y procedimientos pueden variar entre zonas geográficas, ámbitos o sectores de actividad. ¿Cómo establecer entonces la línea divisoria entre lo posible y lo prohibido?

La actitud ética puede verse hoy como el último peldaño de una escalera que ha ido incorporando escalones con el paso del tiempo, pasando de las obligaciones a las acciones voluntarias (Díez y Redondo, 1999).

Hasta hace escasas décadas, la empresa sólo debía responder de sus obligaciones contractuales ante los propietarios del capital y los trabajadores, además 
de cumplir la función económica de unidad de producción básica. El mercado era el único elemento influyente en la actividad empresarial, y aun así de forma muy limitada.

El segundo escalón llega cuando las regulaciones e intervenciones de instituciones públicas empieza a generalizarse. La empresa, en parte por sus muchos abusos previos, se convierte en un objetivo prioritario en la normativización de la actividad económica. Se incrementa el número de prescripciones que deben seguir en su vida cotidiana las empresas.

Ni el mercado ni la intervención pública bastan para que el directivo entre en el ámbito de los problemas sociales. Esto se empieza a producir cuando la sociedad comienza a exigir unos comportamientos éticos a las empresas. Más allá de sus obligaciones económicas o legales, el directivo debe respetar una serie de aspectos no regulados, que inciden en los valores aceptados por la sociedad en que la empresa realiza su actividad productiva.

El cuarto y último peldaño incorpora todo lo que excede de obligaciones para la empresa, reales o morales. Por su carácter voluntario, el factor decisivo es la actitud del equipo directivo. Exige que la dirección quiera actuar de forma que beneficie a la sociedad en su conjunto, que reconozca la gran interdependencia entre las corporaciones y las comunidades en que se asienta y con las que se relaciona.

Dentro de una empresa, los refuerzos de conducta son imprescindibles. En su lado positivo, creando una cultura que potencie el trabajo en equipo, las actitudes humanitarias, el respeto del medio natural, la solidaridad, el mérito o la justicia. En su lado negativo, estableciendo las sanciones necesarias para que los empleados se vean impelidos a no actuar de forma inmoral.

Las normas éticas perfectas no han existido ni existirán jamás. La no existencia de máximas universales en este campo, lleva a la empresa a una difícil situación. Sin puntos de referencia nítidos, con señales contradictorias en la sociedad, con el utilitarismo y el relativismo cultural ganando adeptos, ¿qué debe hacer un directivo en su trabajo diario? No existen respuestas, por lo que el mayor activo para el avance ético seguirá siendo el individuo, su convencimiento de que una actuación moral es positiva.

\subsubsection{La gestión ética en la empresa}

Es conveniente considerar a qué valores o patrones morales nos referimos, porque o acordamos previamente un espacio común, con independencia de ideologías, creencias o tendencias, en el que podamos suscribir los que se denominan valores comunes mínimos; o, ciertamente, todo quedará en planteamientos utópicos abonando la especulación intelectual. Valores como la honradez, la justicia, la honestidad, el bien común se entienden perfectamente asumibles desde cualquier lectura ideológica, económica, política o religiosa.

Haciendo referencia a la etimología del propio término, ética significa "modo acostumbrado de obrar, costumbre; búsqueda del conocer para hacer...". Esta 
definición no es suficiente, si no añadimos que la búsqueda la encontramos en la ley moral, emanada de la ley natural que todo hombre lleva consigo, con independencia de sus creencias religiosas. De esta forma, todo hombre debe tener unas pautas de comportamiento basadas en objetivos morales, ya que todo acto humano es moral. A menudo la opinión que nos formamos de las cosas, acostumbrados a pasarlo todo por el tamiz de nuestra opinión, crea "escuelas éticas" alejadas de la moral, relativizando así la ley natural y haciendo un "traje a medida" de nuestras posiciones.

Lo cierto es que estamos atravesando un período en que lo que teníamos aprendido, lo que conocíamos, lo que nos enseñaron, lo que asumimos como verdad permanente, está en profunda crisis. Han entrado en nuestra cultura una serie de informaciones, conocimientos, realidades que están configurando una nueva manera de "ver", "hacer", "estar", "manifestarse”, en definitiva, una nueva cultura cuya base fundamental debe ser hacer las cosas bien, esto es, con un fundamento ético.

A pesar de los grandes avances científicos y tecnológicos, y del mayor grado de bienestar de la sociedad, se convive con un alto grado de incertidumbre, sobre todo en el ámbito empresarial. Ante la pérdida del referente religioso, la sociedad ha optado por el referente científico. Las consecuencias son claras, ya que la ciencia no puede ser autora de normas morales, ni de pautas éticas de conducta, sino que, bien al contrario, debería estar sujeta a ellas.

Las empresas tienen una responsabilidad desde el momento en que influyen en la sociedad, inciden en el nivel de vida de los ciudadanos, en sus hábitos y costumbres, en el progreso tecnológico o en las relaciones internacionales con otras empresas. En un mundo competitivo como el que nos toca vivir, la conducta ética es una ventaja competitiva clara y un beneficio social y empresarial.

La actividad empresarial debe realizar un análisis reflexivo desde el punto de vista de los valores humanos y comportamientos éticos de los profesionales involucrados en la toma de decisiones, dirigiéndose, no sólo a generar y mantener el capital que la forma, sino a concienciar sobre su trascendencia social. Tal y como afirma Ricardo San José, Director Financiero de Espais, “...no estamos afirmando que la empresa deba convertirse en una ONG, ni que el mundo empresarial deba ser un referente de valores morales, pero ciertamente que no puede ser ajeno a dichos valores, en la medida que su actividad está dirigida a la producción de bienes y servicios para una colectividad, es decir, para la sociedad en su conjunto...".

De esta forma, el objetivo de la empresa de crear valor, del que hablamos al principio, puede demostrar su alcance interno y social (véase la Figura 1.4.).

Teniendo en cuenta lo anterior, comprobamos que el fin último es y debe ser la promoción del desarrollo humano. Cualquier alteración u omisión conduciría a una situación de la que desgraciadamente la humanidad tiene demasiadas experiencias. 
Figura 1.4. Creación de valor en la empresa.

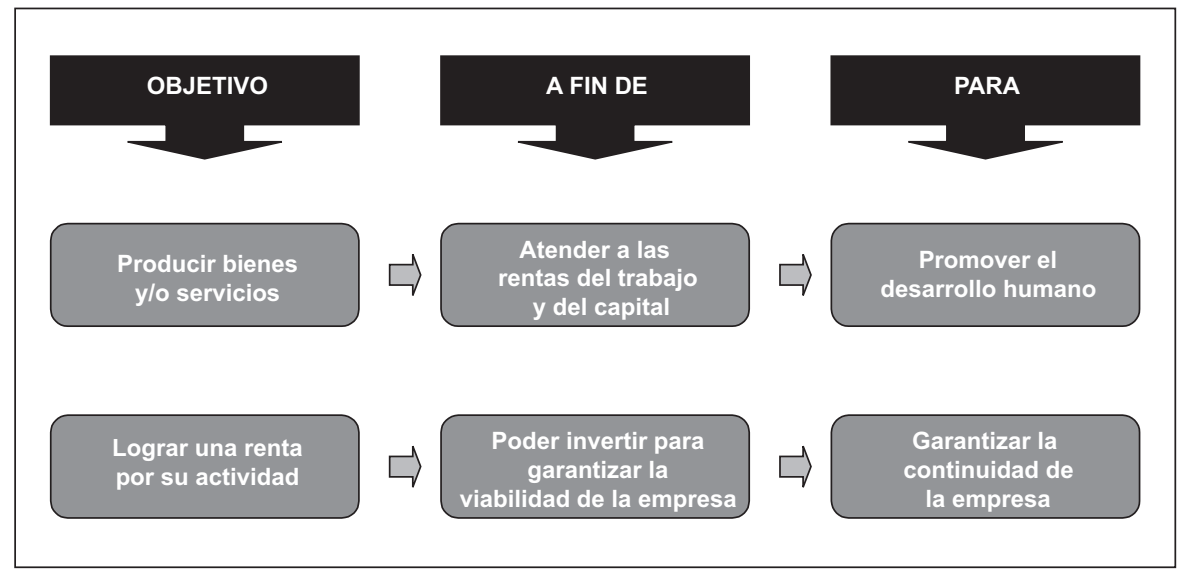

Ha sido muy habitual que las organizaciones fijasen como objetivo principal la consecución de beneficios, lo que ha llevado a considerar determinados comportamientos como meros instrumentos para la consecución del mismo. Con un planteamiento así se corre el riesgo, y así ha ocurrido, de conculcar los derechos, no sólo de las personas sino de otras organizaciones. La organización ha de obtener legitimidad social. Para ello, a la vez que produce los bienes o servicios que se esperan de ella, debe respetar los derechos reconocidos por la sociedad en la que vive, así como los valores que esa sociedad comparte.

Las dificultades para implantar una ética empresarial adecuada son inmensas, debido, sobre todo, a las características del entorno que nos está tocando vivir. Los vertiginosos cambios y la feroz competencia hace muy difícil mantener un equilibrio entre las oportunidades de negocio y los comportamientos éticos en las empresas. Algunas empresas han creado toda una serie de códigos éticos, constituyendo, al mismo tiempo, comités éticos con el objetivo de regular los comportamientos que han de guiar sus actuaciones. En muchos casos se ha cometido el error de pensar que la simple catalogación de conceptos es suficiente para abordar un tema tan profundo como el que nos ocupa. La conducta moralmente ética no se consigue mediante la obtención de un certificado de calidad, sino por una conducta que encuentra su referencia en normas morales que forman parte intrínseca de la persona.

Desgraciadamente, dimensiones como la autorrealización personal, la autoestima, la felicidad y otras dimensiones de la vida moral quedan al margen de la profesión. Las aspiraciones éticas personales se aparcan en la vida privada, se reservan para los fines de semana y se ejercen en el ocio familiar. La fragmentación radical entre vida profesional (pública) y vida familiar (privada) puede ser la excusa adecuada para que se entienda la ética vocacionalmente necesaria, pero profesionalmente imposible. La coherencia está llamada a estar presente para no 
provocar una dicotomía, una fisura entre la moral privada y la pública. El éxito profesional, así como el beneficio económico empresarial no puede estar en contraposición con el beneficio social. Muy al contrario, estamos en el momento de llevar a cabo importantes conquistas sociales.

"Hacer empresa" significa hacer conquistas sociales. Para ello, la empresa debe incorporar como valores en el ámbito de sus responsabilidades un compromiso con la realización de determinados valores fundamentales que son cada vez más demandados y esperados socialmente. Cuando menos, es posible distinguir tres niveles: personal, organizativo y social.

Desde la perspectiva personal, hablar de ética empresarial supone que la calidad es inseparable del desarrollo personal y profesional, así como del sentido que damos a lo que hacemos. Los valores compartidos dentro de la organización son, cada vez más, un elemento clave de la viabilidad de las organizaciones, ya que suponen activar una actitud de disponibilidad para trabajar sobre las maneras de pensar, sentir y hacer de cada persona.

La perspectiva organizativa se justifica porque, aunque los valores se asumen personalmente, se crean, comparten y refuerzan organizativamente. Las empresas son auténticos laboratorios de Valores, en la medida que deberán generar y recrear el compromiso y la perspectiva compartida de las personas que las integran. En este sentido, la ética debe hacer algo más que aportar discursos, debe ser un elemento que apoye y clarifique los procesos de aprendizaje y creación de valores que dan sentido a la organización.

La última de las perspectivas, la social, parte del reconocimiento de que la empresa es una institución económica que, sin dejar de serlo, tienen repercusiones sociales. Repercusiones y responsabilidades que no se refieren a lo que hace como consecuencia de su actividad ordinaria, sino que se refiere a la calidad y el significado humano de todas sus actividades. Los valores éticos de la empresa no sólo son un factor de identidad, también son un factor de diferenciación y de legitimación.

Uno de los retos más cruciales a los que deberá hacer frente la empresa desde ya mismo, está relacionado con los mecanismos de evaluación y verificación. La empresa debe comprobar que ha mejorado y no tan sólo afirmar que es necesario mejorar. Esta búsqueda de lo que alguien ha denominado "auditoría ética" (no se trata de repartir certificados), responde tanto a la necesidad de que las empresas puedan corresponder a la dimensión ética de su actuación, como a la necesidad de evitar que, en nombre de la ética, se vean desbordadas con demandas y expectativas que no les corresponden.

\subsubsection{Normalización en el campo de la ética}

Las empresas que hoy se consideran de éxito y con afán de permanencia responden a la demanda social de que se comporten en sus actuaciones de manera ética. La importancia de la reputación corporativa de las empresas está en alza. En Estados Unidos, por ejemplo, la publicación por la revista Fortune de la lista 
"The most admired companies" crea enormes expectativas, ya que un ascenso o descenso produce importantes cambios en el valor bursátil de las empresa. La reputación corporativa también se aprecia en Europa donde se la considera una fuente de valor empresarial decisiva.

Desde finales de los 70 algunos países como Estados Unidos, Reino Unido o Italia han demostrado una enorme preocupación por demostrar qué empresas tienen un comportamiento ético y social adecuado y que, por tanto, pueden ser receptoras de los fondos provenientes de los instrumentos financieros éticos. Por ejemplo, en Estados Unidos existe el Dow Jones Sustainability que agrupa las empresas que pueden demostrar a la sociedad que tienen un comportamiento ético-social adecuado (certificadas respecto a la SA 8000, AA 1000 y otros estándares de referencia, y el Domini 400 Social Index).

Se ha publicado ya en España un listado de empresas con reputación corporativa, en base a su comportamiento ético-social, para lo cual han tenido que seguir, de una u otra forma, un proceso como el que se recoge la Figura 1.5.

Figura 1.5. Promoción de una cultura de gestión ética en las empresas.

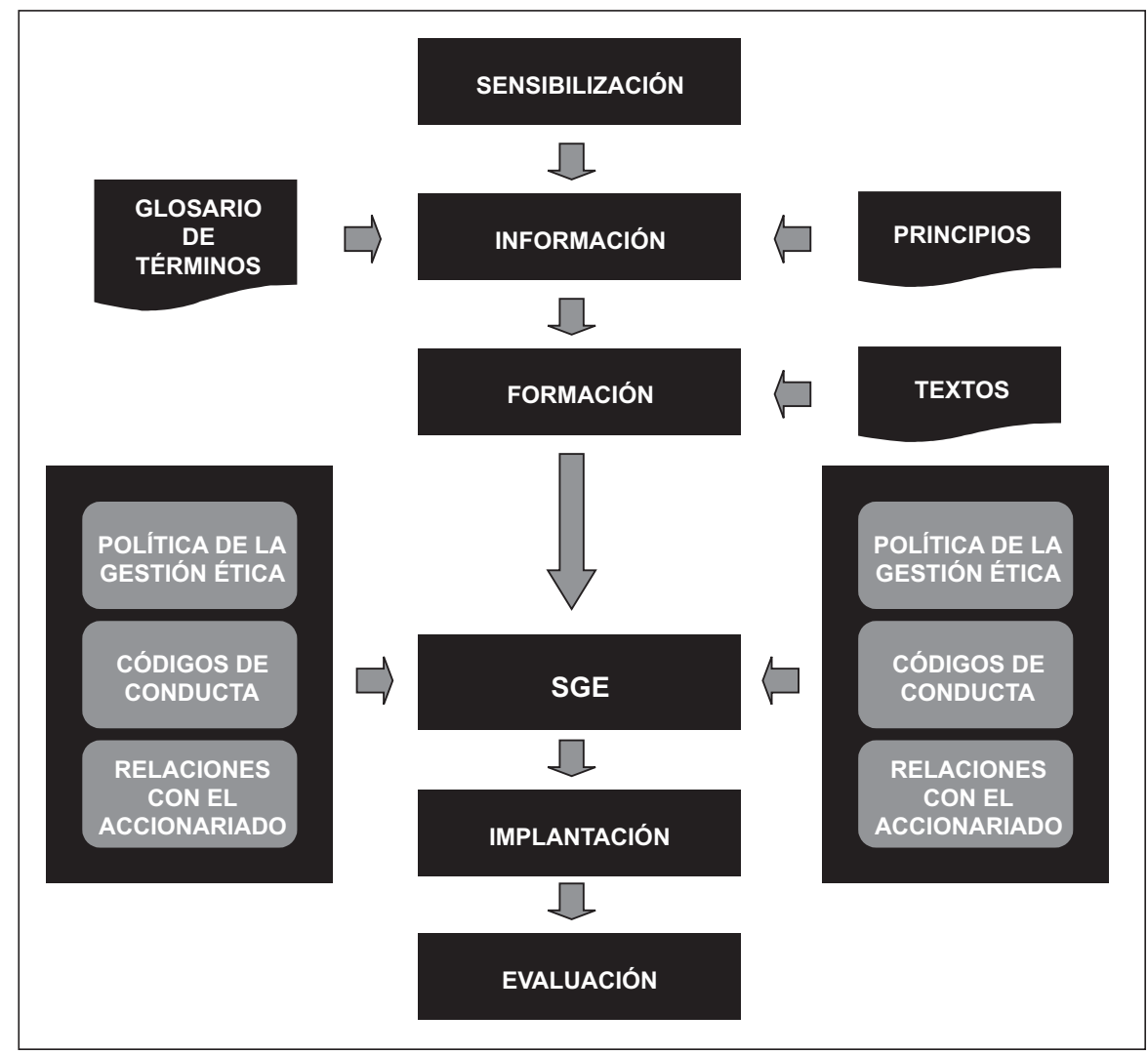

Fuente: http://www.aecientificos.es. 
En el Congreso de Valores de Empresas celebrado en Barcelona en el año 1999 se creó Forética como foro de empresas éticas con el objetivo de desarrollar una certificación ético y social de empresas. Durante los dos últimos años, Forética ha elaborado documentos y actualmente es miembro del Comité de ética de AENOR en representación de, aproximadamente, 40 empresas y entidades. AENOR, a su vez, se encarga de verificar y validar los informes de sostenibilidad de empresas que contemplan el comportamiento ético y social, configurados en el sistema GRI (Global Reporting Initiative).

AENOR constituyó en diciembre de 2000 el Comité Técnico de Normalización 165 "ÉTICA" cuyo objetivo principal es el desarrollo de normas UNE. El comité está formado por un Plenario que incluye a cinco Grupos de Trabajo, cada uno de los cuales se encarga de una parte del amplio espectro que abarca dicho comité en su conjunto (véase la Figura 1.6.).

El GT\#2 es el que se relaciona más directamente con el tema que estamos analizando. Basa su actuación en una serie de principios fundamentales entre los que figuran:

- La relación empresa-sociedad es la base de la actuación empresarial.

- Las empresas que mejor se adaptan a la sociedad en donde actúan son aquellas que comparten sus valores.

- La gestión ética es un nivel de comportamiento que emerge como lógica continuación de la gestión de la calidad y la gestión medioambiental.

- La apelación a la ética se está haciendo a veces de manera confusa y desigual. Se necesita una referencia externa, consensuada y común a todas las empresas.

- Las entidades normalizadas en su gestión ética disponen de un valor añadido que les posibilita compartir valores con la sociedad, aumentar su sostenibilidad o acrecentar su reputación corporativa.

Siguiendo esta tendencia, 98 de las 100 empresas de Fortune ya disponen de un documento formal de ética. Y según un reciente estudio del IESE, el 43\% de las grandes empresas españolas ya cuenta con un código de comportamiento empresarial. En empresas internacionales esta cifra llega al $65 \%$.

Figura 1.6. Grupos de trabajo.

\begin{tabular}{|c|c|}
\hline GT\#1 & Instrumentos Financieros Éticos \\
\hline GT\#2 & Gestión Ética y Social de las Empresas \\
\hline GT\#3 & Códigos Éticos Profesionales \\
\hline GT\#4 & Sistemas de Gestión de ONG y ONL \\
\hline GT\#5 & Bioética y Tecnología \\
\hline
\end{tabular}




\subsubsection{La Norma SA8000: Certificación de la gestión ética}

La sociedad en general y todas las partes involucradas en la actividad empresarial esperan que la empresa se comporte siguiendo una conducta ética. Pero, ¿qué consigue la empresa cuando aplica unos valores y principios éticos en su gestión? La organización se siente más prestigiada, más segura de garantizar el trabajo bien hecho (Samper, 2000) alcanzando así altos niveles de eficacia (Velasco, 2000).

En la práctica, las empresas están incorporando a su gestión diferentes tipos de programas con el fin de paliar esa desconfianza que se está produciendo en todos los órdenes, ya sea económico, social, político, etc., por lo que se considera falta de ética (Urtiaga, 2000). Entre ellos pueden citarse el establecimiento de códigos de internos de conducta; las aportaciones económicas a distintos programas sociales; la contratación de personal con minusvalías; el patrocinio, fundación o mecenazgo; las campañas formativas de carácter social; el apoyo a la gestión de organizaciones sociales; las donaciones en especie; las campañas de marketing con causa; o las campañas de voluntariado.

Esta creciente preocupación de la sociedad por la gestión ética de la empresa ha dado origen a la Social Accountability International (SAI), entidad creada en 1997 bajo el nombre de CEPAA (Council on Economic Priorities Accreditation Agency). Esta organización trata de responder a las inquietudes que los consumidores tienen respecto a las condiciones laborales que existen en el mundo. A principios de los noventa, un gran número de empresa estadounidenses y europeas comenzaron a reaccionar ante estos hechos y a promulgar códigos de conducta aplicables a todo el entorno laboral. Cada empresa comenzó a implantar aisladamente sus propios códigos deontológico, lo que provocó una serie de dificultades para los consumidores que deseaban una transparencia en los datos y para las propias empresas que los aplicaban.

La falta de coherencia entre los distintos códigos llevó a CEPAA a desarrollar una normativa aplicable a las condiciones laborales y un sistema de verificación independiente de la conformidad de las instalaciones productivas.

La normativa desarrollada por SAI se denomina Social Accountability 8000 (Responsabilidad Social 8000) y es una norma universal sobre responsabilidad social, auditable y certificable por tercera parte.

Su sistema de verificación se ampara en estrategias ya consolidadas de aseguramiento de la calidad, añadiendo elementos definidos por expertos internacionales en derechos humanos fundamentales para la auditoría de aspectos sociales.

Se resumen en dos las particularidades de la SA 8000:

1. Es la primera norma que sirve para establecer un sistema auditable y certificable que permite evaluar el cumplimiento de unas condiciones mínimas de relaciones laborales entre el empresario y el trabajador.

2. Promueve prácticas de trabajo aceptables y cubre un amplio campo de áreas partiendo de los principios internaciones aplicables a los derechos 
humanos según se plantean en los Convenios de la Organización Internacional del Trabajo, la Carta de Derechos del Niño y la Declaración Universal de Derechos Humanos de la ONU.

Esta norma emplea el enfoque de sistemas para gestionar los temas relacionados con la responsabilidad social en los negocios. Para ello, establece requisitos de responsabilidad social, donde se especifican las normas básicas sobre derechos laborales básicos, seguridad e higiene, niveles de remuneración, etc.; y elementos del sistema de gestión, necesarios para asegurar que la empresa cumple los requisitos de responsabilidad social establecidos.

El sistema SA 8000 de verificación se ampara en unos procesos profesionales de certificación (actualmente existen aproximadamente 90 empresas certificadas que representan un total de 22 sectores industriales y 22 países) y acreditación con los que se aumenta la objetividad y el control de la calidad.

La actividad empresarial debe contemplar un análisis reflexivo desde el punto de vista de los valores humanos y comportamientos éticos. Hay que avanzar hacia un concepto de organización que sepa combinar su fuerza en el mercado con la sensibilidad ante las necesidades de sus clientes y de sus trabajadores. Aplicar la ética a las distintas actividades tiene que ser un elemento imprescindible para desarrollar el trabajo que, además de basarlo en la experiencia y en los conocimientos adquiridos, debe estar fundamentado en una ética profesional y cívica. La ética es compatible con las exigencias del negocio y con los condicionantes a que se ve sometida la actividad empresarial, económica y la vida de empresa. Es necesario ser muy rotundos en esto: no puede haber calidad profesional sin calidad humana.

\section{Conclusiones}

La gente satisfecha, feliz y apasionada con su trabajo, a la que, además, se le permite "ser libre", desarrolla patrones de comportamiento, profesionales y personales, adecuados y válidos. Esta combinación es la más potente y poderosa fórmula de generar empresas "valiosas". Se trata ¡ni más ni menos! de crecer con y hacer que crezcan personas buenas.

\section{Bibliografía}

- Alfonso GARRE, J. (2001): Normalización en el campo de la ética. Ponencia presentada al II Congreso de Calidad, Santiago de Compostela.

- ANZIZU FUREST, JOSÉ Ma.; GARCÍA SÁNCHEZ, SALVADOR (1997): Dirección por valores ( $D p V$ ). Alta Dirección, $\mathrm{n}^{\circ}$ 191, págs. 59-67.

- APD y HAYGROUP (2000): "Situación en España de la gestión del talento". Jornada La gestión del talento para triunfar en la nueva economía, APD, 22 de junio de 2000.

- ARGANDOÑA, A. (1994): La ética en la empresa. Instituto de Estudios Económicos. 
- ARGANDOÑA, A. et al. (1997): Ética y empresa: una visión multidisciplinar. Fundación Argentaria.

- ARROYO MUÑOZ, A.; GANZARAIN, J. (2003): "La creatividad en el contexto de las organizaciones", Robotiker.

- BADARACCO JR., J.L.; WEBB, A.P. (1995): "Business ethics: A view from the trenches". California Management Review, volumen 37, número 2.

- BETRIOU, J.L.; DE MONTILLE, A. (1992): Analysing the justification of acquisition differences. Memorandum, unpublished.

- BOllaín PASTOR, J. (2001): Certificación de la gestión ética: norma SA 8000. Ponencia presentada al II Congreso de Calidad, Santiago de Compostela, abril.

- CABRERA, J. (2000): "El talento como fuente de innovación", Jornada La gestión del talento, más allá de la gestión del conocimiento, APD, 22 de junio.

- CASTILLEJO, M. (1998): "Códigos de conducta para empresas transnacionales", en RODRÍGUEZ CARRASCO, J.M. y S. GARRIDO (eds), Fundamentos de la dirección estratégica. Lecturas. Ediciones Pirámide.

- CEPAA (2001): Los códigos deontológico y la demanda relativa a una normativa internacional.

- Com. Better management through value analysis. Commision of the European Communities, Luxemburgo-1993.

- CORTINA, A. (1993): Ética aplicada y democracia radical. Tecnos.

- CORTINA, A. (1998): Ética de la empresa. Editorial Trotta.

- CORTINA, A., dir. (1997): Rentabilidad de la ética para la empresa. Fundación Argentaria.

- CUBEIRO, J. (2000): "Claves de la nueva economía: coaching, Capital Intelectual y velocidad". Jornada La gestión del talento, más allá de la gestión del conocimiento, $A P D, 22$ de junio.

- CUBEIRO, J. (2000): TGP (Tu Gurú Particular). Ed. Martínez Roca.

- DÍEZ DE CASTRO, J.; REDONDO LÓPEZ, C. (1994): "A empresa moral: Unha previsión normativa". Revista Galega de Economía, volumen 3, n 1 .

- DÍEZ DE CASTRO, J.; REDONDO LÓPEZ, C. (1999): "En busca de la empresa ética". Alta Dirección, no 204, marzo-abril.

- FLECHA, J. R., editor (1999): Europa, ¿mercado o comunidad? Publicaciones Universidad Pontificia de Salamanca.

- GARCÍA SERENA, I. (2000): "Los nuevos retos de la empresa: creatividad y talento directivo", Jornada Retos y Oportunidades de las empresas: Capacidad creadora y estilos de dirección, hacia la igualdad de oportunidades por el talento, $A P D, 14$ de febrero.

- GAUTHIER, P.Y. (1992): Goodwill; A risk to be assessed. Memorandum unpublished. 
- GEER, H. DE (ed): (1994): Business ethics in progress? Springer-Verlag.

- GÉLINIER, O. (1991): Ética de los negocios. Espasa Calpe-Ciencias de la Dirección.

- GÓMEZ JIMÉNEZ, E.M. (1995): Ética empresarial y códigos de conducta. Esic Market, $n^{\circ} 88$, abril-junio.

- HENDRIKSEN E.S. (1982): Accounting theory. Irwin.

- HICKSON, D.J.; PUGH, D.S. (1995): Management worldwide. The impact of societal culture on organizations around the globe. Penguin Books.

- HINTERHUBER, HANS H.; POPP, WOLFGANG (1992): Cómo distinguir un estratega de un simple directivo. Harvard Deusto Business Review, ${ }^{\circ}$ 51, págs 4-14.

- HOFFMAN, W.M., editor (1994): Emerging global business ethics. Quorum Books.

- HOFSTEDE, G. (1997): Cultures and organizations. Software of the mind. McGraw-Hill.

- HURTADO RODERO, R. (2001): La normalización ética y social. Ponencia presentada al II Congreso de Calidad, Santiago de Compostela, abril.

- JERICÓ, P. (2000): Gestión del Talento. Ed. Prentice Hall.

- KASTIKA, E. (1999): Los 9 mundos de la creatividad en el management. Ed. Macchi, Bogotá.

- LEVESQUE, L.C. (2001): "Creative talent". Executive Excellence, vol. 18, $\mathrm{n}^{\circ} 9$, pág. 15.

- LEWIS, M. (1999): "The new new thing: a Silicon Valley story". Norton \& Company.

- LUSCH, R.; HARVEY, M. (1995): El gestor financiero debe valorar los recursos que no figuran en el balance. Harvard-Deusto Business Review. $\mathrm{N}^{\mathrm{o}}$ 68. También publicado en Sloan Management Review. Referencia $\mathrm{N}^{\mathrm{o}} 0218$.

- LUTBAKIN, M.; CHATERJEE, S. (1991): "The strategy-shareholder value relationship. Testing temporal stability across market cycles". Strategic Management Journal, Vol. 12, págs. 251-270.

- MEDINA, J. (1999): "En busca del talento humano". Jornada La inteligencia emocional de la alta dirección y su impacto en la creación de valor, APD, 23 de noviembre.

- MICHALKO, M. (2001): “Jump start your company's creativity”, SuperVision, vol. 62, nº 1, págs. 14-16.

- MILLER, M. C. (1973): “Goodwill; An aggregation issue”. The Accounting Review, April, págs. 280- 291.

- MOLINA BELlidO, A. (1999): Ética y negocios. Documentos de gestión. 
- MUR, C. (1999): La calidad como puente a la excelencia. Documentos de gestión.

- QUEJIDO, E. (1999): Ética y negocios: Factores de competitividad. La norma SA 8000. Documentos de gestión.

- RODRIGO, J. (2002): "La creatividad en la empresa", Euskotek: Revista de la Red de Parques Tecnológicos de Euskadi, nº 10, págs. 16-19.

- ROSET, M.T.(1999): Ética y negocios: Factores de competitividad. Documentos de gestión.

- SAI (1997): Norma SA 8000 y modificaciones SA 8000: 2001.

- SAMPER, I. (2000): Calidad, ética y gestión. Documentos de gestión.

- SAN JOSÉ, R. (1998): La ética aplicada al mundo empresarial. Documentos de gestión.

- SAVATER, F. (1998): Ética para Amador. Editorial Ariel, 31ª edición.

- SCHEIN, E.H. (1985): Organizational Culture and Leadership. Jossey-Bass.

- SEGURA, I. M. (1998): Ética y negocios. Documentos de gestión.

- SÉRIEYX, H. (1994): El big bang de las organizaciones. Ediciones B.

- TANNER, D. (2003): “Creativity management-roadmap to building a more innovative organization", Strategic Direction, vol. 19, no 4, págs. 2-4.

- URTIAGA DE VIVAR FRONTELO, A. (1999): Ética y negocios: Factores de competitividad. Documentos de gestión.

- URTIAGA DE VIVAR FRONTELO, A. (2000): Certificación de la gestión ética. Documentos de gestión.

- URTIAGA DE VIVAR, FRONTELO, A. (2001): La calidad como modelo para la gestión ética. Foro Internacional de Normas Técnicas y Sistemas de Gestión.

- VELASCO, F. (2000): Management, calidad y ética. Documentos de gestión.

- VERNA, G. (1995): "Ética y productividad: Los efectos de la mundialización". Papeles de Ética, Economía y Dirección, nº 1.

- http://www.cepaa.org

- http://www.SA8000.org 



\section{2 \\ Capital Humano: Medición y gestión}

Carlos López Navaza

Profesor Colaborador de la Escuela de Negocios Caixanova Director de Noroeste y Portugal de Unión Fenosa Comercial 



\section{Introducción}

A lo largo del presente capítulo se quiere poner de manifiesto la necesidad de gestionar el Capital Intelectual en las empresas, y más en concreto el Capital Humano. Pero para poder gestionar es preciso determinar con anterioridad los indicadores más representativos para poder medirlo. Además, se trata de que los lectores, y especialmente los que tienen capacidad de decisión en las empresas, directivos, empresarios, etc., tomen conciencia de la necesidad de implantar en la práctica diaria estos conceptos, ya que son la fuente futura y actual de las ventajas competitivas.

Para estos fines se ha estructurado el artículo en tres grandes apartados:

- Modelos y Activos Intangibles.

- Ejemplos de indicadores de Capital Humano y experiencias prácticas.

- Propuestas de aplicación.

\section{Capital Intelectual}

La importancia de cualquier activo en una empresa se mide en relación a su contribución futura a la creación de valor. En la actualidad, los activos que confieren mayor contribución al valor de la empresa, cuya importancia irá creciendo en el futuro, son los activos intangibles, que conforman lo que se denomina Capital Intelectual de la empresa.

Según la International Accounty Standard Board (IASB), se define como activo intangible al activo identificable de carácter no monetario y sin apariencia física, que se tiene para ser utilizado en la producción o suministro de bienes y servicios, para ser arrendado a terceros, o para funciones relacionadas con la administración de la empresa.

La definición de activos intangibles puede establecerse como el conjunto de recursos y capacidades difíciles de intercambiar, imitar o sustituir, escasos, complementarios, duraderos, apropiables y que confieren a la empresa su ventaja competitiva. La literatura coincide crecientemente en señalar a los activos intangibles como la fuente básica de las competencias distintivas de la empresa (Grant, 1996, Barney, 1991 Amit y Schoemaker, 1993).

Pero ¿en qué partes podemos dividir el Capital Intelectual? Diversos autores lo han analizado y la envolvente más genérica de todas las aportaciones señala que el Capital Intelectual está compuesto de 3 elementos: Capital Humano, Capital Estructural y Capital Relacional. 
Dado que el Capital Intelectual es uno de los activos más importantes cara a la generación de valor de las organizaciones, es importante medirlo, ya que a partir de esta medición será posible su gestión. Se dice que "lo que no se mide, no se gestiona", de ahí la importancia de medirlo, sin embargo, como decía Einstein, la medición es difícil: "Un montón de cosas que pueden ser contadas, no cuentan, y otro montón de cosas que cuentan, no pueden ser contadas".

Figura 2.1. Componentes del Capital.

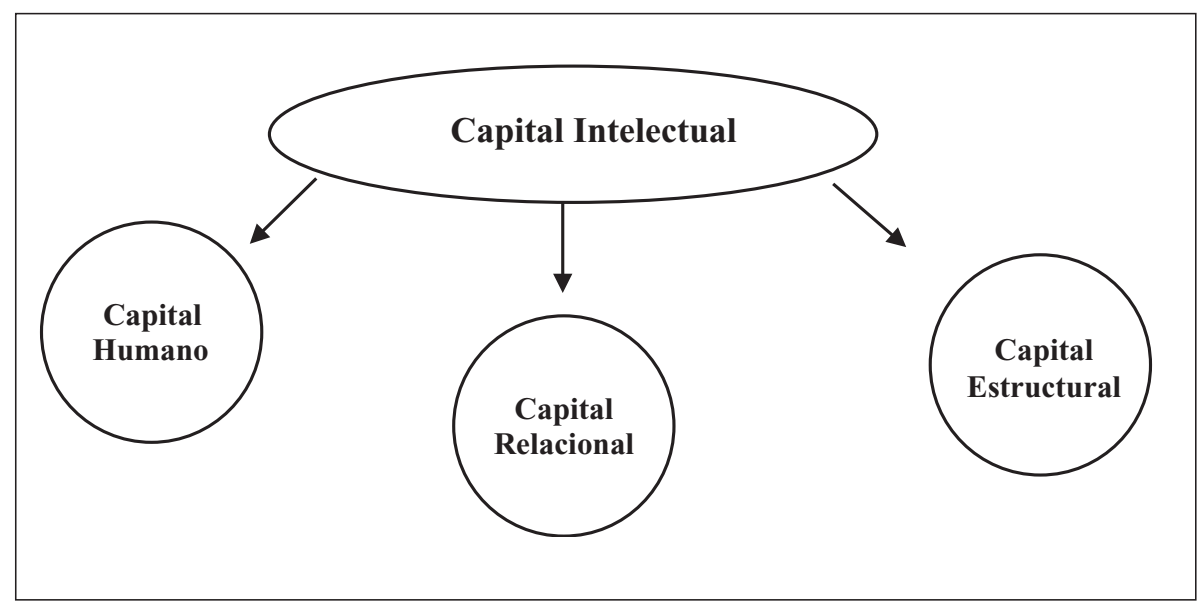

La medición de los activos intelectuales o intangibles presenta serias dificultades. Se han utilizado técnicas de todo tipo para llegar a cuantificar el valor de dichas partidas, algunas de ellas simples formulismos matemáticos exentos de todo contenido económico, pero que, sin embargo, han permitido tomar en consideración la existencia de unas fuentes de valores reales, positivas y fundamentales.

La búsqueda de algún sistema capaz de medir el valor de los activos intelectuales ha provocado la aparición en los últimos años de un amplio abanico de modelos y teorías al respecto. Se recogen en la Tabla 2.1. las aproximaciones más ampliamente aceptadas, que, a su vez, pueden ser clasificadas de un modo más general en cuatro grandes categorías o grupos:

I - Métodos directos (DIC).

II - Métodos basados en la capitalización de mercado (MCM).

III - Métodos basados en la rentabilidad de los activos (ROA).

IV - Métodos de tanteo (SC). 


\section{Tabla 2.1. Métodos de valoración de Activos Intangibles o Capital Intelectual.}

\begin{tabular}{|l|c|c|l|}
\hline \multicolumn{4}{|c|}{ MÉTODOS DE VALORACIÓN DE ACTIVOS INTANGIBLES } \\
O DEL CAPITAL INTELECTUAL
\end{tabular}


Tabla 2.1. Métodos de valoración de Activos Intangibles

o Capital Intelectual. (Cont.)

\begin{tabular}{|c|c|c|c|}
\hline \multicolumn{4}{|c|}{$\begin{array}{l}\text { MÉTODOS DE VALORACIÓN DE ACTIVOS INTANGIBLES } \\
\text { O DEL CAPITAL INTELECTUAL }\end{array}$} \\
\hline Método & Autor & Grupo & Medición \\
\hline $\begin{array}{l}\text { Investor } \\
\text { Assigned } \\
\text { Market } \\
\text { Value } \\
\text { (IAMV) }\end{array}$ & $\begin{array}{l}\text { Stanfield } \\
(1998)\end{array}$ & $\mathrm{MCM}$ & $\begin{array}{l}\text { Toman como cierto el valor de mercado } \\
\text { de la empresa y lo dividen entre el capi- } \\
\text { tal no tangible y le suman otros factores } \\
\text { como el valor de las ventajas competiti- } \\
\text { vas sostenibles. }\end{array}$ \\
\hline $\begin{array}{l}\text { Market-to- } \\
\text { Book } \\
\text { Value }\end{array}$ & $\begin{array}{l}\text { Stewart } \\
(1997) \\
\text { Luthy } \\
(1998)\end{array}$ & $\mathrm{MCM}$ & $\begin{array}{l}\text { Consideran que el valor del Capital In- } \\
\text { telectual es la diferencia entre el valor } \\
\text { de mercado de la empresa y su valor en } \\
\text { libros. }\end{array}$ \\
\hline $\begin{array}{l}\text { Economic } \\
\text { Value } \\
\text { Added } \\
\text { (EVA) }\end{array}$ & $\begin{array}{l}\text { Stewart } \\
(1997)\end{array}$ & $\mathrm{ROA}$ & $\begin{array}{l}\text { Calculan la parte del beneficio generada } \\
\text { por los intangibles. Los cambios en EVA } \\
\text { indican en qué medida es productivo el } \\
\text { Capital Intelectual. }\end{array}$ \\
\hline $\begin{array}{l}\text { Human } \\
\text { Resource } \\
\text { Costing \& } \\
\text { Accounting } \\
\text { (HRCA) }\end{array}$ & $\begin{array}{l}\text { Johansson } \\
\text { (1996) }\end{array}$ & $\mathrm{ROA}$ & $\begin{array}{l}\text { Calculan el valor del Capital Intelectual a } \\
\text { través de la relación entre la contribución } \\
\text { a la empresa de sus Recursos Humanos y } \\
\text { los costes generados por ellos. }\end{array}$ \\
\hline $\begin{array}{l}\text { Calculated } \\
\text { Intangible } \\
\text { Value }\end{array}$ & $\begin{array}{l}\text { Stewart } \\
\text { (1997) } \\
\text { Luthy } \\
(1998)\end{array}$ & $\mathrm{ROA}$ & $\begin{array}{l}\text { Calculan el exceso del beneficio genera- } \\
\text { do por los activos tangibles como base } \\
\text { para el cálculo de la proporción del bene- } \\
\text { ficio atribuible al Capital Intelectual. }\end{array}$ \\
\hline $\begin{array}{l}\text { Knowledge } \\
\text { Capital } \\
\text { Earnings }\end{array}$ & Lev (1999) & ROA & $\begin{array}{l}\text { Calculan el KCE como la porción de los } \\
\text { beneficios no relacionados con las ga- } \\
\text { nancias esperadas por los activos inclui- } \\
\text { dos en libros. }\end{array}$ \\
\hline $\begin{array}{l}\text { Value } \\
\text { Added } \\
\text { Intellectual } \\
\text { Coefficient } \\
\text { (VAIC) }\end{array}$ & Pulic (1997) & ROA & $\begin{array}{l}\text { Miden la capacidad de crear valor de la } \\
\text { empresa y el valor del Capital Intelec- } \\
\text { tual a través de la relación entre el Ca- } \\
\text { pital Financiero, el Capital Humano y el } \\
\text { Capital Estructural. }\end{array}$ \\
\hline $\begin{array}{l}\text { Human } \\
\text { Capital } \\
\text { Intelligence }\end{array}$ & $\begin{array}{l}\text { Jac Fitzenz } \\
\quad(1994)\end{array}$ & $\mathrm{SC}$ & $\begin{array}{l}\text { Capturan y tratan una serie de indicado- } \\
\text { res relacionados con el Capital Humano } \\
\text { a través de una base de datos. }\end{array}$ \\
\hline
\end{tabular}




\section{Tabla 2.1. Métodos de valoración de Activos Intangibles o Capital Intelectual. (Cont.)}

\begin{tabular}{|l|c|c|l|}
\hline \multicolumn{2}{|c|}{ MÉTODOS DE VALORACIÓN DE ACTIVOS INTANGIBLES } \\
O DEL CAPITAL INTELECTUAL
\end{tabular}

Fuente: López Cabarcos y Vázquez, 2001.

El método directo establece el valor del Capital Intelectual en base a una serie de índices o indicadores.

Los métodos basados en la capitalización del mercado, establecen el valor económico del Capital Intelectual a partir del valor reconocido a la empresa por el mercado de valores o similar. 
Los métodos basados en la rentabilidad de los activos, establecen también el valor de los activos intelectuales en términos económicos a partir de beneficios, contribuciones o similar.

Por último, los métodos de tanteo, establecen una serie de indicadores para medir aspectos intangibles.

Cada uno de los grupos citados ofrece ventajas e inconvenientes. Los métodos que arrojan una cifra de valor en unidades monetarias (II y III) son muy útiles cuando se realizan determinadas operaciones entre empresas (fusiones, adquisiciones, etc.), que permiten hacer comparaciones con otras organizaciones pertenecientes a la misma industria, e ilustrar el valor financiero de los activos intelectuales o intangibles. Por el contrario, presentan como desventaja que, al traducir todo a unidades monetarias, estos métodos pueden resultar, cuando menos, insuficientes y excesivamente dependientes de determinadas inquietudes financieras para una correcta gestión.

Los otros dos grupos de métodos, por no basarse en mediciones puramente financieras, son capaces de ofrecer una imagen más real y ajustada de la "salud" de la organización, pudiendo ser aplicados a cualquier tipo de organización y a cualquier nivel dentro de ésta. Las desventajas que presentan están relacionadas con que los indicadores dependen del contexto de cada empresa y del propósito de la valoración, lo que dificulta enormemente hacer comparaciones, además de generar una enorme cantidad de información difícil de analizar y comunicar.

Los modelos constituyen un primer avance en la medición de los activos intangibles, y su valor reside en que son los antecedentes que están sentando las bases de lo que en el futuro se reconocerá como un modelo de validez universal y competitiva. Lo que diferencia a unos modelos de otros es la agrupación de los activos intangibles en grupos o bloques, así como la calidad de los indicadores.

Entre los diferentes modelos, hemos seleccionado los que nos parecen más representativos al objeto buscado de medición, realizando a continuación una síntesis de los mismos.

\subsection{Cuadro de Mando Integral}

El Cuadro de Mando Integral es, más que un modelo que permite la medición de intangibles, un sistema de gestión que tiene en consideración, tanto los medidores clásicos de una empresa -los financieros- como los medidores de Capital Intelectual.

El Cuadro de Mando surge como un sistema de medición para facilitar a las empresas la tarea de la administración, con la finalidad de mejorar la creación de valor a largo plazo.

El modelo propone la medición de cuatro perspectivas de la empresa con características homogéneas entre sí. Una primera perspectiva es la financiera. Esta medida posee una serie de indicadores que son outcome measures, es decir, medidas de resultado. 
Las tres perspectivas restantes poseen en común que sirven para la medición de activos intangibles, proporcionando a la empresa performance drivers, es decir, indicadores de actuación futura.

Dichas perspectivas son la perspectiva de clientes, la perspectiva de procesos internos de negocios, y la perspectiva de aprendizaje y crecimiento.

La perspectiva de clientes identifica los valores relacionados con los clientes que aumentan la capacidad competitiva de la empresa. La perspectiva de procesos internos de negocio analiza la adecuación de los procesos internos de la empresa a la obtención de la satisfacción del cliente, y a conseguir altos niveles de rendimiento financiero. Es decir, esta perspectiva no se observa de modo independiente, sino que relaciona la mejora en ella con la mejora de los procesos financieros.

Dentro de esta perspectiva se diferencian tres tipos de procesos:

1. Procesos de Innovación: Se trata de procesos de difícil medición por su intangibilidad.

2. Procesos de Operaciones: Son aquéllos desarrollados a través de los análisis de reingeniería y calidad.

3. Procesos de servicio postventa: Todos aquellos derivados de la relación con los clientes en base a los productos ya vendidos, buscando mejorar la calidad de los mismos y el servicio ofrecido.

La perspectiva de procesos internos proporciona a la empresa la capacidad de mejorar las relaciones con los clientes a través de los tres procesos comentados. A su vez, las relaciones con los clientes incidirán sobre una mejora en los resultados financieros, tal y como apuntamos anteriormente.

La perspectiva del aprendizaje dota a la empresa de la capacidad de aprender y mejorar. La contabilidad tradicional considera la formación como un gasto, en contraposición con la visión de Kaplan y Norton, que la considera una inversión que ha de generar flujos de caja en el futuro.

Esta perspectiva influye a las restantes del modelo, incidiendo, de modo directo o indirecto (a través de las otras dos perspectivas relativas a intangibles) en el resultado de la empresa.

Se clasifican los activos relativos al aprendizaje y mejora en tres categorías:

1. Capacidad y competencia de las personas (gestión de los empleados).

2. Sistemas de información (soporte físico y humano a través del cual circula la información de la empresa).

3. Cultura-clima-motivación para el aprendizaje y la acción.

De todo lo comentado destacan dos aspectos clave en el Cuadro de Mando Integral:

1. Interrelación entre los elementos componentes: Los componentes no son compartimentos estancos que funcionen de modo independiente unos de 
otros, sino que existen relaciones entre ellos. El buen funcionamiento de unos incide sobre los restantes en un proceso continuo. La Figura 2.2. muestra dichas relaciones a través de las flechas que representan flujos entre las cuatro perspectivas.

Existe una relación causa-efecto en el modelo. Un ejemplo sería el siguiente: la capacitación y motivación del personal (perspectiva de aprendizaje y crecimiento) se encuentra en disposición de realizar productos y servicios de calidad, (perspectiva de los procesos internos). Los productos y servicios de calidad consiguen una mayor satisfacción de los clientes, y es probable que éstos los compren repetidamente (perspectiva del cliente). A su vez, la repetición de compras de dichos clientes incrementa la rentabilidad de la empresa (perspectiva financiera). El incremento de la rentabilidad provoca que accionistas o titulares de la empresa estén conformes, y continuen la inversión en programas de capacitación y motivación de los empleados.

2. La estrategia de la empresa debe ser el denominador común que mantenga la unidad de objetivos entre las cuatro perspectivas. Por ello, a la hora de la elaboración del Cuadro de Mando Integral, deben establecerse los objetivos para cada unidad de negocio en función de la estrategia, de modo que la actuación de unas áreas resulte coherente con los objetivos de las restantes. Este aspecto también aparece recogido en la Figura 2.2. que se recoge a continuación.

Figura 2.2. Representación esquemática del Cuadro de Mando Integral.

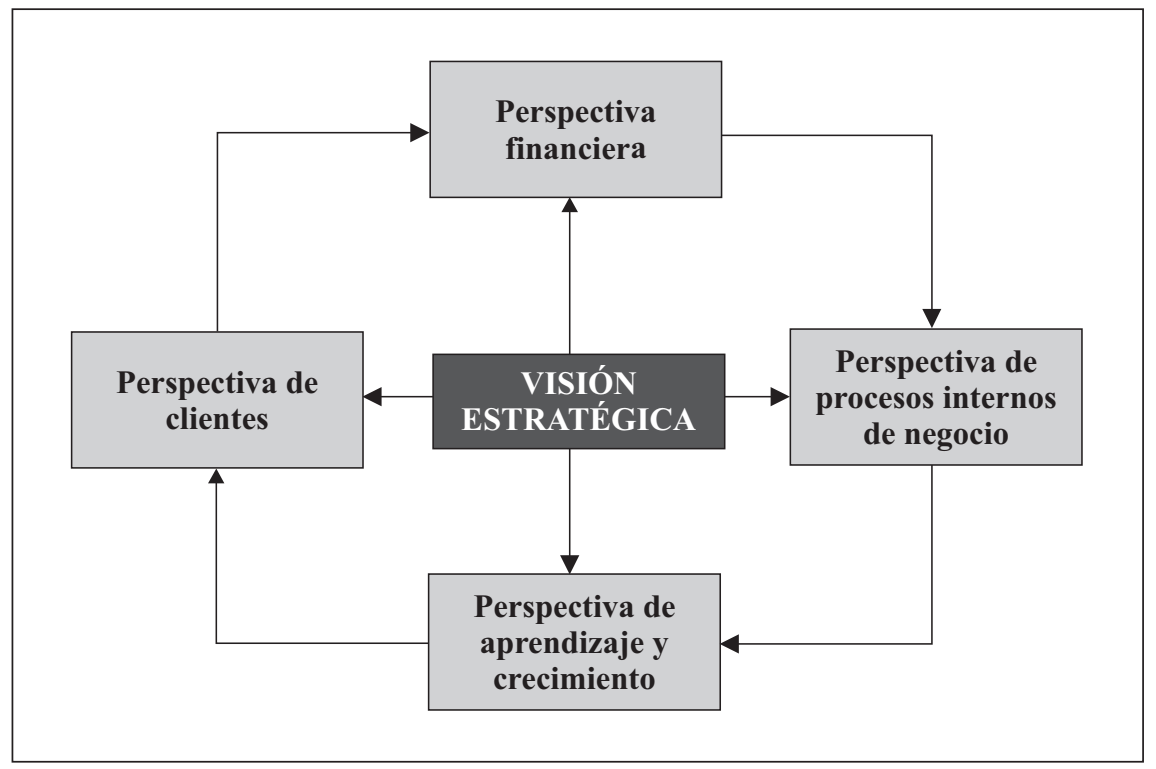

Fuente: Kaplan y Norton, 1997. 


\subsection{Modelo Technology Broker}

En el modelo desarrollado por Brooking (1996), el Capital Intelectual está compuesto por los activos inmateriales que permiten a la empresa funcionar.

Empresa $=$ Activos materiales + Capital Intelectual

Asimismo, identifica cuatro grandes grupos que integran el Capital Intelectual:

- Activos de mercado: Incluyen activos tales como la marca, la clientela y su fidelidad, la repetición del negocio, la reserva de pedidos, los canales de distribución, diversos contratos, y acuerdos como licencias y franquicias. Se trata de las ventajas que la empresa posee en el mercado procedente de activos inmateriales.

- Activos centrados en el individuo: Son todos aquellos activos que están en posesión de los trabajadores de la empresa. Por lo tanto, no son propiedad de la misma, sino que ésta únicamente los arrienda. Se incluye la capacidad de trabajar en grupo, la habilidad para la resolución de problemas, el liderazgo, la capacidad empresarial y de gestión (en este caso relativa a los empresarios).

- Activos de propiedad intelectual: Se trata de elementos tales como el know-how, los secretos de fabricación, el copyright, las patentes y marcas de fábrica y de servicios.

- Activos de infraestructura: Incluye tecnologías, metodologías y procesos que permiten el funcionamiento de la empresa. En este grupo se incluye la cultura organizativa, las metodologías para el cálculo de riesgos, métodos de dirección de la fuerza de ventas, la estructura financiera, las bases de datos que informan sobre el mercado o los clientes, así como los sistemas de comunicación como el e-mail y los nuevos sistemas de teleconferencia.

Figura 2.3. Composición del Capital Intelectual.

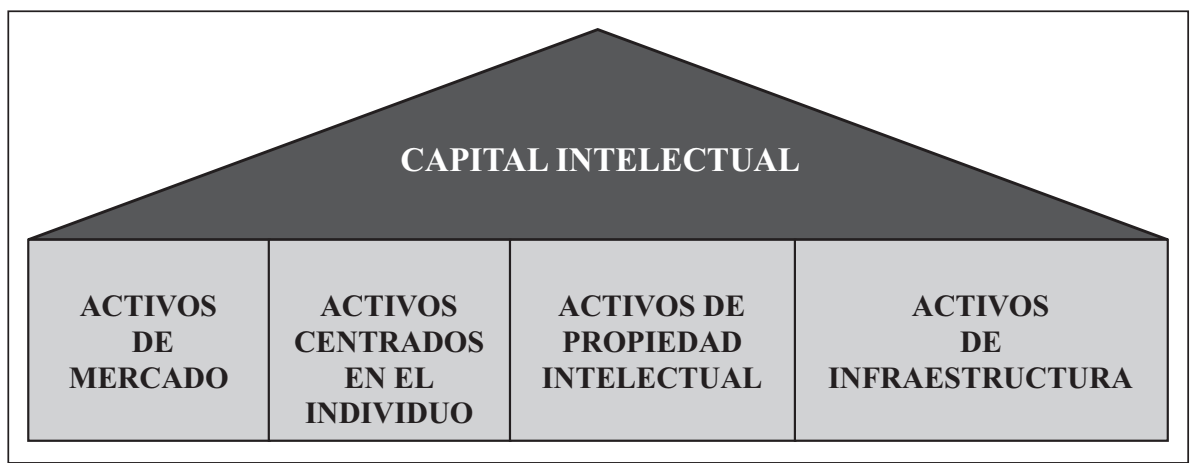

Fuente: Brooking, 1997.

La importancia del Capital Intelectual se justifica por los cambios producidos en la economía. Antes, la competitividad de una empresa se medía en términos 
de activos tangibles, siendo la mano de obra relativamente barata y fácilmente sustituible en la mayor parte de los casos, por tratarse de tareas que casi cualquier persona con una escasa formación podría realizar. Se trataba de la "cosificación" del trabajador. El trabajador no era considerado como persona con unos conocimientos útiles, sino como una herramienta más del proceso productivo.

En la actualidad, y más en el futuro, las empresas de servicio necesitarán una infraestructura mínima, consistente principalmente en tecnología informática. Las personas precisarán de los conocimientos técnicos adecuados. A través de la utilización de los sistemas informáticos y la aplicación de los conocimientos de los trabajadores, se prestará el servicio correspondiente.

Annie Brooking distingue numerosos elementos en cada uno de los grupos de Capital Intelectual. Por ello, pasamos a definir en mayor profundidad cada uno de los grupos, definiendo los distintos subgrupos que los componen.

\section{Activos de Mercado}

Surgen de la relación satisfactoria de la empresa con el mercado y sus clientes. La diferencia entre el precio de adquisición de una empresa y su valor contable responde, en numerosas ocasiones, a la valoración que se hace de los activos de mercado.

Los activos de mercado se conforman de los siguientes elementos:

- Marca.

- Valía de los clientes.

- Repetibilidad del negocio.

- Canales de distribución.

- Derechos favorables de patente y otros tipos de contrato.

\section{Marcas de fábrica y de servicio}

Una marca de fábrica puede ser un nombre, un rótulo con un diseño determinado, una fotografía, un dibujo, un logotipo o la combinación de varios de los elementos comentados. La marca de fábrica se asocia a una empresa y sus productos, distinguiéndolos de otros. La marca de fábrica se puede registrar, protegiendo del uso fraudulento por terceros.

Las marcas de servicio se diferencian de las de fábrica en la naturaleza de la empresa, siendo en este caso una empresa de servicios quien las utiliza, frente al caso anterior que eran empresas industriales.

\section{Secretos de fabricación}

Los secretos de fabricación abarcan un amplio campo de elementos, resultando todos ellos positivos para la empresa. Evitan que sean transmitidos a terceros, protegiéndolos a través de acuerdos de confidencialidad y de no publicación con los empleados.

Un secreto de fabricación es una fórmula de protección que se emplea para elementos tales como un invento sin patentar, una serie de datos, un invento de nueva creación o un procedimiento de fabricación. 


\section{Know-how}

El know-how es un cúmulo de conocimientos, tácitos o explícitos, que en conjunto confieren al individuo la habilidad en la realización de determinadas tareas y la resolución de problemas.

El know-how es inherente al individuo y resulta muy difícil de almacenar externamente. Tan sólo se podrá hacer esto para ciertos tipos de conocimientos fácilmente explicitables.

\section{Activos centrados en el individuo}

En la actualidad la actividad que desarrollan muchos trabajadores se ve limitada a unas tareas muy concretas, derivadas del puesto que desempeñan en la empresa. Se puede ocasionar un uso ineficiente de los conocimientos de la empresa si cada uno es un puesto y necesita responder únicamente de los resultados de dicho puesto, en lugar de cubrir las necesidades de la empresa y de sus clientes de un modo más general.

La empresa debe estar en disposición de cubrir las necesidades del mercado. Por ello, sus productos y servicios deben adaptarse a las nuevas necesidades que surgen en un entorno cambiante. Debido a ello, es preciso el empleo más eficiente de los conocimientos en la empresa. Annie Brooking distingue tres tipos de conocimiento. Conocimiento tácito, explícito e implícito.

El individuo, con una capacidad de cálculo inferior, desarrolla mejores respuestas, al ser capaz de descartar algunas posibilidades o grupos de ellas, de modo consciente o inconsciente.

Los activos centrados en el individuo son, para Brooking, los de mayor importancia, puesto que los restantes se derivan.

- Conocimiento tácito: Es conocimiento inherente a los individuos, pudiendo hacer uso de él, pero resultando muy difícil su transmisión. Se trata de conocimiento subconsciente, por lo que no resulta fácil su paso al plano consciente.

- Conocimiento explícito: Puede ser documentado por escrito con facilidad, puesto que el individuo es consciente de su existencia. En algunos casos se trata de un problema sistemático fácilmente transmisible al papel.

- Conocimiento implícito: Annie Brooking diferencia un tercer tipo de conocimiento, el implícito. La diferencia entre tácito e implícito se encuentra en que el primero reside en las personas, mientras que el segundo lo hace a nivel grupal. Se halla en los procedimientos operativos, en los métodos y en la cultura de la empresa. Se trata de un conocimiento grupal.

Los conocimientos son la base para la competitividad de la empresa. Por lo tanto, los individuos son la clave para poseer dicha competitividad. Aún cuando se han intentado desarrollar sistemas expertos basados en inteligencia artificial, éstos sólo resultan interesantes para problemas sistemáticos. 


\subsubsection{Activos de infraestructura}

Los activos de infraestructura dotan a la empresa de la capacidad de interrelacionar a sus miembros, permitiendo que se trabaje como un grupo y no como una desaprovechada suma de individualidades desorganizadas entre sí. La carencia de una infraestructura sólida provoca la entrega de productos y la prestación de servicios de baja calidad, lo que lleva a menudo al desánimo y a la desmotivación entre los empleados. La infraestructura corporativa posee los siguientes elementos:

- Filosofía de gestión: Es la forma de pensar de los líderes de la compañía sobre la organización y los empleados. La filosofía de gestión puede ser un activo para la empresa cuando ésta se adecua a sus necesidades y se actualiza. De la misma forma, una filosofía de gestión anticuada puede ser un pasivo para la empresa.

- Cultura corporativa: La cultura corporativa determina la forma en que se realizan las tareas en la empresa. Integra una serie de elementos como los valores, los héroes, los ritos y rituales aceptados y compartidos por la fuerza de trabajo. La cultura corporativa se genera en las altas esferas de la compañía y dota a la empresa de capacidad de reacción ante el mercado.

Existen numerosos tipos de cultura que determinan la forma de trabajar y de interrelacionarse entre los individuos: cultura machista, trabaja duro/juega duro, alto riesgo/alta recompensa, familiar, basada en un proceso, basada en un héroe, basada en el trabajo en equipo, etc.

\subsection{Intelectual assets monitor}

Sveiby (1997), determina tres tipos de activos intangibles en las empresas: la competencia de los colaboradores, el componente interno y el componente externo. La Tabla 2.2. recoge dicha división, junto con algunos de los elementos que componen cada una de las categorías.

Tabla 2.2. Capital visible y activos intangibles.

\begin{tabular}{|c|c|c|c|}
\hline \multirow[b]{2}{*}{$\begin{array}{l}\text { Capital visible } \\
\text { (valor contable) } \\
\text { activos materiales } \\
\text { menos deuda } \\
\text { visible }\end{array}$} & \multicolumn{3}{|c|}{$\begin{array}{c}\text { Acivos intangibles } \\
\text { (valoración del precio de las acciones por el mercado) }\end{array}$} \\
\hline & $\begin{array}{l}\text { Componente } \\
\text { externo } \\
\text { (marcas, } \\
\text { relaciones con } \\
\text { los clientes y } \\
\text { proveedores). }\end{array}$ & $\begin{array}{l}\text { Componente } \\
\text { interno } \\
\text { (marcas, } \\
\text { relaciones con } \\
\text { los clientes y } \\
\text { proveedores). }\end{array}$ & $\begin{array}{l}\text { Competencia } \\
\text { individual } \\
\text { (educación y } \\
\text { experiencia). }\end{array}$ \\
\hline
\end{tabular}

Fuente: Sveiby, 1997.

La Figura 2.4. posee la estructura del balance de una hipotética empresa intensiva en conocimiento. En ella se ponen de manifiesto los elementos 
pertenecientes a un balance clásico junto con los elementos que conformarían el balance intangible.

Previamente a la medición de los activos intangibles de una empresa, es preciso determinar el objetivo de dicha medición teniendo en cuenta quién va a ser el usuario final. Así, existe una doble orientación: hacia el exterior, para informar a clientes, accionistas y proveedores; $y$ hacia el interior, recogiendo la información relevante para que el equipo directivo conozca la marcha de la empresa y pueda adoptar las medidas necesarias.

Figura 2.4. Balance financiero de una empresa junto con el balance de intangibles.

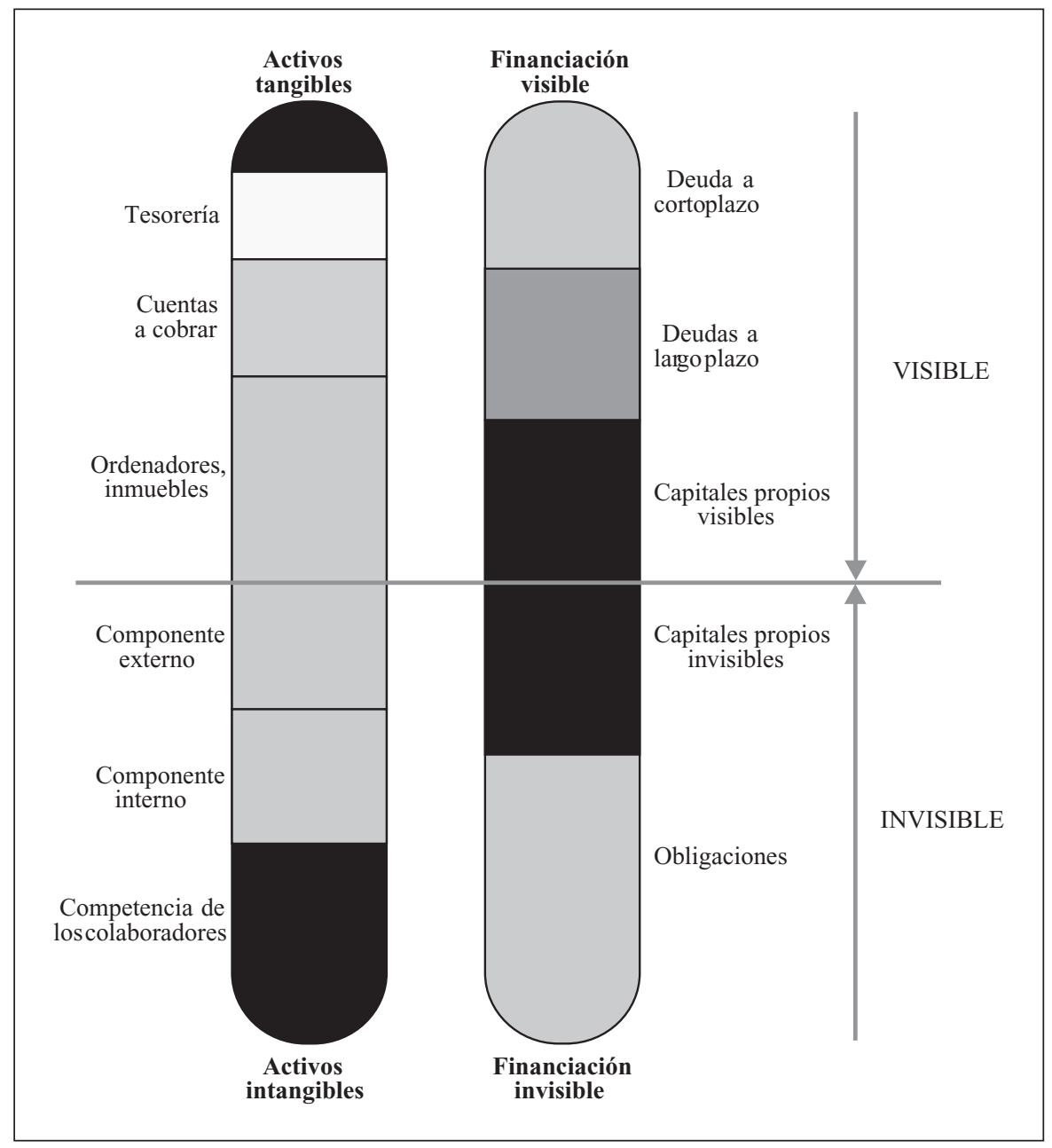

Para cada uno de los componentes se distinguen tres tipos de medidores distintos: 
- Indicadores de crecimiento/innovación: Muestran el cambio que se produce en los conocimientos de la empresa, que a su vez determinan, de forma directa o indirecta, el Capital Intelectual de la misma.

- Indicadores de la eficiencia: Muestran el grado de aprovechamiento de los distintos activos intangibles.

- Indicadores de estabilidad: Miden el grado de permanencia que poseen los distintos activos intangibles en la empresa, o lo que es lo mismo, el grado de estadía en la empresa de los conocimientos que generan el Capital Intelectual.

Combinando los tres tipos de indicadores con los tres tipos de intangibles existentes en la empresa, se obtienen una serie de medidores agrupados en nueve categorías distintas.

Tabla 2.3. Indicadores de los activos intangibles.

\begin{tabular}{|l|l|l|}
\multicolumn{1}{|c|}{ Competencia } & \multicolumn{1}{|c|}{ Componente interno } & \multicolumn{1}{c|}{ Componente externo } \\
\hline $\begin{array}{l}\text { Indicadores de } \\
\text { crecimiento/renovación }\end{array}$ & $\begin{array}{l}\text { Indicadores de } \\
\text { crecimiento/renovación }\end{array}$ & $\begin{array}{l}\text { Indicadores de } \\
\text { crecimiento/renovación }\end{array}$ \\
\hline Indicadores de eficiencia & Indicadores de eficiencia & Indicadores de eficiencia \\
\hline $\begin{array}{l}\text { Indicadores de } \\
\text { estabilidad }\end{array}$ & Indicadores de estabilidad & Indicadores de estabilidad \\
\hline
\end{tabular}

Fuente: Sveiby, 1997.

Pasamos a detallar los distintos indicadores que propone Sveiby para cada una de las categorías anteriores, teniendo en cuenta que dicha enumeración no resulta exhaustiva, aún cuando es muy completa y trata aspectos relevantes.

\section{- Medidas de la competencia}

La competencia de los empleados es un componente doblemente importante, tanto en sí mismo, como en la medida en que es generador de los componentes interno y externo de la empresa. Sveiby, cuando habla de competencia, se refiere a la competencia de los expertos, que son aquellas personas especializadas en temas concretos con alta capacidad resolutiva.

\section{- Medidas de crecimiento/renovación de la competencia}

Dentro de este grupo distingue los años de ejercicio de la profesión, el nivel de formación, las inversiones en formación, la evaluación, la rotación del personal y la aportación de los clientes a la competencia.

- Años de ejercicio de la profesión: Cuantos más años de ejercicio de profesión, existe una mayor competencia y experiencia previa para la resolución de los problemas por parte de los expertos. 
- Nivel de formación: Un mayor nivel de formación proporciona a los expertos un mayor nivel de evaluación de las competencias. En empresas que realizan una profesión específica (una empresa auditora, por ejemplo) puede medirse a través del número de expertos. En todo caso, podría emplearse la media de años de formación, lo que ayudaría a saber si el nivel ha bajado o se ha incrementado a lo largo del tiempo.

- Inversiones en formación: Aún cuando la mayor parte de la formación de los expertos es adquirida en el desarrollo de su actividad, deben ser contabilizados los gastos explícitos de formación oficial. Dichas partidas pueden ser medidas como un porcentaje de la facturación, o bien como el número de días dedicado por empleado. Tampoco debe desestimarse el tiempo ocupado en formación, puesto que supone un coste en la medida en que el empleado no ocupa dicho tiempo en su trabajo.

- Evaluación: Todas las medidas anteriores son medidas de los inputs empleados en formación, pero no hacen referencia al resultado que se obtiene sobre el trabajador, medido en términos de cómo mejorar su competencia. Por lo tanto, es preciso realizar una medición de cómo dicha formación revierte en el desempeño de los empleados. Para desarrollar dicha evaluación y poder comparar la evolución de los expertos es preciso tomar medidas a lo largo del tiempo.

- Rotación del personal: El personal de una empresa puede abandonarla o bien cambiar de puesto. Sveiby plantea que debe ser medida la competencia ganada o perdida como consecuencia de las variaciones de personal producidas en la empresa, midiendo dichas variaciones en años de experiencia.

- Aportación de los clientes a la competencia: La competencia puede ser incrementada a través de acciones orientadas a la obtención de información de los propios clientes de la empresa, de modo que los expertos adapten sus labores a las necesidades de éstos.

\section{- Medidas de eficiencia de la competencia}

Dentro de este grupo se analiza el porcentaje de expertos en la empresa, el efecto palanca y el valor añadido por experto.

- Porcentaje de expertos en la empresa: El autor concede especial importancia a la presencia de los expertos en las organizaciones intensivas en conocimiento, sosteniendo que la competencia de una empresa depende de los mismos. El cociente de dividir el número de expertos entre el de trabajadores totales en la empresa, no sólo sirve como medida comparable entre distintos períodos dentro de la propia empresa, sino que debe ser comparada con otras empresas del mismo sector.

- El efecto palanca: El efecto palanca es una medida que permite medir la participación de los expertos en la generación de volumen atribuible a los expertos. La Figura 2.5. contiene la fórmula para su cálculo. 
Figura 2.5. Formulación del cálculo del efecto palanca.

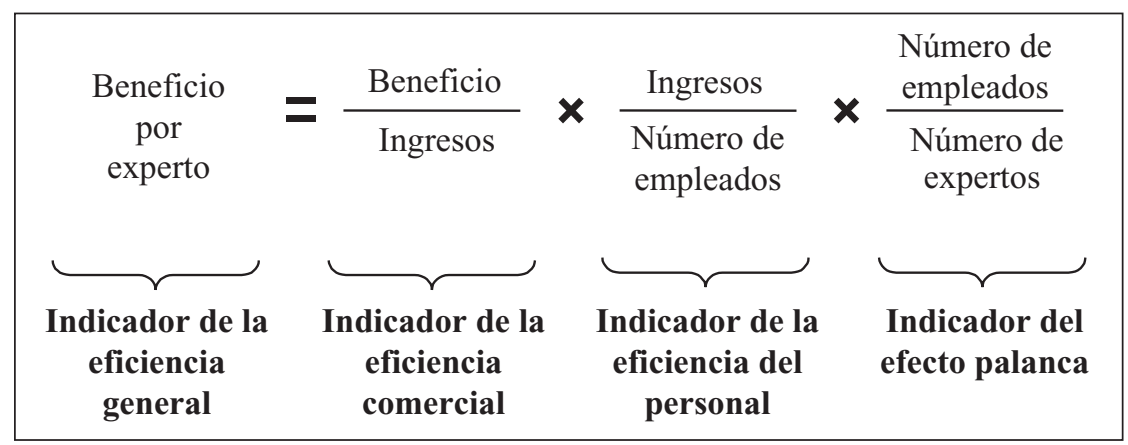

- Valor añadido por experto: En las empresas intensivas en conocimiento, son los expertos los que añaden valor a la misma, puesto que son sus conocimientos por los que pagan los clientes. De ahí que el valor añadido o generado por expertos sea la medida más exacta sobre la capacidad de las empresas intensivas en conocimiento para generar valor. La totalidad de los gastos son, directa o indirectamente, derivados de los expertos: su salario (gasto directo), gastos de desplazamiento, gastos de secretariado y gastos de dirección de personal, entre otros. El ingreso generado por los expertos debe ser suficiente para recuperar dichos gastos y generar valor para la empresa.

\section{- Medidas de la estabilidad de la competencia}

Dentro de este apartado se incluyen medidores como la edad media, la antigüedad, la situación salarial relativa y la rotación de los expertos.

- Edad media: La edad media puede ser tomada como una medida de estabilidad. Los empleados de menor edad tienen mayor tendencia a abandonar la empresa. La edad media ideal debe tomar valores intermedios, que garanticen cierta estabilidad del personal, al tiempo que incrementen las nuevas ideas y una mayor asunción de riesgos (propia de los jóvenes).

- Antigüedad: La antigüedad indica el número de años de permanencia en la misma empresa. Respecto a los expertos, es un indicador de estabilidad de la competencia. Los mismos expertos, aún cuando tenga pequeñas variaciones en su competencia de un año a otro, mantendrán valores similares.

- Situación salarial relativa: Se trata de un índice que relaciona la competencia de los expertos con los salarios recibidos. Comparándolo con los índices de los competidores se puede saber la mayor o menor tendencia de los expertos a abandonar la empresa.

- Rotación de los expertos: La rotación hace referencia al abandono y nueva contratación de expertos. El porcentaje de expertos que rotan debe tomar unos valores intermedios. Un valor demasiado bajo indica una excesiva estaticidad en los puestos, lo que perjudica el incremento de 
las competencias de los expertos a través del desarrollo de actividades variadas. Por el contrario, una rotación demasiado alta muestra una insatisfacción en el personal. Una medida básica de la rotación es el número de despidos registrados a lo largo del año dividido por el número de personas empleadas en el mismo período.

\section{- Medida del componente interno}

El desarrollo del trabajo del componente interno es realizado por los distintos departamentos de gestión, como el departamento de dirección general, de contabilidad, de Recursos Humanos, de recepción y otros servicios. En conjunto son el denominado por Sveiby "personal administrativo".

- Medidas del crecimiento/renovación del componente interno

Dentro de este grupo, Sveiby analiza las inversiones en componente interno, inversiones en sistemas de tratamiento de la información y contribución de los clientes al componente interno.

- Inversiones en el componente interno: Suelen materializarse en creación de filiales o elaboración y desarrollo de metodologías y sistemas de trabajo. Dichas cuestiones se contabilizan como gastos en la contabilidad, por lo que pueden ser medidas como la relación entre dichos gastos y la facturación o el valor añadido de la empresa.

- Inversiones en los sistemas de tratamiento de la información: Pueden medirse, entre otras formas, relacionando el gasto en sistemas informáticos con la edad media de los equipos. Se mide la preocupación de la empresa por los sistemas a través de los que discurre la información.

- Contribución de los clientes al componente interno: El desarrollo de actividades para los clientes influye en la capacidad del personal administrativo, por lo que la contribución debe ser considerada y medida. Una medida a utilizar puede ser el crecimiento del volumen de negocio por miembro del personal administrativo.

\section{- Medidas de eficiencia del componente interno}

Las medidas correspondientes a esta categoría son la proporción representada por el personal administrativo, el volumen de negocio por miembro de personal administrativo y la medida de los valores y de la actitud.

- Proporción representada por el personal administrativo: Indica la eficiencia del componente interno, mostrando la evolución, positiva o negativa, a lo largo del tiempo.

- Volumen de negocio por miembro del personal administrativo: Muestra la capacidad de procesamiento del personal administrativo para un determinado volumen de negocio. Las variaciones muestran mejoras o deterioros en la eficiencia. 
- Medida de los valores y de la actitud: Recoge aspectos como la actitud de los empleados con respecto a su entorno profesional, a sus superiores y a los clientes de la empresa. Dicha actitud suele englobarse en el concepto de espíritu corporativo o el más usual de cultura de empresa. Actitudes no favorables pueden convertir en inútiles algunas inversiones realizadas por la empresa. La medida se realiza utilizando cuestionarios de opinión.

\section{- Medida de la estabilidad del componente interno}

En este grupo de medidores del componente interno, se analiza la edad de la empresa, la rotación del personal administrativo y el ratio de nuevos empleados.

- Edad de la empresa: Influye en el mismo sentido que en el caso de las competencias. Personal administrativo de más edad implica mayor estabilidad en los puestos de trabajo, y viceversa.

- Rotación del personal administrativo: El personal administrativo, a diferencia de los expertos, no precisa una rotación tan alta, puesto que la cantidad de conocimientos necesarios en este sector resulta inferior. La estabilidad es importante. Aún así, es preciso una rotación, que Sveiby sin explicar la razón (probablemente debido a su praxis como gestor en empresas intensivas en conocimiento) cuantifica entre el 3 y el 7\% anual.

- Ratio de nuevos empleados: Una fórmula de medida es calcular la proporción de empleados con una antigüedad inferior a dos años en la empresa. Los empleados con menos de dos años en la empresa poseen una eficacia inferior, por carecer del tiempo de adaptación preciso para integrarse plenamente en la empresa. Además, por el mayor abandono o despidos de estos trabajadores, una alta proporción de ellos indica una menor estabilidad en la plantilla.

\section{- Medida del componente externo de la empresa}

Las relaciones con los clientes son la parte de mayor importancia del componente externo, razón por la cual las medidas propuestas se centran en su análisis.

Los clientes no son un grupo homogéneo, sino que contribuyen en distinta medida a la rentabilidad de la empresa. Por ello, para medir la tasa de crecimiento y renovación, así como la eficiencia y estabilidad de su componente externo, es preciso proceder a la clasificación de los clientes.

Basándose en la experiencia de la empresa de consultoría PLS-Consult, los clientes pueden tener una, varias o ninguna de las siguientes cualidades positivas para la empresa:

- Rentabilidad de las operaciones con ellos.

- Incremento de la competencia de sus ingenieros a través de los trabajos desarrollados.

- Contribución a la construcción del componente interno. 
- Mejora de la imagen a través de referencias a otros clientes existentes o potenciales.

Los clientes que no contribuyan en ninguna de las áreas anteriores deben ser desechados.

\section{- Medida del crecimiento/renovación del componente externo}

La medida del crecimiento y la renovación del componente externo se realiza a través de la medición de la rentabilidad por cliente y el crecimiento orgánico.

- Rentabilidad por cliente: Puesto que los gastos se imputan de modo global en la empresa, se desconoce la no rentabilidad de muchos clientes. Por ello, debe ser controlado el grado de rentabilidad obtenido de las operaciones con cada uno de ellos.

- Crecimiento orgánico: Se refiere al aumento de la facturación fruto de la actividad a que se dedica la empresa. No se incluyen, por ejemplo, la venta de un local que se ha dejado de utilizar.

\section{- Medida de eficiencia del componente externo}

Dentro de esta categoría, el análisis se realiza a través del índice de satisfacción de los clientes, del índice de ganancia / pérdida de contratos y de las ventas por cliente.

- Índice de satisfacción de los clientes: Se trata de una medida que anticipa el incremento o reducción de los ingresos obtenidos de cada uno de los clientes. Actualmente se realiza dicho análisis en el área de marketing, no en el área financiera. Un método para su cálculo es la realización periódica de encuestas para analizar la evolución de la satisfacción.

- Índice de ganancia o pérdida de contratos: Se trata de un índice indicado para empresas con contratos adjudicados sobre licitaciones. El índice compara el número de contratos ganados con el número de licitaciones perdidas. La evolución de dicho índice muestra la situación de la empresa en dicho aspecto.

- Ventas por cliente: Un incremento de ventas en los clientes existentes resulta más simple de alcanzar que nuevos clientes. Por ello, se debe medir la eficiencia con cada cliente a través de las ventas por cliente.

\section{- Medida de estabilidad del componente externo}

Dentro de este último grupo se emplea el porcentaje de clientes de "grandes cuentas", la pirámide de edad de los clientes, el ratio de los clientes fidelizados y la frecuencia de pedidos sucesivos.

- Porcentaje de clientes de "grandes cuentas": Una alta dependencia de pocas empresas que generen la mayor parte del volumen de negocio, implica una posición frágil, muy variable frente a ganancias/pérdidas de clientes. Se puede medir a través del porcentaje de facturas emitidas para 
los cinco clientes más importantes, o a través del número de clientes que representan el $50 \%$ de la facturación.

- Pirámide de edad de los clientes: Se trata de medir el tiempo de permanencia de los clientes con la empresa. Una mayor longevidad indica una mayor propensión a la permanencia como cliente.

- Ratio de clientes fidelizados: Se mide a través del porcentaje de ventas atribuible a empresas que son clientes desde hace más de cinco años. Es un símbolo de estabilidad que, evidentemente, no resulta aplicable a las empresas de nueva creación.

- Frecuencia de los pedidos sucesivos: Una alta frecuencia de pedidos sucesivos indica la satisfacción del cliente. El incremento de la frecuencia es un indicio de la confianza en la calidad.

El Intellectual Assets Monitor centra su función en la medición de los intangibles, pero en ningún momento los relaciona con los resultados financieros de la empresa. Cabe preguntarse cuáles de las anteriores mediciones intervienen en mayor medida en el resultado, o por ejemplo, cuáles resultan necesarias en un nivel mínimo para la consecución del objetivo de la empresa, aún cuando no precisen valores extremos en su cuantía.

Otra de las críticas que se realiza al modelo es su óptica eminentemente estática. Muestra cómo realizar medidas en un momento concreto, cuantificando el Capital Intelectual como una variable stock y no flujo. Además, no muestra cómo se debe gestionar el conocimiento, base del Capital Intelectual, para incrementarlo. Es decir, no trata la problemática de la gestión del conocimiento.

Por último, plantea una serie de medidores, que se recogen de modo extractado en la Tabla 2.8 y que sirven para gestionar la evolución del Capital Intelectual. La mayoría de los medidores propuestos son empleados en posteriores trabajos.

\subsection{Modelo Intelect}

Desarrollado por Eurofórum, (1998), es el primer intento a nivel español de establecer las bases teóricas y conceptuales sobre las cuales desarrollar posteriores trabajos. El modelo se desarrolló considerando la realidad española y adaptándolo a ella, realizando pruebas piloto en empresas para probar la validez del modelo en la praxis.

Las cuestiones generales que sirven de base para el desarrollo del modelo Intelect están basadas en el análisis de los distintos modelos de valoración del Capital Intelectual:

- Alto grado de similitud en los estudios previos. Los conceptos en todos los estudios son los mismos, existiendo diferencias en cuestiones irrelevantes. Existen diferencias de lenguaje entre unos y otros estudios, debido a la juventud de la materia y a la falta de estandarización del lenguaje empleado. 
- Los modelos proponen, aún cuando no se encuentre homogeneizada, la terminología para hablar de los intangibles.

- Debe existir relación entre el modelo y la estrategia de la empresa.

- Los modelos precisan de adaptación a las circunstancias concretas de cada empresa u organización. No existe una fórmula única que sea de utilidad para todo tipo de empresas.

- Los modelos tienen una clara orientación de futuro. Buscan los activos que son generadores de la riqueza futura de la empresa.

El modelo Intelect "responde a la necesidad de recoger en un esquema fácilmente compresible todos aquellos elementos intangibles que generan o generarán valor para la empresa" (Eurofórum, 1998).

El modelo no busca inventariar la totalidad de intangibles, sino realizar un juicio acerca de su capacidad de aportar valor a la empresa. Desarrolla un proceso de identificación, selección, estructuración y medición de activos que hasta el momento no habían sido considerados, al menos de forma estructurada. Las características del modelo que permiten aplicar e interpretar los resultados del mismo son:

- Enlace entre el modelo de Capital Intelectual y la estrategia de la empresa: Es preciso la existencia de un enlace entre Capital Intelectual y estrategia para el desarrollo del modelo. "Los indicadores de Capital Intelectual evalúan los elementos intangibles que permiten avanzar en la consecución de los objetivos estratégicos de la organización" (Eurofórum, 1998).

- Modelo personalizado para cada empresa: Existe un gran número de activos intangibles cuya importancia varía de una empresa a otra, no pudiendo ni siquiera establecer una serie de activos clave para un sector. El elemento clave que determina las necesidades del modelo de medición de intangibles en cada empresa es la estrategia, razón por la cual cada una adaptará el método de medición de intangibles a sus necesidades.

- Modelo abierto y flexible: El modelo Intelect plantea un esquema general y abierto, debido a la necesidad de adaptar el mismo a las distintas empresas. El modelo plantea una serie de indicadores a modo de guía.

- Medición no sólo de resultados, sino también de los procesos que los generan: El estudio de los procesos que generan conocimiento llevan al descubrimiento de nuevos intangibles sobre los que se fundamenta la creación de valor para la empresa.

- Visión sistemática del modelo: La generación óptima de valor se produce por el conocimiento de los intangibles y de las relaciones existentes entre ellos. Por lo tanto, los intangibles deben ser desarrollados coherentemente.

- Aplicabilidad: Para que el modelo sea aplicable y relevante se precisa equilibrio entre el rigor conceptual, la sencillez y facilidad de aplicación (Eurofórum, 1998). 
- Combinación de unidades de medida diversa: No existe una única unidad de medida que permita el control de la totalidad de intangibles precisos, por lo que el modelo debe emplear diversas unidades de medida. Considerando que algunos de los elementos es necesario valorarlos de modo cualitativo.

- Estimación del nivel de riesgo o estabilidad de los intangibles: El modelo no sólo debe identificar y medir los activos intangibles, sino que debe realizar una estimación de la variabilidad de los mismos.

\subsubsection{Elementos componentes del modelo y estructuración}

El modelo se estructura en base a tres tipos de componentes: los bloques, los elementos y los indicadores. Los bloques son los tres grandes grupos en que se clasifican los intangibles de las empresas. Los elementos son los activos intangibles que se consideran en cada uno de los bloques. Para cada uno de los elementos se emplean una serie de indicadores que permiten su medición/evaluación. La Figura 2.6. muestra los distintos componentes junto con su definición y características.

Los distintos bloques que diferencian el modelo son: Capital Humano, Capital Estructural y Capital Relacional.

- Capital humano: El Capital Humano incluye dos elementos. Por una parte, el conocimiento tácito o explícito, poseído por las personas y equipos. Por otra parte, el Capital Humano se complementa con la capacidad de regenerar el conocimiento, es decir, con la capacidad de aprender. La clave para diferenciarlo de los otros dos bloques reside en que el Capital Humano no es propiedad de la empresa. Ésta lo arrienda a los trabajadores que tenga contratados.

- Capital estructural: Parte del conocimiento perteneciente al Capital Humano, en la medida en que se consiga explicitarlo, sistematizarlo e a eficacia y eficiencia interna de la empresa, como los sistemas de información y comunicación, la tecnología disponible, los procesos de trabajo, las patentes, los sistemas de gestión, etc. El Capital Estructural pertenece a la empresa e incluye los protocolos de transmisión de información formales. Un sólido Capital Estructural facilita los flujos de información, incidiendo positivamente sobre la eficiencia de la organización.

- Capital Relacional: Engloba el valor del conjunto de relaciones que una empresa mantiene con el exterior. Dichas relaciones se consideran en un bloque distinto por la importancia y características diferenciadas que poseen. La calidad y sostenibilidad de la base de clientes de una empresa, y su potencialidad para generar nuevos clientes en el futuro, son evidentemente cuestiones claves para su éxito, como también lo es el conocimiento que puede obtenerse de la relación con otros agentes del entorno (alianzas, proveedores, etc.). 
Figura 2.6. Componentes del modelo Intelect.

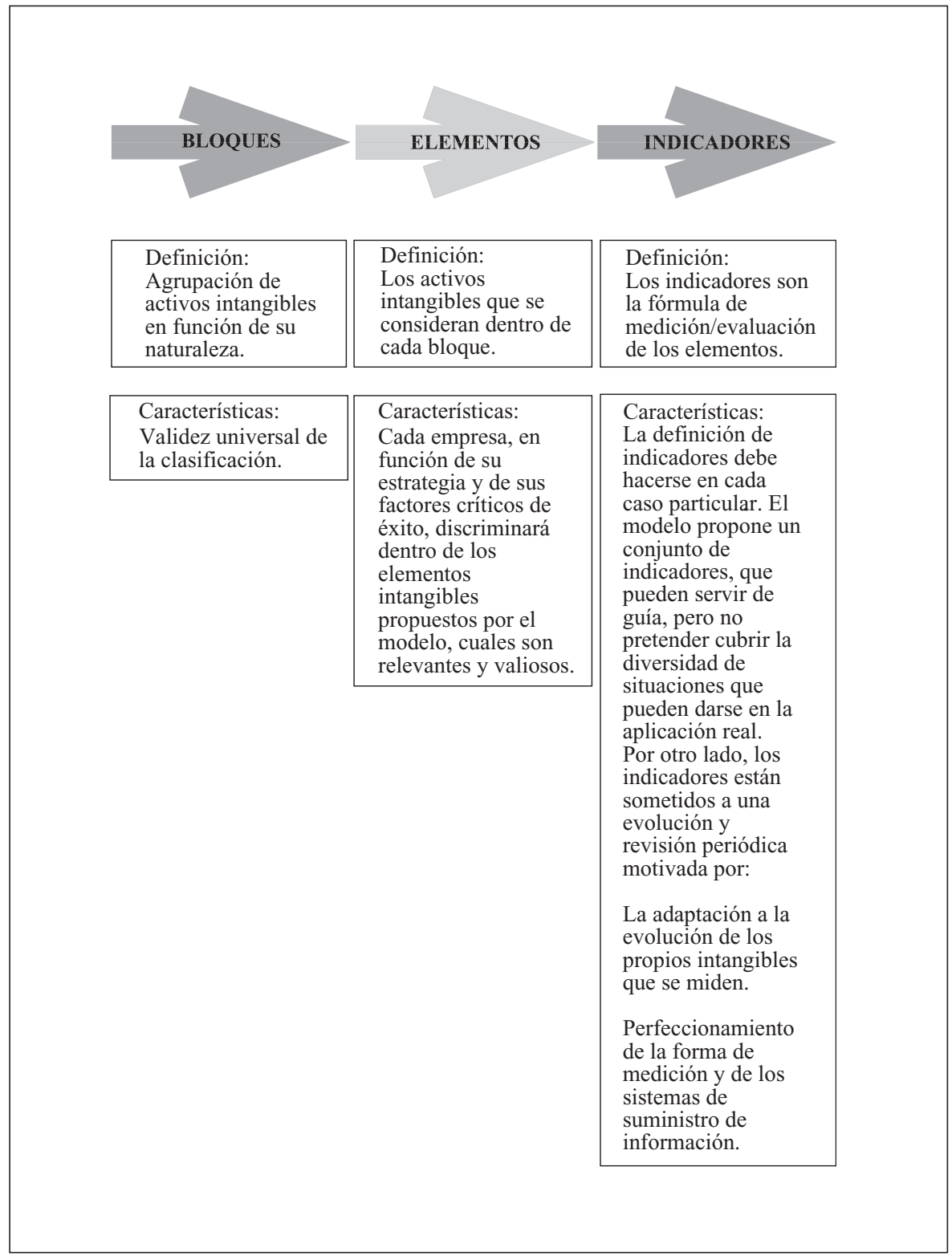

Fuente: Eurofórum, 1998.

El modelo, además, tiene en consideración el componente temporal, estableciendo elementos para ser medidos en el presente y elementos futuros hacia los que debe orientarse cada uno de los bloques. La Figura 2.7. recoge la estructura del modelo Intelect. 
Figura 2.7. Estructura del modelo Intelect.

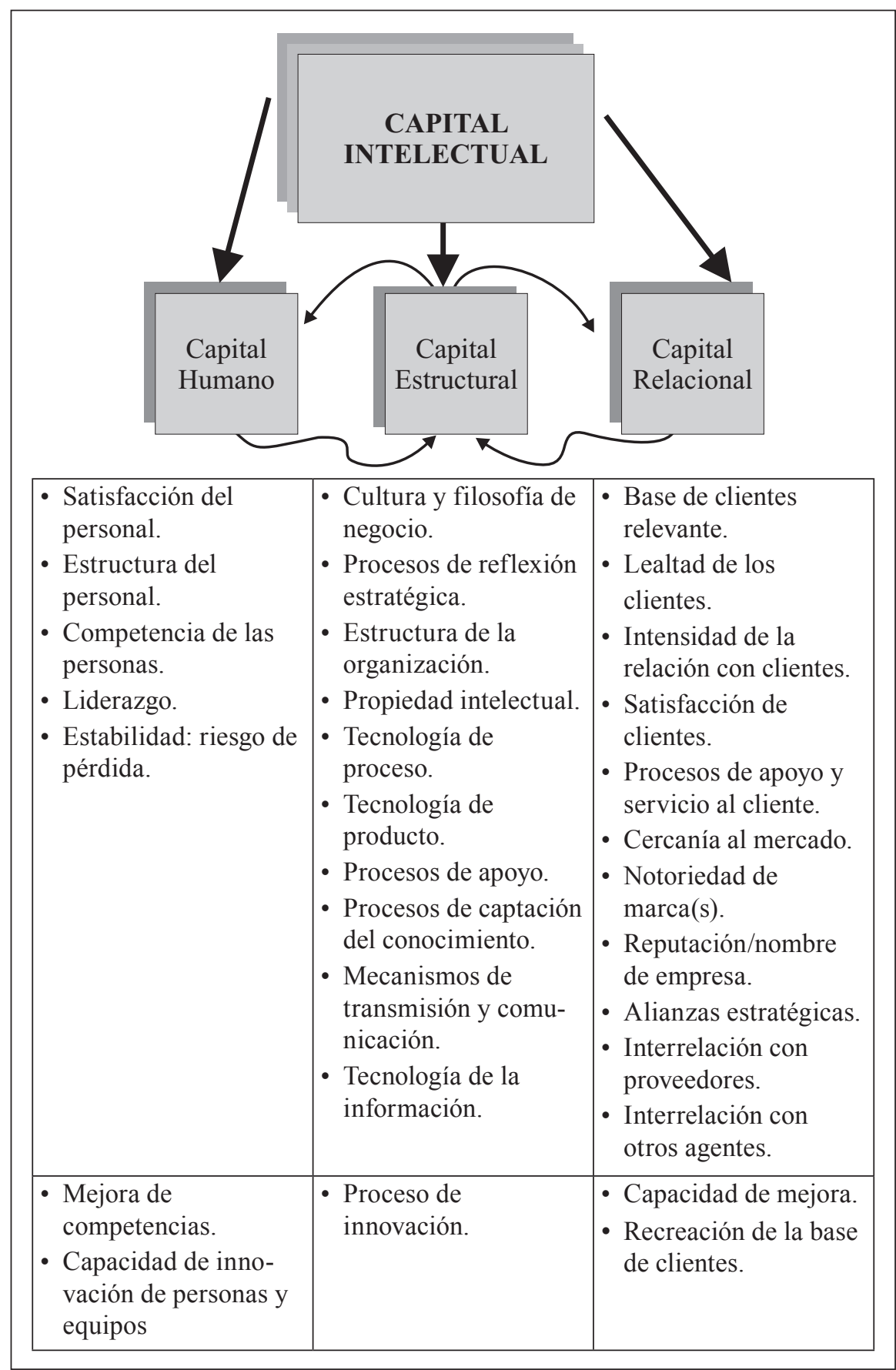

Fuente: Eurofórum, 1998. 


\subsection{Navigator Skandia}

Skandia se fijó las siguientes metas para su trabajo:

1. Identificar y realzar la visibilidad y mensurabilidad de los activos intangibles.

2. Captar y sostener la accesibilidad mediante tecnología de intercambio de conocimientos.

3. Cultivar y canalizar el Capital Intelectual por desarrollo profesional, entrenamiento e intercambio de información computerizada.

4. Capitalizar y fortalecer, agregando valor mediante un reciclaje más rápido de los conocimientos y aumentando la transferencia de destrezas y experiencia aplicada.

5. Integrar el conocimiento corporativo adquirido en activos tangibles, capacitando a la empresa para aplicar dichos activos con el máximo efecto competitivo.

\section{Implementación de las teorías}

El modelo de Edvinsson y Malone supone el asentamiento de las bases para la aplicación y capitalización de la teoría.

La aplicación se extenderá por las empresas, grandes y pequeñas. Únicamente a través de la "contabilidad" del Capital Intelectual se puede reconocer lo que en la economía moderna de empresas genera ventajas.

Las principales ventajas que buscan las empresas de la nueva economía son:

- Fuertes y duraderas relaciones de negocios en sociedades estructuradas en red.

- Lealtad perdurable de los clientes.

- El rol desempeñado por los empleados clave. Sobre sus conocimientos descansa la capacidad de competir y el futuro de la empresa.

- El compromiso entre empleados y empresa para aprender y renovarse a lo largo del tiempo. Es necesario destacar el papel fundamental que han de desarrollar el carácter y los valores de la empresa. Este modelo es un medio de evaluación para inversores y de gestión para ejecutivos en casos de fusiones, adquisiciones, alianzas, contratación de personal y asociaciones.

Se trata de uno de los primeros esfuerzos sistemáticos para descubrir los factores esenciales de la empresa y establecer un sistema de medida. El sistema se va perfeccionando a través de pruebas y ensayos. Los indicadores que midan mejor el Capital Intelectual que afecta a los resultados futuros se convertirán en normas de uso general para identificar y gestionar el Capital Intelectual.

La capitalización del modelo implica la búsqueda de la medición del mismo. El modelo propone una fórmula abierta para su medición, como primer paso para 
el futuro desarrollo de una fórmula que identifique en mayor medida el valor del Capital Intelectual.

El Capital Intelectual se divide en Capital Humano y Capital Estructural.

$$
\text { Capital Humano }+ \text { Capital Estructural }=\text { Capital Intelectual }
$$

A su vez, dentro del Capital Estructural se diferencian dos categorías más: Capital Clientes y Capital Organizativo, compuesto este último del Capital de Procesos y del Capital de Renovación y Desarrollo.

\section{- Capital Clientes}

Actualmente las relaciones con los clientes se prolongan a lo largo del tiempo a través de una serie de servicios complementarios, por lo que la empresa debe conocer en cada momento lo que el cliente desea. Dicha tarea no resulta fácil porque:

1. El cliente no siempre conoce lo que desea, especialmente cuando se enfrente a nuevos productos. Para evitarlo se precisa conocer a fondo los gustos, necesidades e intereses del cliente para poder anticiparse a sus demandas.

2. Se necesita gran confianza para poder recabar dicha información de los clientes. Dicha confianza se gana a lo largo del tiempo. Surge en el nuevo marco competitivo la necesidad de medir al cliente. La tarea consiste en encontrar medidas que capten de modo fiel la nueva realidad en las relaciones empresa-cliente.

Los aspectos clave definitorios de un cliente son:

1. Tipo de cliente: Debe responder a las preguntas: “¿Cuál es el perfil de un cliente típico para el producto de la empresa, y cómo es congruente con la evolución de la empresa a la larga?”. (Edvinsson y Malone, 1997).

2. Duración del cliente: Las cuestiones a resolver son: “¿Cuál es el índice de rotación de la actual base de clientela? ¿Cuál es el tiempo medio durante el cual un cliente ha venido comprando lealmente a la empresa? ¿Cómo se comparan estos dos indicadores con el promedio para el sector? (Edvinsson y Malone, 1997).

3. Papel del cliente: En este caso la problemática se centra en los siguientes aspectos: “¿Cuál es el papel del cliente en el diseño del producto, producción, entrega o servicio? ¿Cuál es el valor añadido por esta participación y colaboración? (Edvinsson y Malone, 1997).

4. Apoyo al cliente: “Qué programas independientes, aparatos y tecnologías se han instalado para asegurar el más alto nivel de satisfacción y éxito del cliente? ¿Qué valor tienen? (Edvinsson y Malone, 1997).

5. Éxito con el cliente: “¿Cuáles son los niveles de éxito con el cliente según medidas tales como el índice de compras anuales, clientes que tienen quejas y que no las tienen, clientes nuevos y viejos, sexo, ingresos, profesión, nacionalidad, edad? (Edvinsson y Malone, 1997). 


\section{- Capital de Procesos}

El enfoque de procesos tiene relación con el papel que la tecnología desempeña como herramienta para sostener la creación de valor.

Los semiconductores, ordenadores y telecomunicaciones han hecho a las empresas más rápidas y adaptables, de modo que tengan la capacidad de ofrecer productos de alta calidad y puedan acceder a mercados mundiales antes inaccesibles.

La tecnología permite una mayor flexibilidad organizacional, llegando incluso a determinar las relaciones con clientes y proveedores. Es preciso la adopción de una tecnología y aplicaciones adecuadas a las necesidades y disponibilidades de la empresa, de modo que permitan el intercambio de información con clientes y proveedores.

\section{- El Capital de Renovación y Desarrollo}

El enfoque de renovación y desarrollo define el futuro de la empresa. Se trata de captar las oportunidades que marcarán el devenir de la misma. El futuro reside en los siguientes elementos:

1. Clientes: “QQué cambios se esperan en la clientela, en términos de valores absolutos, composición demográfica, hábitos de compra, ingresos, educación, edad y otros aspectos de este tipo?"

2. Atractivo en el mercado: “¿Cuánto está invirtiendo la empresa en investigación de mercado? ¿Qué porcentaje de esa suma se destina a los mercados actuales?"

3. Productos y servicios: “Cuántos productos o servicios nuevos tiene actualmente la lempresa en desarrollo? ¿Cuál es la probabilidad histórica de que las innovaciones que están ahora en desarrollo lleguen al mercado? ¿Cuál es la rapidez con que esto sucede históricamente?”

4. Socios estratégicos: “¿Cuánto invierte la empresa en desarrollo y comunicación con socios estratégicos? ¿Cuántos empleados de la empresa trabajan de forma fija en instalaciones de dichos socios?"

5. Infraestructura: “¿Cuál es el valor, edad y expectativa de vida de los medios de apoyo de Capital Organizacional de la empresa? ¿Qué adquisiciones de capital prevé la empresa para los próximos tres años?"

6. Empleados: “¿Cuál es actualmente el nivel medio de formación de los empleados de la empresa? ¿Cuántos tienen grado de máster en administración de empresas?"

\section{- Capital Humano}

Es un factor necesario para el funcionamiento de los restantes tipos de capital, que actúa como nexo de unión entre los mismos. Este enfoque plantea un sistema de medición, que debe cuantificar cuestiones difícilmente observables, como la conducta o la motivación. Por ello, cualquier sistema de indicadores debe cumplir los siguientes requisitos. 
1. Debe estar bien pensado, identificando y midiendo los elementos clave.

2. Debe tener un buen diseño para que no exista ruido de otras variables subjetivas.

3. Debe ser teleológico. Las medidas no sólo deben mostrar dónde se encuentra la empresa, sino también dónde debería estar.

La nueva era, la era de la información, posee también una nueva tipología de empleados. Edvinsson y Malone identifican cuatro grupos, que denominan administrativos, teleempleados, guerreros del camino y los gitanos de empresa.

En el grupo de los administrativos se incluyen todos aquellos trabajadores que acuden diariamente al lugar de trabajo, mientras que los teleempleados trabajan a distancia empleando las Nuevas Tecnologías. Los guerreros del camino son aquellos trabajadores que no tienen un lugar fijo para el desarrollo de su actividad. Se desplazan continuamente y acuden a la oficina muy pocas veces al mes. Se encuentran en el centro de creación de valor de la empresa.

En los gitanos de empresa, a su vez, se distinguen tres subgrupos. El primero, de menor tamaño, incluye aquellos trabajadores de la empresa que desarrollan su actividad en las instalaciones de otra empresa (clientes o proveedores). El segundo grupo, más numeroso, está constituido por los contratistas, empleados a tiempo parcial, asesores y empleados temporales. El tercer grupo está formado por trabajadores que a través de Internet venden sus trabajos a diversas empresas.

\section{El Navegador de Skandia}

El Navegador relaciona los cinco tipos de capital existentes en la empresa, dotándolos de estructura, clasificando los elementos temporalmente y estableciendo relaciones entre ellos. Para ello, el modelo hace referencia a enfoques en lugar de a capitales.

El Navegador se conforma de tres tareas:

1. Mirar hacia dentro, a los indicadores: Debe servir de guía, permitiendo seleccionar el conjunto correcto de medidas, vinculándolas entre sí por categorías de forma coherente. Dichas mediciones deben mostrar posición, velocidad y dirección de la organización.

2. Mirar hacia arriba, hacia más amplias medidas de valor: Debe ser capaz de poseer perspectiva de futuro. Han de establecerse una serie de índices principales, con los que juzgar la fortaleza del Capital Intelectual de la empresa.

3. Mirar hacia fuera, hacia el usuario: La contabilidad relacionada con el Capital Intelectual debe ser fácilmente observable y, a diferencia de la contabilidad tradicional, poseer conceptos claros y precisos. 
Skandia no emplea únicamente los datos sobre su Capital Intelectual para la gestión de la empresa, sino que va más allá, facilitando dicha información a accionistas, inversores y público en general, a través de la incorporación de suplementos a sus informes financieros. En dichos suplementos presenta una amplia serie de indicadores del Capital Intelectual para cada empresa que compone el grupo.

\section{Capital Humano}

Dentro de los recursos intangibles de la empresa, sin duda, el Capital Humano constituye el recurso más estratégico, y también el más complejo de gestionar. El Capital Humano, esto es, el conjunto de habilidades, conocimientos y competencias de las personas que trabajan en la empresa, es una fuente incuestionable de ventajas competitivas a largo plazo.

Según el modelo Navegator de Skandia, el Capital Humano es el conjunto de las capacidades, conocimientos, destrezas, y la experiencia de los empleados y directivos de la empresa. Pero tiene que ser algo más que la suma simple de estas medidas, ya que debe captar igualmente la dinámica de una organización inteligente en un ambiente competitivo cambiante.

El modelo Intelect define el Capital Humano como: el conocimiento (explícito o tácito) útil para la empresa que poseen las personas o equipos de la misma, así como su capacidad para requerirlo, es decir, su capacidad de aprender.

La relevancia del Capital Humano dentro de los activos intangibles es enorme y creciente. Según Tom Watson, Jr. cargo de IBM: "Todo el valor de esta empresa está en su gente. Si ardieran todas nuestras fábricas y nuestros archivos de información, pronto seríamos tan fuertes como siempre. Llévense a nuestro personal y podríamos no recuperarnos nunca".

El Capital Humano es, en la mayor parte de las organizaciones, el activo más importante, ya que genera el Capital Estructural y Relacional de la compañía

Destacada la importancia del Capital Humano, es preciso gestionarlo y previamente medirlo. La dificultad de la medición, señalada ya para el Capital Intelectual, adquiere en el caso del Capital Humano cotas más elevadas. Así, Edwinsson y Malone indican: "medir el enfoque humano es la parte más difícil del modelo de Capital Intelectual”, lo cual explica toda la investigación, desde contabilidad de Recursos Humanos hasta el trabajo Capital Humano del premio Nóbel Gary Becker. No hay una manera sencilla de medir lo que está en la mente y en el corazón de los directivos y los empleados. No hay columnas de números para sumar, un manómetro para verificar, ni medidores que leer. Asignar un valor a la conducta o motivación es algo muy distinto y extraordinariamente complejo.

Al ser el Capital Humano uno de los componentes principales del Capital Intelectual, todos los modelos e indicadores planteados para la medición de éste 
último incorporan mediciones del Capital Humano. No obstante, hay algunas singularidades derivadas de su propia importancia que es preciso resaltar.

Las investigaciones efectuadas en la medición del Capital Humano se han orientado principalmente en tres categorías o grupos:

(i) Medición del Capital Humano como un todo y parte del Capital Intelectual.

(ii) Medición de variables significativas del Capital Humano.

(iii) Medición de indicadores relacionados como aspectos de detalle del Capital Humano.

Dentro del primer grupo, señalamos como reciente, el trabajo publicado por Domingo Nevada y Víctor Raúl López (2002), que, además de introducir un análisis matemático para la valoración y medición del Capital Intelectual, relacionándolo con el valor extracontable a través de un modelo econométrico cuyo sistema de información se nutre de los indicadores establecidos y de la estimación y aceptación de dicho modelo, establece también una desagregación del Capital Intelectual explicitado en Capital Humano y Capital Estructural y, a su vez, el Capital Estructural en Capital de Procesos, Comercial, Comunicacional y de Innovación y Desarrollo.

En este grupo también se incluyen todos los medidores efectuados a partir de la relación ingresos y gastos, como el Valor Económico Humano Añadido (VEHA), explicitado como:

$$
V E H A=\frac{\text { Beneficio operativo neto después de impuestos }- \text { Coste Capital }}{E T C S}
$$

Donde ETCs es el equivalente de trabajo a tiempo completo. y todos los similares: Valor Añadido del Capital Humano (VACH), Rendimiento de la Inversión del Capital Humano (ROICH), etc.

En el segundo grupo se han establecido medidores de variables significativas del Capital Humano como: innovación, actitudes, motivación, etc., a través de indicadores relacionados con las mismas.

Por último, en el tercer grupo, indicadores de Capital Humano, ha habido una gran profusión de los mismos.

En este sentido, un estudio que recoge un exhaustivo análisis sobre informes de medición del Capital Humano realizado por empresas pioneras a nivel nacional, publicado por Patricia Ordóñez de Pablos, muestra que los indicadores de Capital Humano se pueden agrupar en seis categorías básicas: 1) Perfil del empleado, 2) Rotación de personal, 3) Educación, 4) Compromiso y Motivación, 5) Formación, y 6) Resultados. 


\section{Perfil del empleado}

Esta sección proporciona la información sobre la distribución de edades y sexo de los empleados, número de empleados que trabajan en los departamentos de producción, distribución, tecnología de la información, ventas, marketing y administración.

\section{Rotación del personal}

Incluye diversos datos sobre los empleados recién contratados, aquellos que dejan la empresa, porcentaje de rotación de personal, etc.

\section{Educación}

Muestra información sobre la formación académica de los empleados y su experiencia (no cualificados, cualificados, doctores, con experiencia internacional, etc.).

\section{Compromiso y motivación}

Entre los indicadores de compromiso, se incluyen los siguientes: porcentaje de personal ascendido/total del personal, antigüedad de los empleados, etc.

Entre los de motivación se encuentran el pocentaje de empleados que sienten un reconocimiento explícito en la empresa, \% de empleados que consideran que sus opiniones son tenidas en consideración o que están satisfechos con su entorno de trabajo, etc.

\section{Formación}

Incluye indicadores sobre las inversiones en formación para empleados que realiza la empresa. Entre ellos destacan los siguientes: número de días de formación por empleados, ratio de horas de formación/horas de trabajo (anual), inversión en formación por empleado al año, etc.

\section{Resultado}

Este grupo de indicadores muestra la satisfacción global con el trabajo desempeñado. Generalmente se mide a través de un índice de satisfacción del empleado.

Entre los indicadores propuestos se señala: En cuanto a perfil del empleado los indicadores contemplan número total de empleados, distribución por cualificación, sexos, edad, etc. En cuanto a Rotación del personal se incluyen número de incorporaciones recientes, índice de rotación, etc. Los indicadores de educación incluyen el número de empleados según formación académica, número de planes de desarrollo de carreras, experiencia, etc. En lo referente a compromiso y motivación se incluyen resultados de reconocimiento, promociones, sistemas de sugerencia, etc. En cuanto a Formación, se mide la actividad realizada con indicadores como días de formación por empleado, ratios de coste de formación sobre salarios totales, etc. Por último, en cuanto a resultados se incluyen: índices de satisfacción, absentismo, etc. 
Un análisis más completo, por disponer de stocks y de flujos de relación lo realiza la empresa Unión Fenosa (véase la Figura 2.8.).

\section{Figura 2.8. Modelo de Gestión del Capital Intelectual.}

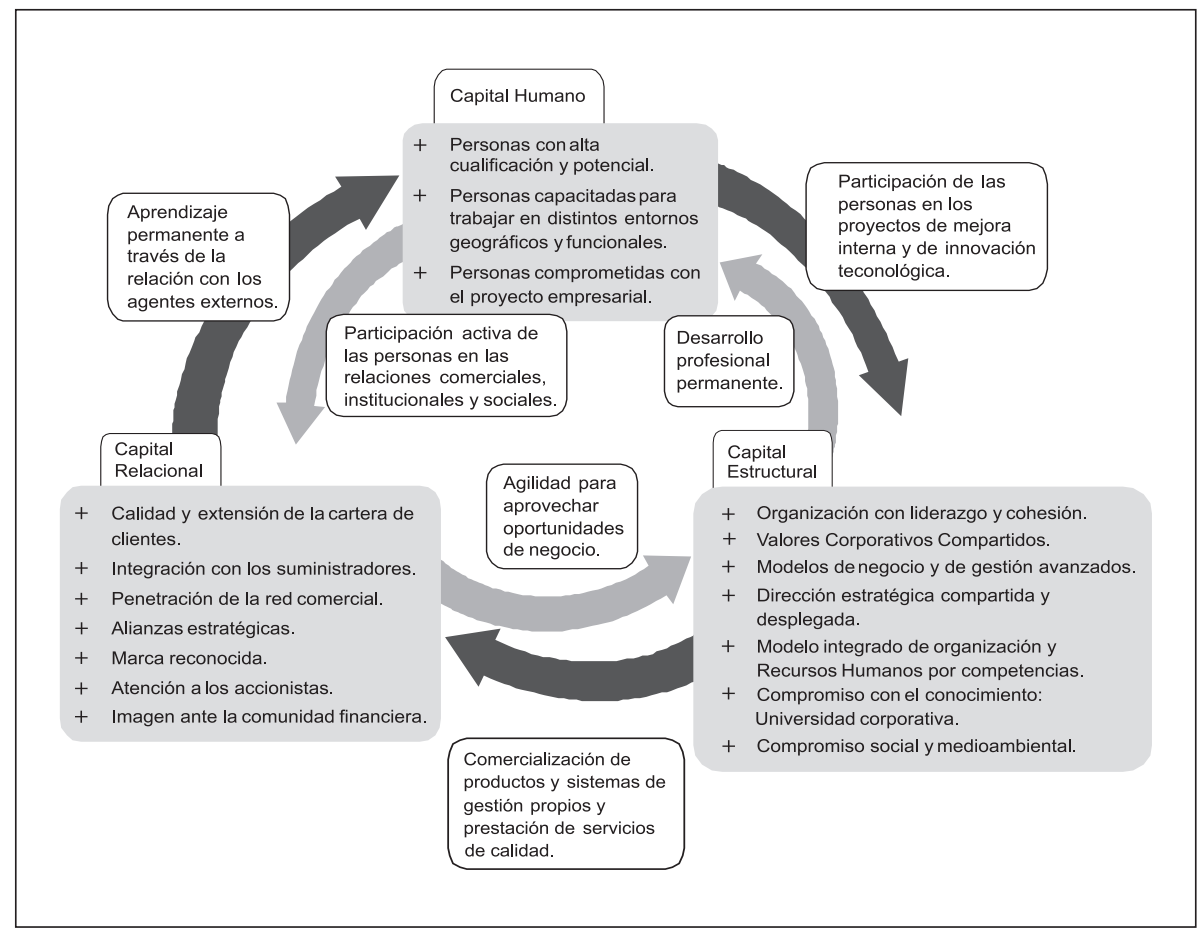

\section{Fuente: Unión Fenosa.*}

Caso real es el Sistema de Medición del Capital Intelectual del Personal adscrito al servicio de prevención de la Dirección General de Tráfico, publicado por Bosni; A, Fuentes; Y, y Serrano; C, en el 2001.

Este modelo que se recoge en la Figura 2.9., se basa en una escalera con tres peldaños en un gráfico de ordenadas y abscisas (xy), donde aparece resaltada la estrategia de mejora continua del servicio de prevención hacia la excelencia administrativa y el incremento de la calidad del servicio público que tiene encomendado. De forma metafórica la escalera recorre este camino, y en su interior se encuentran los conceptos o factores que manejan los responsables de esta unidad. Para cada concepto se detallan los indicadores que lo cuantifican.

El primer peldaño de la escalera corresponde al nivel operativo, para su control, el jefe de Servicio de Prevención manejará conceptos típicos de la contabilidad pública. 
Figura 2.9. Modelo de Capital Intelectual para el Servicio de Prevención de la Dirección General de Tráfico.

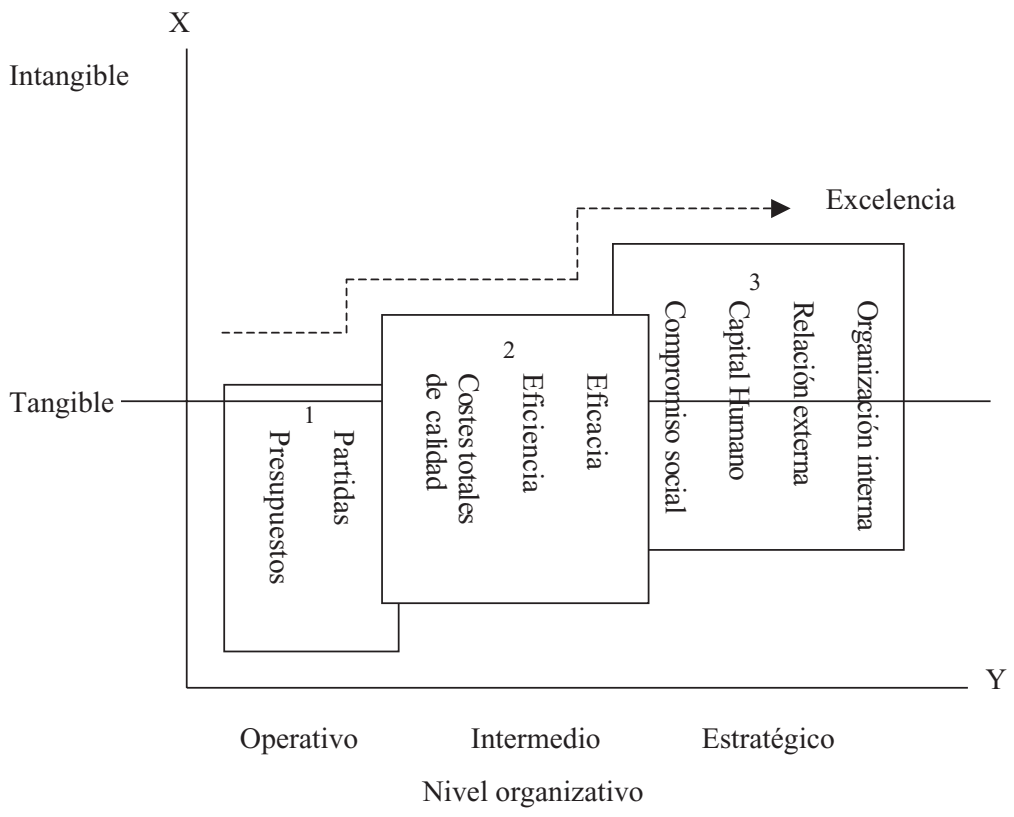

Fuente: Bosi, Fuertes y Serrano, 2001.

El segundo peldaño corresponde al nivel de gestión preventiva calificado como intermedio. Los conceptos utilizados por el Servicio de Prevención para la objetivación y racionalización de su gestión se refieren a aspectos como la eficiencia, la eficacia o los costes totales de la calidad de la gestión desarrollada.

La selección final de indicadores, tangibles e intangibles, elegidos revelará el día a día del Servicio de Prevención.

Tras superar el segundo escalón, en el Servicio se abordarán conceptos estratégicos e intangibles, como la imagen de la unidad, la motivación de la plantilla, la responsabilidad social, etc., por lo que su grado de desarrollo se corresponderá con el nivel estratégico alcanzado.

Conforme el Servicio de Prevención consiga avanzar en su nivel de gestión (eje x), los conceptos se harán más intangibles (eje y), por lo que el gráfico adopta forma de escalera. De ahí que la escalera sea acumulativa y para llegar al último peldaño haya que pasar por los anteriores. Se comprueba así que el cambio a la excelencia administrativa pasa por el cumplimiento de los requisitos de ajuste al presupuesto, costes totales de la calidad, eficacia y eficiencia. 


\section{Conclusiones}

La constatación del Capital Humano como un activo, es decir, un recurso controlado por la empresa y del que se espera obtener en el futuro beneficios económicos para la entidad, implica que, como tal activo, las empresas han de valorarlo o medirlo, gestionarlo y rentabilizarlo.

La necesidad de medir y gestionar estos activos está fuera de toda duda, cuando ya se constata que son los recursos intangibles la fuente de obtención de ventajas competitivas sostenibles en el tiempo y, a partir de las mismas, de la generación de valor.

La realidad, sin embargo, muestra que se está lejos de alcanzar una situación satisfactoria. Así un estudio de Bearing Point publicado en el año 2004, indica que un número reducido de empresas pertenecientes al IBEX 35, se apoyo en un modelo explícito de Capital Intelectual, y de las pocas que lo hacen, el bloque de Capital Humano es el menos medido, así, sólo el 9\% de las empresas incluye indicadores sobre liderazgo; el 12\% sobre trabajo en grupo, y el 24\% sobre estabilidad, entendida como riesgo de pérdida de mejoras.

Resulta evidente, por un lado, la necesidad de medir y, por otro, el que en general no se está haciendo. Por tanto, a partir de esta conclusión es obvio que la primera propuesta o recomendación que hemos de efectuar es la de que las empresas midan el valor de su Capital Humano.

Adoptada esta decisión el problema que se plantea es el relativo al método a adoptar. La respuesta es sencilla, el que mejor se adapte a la empresa, las circunstancias y el propósito u objetivo de la valoración. El objetivo de la valoración puede ser informar, gestionar o utilizar (véase la Figura 2.12).

Figura 2.10. Objetivos de la Valoración de Intangibles.

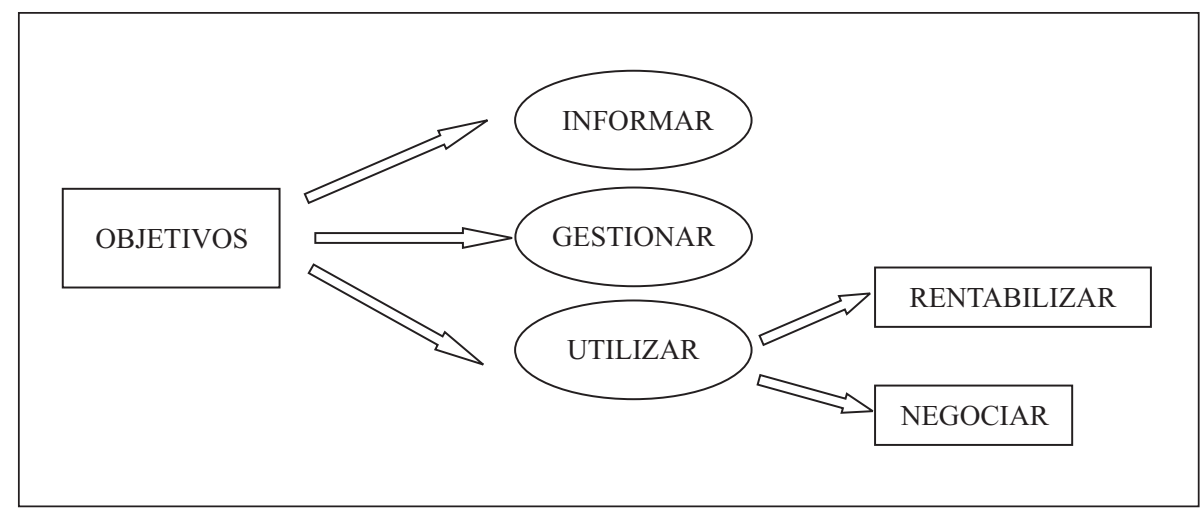

Fuente: Elaboración propia.

Si nos centramos un poco más en los objetivos de gestionar y rentabilizar, funciones propias del ámbito interno de las organizaciones y los directivos de las mismas, hay bastante unanimidad entre los investigadores en que el método de 
los indicadores es el más idóneo. De todos modos, sea el que sea el método utilizado, lo que no plantea ninguna duda es que las partidas de naturaleza intangible deben ser tratadas, gestionadas y medidas con sistemas diferentes a los utilizados para el resto de partidas. Como dice Sveiby "si medimos lo nuevo, como el conocimiento, con herramientas del pasado, no seremos capaces de ver lo nuevo".

El establecimiento de la medición en una organización ha de someterse a un serie de principios básicos de partida para garantizar el logro de intangibles del objetivo perseguido:

- Deben proporcionar una imagen veraz de la actividad que están midiendo.

- Han de ser adaptados a la situación de la empresa.

- Han de reflejar la adecuación a la estrategia propuesta y futura.

En este sentido, Thomas O. Davenport (1998) relaciona la estrategia empresarial y el Capital Humano a través de las capacidades organizativas, es decir, de las destrezas colectivas del nivel empresarial, las cuales son cruciales para la aplicación de la estrategia, elaboradas y promovidas por, entre otros factores, el Capital Humano.

Además, como indican Edwinsson y Malone, han de ser necesariamente:

1. Bien pensados, a fin de no medir algo que parece importante, pero que en realidad no significa nada.

2. Bien diseñados, para no recoger los ruidos de otras variables subjetivas.

3. Teleológicos, por que el acto en sí de medir un sistema métrico refleja los prejuicios de los Recursos Humanos de la empresa misma. Por consiguiente, es preciso escoger las medidas de forma que reflejen no sólo donde está la empresa, sino dónde debería estar.

Llegados a este punto, es preciso plantear algún modelo, lógicamente flexible, y que en su esquema permita a cualquier organización sistematizar sus activos intangibles y estratégicos. Volvemos a reincidir en la importancia de que estén relacionados con la estrategia, y para ello recogemos lo señalado por Norton (1996):

"El diferenciador principal es que el Cuadro de mando integral se fundamenta en la estrategia de la organización. Muchas personas son capaces de hacer una lista de medidas que no son financieras y creer que disponen de un Cuadro de Mando Integral; sin embargo, en nuestro enfoque el marcador tiene que indicar la historia de nuestra estrategia. El mayor error que comenten las organizaciones es pensar que el marcador sólo tiene que ver con distintas medidas".

La elección de un modelo, obviamente, no implica desechar el resto, sino facilitar la elección a las empresas no iniciadas en este aspecto.

Nos inclinamos por proponer el modelo Intelect por ser genuinamente español, pero, a la vez, integrado en las corrientes mundiales y, además, por ser el más aplicado en el ámbito empresarial español, lo que facilitará los trabajos de 
homogeneización, comparación, especialización, etc. Además, una de sus mayores virtudes es la de recoger el conocimiento ya elaborado de los centros internacionales y adaptarlo a la realidad española, al tiempo que crea un marco conceptual estandarizado.

Este modelo o método nos permitirá medir el Capital Humano mediante indicadores apropiados, no obstante, de manera más global es preciso también establecer modelos que interrelacionen el Capital Intelectual y la Estrategia de una empresa, modelos de aplicación práctica, pero además, es preciso que en la mentalización estratégica de los líderes empresariales se incorpore el Capital Intelectual, y especialmente sus componentes como rutina de pensamiento.

Como modelo que facilite la comprensión de esta interrelación proponemos el expuesto en la Figura 2.11.:

\section{Figura 2.11. Modelo de interrelación Capital Intelectual-Estrategia.}

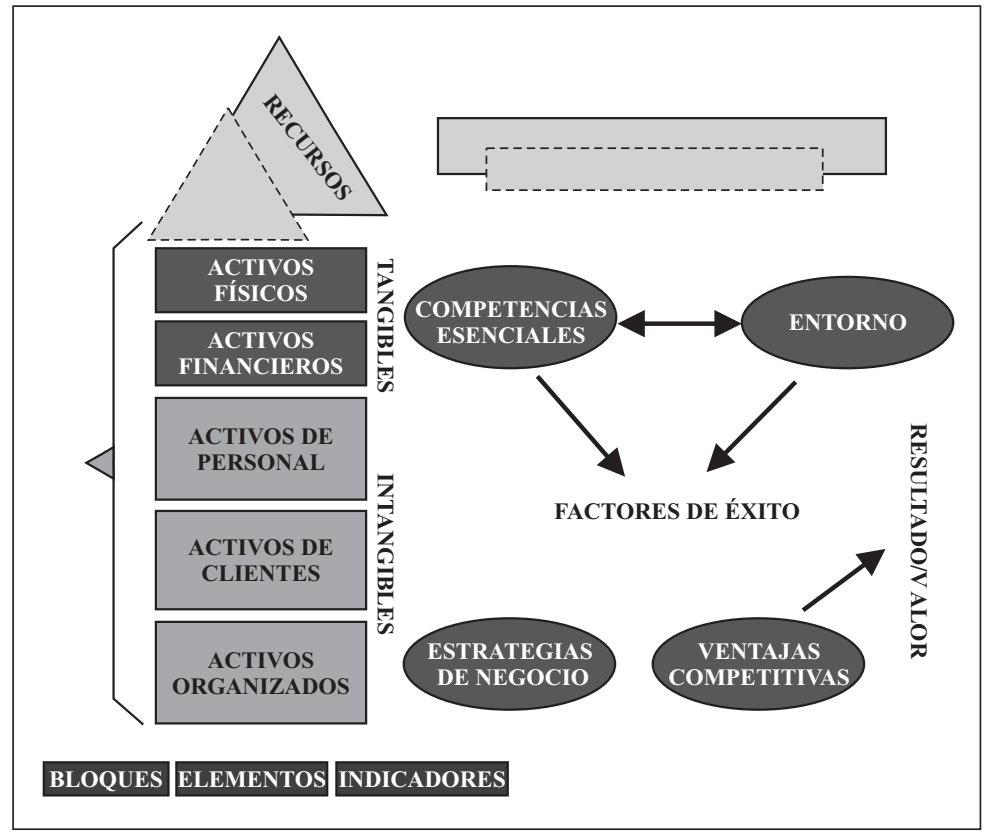

Fuente: Elaboración propia.

De este modelo se concluye que el conjunto de activos, tanto tangibles como intangibles de una empresa puede dar lugar a una elección estratégica en base a:

a. Establecimiento de ventajas competitivas dentro del negocio que la empresa viene desarrollando.

b. Incorporación a otros negocios en los que la organización presenta ventajas competitivas respecto a los partícipes actuales.

En cuanto al primer apartado, los puntos fundamentales de aplicación son: 
1. Las competencias internas han de evaluarse y ponerse de manifiesto en el análisis estratégico $\mathrm{y}$, por tanto, considerar fundamentalmente las correlacionadas con los factores de éxito del negocio.

2. Si las competencias son superiores a las que mantiene la competencia, posibilitan fortalezas que permiten establecer estrategias competitivas en base a las mismas y adoptar medidas para potenciarlas a fin de seguir manteniendo el diferencial.

3. Si se presentan debilidades, es decir, las competencias mantienen menor valor que la competencia, es preciso establecer acciones futuras para su creación y dirigir las ventajas competitivas hacia otros factores.

4. Es preciso además detectar aquellas nuevas competencias que es preciso desarrollar internamente para el éxito futuro del negocio.

5. En todos los casos, es preciso descomponer estas competencias en los componentes de Capital Intelectual a fin de gestionarlos.

En cuanto a la Estrategia de Negocios, ésta viene generada fundamentalmente por la interrelación del Capital Intelectual con el entorno, derivándose de las mismas competencias que se puedan rentabilizar en otros sectores o actividades. Como aspectos relevantes se señalan:

1. Las competencias internas se pueden poner en valor constituyendo con ellas unidades de negocio que permitan diversificarse en negocios en los que se posee una competencia esencial.

2. Las competencias internas permiten establecerse en otros negocios, en los que en ese momento la estrategia competitiva se puede establecer en base a competencia similares.

3. Ciertas competencias internas permiten mejorar el ámbito relacional y, por tanto, detectar oportunidades de negocio en el mercado actual o en otros mercados en cualquiera de los dos aspectos anteriores.

El siguiente esquema permite sintetizar estos aspectos:

Figura 2.12. Esquema de aplicación de competencias.

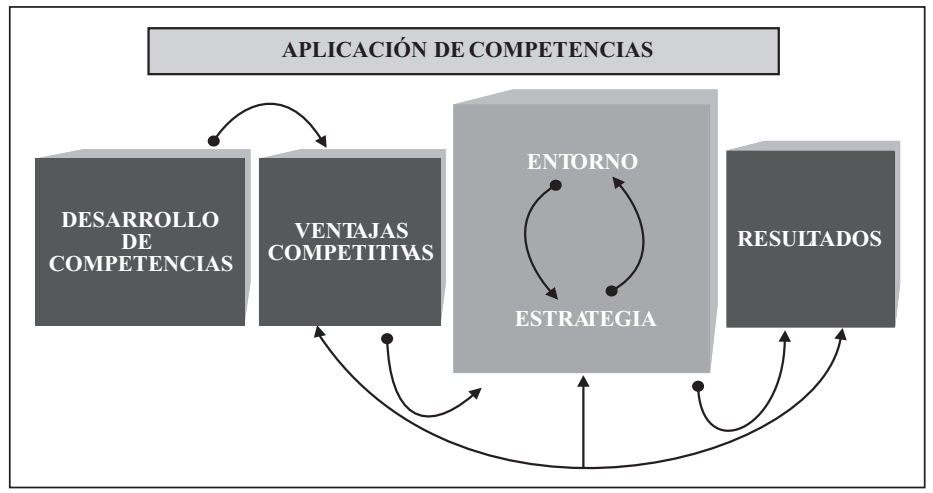

Fuente: Elaboración propia. 
En base a todo lo expuesto, proponemos como recomendaciones para los empresarios y directivos:

- Apreciar y ocuparse del Capital Intelectual, ya que tiene una influencia cada vez más decisiva en la capacidad de generar resultados.

- Es necesario estructurar y medir el Capital Intelectual de una empresa. A pesar de su dificultad hay que tener presente que el camino se hace andando, y este inicio les posibilitará una senda de aprendizaje que en el futuro les reportará grandes beneficios.

- En cualquier proceso o reflexión estratégica es preciso que se incluya el Capital Intelectual como un factor o recurso fundamental, y por tanto, su análisis y diagnóstico en consonancia con los factores de éxito del negocio.

\section{Bibliografía}

- BONTIS, N., DRAGONETTI, N, JACOBSEN, K., ROOS, G. (1999): “The knowledge toolbox: A review of the tools available to measure and manage intangible resources". European Management Review, under review.

- BOSI, A., FUERTES, Y. y SERRANO, C. (2001): "El Capital Intelectual en el Sector Público", 5campus.org, Capital Intelectual, www.5campus.org/ leccion/cipub (04/04/2002).

- BROOKING, A. (1997): El Capital Intelectual: El principal activo de la empresa del tercer Milenio. Ediciones Paidós Ibérica, Barcelona.

- BUENO CAMPOS, E. (1998): “El capital intangible como clave estratégica en la competencia actual”. Boletín de Estudios Económicos, Vol. LIII, Agosto, págs. 207-22.

- BUENO CAMPOS, E. (1998): Modelo de Dirección estratégica por Competencias: El Capital Intangible. www.gestiondelconocimiento.com/modelos bueno.htm (03/04/2002).

- BUENO, E. Y ARZÚA, S. (1998). “Medición del Capital Intelectual: Modelo Intelect". Eurofórum, Madrid.

- BUENO, E. (2000): "La Gestión del Conocimiento en el nuevo milenio (II): La incorporación del Capital Intelectual como elemento clave del valor de mercado del valor de una empresa". Fórum Calidad 117, págs. 41-46.

- CAÑIBANO CALVO, L. y SÁNCHEZ, M. P. (1997): “La valoración de los intangibles: estudios de innovación versus información contable financiera". IX Congreso de AECA, tomo 1, Salamanca, págs. 286-308.

- CHAMPY, J.; HAMMER, M. (1993): Reengineereng the Corporation: A Manifesto for Business Revolution. New York.

- CHANDLER, A. D. Jr. (1990): Scale and Scope: the Dynamics of Industrial Capitalism. Harvard university press, Cambrigde. 
- CHANDLER, A. D. Jr. (1962): "Strategy and Structure:Chapters in the History of the American Industrial Enterprise". M.I.T., Cambridge, Massachussets.

- DAVENPORT, T. H. (1994): "Saving it's Soul: Human-Centered Information Management". Harvard business review.

- DAVENPORT, T. H., y PRUSAK, L. (1998): "Working Knowledge: How Organizations Manage What They Know". Harvard Business School Press.

- EDVINSSON, L. y MALONE, M.S. (1997): Intellectual Capital Realizing Your Company's True Value by Tinding Its Hidden Brainpower, Harper Collins Publishers, Inc., New York.

- EDVINSSON, L. y MALONE, M. S. (1999): El Capital Intelectual: cómo identificar y calcular el valor de los recursos intangibles de su empresa. Gestión 2000.

- GRANT, R. (1991): "A resource-based theory of competitive advantage: Implications for strategy Formulation". California Management Journal, vol. 33, no 3, págs. 114-135.

- GRANT, R. (1996): Dirección estratégica: Conceptos, técnicas y aplicaciones. Editorial Civitas, Madrid.

- GRANT, R. (1998): Contemporary Strategy Analysis. Blackwell Publishers Ltd., Oxford. U.K.

- HALL, R. (1992): "The strategy analysis of intangible resources", Strategic Management Journal, Vol. 14, págs. 135-144.

- HALL, R. (1993): "A framework linking intangible resources and capabilities to sustainable competitive advantage". Strategic Management Journal, Vol. 14, págs. 607-618.

- KAPLAN, R. S. y NORTON, D. P. (1992): “The balanced scorecard: measures that drive performance". Harvard Business Review. Enero-Febrero, págs. 71-79.

- KAPLAN, R. S. y NORTON, D. P. (1996): “The balanced scorecard: traslating strategy into action". Harvard Business School Press. Hardcover. September.

- KAPLAN, R. S. y NORTON, D. P. (1997): Cuadro de Mando Integral (The Balanced Scorecard). Gestión 2000.

- KAPLAN, R. S. y NORTON, D. P. (2000): "Having trouble with your strategy? Then Map It". Harvard Business Review. Septiembre-Octubre.

- KAPLAN, R. S. y NORTON, D. P. (2001): Cómo utilizar el Cuadro de mando integral. Gestión 2000.

- KPMG PEAT MARWICK (1999): "La incorporación del Capital Intelectual como elemento clave del valor de mercado de una empresa". Seminario sobre Gestión del Conocimiento'99, organizado por Recoletos, Madrid, febrero. 
- LEV, B. (2001): “The knowledge scorecard a primer", conferencia sobre "Nuevas Aproximaciones a la Medición, Gestión y Publicación de Información Sobre los Activos Intangibles: Hallazgos de la Investigación y Oportunidades Futuras", Sevilla, marzo, 2001, págs. 1-20.

- LEV, B. (2001): “Can corporate knowledge (intangibles) by measured?". The 4th Intangibles Conference, New York University, Work in progress.

- LÓPEZ CABARCOS, M. A. y VÁZQUEZ RODRÍGUEZ, P. (2001): “La importancia de gestionar el valor que no se ve". Harvard Deusto Business Review.

- MARTÍNEZ OCHOA, L. (1997): "Activos Intangibles e información contable". Partida Doble, no. 81, septiembre, págs. 16-23.

- MOURITSEN, J. (2001): "Reading an Intellectual Capital Statement" Paper The 4th. Intangibles conference en Stern School of Business New York University.

- MOURITSEN, J., LARSEN, H. T. y BUKH, P. N. D. (2001): "Intellectual Capital and the Capable Firm: narrating, visu.alising and numbering for managing knowledge". European Accounting Asociation Conference, Atenas, Abril.

- MOURITSEN, J., LARSEN, H. T., BUKH, P. N. D. y JOHANSEN, M. R. (2001): "Reading an intellectual Capital Statement: describing and proscribing knowledge management strategies". The IV Intangibles Conference, New York University, Mayo.

- NEVAdO PEÑA, D. y LÓPEZ RUIZ, V. R. (2002): El Capital Intelectual: valoración y medición. Financial Times/Prentice Hall.

- ORDOÑEZ DE LA HOZ, P. (2002): “Capital Intelectual Capital Económico: Las Claves para la competitividad de las empresas en la nueva economía". Alta Dirección, nº 225, págs. 65-74.

- PORTER, M. (1982): Estrategia competitiva. CECSA. México.

- PORTER, M. (1985): Competitive Advantage. Free Press, New York.

- PRAHALAND, C. K. y HAMEL, G. (1990): "The core competence of the corporation". Harvard Business Review. vol. 68, n 3.

- PRAhaland, C. K. y HAMEL, G. (1995): Compitiendo por el futuro. Editorial Ariel, Barcelona.

- RODRÍGUEZ JERICÓ, P. (1999): "El Capital Intelectual y el modelo Intelect". Boletín AECA. no. 48, diciembre, 1998 y marzo 1999, págs. 66-68.

- ROSS, J. (1997): "Capital Intelectual: lo que se puede medir se puede gestionar", Harvard Deusto Business Review, no. 78, mayo-junio, págs. 22-25.

- SVEIBY, K. E. (1997): Capital Intelectual: la nueva riqueza de las empresas. Gestión 2000. 
- SVEIBY, K. E. (1997): "The intangible assets monitor", Journal of Human Resource Costing \& Accounting, vol.2, $\mathrm{n}^{\mathrm{o}}$ 1, primavera.

- SVEIBY, K. E. (2000): Capital Intelectual, la nueva riqueza de las organizaciones: cómo medir y gestionar los activos intangibles para crear valor. Máxima.

- VIEDMA MARTI, J. M. (2002): “Un nuevo paradigma emergente de Capital Intelectual”. XVI Congreso Hispano-Francés La empresa intangible AEDEM, Alicante, 5, 6 y 7 de Junio de 2002.

- www.unionfenosa.es 



\section{ANEXO \\ Indicadores de Unión Fenosa}

\section{CAPITAL HUMANO}

PROYECTOS EN DESARROLLO

- Universidad Corporativa UNION FENOSA (UCUF): Promueve el desarrollo permanente de los profesionales del Grupo, alineando la formación con las estrategias de negocio.

- Proyecto STAR: Identifica, desarrolla y fideliza a las personas con capacidad para desempeñar las nuevas ocupaciones clave.

- Cursos Superiores de Negocio: Capacitan a los profesionales de las empresas para desempeñar funciones gerenciales en los diversos ámbitos del Grupo.

- Escuela de Liderazgo: Forma en las habilidades requeridas por los seis valores corporativos del Grupo.

- Proyecto selección 100 profesionales: Selección de los mejores profesionales para dar respuesta a las necesidades de negocio.

\section{CAPITAL HUMANO}

INTANGIBLES, FLUJOS DE RELACIÓN E INDICADORES 2001-2002-2003

Personas con alta cualificación y potencial para cubrir las necesidades de negocio de UNION FENOSA.

\begin{tabular}{|l|r|r|r|}
\hline - Personas del Grupo (plantilla operativa).* & 24.501 & 22.913 & 20.127 \\
\hline $\begin{array}{l}\text { - Personas de SOLUZIONA } \\
\text { (servicios profesionales). }\end{array}$ & 8.430 & 8.241 & 7.910 \\
\hline $\begin{array}{l}\text { - } \% \text { de personas con titulación universitaria en } \\
\text { UNION FENOSA en España.* }\end{array}$ & $65 \%$ & $58 \%$ & $58 \%$ \\
\hline $\begin{array}{l}\text { - } \% \text { de personas con titulación universitaria en } \\
\text { SOLUZIONA en España.* }\end{array}$ & $83 \%$ & $75 \%$ & $74 \%$ \\
\hline $\begin{array}{l}\text { - de personas con titulación post-grado en } \\
\text { UNION FENOSA. }\end{array}$ & - & $6,6 \%$ & $10,7 \%$ \\
\hline
\end{tabular}

Personas capacitadas para trabajar en distintos entornos geográficos, funcionales y de negocio para atender a la expansión internacional de la empresa y el posicionamiento en nuevos sectores.

- \% de personas del Grupo que trabajan de forma permanente fuera de España.

\begin{tabular}{|l|l|l}
$56,5 \%$ & $54,3 \%$ & $50,0 \%$ \\
\hline
\end{tabular}




\section{CAPITAL HUMANO (Continuación).}

\begin{tabular}{|l|r|r|r|}
\hline $\begin{array}{l}\text { Personas que han trabajado en más de una } \\
\text { empresa del Grupo. }\end{array}$ & 1.084 & 1.348 & 1.617 \\
\hline \begin{tabular}{l} 
- $\begin{array}{l}\text { No de personas formadas en Cursos Superiores } \\
\text { de la Universidad Corporativa (acumulativo). }\end{array}$ \\
\hline
\end{tabular} & 234 & 319 & 414 \\
\hline
\end{tabular}

Personas comprometidas con el proyecto empresarial y que comparten una cultura común.

\begin{tabular}{|l|r|r|r|}
\hline $\begin{array}{l}\text { - \% de cumplimiento de los objetivos de las perso- } \\
\text { nas fijados en la gestión del desempeño. }\end{array}$ & $94,0 \%$ & $95,0 \%$ & $91,5 \%$ \\
\hline - Índice de rotación externa en España. & $7,7 \%$ & $6,6 \%$ & $6,0 \%$ \\
\hline
\end{tabular}

Desarrollo profesional permanente mediante la formación interna y la planificación y seguimiento de carreras profesionales.

- Inversión total en formación (millones de euros).

- Inversión en formación medida en \% sobre gastos de personal.

- \% de personas del Grupo que han recibido formación a lo largo del año.

- $\mathrm{N}^{\mathrm{o}}$ medio de horas de formación por persona y año.

- $\mathrm{N}^{\mathrm{o}}$ medio de horas de formación on-line por persona y año.

- Índice de satisfacción con la formación (máximo 10).

\begin{tabular}{|r|r|r|}
\hline 31,4 & 27,1 & 31,0 \\
\hline $5,0 \%$ & $3,7 \%$ & $4,7 \%$ \\
\hline $79 \%$ & $81 \%$ & $83 \%$ \\
\hline 42 & 37 & 42 \\
\hline- & 1,8 & 2,7 \\
\hline 8,4 & 8,4 & 8,4 \\
\hline
\end{tabular}

Aprendizaje permanente por medio de la relación con los agentes externos, aprovechando la experiencia adquirida en las actividades acometidas en el exterior.

- Alianzas y colaboraciones con instituciones académicas y de investigación.

92

78

Capacidad de atraer $\mathrm{y}$ retener a personas de alto potencial $\mathbf{y}$ vincularlas al proyecto empresarial.

- $\mathrm{N}^{\mathrm{o}}$ de personas clave identificadas. 


\section{La dirección por implicación} (DPI): Cómo implantar el cambio estratégico en la empresa para competir en base al
Capital Humano

Jose Carlos Álvarez Fernández Catedrático de Organización de Empresas Universidad de Vigo 



\section{El reto estratégico de las organizaciones del siglo XXI: Adecuarse para competir en base al talento}

\subsection{Las empresas deberán de adaptarse a la Sociedad del Conocimiento, que es algo más que la Sociedad de la Información}

El cambio no es una característica diferenciadora de la sociedad actual ${ }^{1}$. Lo que sí lo es, es el ritmo del cambio. Durante miles de años la forma de organización adoptada por la sociedad fue muy simple. El hombre utilizaba los recursos tal como los daba la naturaleza: Vivía en cuevas, se vestía con pieles o se alimentaba de la caza y de la pesca. La actividad humana apenas añadía valor a lo que se obtenía directamente de la naturaleza. En estas circunstancias no se podía hablar de la existencia de un sistema económico con la misión de asignar los recursos para añadir valor. Más tarde, transcurridos millones de años, la sociedad empezó a cuidar los animales que le servirían de alimentación y también a labrar la tierra. Así, se da paso a la forma más primaria de la economía, dando lugar a lo que podemos llamar economía agrícola, o economía de la primera ola.

Si consideramos cuatro tipos de recursos básicos para producir: (Naturaleza, Trabajo, Capital Financiero y Capital Intelectual), durante la economía agrícola, el producto final que consumía la sociedad estaba formado casi exclusivamente por Naturaleza y Trabajo. Era muy poco el Capital Financiero incorporado y prácticamente nulo el Capital Intelectual.

Con la Revolución Industrial, sobre todo a partir de la producción en masa, la mayor parte del valor añadido al producto final procede del Capital Financiero, aplicado a la fabricación de lo que demanda el mercado. Esto dio lugar a lo que se conoce como economía industrial o economía de la segunda ola. Ha durado prácticamente hasta nuestros días. Durante esta ola las empresas seguían el lamado sistema clásico de dirección y su competitividad se basaba en la disponibilidad de Capital Financiero. Una parte importante del precio estaba formado por el coste de la mano de obra, los materiales y las amortizaciones de los activos fijos de todo tipo (maquinaria e instalaciones) que se consumían a medida que eran utilizados. Durante esta segunda ola de la economía fue habitual fijar el precio como el resultado de añadir al coste un margen de beneficio

A partir de la década de los 90, el panorama económico está cambiando radicalmente. Entramos en la economía post-industrial o de la tercera ola. Lo fundamental para competir en las nuevas circunstancias es el Capital Intelectual, que es un intangible, integrado, básicamente, por conocimiento, de ahí que también sea frecuente referirse a esta tercera ola como la Economía del conocimiento o, de una forma más global, la Sociedad del Conocimiento.

A diferencia de lo que ocurre con el Capital Financiero, el Capital Intelectual no se consume con el uso. Si una persona comparte con otra su conocimiento, no

Heraclitus en el año 501 a.C. ya dijo que "no existe nada permanente, a excepción del cambio". 
por ello lo pierde, sino más bien ocurre lo contrario. Por lo tanto, no tiene sentido hablar de su amortización para imputarlo a los costes del producto. Cuando el Capital Intelectual es la base del producto, el precio no guarda relación directa con el coste del producto. Lo que el cliente está dispuesto a pagar por un producto donde el conocimiento es su principal componente, depende de cómo el conocimiento que lleva empaquetado se transforma en valor para el cliente, y no de los habituales factores de la economía industrial: mano de obra o materia prima.

De una forma gráfica, podemos representar las tres olas de la economía tal como muestra la Figura 3.1.

Figura 3.1. Las tres olas de la economía.

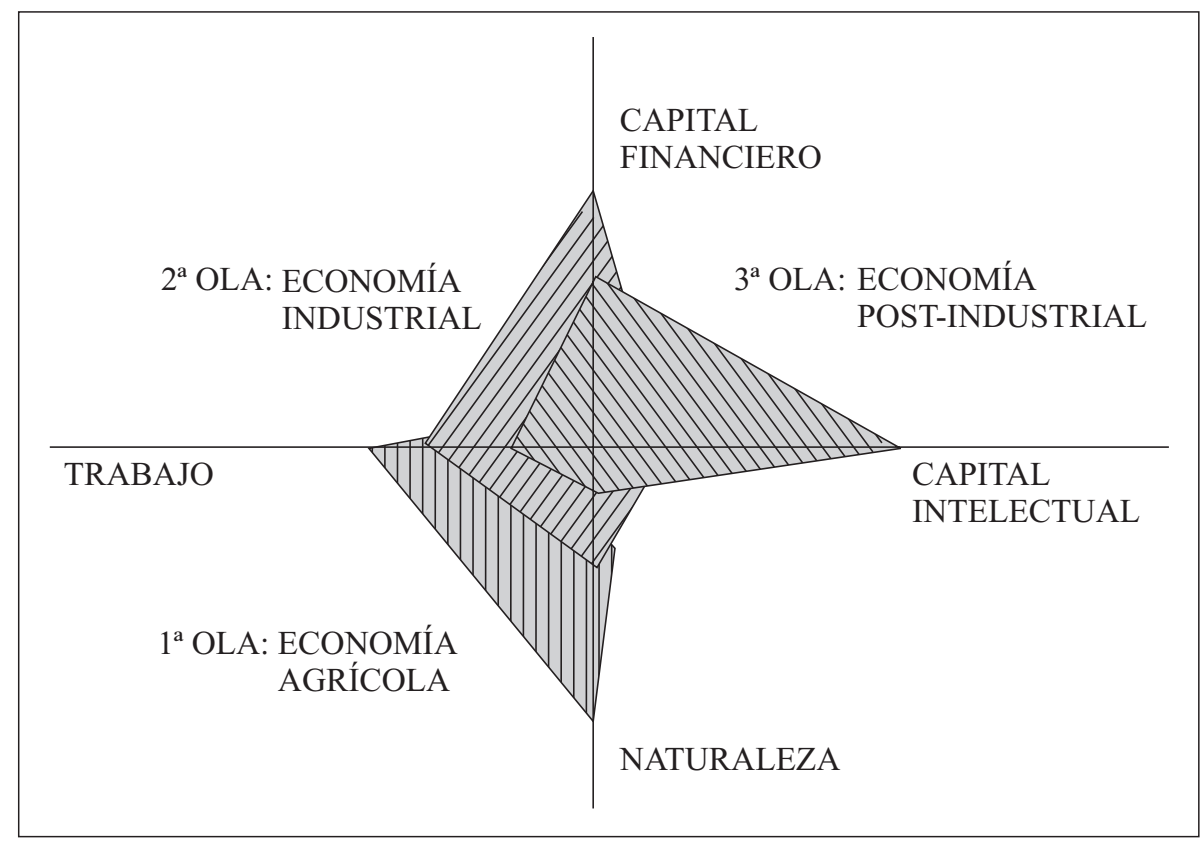

Fuente: Tissen, Andriessen y Deprez (1998) y adaptación propia.

De acuerdo con las ideas expuestas, puede afirmarse que el conocimiento se ha convertido en el factor por excelencia para explicar la competitividad de las empresas. No es de extrañar, por lo tanto, que según explicamos a lo largo del presente trabajo, una función clave de los directivos del siglo XXI sea propiciar el aprendizaje en la empresa, como proceso de creación, desarrollo y aplicación del conocimiento a la innovación.

Cada vez son más los autores que coinciden al valorar la importancia del aprendizaje en la organización, aceptando que la única fuente de ventajas competitivas sostenibles se asocia a la capacidad de aprendizaje. 
Consideramos oportuno aclarar que aunque es frecuente hablar de "Sociedad de la Información" y de "Sociedad del Conocimiento" como expresiones con el mismo significado, se trata de algo diferente, del mismo modo que información es distinto que conocimiento. La Sociedad de la Información hace énfasis en la tecnología; tiene mucho que ver con el desarrollo e implantación de Tecnologías de Información y Comunicación; es algo donde los tecnólogos desempeñan el papel clave.

La Sociedad del Conocimiento es mucho más que eso; se refiere a una nueva forma de vida, tanto en familias como en organizaciones, que supone liberar y aplicar el talento humano en mucha mayor medida que durante la economía industrial. Hace énfasis en las personas como usuarios de las tecnologías para apoyar el aprendizaje y la aplicación del conocimiento derivado del mismo. El desarrollo de las tecnologías impulsa la Sociedad del Conocimiento, pero representa sólo una parte de la misma. En una empresa pueden estar implantadas las tecnologías más avanzadas y, sin embargo, utilizarlas para reforzar un sistema de dirección basado en la autoridad y la jerarquía. Las tecnologías son indispensables para captar, almacenar, procesar y distribuir la información para ponerla a disposición del usuario, pero esto es sólo una pequeña aportación que hacen en la nueva sociedad. Además serán la base para crear y utilizar conocimiento. En este sentido, puede afirmarse que la Sociedad de la Información es un puente entre la sociedad industrial y la Sociedad del Conocimiento.

Desde las Administraciones Públicas es más frecuente hablar de Sociedad de la Información que de la Sociedad del Conocimiento. La razón más evidente para que esto sea así es porque, al no ser todavía adecuadas las dotaciones de infraestructura, su principal preocupación es dar este primer paso necesario. Sin embargo, no debemos olvidar que el éxito no está en las tecnologías, sino en su uso eficiente y esto depende, fundamentalmente, de los usuarios. De ahí que sea fundamental un mayor esfuerzo por llevar a cabo los cambios necesarios en las organizaciones para que éstas se preparen para competir en la Sociedad del Conocimiento.

\subsection{Los nuevos tiempos demandan un nuevo concepto de estrategia: Integración y cambio}

\subsubsection{La estrategia como integración de futurización y planificación}

En la Sociedad del Conocimiento, una función muy importante de la dirección es aportar una visión o proyecto del tipo de empresa que se quiere ser y, luego, propiciar el aprendizaje colectivo para definir y ajustar continuamente la estrategia, mediante la innovación, para avanzar hacia la visión. 
Pero esa visión no es el resultado de una planificación ${ }^{2}$. El proceso para crearla es diferente.

En los tiempos que vivimos, de fuertes cambios y de un futuro imprevisible, para tener éxito no se puede hacer un plan para decidir a dónde queremos ir ¿qué hacer entonces? A falta de una palabra que pueda explicar qué hacer para definir el destino que se desea, algunos autores hablan, sencillamente, de futurización ${ }^{3}$. Futurizar es decidir lo que se quiere ser, formándose una imagen del futuro deseado unido al compromiso de buscar un camino adecuado para avanzar hacia ese futuro y de ponerlo en práctica. Luego, se realizará la planificación que nos lleve a ese futuro. Por lo tanto, la moderna estrategia empieza por la futurización. De una forma gráfica, podemos establecer la comparación entre planificación y futurización, según muestra la Figura 3.2.

Figura 3.2. Comparación entre futurización y planificación.

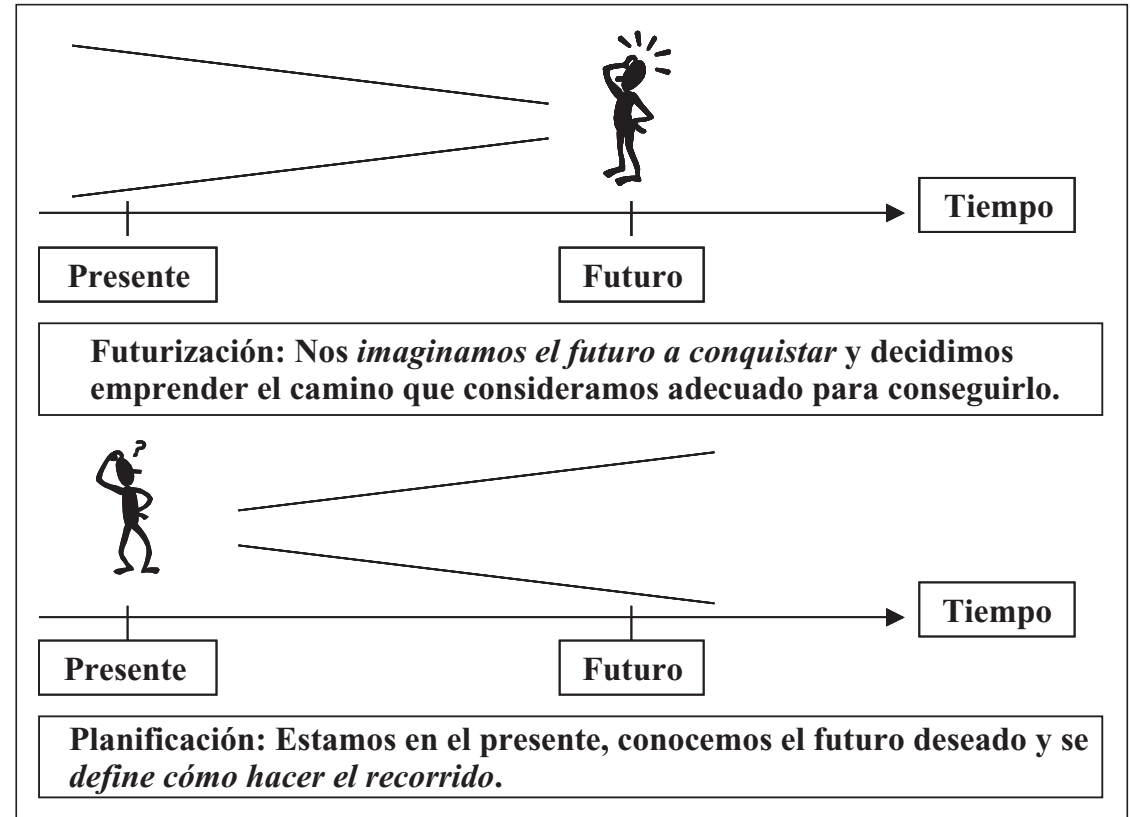

2 La palabra planificación sigue siendo una de las más utilizadas en la dirección actual, pero deberá dársele un significado diferente al que tuvo en el pasado. Ahora la planificación debe tener un sentido mucho más limitado. Se planifican los pasos a dar para recorrer un camino que nos lleve a un futuro deseado y ya decido. La planificación no sirve para decidir el futuro, como se hacía en el sistema clásico. No puede constituir un fin en sí misma, sino un medio para llegar a ese futuro que ya está imaginado y que se ha decidido alcanzar. Mientras que en el modelo clásico se planificaba únicamente hacia adelante, partiendo de la historia y del presente, ahora la planificación se hace en los dos sentidos: a corto plazo se deberá partir del presente, pero a largo plazo es necesario situarse en el futuro deseado y planificar hacia atrás.

3 El autor que ha utilizado por primera vez el término futurización fue Albrecht en 1994. 
La futurización se ha convertido en la base de la dirección moderna. Conviene tener en cuenta que las personas no tienen una actitud pasiva ante lo que ocurre en su entorno, sino que consciente o inconscientemente desean participar ${ }^{4}$. Por lo tanto, las personas dan mucho más lo que llevan dentro cuando encuentran significado a lo que se les pide que hagan. Ese significado lo proporciona lo que actualmente se llama visión del proyecto empresarial, que es el resultado de un proceso de futurización (dimensión humana) y no de planificación (dimensión fundamentalmente técnica).

El éxito de la empresa exige, en general, dar importancia a la vez a la futurización (el directivo como líder) y a la planificación (el directivo como líder y como gestor).

\subsubsection{Integración de la estrategia intencional y de la emergente}

Ya han quedado atrás los tiempos en que el plan estratégico se consideraba como una panacea para poder competir en el futuro. Sin negar la importancia de la planificación, cuando el entorno es tan cambiante como ocurre actualmente, la base para ser competitivo es la capacidad de la empresa para futurizar y para aprender y adaptarse a nuevas situaciones. Es decir, de su capacidad para generar estrategias emergentes.

El concepto de estrategia emergente tuvo su origen en un artículo escrito por Mintzberg y Waters ${ }^{5}$ en 1985. Consideran necesario contemplar dos tipos de estrategias que se complementan entre sí: la estrategia intencional, que constituye el plan de la empresa y la estrategia emergente, que surge como un proceso de aprendizaje a partir de la experiencia.

La Figura 3.3. muestra gráficamente la relación entre estos tipos de estrategias ${ }^{6}$.

4 Linda Gratton (2001), sostiene que "los seres humanos no somos receptores pasivos de todo lo que la vida nos ofrece. Por el contrario, participamos activamente en ella. Nos esforzamos en atribuir un significado a las diversas señales y estímulos que recibimos $y$ en comprender las contradicciones que enfrentamos". L. Gratton es profesora de la London Business School. En 1992 organizó en esta Escuela de Negocios el Leading Edge Research Consortiun, en colaboración de importantes empresas como Hewlett Packard, Glaxo Wellcome, etc., y que ella misma dirige.

5 En el núm. de julio/septiembre de 1985 de Strategic Management Journal, Henry Mintzber y James Waters, han escrito el artículo "Of Strategies, deliberate and emergent", donde se habla por primera vez de estrategia emergente. La estrategia emergente adquiere un especial interés cuando el entorno experimenta cambios rápidos y profundos como ocurre en el momento actual.

6 Las aportaciones más recientes sostienen que a medida que se consolida la Sociedad del Conocimiento, la estrategia emergente adquiere un peso creciente para explicar el éxito de las organizaciones. Moshe F. Rubinstein y Iris R. Firstenberg en su libro La organización pensante, escrito en 2000, afirman que "a medida que el mundo se vuelve más interconectado, se hace más difícil planificar el futuro. En el pasado, casi todas las acciones de una organización se basaban en planes que habían sido concebidos al principio. En el presente, el equilibrio se está rompiendo de manera que la mayor parte de las acciones son resultado de decisiones no planificadas que se toman en el momento que surgen a medida que se desarrollan acontecimientos inesperados y que requieren un respuesta creativa y oportuna". 
Figura 3.3. Estrategia intencional y estrategia emergente.

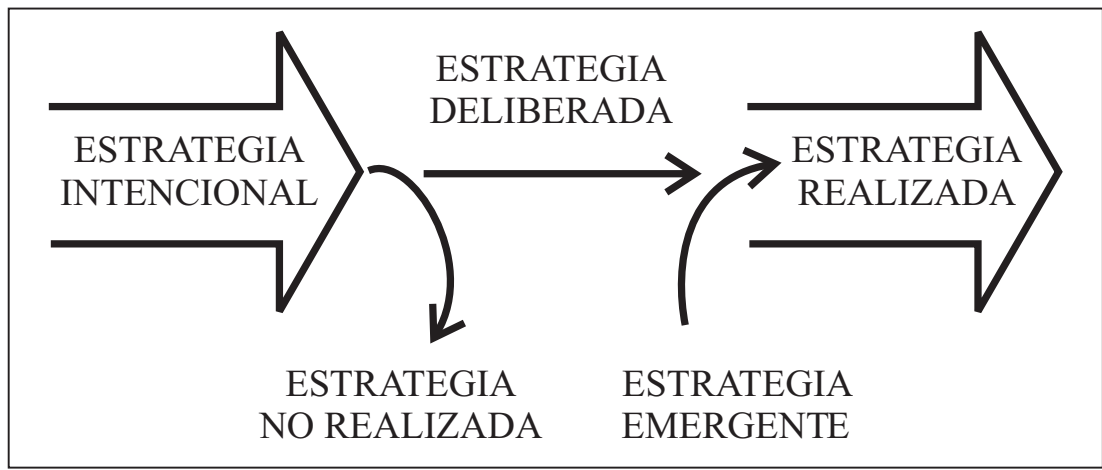

La estrategia intencional está definida por el plan estratégico de la empresa, pero nunca será un fin en si mismo. Durante su ejecución la empresa, intuitivamente, o de forma más racional, en función de la evolución del entorno, de la propia organización y del aprendizaje resultante de la experiencia, tomará decisiones que supongan no realizar determinados aspectos del plan e incorporar otros nuevos. Surge así el concepto de estrategia deliberada, parte de la estrategia intencional que se lleva a cabo y que, unida a las estrategia emergente da lugar a la estrategia realizada por la empresa.

El éxito depende de que la empresa sea capaz de integrar dinámicamente la estrategia intencional con la emergente.

\subsubsection{La estrategia como integración de lo técnico y de lo humano}

La integración de la planificación y la futurización, y también de lo intencional y de lo emergente, exige que las empresas den respuesta a la que llamamos la gran paradoja del management moderno, la paradoja humano-técnica, que se puede enunciar del siguiente modo: potenciar el cambio y al mismo tiempo controlar el riesgo asociado al mismo.

Para potenciar el cambio, los líderes deberán liberar la capacidad creativa de los empleados como medio para fomentar la innovación. Deberán repartir el poder de decisión para que los empleados que actúan directamente con los clientes estén autorizados a aportar soluciones innovadoras a los problemas y necesidades planteadas. Tienen que despojar a sus colaboradores de las ataduras de los sistemas que los encorsetan e incapacitan para hacer uso de su potencial como personas. Tienen que poner, en definitiva, entre sus prioridades la dimensión humana de la empresa.

Para controlar el riesgo asociado al cambio deseado, sin tener que recurrir a la tiranía de los sistemas, la dirección deberá potenciar la implantación de sistemas para autogestionar el aprendizaje que propicie que los que tienen el poder, incluidos los empleados del nivel operativo, lo ejerzan basándose en el conocimiento adecuado y, además, puedan realizar el autocontrol del proceso. 
Para comprender la importancia de esta paradoja, contemplaremos la empresa como una combinación de personas y de tecnologías ${ }^{7}$. Empleamos la palabra tecnología en un sentido muy amplio, para indicar la "dimensión técnica" de la empresa. Abarca no sólo los factores técnico-físicos (máquinas, instalaciones, ordenadores, redes, etc.), sino también los factores técnico-formales (sistemas, procedimientos, software, etc.) que condicionan, de forma importante, la manera de llevar a cabo el conjunto de los procesos que se realizan en la empresa. Abarca, por lo tanto, factores tangibles y factores intangibles ${ }^{8}$.

Aunque hablemos de dos dimensiones en la empresa, ambas forman, a su vez, un todo inseparable (se relacionan para conseguir un objetivo común: ser competitivo). Lo que incluimos en la dimensión técnica contribuye de forma decisiva a que la empresa pueda conseguir sus objetivos, pero con eso no basta, la dimensión humana aporta lo más importante para que eso realmente suceda: el talento. Podemos expresar esta idea como sigue:

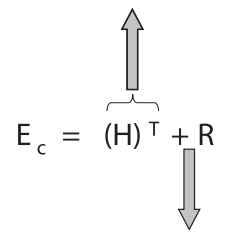

$\mathrm{E}_{\mathrm{c}}=$ Nivel de éxito esperado con el cambio.

$\mathrm{H}=$ Grado de desarrollo de la dimensión humana

$\mathrm{T}=$ Grado de desarrollo de la dimensión tecnológica

$\mathrm{R}=$ Riesgo de que no se consiga el éxito esperado

El éxito de la empresa depende del desarrollo e interacción de ambas dimensiones a lo largo del tiempo: la base está en lo humano, pero lo tecnológico es un potenciador. Conseguir que esto ocurra de forma adecuada es el principal reto de la dirección estratégica moderna.

7 La empresa puede ser estudiada desde enfoques muy diversos, en función de lo que se pretende. Dado que el objetivo del presente trabajo es plantear un sistema de dirección que haga posible el cambio estratégico que deben afrontar las empresas para ser competitivas en la Sociedad del Conocimiento, las veremos como una combinación de personas y de tecnologías.

8 Un componente que adquiere un peso creciente dentro de la dimensión técnica de la empresa son los sistemas. Se trata de un concepto que no siempre se utiliza de la misma manera. En el presente trabajo, el término sistema significa el conjunto de reglas, directrices y procedimientos, más o menos formalizadas y más o menos apoyados por factores técnicofisicos, que hacen que la organización funcione. De acuerdo con este concepto tan amplio, la idea de sistema abarca aspectos tangibles y también intangibles, ganando peso estos últimos a medida que se consolida la Sociedad del Conocimiento. En efecto, si pensamos, por ejemplo, en el sistema de producción podemos entender que comprende no sólo procedimientos, software, etc., sino también el hardware e incluso la maquinaria y equipos con que se llevan a cabo los procesos propios de la función de producción. 
Aunque la expresión adopta forma matemática, no debe llevarnos a pensar que en la práctica convenga relacionar de forma estrictamente numérica la relación entre lo humano y lo tecnológico. Sin embargo, sí es válida para transmitir la idea de que cuando fijamos unos objetivos para el cambio, el grado de éxito que cabe esperar del cumplimiento de esos objetivos $\left(\mathrm{E}_{\mathrm{c}}\right)$ aumenta cuando lo hace el nivel de talento empleado (desarrollo de $\mathrm{H}$, que actúa como base) y también del desarrollo tecnológico de la empresa (dimensión T, que hace de potenciador del talento). Como muestra la expresión, cuando aumentan H y T, disminuye el riesgo de que los objetivos no sean alcanzados.

En definitiva, en la nueva sociedad las personas son la base, pero para que sean eficaces hay que apoyarse en las tecnologías. Algunas organizaciones, sobre todo las que tienen mucho poder económico para hacer frente a las inversiones necesarias, cometen el error de centrarse demasiado en las tecnologías, y se olvidan de las personas, que son la base para hacer eficaces las tecnologías. Esto equivale a decir que muchas empresas se centran demasiado en los datos y en la información, y poco en el conocimiento y en el talento.

Durante la economía industrial se ha prestado especial interés a la dimensión técnica de la empresa, limitándola a factores tangibles ya que las ventajas competitivas se asociaban a los recursos físicos y financieros. Sin embargo, ahora, en la Sociedad del Conocimiento, el reto de los directivos, está en desarrollar y aprovechar al máximo el talento personal y el de la propia organización, por lo que adquiere especial relevancia la dimensión humana de la empresa.

Dado que en las empresas existe mucho talento que está inactivo, actualmente se repite hasta la saciedad por los gurús del management que el principal reto de los directivos del siglo XXI es liberar el talento existente en las organizaciones y transformarlo en innovación. El camino es hacer que las empresas sean más inteligentes, que aprendan y actúen de forma espontánea. Para conseguirlo la clave está en la dimensión humana de la empresa, pero apoyándose de forma creciente en la dimensión técnica.

En conclusión, la moderna estrategia ha de ser dual, ha de utilizar todo el cerebro ${ }^{9}$ de la organización, que es algo más que la suma de los cerebros de las personas que la forman. La planificación que conduzca a la estrategia intencional corresponde a la dimensión técnica de la empresa y demanda la actuación del directivo como gestor apoyándose en las tecnologías. Es decir, exige utilizar el hemisferio izquierdo del cerebro de la organización. Pero la planificación por sí sola no conduce al éxito deseado; el cumplimiento de lo futurizado demanda aprender e incorporar estrategias emergentes. Para que esto ocurra es necesario que funcione el hemisferio derecho del cerebro de la organización.

9 En los últimos años han proliferado las teorías sobre el cerebro humano. Una muy conocida considera que en el cerebro hay dos hemisferios: el izquierdo que está especializado en los procesos racionales y el derecho que lo está en los procesos intuitivos. 


\subsubsection{Para muchas empresas, una función clave de la dirección estratégica debe ser dirigir el cambio estratégico}

Aunque la Dirección es única, sigue siendo frecuente distinguir la dirección estratégica de la operativa. La Dirección operativa tiene mucho que ver con la dimensión del directivo como gestor. No está orientada al cambio. Su objetivo es que se hagan las cosas adecuadamente sacando el máximo provecho de lo que hoy es la organización: sus productos actuales, clientes actuales, personal actual, etc. A corto plazo, meses, es poco lo que puede cambiar la empresa en estos aspectos.

Si consideramos un período de tiempo más largo la empresa requerirá cambios importantes si quiere competir. En el futuro deberá estar haciendo lo que sea adecuado para ese momento, en función de las necesidades que desean cubrir los clientes. Deberá, en definitiva, ofrecer ventajas competitivas suficientes para atraer y mantener clientes.

$\mathrm{Si}$, como ya hemos comentado, actualmente la base para competir está en el Capital Intelectual, son muchas las empresas que tienen que hacer importantes cambios para adaptarse a la nueva situación. En consecuencia el objetivo de la dirección estratégica moderna es dar respuesta a tres grandes interrogantes: ¿Hacia dónde debemos de cambiar?, ¿qué tenemos que cambiar? y ¿cómo hacer el cambio?

Contestar a la primera de las cuestiones es fijar el rumbo, crear una visión. La respuesta a las otras dos preguntas es definir el camino, la estrategia, para alcanzar la visión deseada.

Sin embargo, no basta con que la estrategia sea coherente con la visión. No debemos olvidar que al futuro sólo se llega desde el presente. El largo plazo únicamente se alcanza si se superan los obstáculos que aparezcan en el corto plazo. Sólo así se asegura la supervivencia. Por lo tanto, la estrategia incluye también la operativa, al menos en lo referente a la puesta en práctica del cambio para asegurar el futuro.

En definitiva, la Dirección es un proceso continuo, de modo que si nos desplazamos desde lo más operativo hacia lo más estratégico, adquiere más peso la función de liderazgo frente al de gestión, según muestra la Figura 3.4., pero ambas son indispensables para el éxito.

Es necesario que en la empresa existan buenos líderes para que anticipen el futuro que garantice la competitividad de la empresa (crear la visión, crear una coalición de interesados por esa visión y propiciar el aprendizaje para disponer en cada momento del conocimiento necesario), pero también han de existir buenos gestores para desarrollar una eficaz dirección operativa (para hacer bien las tareas del día a día) que garantice la competitividad a corto plazo.

No existe una frontera clara que diga donde acaba lo operativo y empieza lo estratégico, lo mismo que no la hay para separar la gestión y el liderazgo al poner en práctica esta doble dimensión del directivo. 
Resumiendo lo dicho hasta aquí, podemos afirmar que, para la mayoría de las empresas, la dirección estratégica tiene como uno de los principales objetivos, dirigir el cambio empresarial para que la empresa sea competitiva en la Sociedad del Conocimiento. Para definir este cambio es necesario poner en juego la capacidad del directivo como líder, crear la visión, pero también su capacidad de gestión, para que, combinada con el liderazgo, pueda definir e implantar la estrategia que lleve a la empresa hacia la visión creada.

Figura 3.4. Relación de la gestión y el liderazgo con los niveles de dirección.

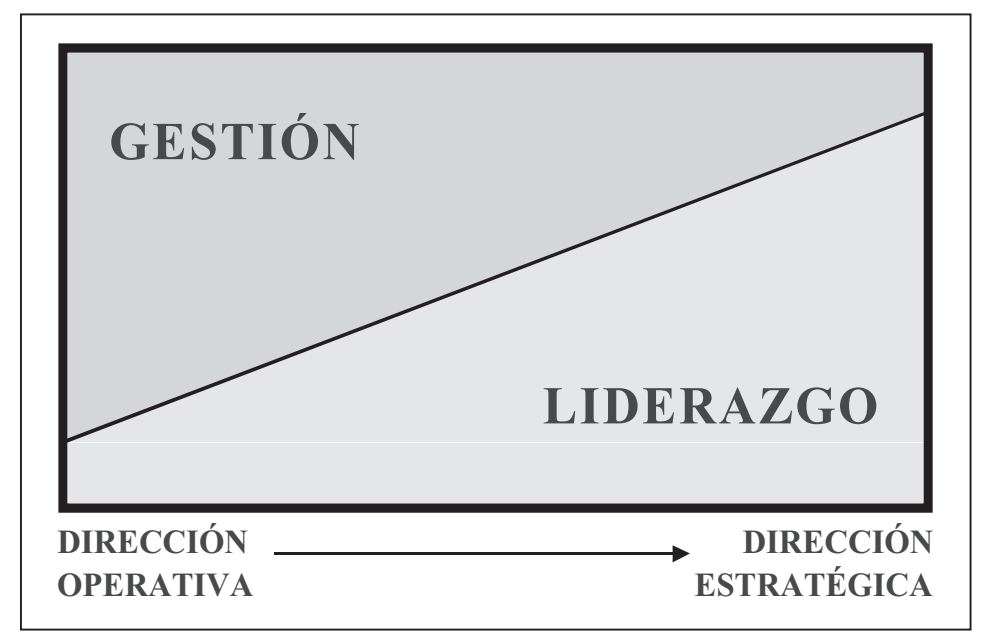

\section{Una tipología de empresas en base a su capacidad para liberar, desarrollar y aplicar el talento de sus empleados}

\subsection{La empresa como una combinación de personas y tecnologías: La} matriz T-H de estilos de dirección

Retomando la idea de la empresa como una combinación de personas y de tecnologías, el estilo de dirección podemos asociarlo al nivel de desarrollo de cada una de las mencionadas dimensiones: la técnica y la humana. De acuerdo con el nivel de desarrollo de la dimensión técnica, podemos distinguir tres estilos de dirección:

Improvisador, que maneja, en su mayor parte, el conocimiento de forma intuitiva, con poca formalización y sin penetrar en el futuro de forma consciente. Apenas se apoya en sistemas. No puede considerarse que la improvisación asociada a la intuición sea mala por principio para la dirección, pero una dirección basada totalmente en la improvisación sólo sirve para microempresas donde hay una constante interacción entre todo su personal. En todo caso, lo importante es conseguir un adecuado equilibrio entre intuición y planificación. 
Administrador, que considera de forma explícita un horizonte temporal de cierto tiempo, incluso de varios años. Cuenta con sistemas formalizados para apoyar la reflexión y la toma de decisiones. Inicialmente los sistemas apoyan la administración: fijación de objetivos y líneas de actuación (planificación), asignación de recursos (organización) y el control, que le permita comparar el objetivo y los resultados y tomar medidas correctivas. Pero a medida que la empresa desarrolla su dimensión técnica se amplía el ámbito de los sistemas, de modo que cubren todos los aspectos de la vida de la organización: gestión del desempeño, aprendizaje organizativo, innovación, etc.

Anticipador, que va más allá de la planificación: desarrolla una visión imaginándose un futuro diferente. Rompe con las reglas de juego actuales, revolucionando el funcionamiento de las actividades en que actúa. Sin embargo, conviene matizar que lo que realmente da la categoría de anticipador no es únicamente esa imagen y deseo de un nuevo futuro, sino también la capacidad de la empresa para hacerlo realidad. La anticipación se transforma en una innovación revolucionaria de productos-mercados y en la forma de llevar a cabo el negocio. Eso requiere que la empresa en la que se practica este estilo de dirección disponga de los recursos y capacidades necesarias para poder llevar a cabo la estrategia de anticipación. En consecuencia, este estilo, en la generalidad de los casos, es privativo de las grandes empresas, líderes a nivel mundial.

Claros ejemplos de empresas anticipadoras, en el sentido que le damos al término, son Federal Express, Microsoft y ZARA. Cada una en su campo, ha sido capaz de romper las reglas de juego, reinventando sus respectivos sectores.

Pasar de la improvisación a la administración supone "profesionalizar" la dirección mediante la incorporación de sistemas, lo que se traduce básicamente en apoyar la planificación, la organización y el control en herramientas técnicas (sistemas). La empresa que quiera hacer esto siempre lo podrá conseguir. Por el contrario, la anticipación ya no es sólo cuestión de querer. Es propia de las empresas líderes en cada sector, ya que han sido capaces de hacer realidad su visión, acertando (y acertar, en gran medida, requiere como aliado la suerte) en el diseño e implantación de estrategias de cambio revolucionario. Además, se trata de cambios que requieren grandes inversiones, por lo que demanda capacidad financiera, humana y tecnológica. De acuerdo con esta idea, puede afirmarse que las empresas de reducida dimensión en el contexto mundial, como hemos dicho, tienen pocas posibilidades de seguir un estilo de anticipación en los términos en que se ha definido.

El desarrollo de la dirección en su aspecto humano empieza con el nivel y forma de delegar funciones y de asumir responsabilidades, pero va más allá. Se refleja, básicamente, por la capacidad para liberar el talento existente en la organización. Considerando esta idea de desarrollar, liberar y aplicar el talento, podemos distinguir también tres tipos de directivos: 
Ejecutor, que corresponde a los directivos que realizan directamente una gran actividad ejecutiva y operativa. No aprovechan más que una pequeña parte del potencial de sus colaboradores. No delegan lo suficiente ya que, en cierto modo, consideran a sus colaboradores como "menores de edad" a efectos de asumir responsabilidades en la empresa. En definitiva, con este estilo de dirección apenas se hace uso del cerebro de los colaboradores. Sólo se utiliza el talento de los jefes.

Delegador, que está presente cuando el directivo ya ha sido capaz de crear una estructura organizativa que le ayuda a repartir juego y ejercer una adecuada supervisión. Las diferentes tareas que se deben realizar en la empresa están definidas y asignadas a responsables concretos, a los que se les ha dotado de la autoridad necesaria. Este estilo, además, ya presupone un mínimo de confianza del director en sus colaboradores. Los considera "mayores de edad" a efectos de asumir responsabilidades.

Implicador, que significa que el directivo ya ha sido capaz de desarrollar el principio de pertenencia en una mayoría del equipo humano de la empresa. Esta situación permite que la organización se comporte como una verdadera coalición de intereses, donde un porcentaje suficiente de empleados actúan como propios dueños. Propicia que los empleados de la empresa pongan en juego todo el potencial de talento de que disponen, siendo habitual el autocontrol como vía para guiar su actividad. La implicación es algo más que la delegación. Cuando hay implicación el superior confía en sus colaboradores (no los considera subordinados) y sabe que harán todo lo posible para conseguir los objetivos consensuados, lo mismo que lo haría él.

Debemos insistir en que si bien es cierto que la capacidad de la empresa para liberar, desarrollar y aplicar talento depende fundamentalmente de la dimensión humana, la parte técnica también tiene un papel clave.

Si combinamos las dimensiones técnica y humana de la dirección obtenemos la "matriz T-H de tipos de empresa según estilos de dirección", como muestra la Figura 3.5., que ofrece una tipología en base a tres tipos básicos de empresas, que tomaremos como referencia. Estos tres estilos ${ }^{10}$ se caracterizan, por un equilibrio en el desarrollo de las dos dimensiones:

- Estilo Director-Jefe: bajo nivel de desarrollo de las dimensiones técnica y humana.

- Estilo Director-Gestor: nivel medio de desarrollo técnico y humano.

- Estilo Director-Líder: alto nivel de desarrollo técnico y humano.

10 Hablaremos indistintamente de tipos de empresas según el estilo de dirección o, simplemente de estilos de dirección. 
Figura 3.5. Matriz T-H de tipos de empresas según los estilos de dirección.

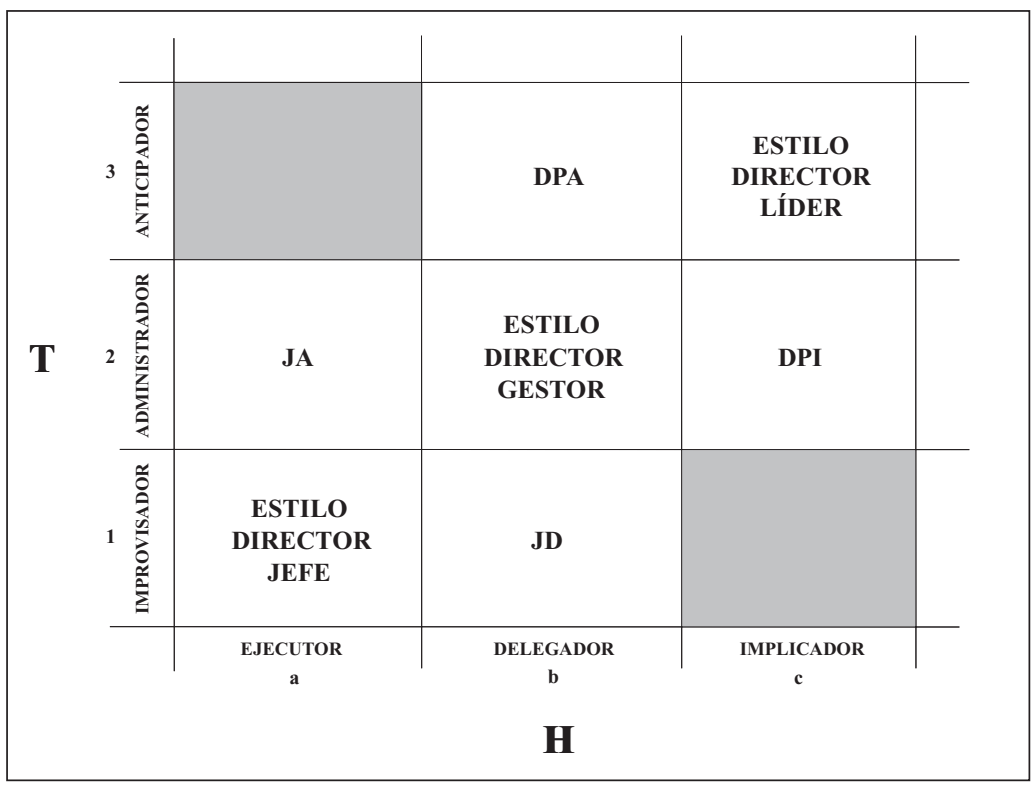

\subsection{Características de los tipos de empresa de referencia}

La Tabla que presentamos a continuación ofrece una comparación de los tres tipos de empresas tomados como referencia atendiendo a los siguientes aspectos: Proyecto-actividad, actitud ante el entorno, organización, forma de dirigir, trabajo habitual de los directivos, relación directivos-empleados, interés por los Recursos Humanos, comunicación, de incorporación y uso de las tecnologías, desarrollo de sistemas, aprendizaje e innovación y cultura.

Tabla 3.1. Comparación de tipos de empresa.

\begin{tabular}{|c|c|c|c|}
\hline \multirow{2}{*}{ Aspectos } & \multicolumn{3}{|c|}{ Rasgos característicos } \\
\hline & D-J & D-G & D-L \\
\hline $\begin{array}{l}\text { Proyecto- } \\
\text { Actividad }\end{array}$ & $\begin{array}{l}\text { No se tiene claro hacia } \\
\text { dónde va la empresa. } \\
\text { No hay proyecto o no } \\
\text { está comunicado. No } \\
\text { está bien definido el } \\
\text { negocio (actividad) de } \\
\text { la empresa. }\end{array}$ & $\begin{array}{l}\text { No es todavía habitual } \\
\text { que exista una decla- } \\
\text { ración de visión en las } \\
\text { empresas de este estilo. } \\
\text { Si existe proyecto sue- } \\
\text { le reducirse a un plan } \\
\text { de negocio a largo pla- } \\
\text { zo. El negocio hace én- } \\
\text { fasis en los tangibles. }\end{array}$ & $\begin{array}{l}\text { Existe una declaración } \\
\text { de la visión comparti- } \\
\text { da, que atiende las ex- } \\
\text { pectativas de los di- } \\
\text { versos stakeholders. } \\
\text { El negocio está defi- } \\
\text { nido en el marco de la } \\
\text { misión de la empresa, } \\
\text { integrado en el con- } \\
\text { junto de la estrategia. }\end{array}$ \\
\hline
\end{tabular}


Tabla 3.1. Comparación de tipos de empresa. (Cont.)

\begin{tabular}{|c|c|c|c|}
\hline \multirow{2}{*}{ Aspectos } & \multicolumn{3}{|c|}{ Rasgos característicos } \\
\hline & D-J & D-G & D-L \\
\hline Entorno & $\begin{array}{l}\text { No está formalizado } \\
\text { el proceso para cono- } \\
\text { cer el entorno, el cual } \\
\text { no es un elemento cla- } \\
\text { ve para la dirección. }\end{array}$ & $\begin{array}{l}\text { Cierto preocupación } \\
\text { por el entorno, pero } \\
\text { bastante centrado en } \\
\text { lo que se refiere direc- } \\
\text { tamente al negocio. }\end{array}$ & $\begin{array}{l}\text { Captación sistemáti- } \\
\text { ca de conocimiento y } \\
\text { preocupación por nue- } \\
\text { vas amenazas y opor- } \\
\text { tunidades. La empresa } \\
\text { es capaz de anticipar- } \\
\text { se cambiando las re- } \\
\text { glas de juego del sec- } \\
\text { tor para que las opor- } \\
\text { tunidades jueguen a } \\
\text { su favor. }\end{array}$ \\
\hline Organización & $\begin{array}{l}\text { La falta de definición } \\
\text { de la estructura orga- } \\
\text { nizativa (funciones y } \\
\text { puestos de trabajo) y } \\
\text { de los procesos hace } \\
\text { que unos empleados } \\
\text { desconozcan lo que } \\
\text { hacen otros. }\end{array}$ & $\begin{array}{l}\text { Unidades organizativas } \\
\text { (funciones, divisiones, } \\
\text { unidades de negocio, } \\
\text { etc.). bien definidas. } \\
\text { Sistemas que estable- } \\
\text { cen niveles de delega- } \\
\text { ción claros y mecanis- } \\
\text { mos de coordinación } \\
\text { formalizados (planes, } \\
\text { manuales de procesos, } \\
\text { de calidad, etc. }\end{array}$ & $\begin{array}{l}\text { Coexiste una estructu- } \\
\text { ra "oficial", similar a } \\
\text { la del estilo Director- } \\
\text { Gestor, y una estructu- } \\
\text { ra "oficiosa", que fun- } \\
\text { ciona como una red de } \\
\text { relaciones informales, } \\
\text { propiciando la iniciati- } \\
\text { va individual para po- } \\
\text { tenciar el aprendiza- } \\
\text { je y aplicarlo a la solu- } \\
\text { ción de problemas y a } \\
\text { la innovación. }\end{array}$ \\
\hline $\begin{array}{l}\text { Forma de } \\
\text { dirigir }\end{array}$ & $\begin{array}{l}\text { Paternalista. Conduc- } \\
\text { ta de "seguidismo" al } \\
\text { jefe por los emplea- } \\
\text { dos. Escasa delega- } \\
\text { ción. Dirección por } \\
\text { sucesos. No hay cons- } \\
\text { ciencia del comporta- } \\
\text { miento paradójico de } \\
\text { la empresa. }\end{array}$ & $\begin{array}{l}\text { Más énfasis en la ges- } \\
\text { tión que en el lide- } \\
\text { razgo. Es habitual la } \\
\text { DPO. Se presta mucha } \\
\text { importancia a la plani- } \\
\text { ficación, organización } \\
\text { y control. No se ma- } \\
\text { neja adecuadamente la } \\
\text { gran paradoja del ma- } \\
\text { nagement: los directi- } \\
\text { vos, inconscientemen- } \\
\text { te, suelen poner por } \\
\text { delante la dimensión } \\
\text { técnica de la empresa. }\end{array}$ & $\begin{array}{l}\text { Los directivos tie- } \\
\text { nen claro el compor- } \\
\text { tamiento paradójico } \\
\text { de la empresa, que es } \\
\text { considerada como un } \\
\text { organismo. Énfasis en } \\
\text { el liderazgo, que man- } \\
\text { tiene la coalición de in- } \\
\text { tereses en torno a la vi- } \\
\text { sión compartida. Pro- } \\
\text { picia el aprendizaje li- } \\
\text { berando y aplicando el } \\
\text { talento colectivo. }\end{array}$ \\
\hline
\end{tabular}


Tabla 3.1. Comparación de tipos de empresa. (Cont.)

\begin{tabular}{|c|c|c|c|}
\hline \multirow{2}{*}{ Aspectos } & \multicolumn{3}{|c|}{ Rasgos característicos } \\
\hline & D-J & D-G & D-L \\
\hline $\begin{array}{l}\text { Trabajo } \\
\text { habitual de } \\
\text { los jefes }\end{array}$ & $\begin{array}{l}\text { "Apagar fuegos". Tra- } \\
\text { bajan muchas horas } \\
\text { y tienen la sensación } \\
\text { de que no les llega el } \\
\text { tiempo. }\end{array}$ & $\begin{array}{l}\text { El directivo dedica } \\
\text { bastante tiempo al se- } \\
\text { guimiento de los obje- } \\
\text { tivos con los emplea- } \\
\text { dos. }\end{array}$ & $\begin{array}{l}\text { El directivo dedica bas- } \\
\text { tante tiempo al man- } \\
\text { tenimiento de la coali- } \\
\text { ción de intereses en tor- } \\
\text { no a la visión comparti- } \\
\text { da, al aprendizaje y a la } \\
\text { enseñanza. }\end{array}$ \\
\hline $\begin{array}{l}\text { Relación di- } \\
\text { rectivos-em- } \\
\text { pleados }\end{array}$ & $\begin{array}{l}\text { Se basan en el poder } \\
\text { y la autoridad. El Jefe } \\
\text { "manda", no dirige. } \\
\text { Utiliza poco el cono- } \\
\text { cimiento de sus su- } \\
\text { bordinados. }\end{array}$ & $\begin{array}{l}\text { Se basan en la autori- } \\
\text { dad de los directivos. } \\
\text { Preponderancia de la } \\
\text { jerarquía Los directi- } \\
\text { vos suelen apropiar- } \\
\text { se de las iniciativas de } \\
\text { sus empleados. }\end{array}$ & $\begin{array}{l}\text { Se basan en la confian- } \\
\text { za. Se potencia los pun- } \\
\text { tos fuertes de los cola- } \\
\text { boradores. }\end{array}$ \\
\hline $\begin{array}{l}\text { Interés por } \\
\text { los Recursos } \\
\text { Humanos }\end{array}$ & $\begin{array}{l}\text { Poco. Bajo nivel de } \\
\text { formación con pocos } \\
\text { titulados en la plan- } \\
\text { tilla. }\end{array}$ & $\begin{array}{l}\text { Las personas son un re- } \\
\text { curso importante para } \\
\text { la empresa, pero toda- } \\
\text { vía no se ven como Ca- } \\
\text { pital Humano. Para la } \\
\text { compensación se tie- } \\
\text { nen en cuenta funda- } \\
\text { mentalmente objetivos } \\
\text { de tipo financiero. }\end{array}$ & $\begin{array}{l}\text { Las personas son si- } \\
\text { tuadas en el centro de } \\
\text { la estrategia y son di- } \\
\text { rigidas como Capital } \\
\text { Humano. Para la com- } \\
\text { pensación se tienen en } \\
\text { cuenta la contribución } \\
\text { al proyecto. }\end{array}$ \\
\hline Comunicación & $\begin{array}{l}\text { Básicamente de arri- } \\
\text { ba hacia abajo. Proce- } \\
\text { so poco formalizado. }\end{array}$ & $\begin{array}{l}\text { Bastante formalizada, } \\
\text { prevaleciendo la de } \\
\text { tipo descendente. }\end{array}$ & $\begin{array}{l}\text { En todas las direccio- } \\
\text { nes, equilibrando la for- } \\
\text { mal con la informal. }\end{array}$ \\
\hline $\begin{array}{l}\text { Nivel de } \\
\text { incorporación } \\
\text { y uso de las } \\
\text { TICs }\end{array}$ & $\begin{array}{l}\text { Bajo nivel de incor- } \\
\text { poración y de uso de } \\
\text { las existentes. }\end{array}$ & $\begin{array}{l}\text { Buen nivel de incor- } \\
\text { poración, pero se utili- } \\
\text { zan básicamente para } \\
\text { apoyar la operativa y } \\
\text { la gestión. }\end{array}$ & $\begin{array}{l}\text { Buen nivel de incorpo- } \\
\text { ración y uso, tanto con } \\
\text { fines operativos como } \\
\text { estratégicos. }\end{array}$ \\
\hline
\end{tabular}


Tabla 3.1. Comparación de tipos de empresa. (Cont.)

\begin{tabular}{|c|c|c|c|}
\hline \multirow{2}{*}{ Aspectos } & \multicolumn{3}{|c|}{ Rasgos característicos } \\
\hline & D-J & D-G & D-L \\
\hline $\begin{array}{l}\text { Desarrollo } \\
\text { y uso de } \\
\text { sistemas }\end{array}$ & $\begin{array}{l}\text { Sólo existen los bá- } \\
\text { sicos. El de informa- } \\
\text { ción suele limitarse a } \\
\text { la contabilidad y al- } \\
\text { gunas estadísticas de } \\
\text { producción y ventas. }\end{array}$ & $\begin{array}{l}\text { Existen sistemas para } \\
\text { casi todo lo relaciona- } \\
\text { do con el negocios, con } \\
\text { los procesos operativos } \\
\text { que lo apoyan y con el } \\
\text { control de los resulta- } \\
\text { dos financieros. Los } \\
\text { sistemas llegan a ser } \\
\text { tan potentes que casi } \\
\text { constituyen fines en sí } \\
\text { mismos. La empresa } \\
\text { es considerada como } \\
\text { una máquina. }\end{array}$ & $\begin{array}{l}\text { Existen sistemas para } \\
\text { apoyar la operativa } \\
\text { y la estrategia, pres- } \\
\text { tando especial interés } \\
\text { a los que potencian } \\
\text { el aprendizaje (ges- } \\
\text { tión del conocimien- } \\
\text { to). Los sistemas son } \\
\text { medios al servicio de } \\
\text { las personas, no "ca- } \\
\text { misas de fuerza" que } \\
\text { constriñen la iniciati- } \\
\text { va individual. }\end{array}$ \\
\hline $\begin{array}{l}\text { Aprendizaje } \\
\mathrm{e} \\
\text { Innovación }\end{array}$ & $\begin{array}{l}\text { Básicamente se } \\
\text { aprende de la expe- } \\
\text { riencia individual. } \\
\text { Conocimiento táci- } \\
\text { to personal. No están } \\
\text { formalizados los pro- } \\
\text { cesos de aprendizaje } \\
\text { e innovación. }\end{array}$ & $\begin{array}{l}\text { Proceso de aprendiza- } \\
\text { je poco formalizado. } \\
\text { Enfoque excesivamen- } \\
\text { te técnico de la innova- } \\
\text { ción. En algunos casos } \\
\text { se empieza a hablar de } \\
\text { sistemas de gestión de } \\
\text { conocimiento. }\end{array}$ & $\begin{array}{l}\text { Sistemas de aprendi- } \\
\text { zaje en equipo, com- } \\
\text { binando lo formaliza- } \\
\text { do con lo espontáneo. } \\
\text { Innovación en base al } \\
\text { talento personal y or- } \\
\text { ganizativo. }\end{array}$ \\
\hline Cultura & $\begin{array}{l}\text { No hay consciencia } \\
\text { de su existencia. }\end{array}$ & $\begin{array}{l}\text { No existe una preocu- } \\
\text { pación sistemática por } \\
\text { los valores y actitudes } \\
\text { compartidas, Se asu- } \\
\text { me que la cultura es un } \\
\text { dato y no se gestiona. }\end{array}$ & $\begin{array}{l}\text { Existe un conjunto de } \\
\text { valores compartidos } \\
\text { que constituyen el mo- } \\
\text { tor del éxito. }\end{array}$ \\
\hline
\end{tabular}

Además de los estilos jefe, gestor y líder que, como dijimos combinan lo técnico y lo humano de forma equilibrada, hay otros estilos que hacen énfasis en una de las dos dimensiones citadas.

El estilo jefe puede hacer énfasis bien en lo técnico, dando origen al estilo Jefe-administrador (JA), bien en lo humano, Jefe-delegador (JD).

El estilo JA está presente en algunas empresas de cierta dimensión, excesivamente burocratizadas, con estructuras organizativas muy mecanicistas, poco innovadoras.

El estilo JD es seguido, básicamente, por PYMES dirigidas de forma muy intuitiva, donde no existen sistemas formalizados para apoyar la gestión, pero en 
las que el empresario-director posee un alto potencial de liderazgo innato, que hace que se sienta a gusto contando con sus colaboradores, a los que permite cierta libertad para que pongan en práctica sus iniciativas. Sin embargo, al darse una clara carencia de "gestión" en la dirección de la empresa, el caos de administración en que vive la empresa puede llegar a poner en peligro su supervivencia.

Tanto el estilo JA como el JD, no alcanzan el equilibrio profesional mínimo para asegurar el desarrollo adecuado de la empresa. El estilo JA no aprovecha suficientemente el talento humano de la organización y el JD no dispone de los sistemas mínimos necesarios para sacar provecho de los recursos de que dispone y para controlar los riesgos inherentes a toda actividad empresarial.

En torno al estilo director-gestor, también se desarrollan estilos con el predominio de una de las dos dimensiones que venimos comentando. En efecto, existe el estilo Director por anticipación (DPA), con énfasis hacia lo técnico, y el estilo de Dirección por implicación (DPI), que, teniendo un desarrollo técnico adecuado, llega al nivel del estilo líder en lo humano.

El estilo DPA es propio de grandes organizaciones con estructuras mecanicistas, donde la función de I+D es muy potente, pero muy centralizada, no siendo suficiente para mantener de forma sostenida el liderazgo como empresa a nivel mundial. En algún momento encuentran la suerte como aliado y consiguen reinventar sus propias actividades creando e implantando nuevas reglas de juego.

El estilo DPI, por el contrario, no está vinculado al tamaño de la empresa. Una PYME puede basarse en la implicación de su personal. Este será el estilo al que dedicaremos el presente trabajo, por considerar que debe constituir un objetivos para las empresas que quieran adaptarse para ser competitivas en la Sociedad del Conocimiento.

El éxito de la estrategia de anticipación, como hemos dicho, hay que asociarlo a cierto nivel de suerte que tiene lugar en un momento dado. No ocurre lo mismo con la estrategia de implicación: es más cuestión de compromiso y de voluntad que de suerte. Además, cuando las ventajas competitivas de la empresa se asocian a la dimensión humana, o sea al talento, son más sostenibles.

\section{Hacia la DPI: La ruta ideal del cambio estratégico}

\subsection{La DPI como vía de creación de ventajas competitivas sostenibles basadas en el Capital Intelectual}

De los diversos tipos de competencias de que dispone la empresa ${ }^{11}$, las más distintivas son las humanas, ya que proporcionan mayor sostenibilidad a las ventajas

11 Aunque cada vez es más frecuente hablar de competencias en la empresa, todavía existe un gran confucionismo a la hora de su aplicación práctica. En un lenguaje próximo al mundo de la empresa, entendemos por competencias lo que se quiere (Q), y/o se sabe (S), y/o se puede $(\mathrm{P})$ hacer suficientemente bien. De acuerdo con este concepto, cabe afirmar que cuando se emprende alguna tarea, el éxito que se obtenga estará en función de las competencias empleadas para llevarla a cabo. Podemos distinguir entre competencias individuales y organizativas y también entre humanas y técnicas. 
competitivas. Esto es debido a que, en gran medida, son desarrolladas internamente por la empresa, como resultado de un proceso de aprendizaje.

Dado que la DPI hace énfasis en la dimensión humana de la empresa, proponiendo la metodología y técnicas para potenciar el aprendizaje individual y organizativo como base de la innovación, podemos afirmar que se trata de un sistema de dirección adecuado para desarrollar competencias distintivas en base al Capital Humano y, en consecuencia, ventajas competitivas sostenibles en la Sociedad del Conocimiento. Todo esto requiere una nueva visión de empresa y, más concretamente, una nueva cultura, como ingredientes indispensables para abordar con un enfoque actual y práctico el tema de la dimensión humana de la empresa.

La Figura 3.6. resume la esencia de la DPI, que plantea el cambio (la innovación) como un proceso basado en el aprendizaje organizativo. Esto demanda que la empresa genere y mantenga una cultura basada en la confianza en todo tipo de relación interpersonal y en todas las direcciones. Los empleados deberán confiar mutuamente entre sí, pero además esa confianza también ha de ser recíproca entre directivos y empleados.

Figura 3.6. Relación entre aprendizaje e innovación.

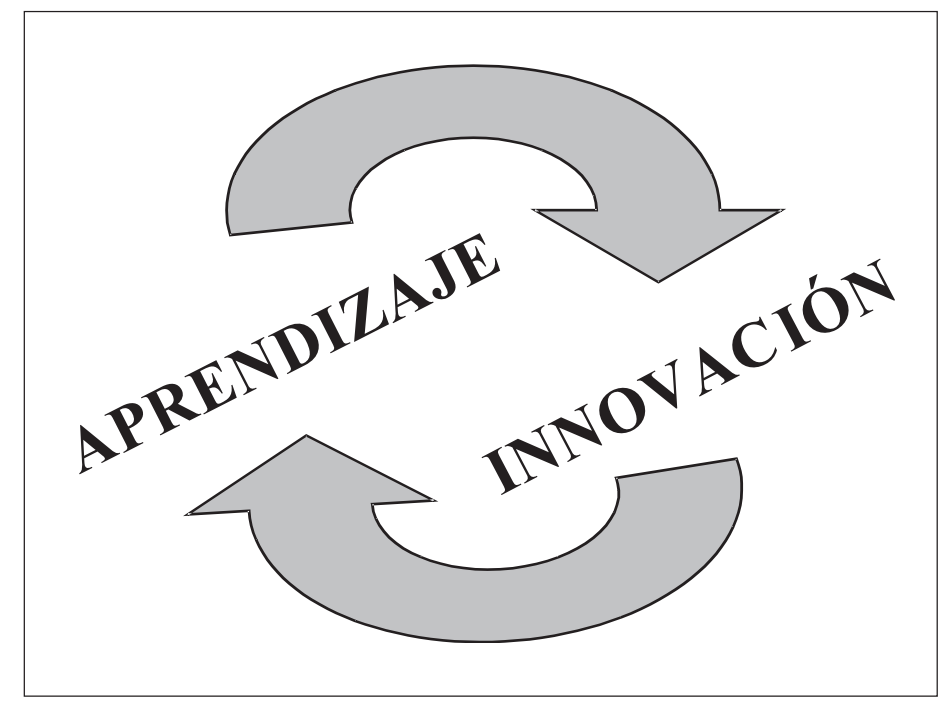

Esto propiciará ir más allá de la delegación de tareas, haciendo posible la implicación, que conlleva la delegación de autoridad. Para que la delegación de tareas funcione de forma eficiente basta con que el personal en quien se delega esté suficientemente formado y motivado, pero la implicación exige más; exige que los empleados estén autorizados y quieran actuar como verdaderos dueños. Para que esto ocurra es indispensable que los directivos actúen como líderes: que tengan un proyecto compartido con sus colaboradores (han creado una visión y 
formado una coalición de intereses en torno a la misma) y que los formen y confíen ellos, propiciando su libertad de acción para que liberen su talento y lo pongan en funcionamiento contribuyendo a la innovación ${ }^{12} \mathrm{y}$, de esta forma, ayuden a avanzar hacia el cumplimiento de la visión compartida.

Todo esto sólo será posible si la empresa funciona como una coalición de intereses en torno a un proyecto compartido. Sabemos que eso exige una cultura basada en la confianza y en esto todavía hay más teoría que realidad. Sin embargo, cada vez hay más consenso en torno a la idea de que, como indica Linda Gratton ${ }^{13}$ "una empresa con bajo nivel de confianza y compromiso está en quiebra, tanto como otra con bajos niveles de Capital Financiero, y es esencialmente una empresa agonizante".

En las empresas con una dirección estilo jefe, según la terminología de la matriz T-H, el poder sigue siendo la base de las relaciones entre el jefe y los subordinados, pero a medida que avanzamos a estilos más profesionales y acordes a los tiempos actuales el poder es sustituido por la confianza. Sin embargo, la razón por la que los colaboradores confían en los directores no es la misma en el estilo director-gestor que en el estilo director-líder. En una empresa con una dirección altamente profesionalizada, pero en la que todavía no se han alcanzado suficientes niveles de implicación, la confianza tiene mucho que ver con las competencias de saber y poder que los empleados esperan de los directores. Así, las personas de un departamento confían en su director porque esperan que cuando tengan problemas con su trabajo les ayudará a resolverlos. Con estructuras jerárquicas con fuerte especialización de sus unidades organizativas, como ocurría durante la vigencia de la economía industrial, este tipo de confianza basada en las competencias podía ser suficiente para que las empresas alcanzasen el liderazgo, pero ¿es posible esto en la Sociedad del Conocimiento? Desde luego, las competencias de saber y poder siguen desempeñando un importante papel en las relaciones de superiores y subordinados, pero para comprender la función que la confianza juega en la sociedad actual se necesita un análisis más complejo, donde las competencias asociadas al querer son fundamentales.

$\mathrm{Si}$ insistimos en que la DPI requiere una cultura basada en la confianza es porque ésta constituye una condición necesaria para que la organización aprenda e innove eficazmente, $y$, en consecuencia, porque creemos que es el factor que aporta mayor caudal explicativo del comportamiento competitivo de la empresa en la Sociedad del Conocimiento. En este caso los colaboradores no confían en sus superiores porque esperen que sepan y puedan ayudarles, sino porque con su

12 La relación de la confianza con el proceso de innovación ha sido tratada en múltiples trabajos de investigación. Recientemente en un estudio realizado por PriceWaterhouseCoopers sobre la innovación en las empresas que aparecen en Financial Times 1000, se pone de manifiesto que la confianza es la principal variable que explica la diferencia entre las empresas que se encuentran en el grupo formado por el $20 \%$ con resultados superiores y el formado por el $20 \%$ con los resultados más bajos.

13 Obra citada. 
capacidad de liderazgo han marcado un rumbo, han definido un proyecto que conecta con las ambiciones de los colaboradores. Ahora se trata en una confianza mutua en un ambiente donde funciona el "gano-ganas", ya que superior y colaborador quieren lo mismo: contribuir al cumplimiento de la visión.

\subsection{La ruta ideal del cambio estratégico}

Llegados a este punto, es interesante que nos hagamos la siguiente pregunta: ¿existe una ruta ideal a seguir por una empresa en su camino hacia la DPI?

Para responder a esta cuestión, debemos situarnos en el momento actual, los albores del tercer milenio, cuando se camina con firmeza hacia la consolidación de la Sociedad del Conocimiento. Según hemos explicado, la base para competir es el talento, por lo tanto la empresa debe centrar sus esfuerzos en mejorar todo aquello que favorezca el aprendizaje organizativo. Transformando continuamente el conocimiento en innovación la empresa avanzará hacia la excelencia y también hacia el estilo director-líder. La Figura 3.7. muestra los caminos alternativos para realizar este avance.

Figura 3.7. Rutas alternativas hacia el estilo Director-Líder.

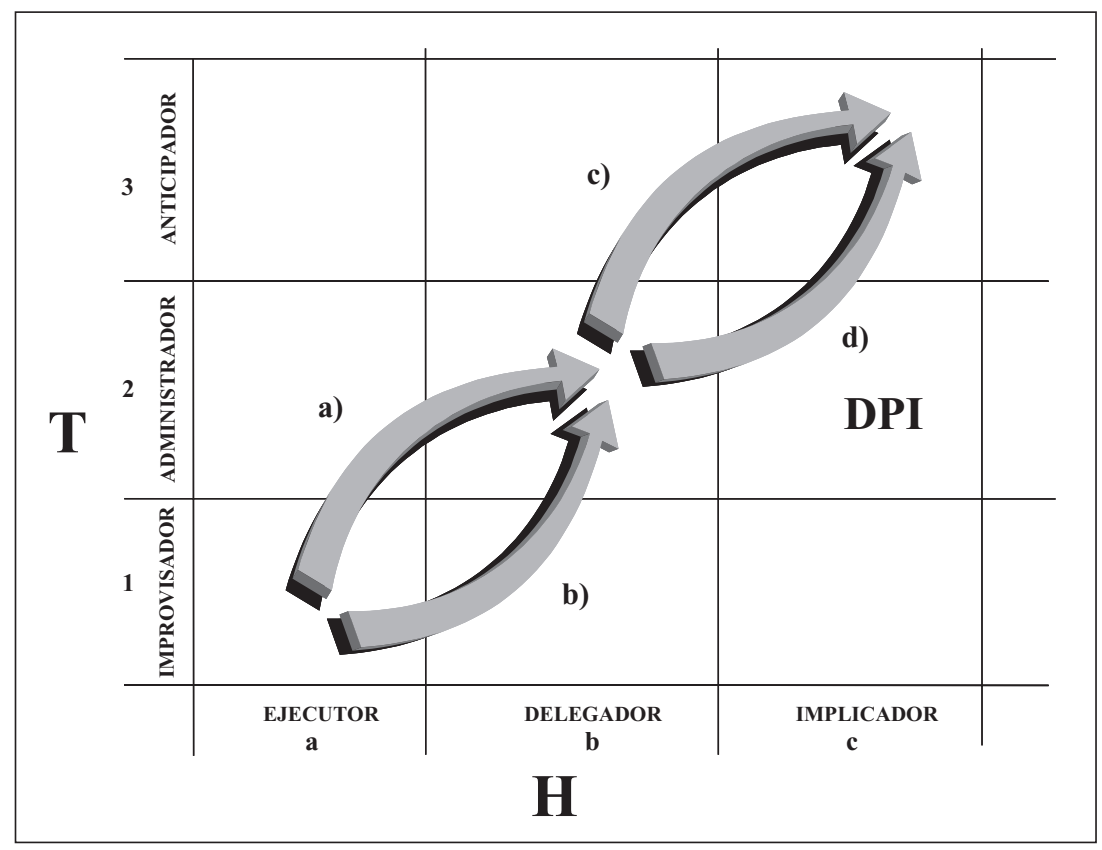

El cambio del estilo Director-Jefe al de Director-Gestor puede hacerse por la ruta a) o por la b). La primera supone empezar haciendo énfasis en lo técnico y luego, en una segunda fase centrarse en lo humano. La segunda ruta supondría el comportamiento contrario. Cuando planteamos un plan de cambio como algo racional, la ruta adecuada es la a), cambiar de D-J a D-G pasando por J-A 
(Jefe-Administrador) ya que, en la generalidad de los casos, no sería conveniente empezar el cambio de estilo de dirección intentando repartir el juego a través de la delegación. En el estilo jefe las personas han sido consideradas como "menores de edad" para actuar por su cuenta, por lo que no están preparadas para tomar decisiones y asumir responsabilidades. Con un cambio drástico sería peor el remedio que la enfermedad. En consecuencia, los primeros esfuerzos se centrarían en desarrollar los sistemas básicos a la vez que se va preparando a las personas para que hagan uso adecuado de los mismos.

Sin embargo, también es posible la ruta b). Esto ocurre, como hemos dicho anteriormente, cuando un emprendedor, con perfil de líder, da cancha a sus colaboradores dejándolos hacer. Si en la empresa existe déficit de gestión es posible que espontáneamente pase del estilo J-G al estilo J-D. Si en este momento se afronta un proyecto de cambio hacia la DPI, antes de pensar en la DPI sería necesario dotar a la empresa de los sistemas necesarios para apoyar una gestión eficaz. Por lo tanto, la ruta a seguir pasaría, lo mismo que si hubiésemos seguido la alternativa a), por el estilo D-G.

Una vez alcanzado el estilo Director-Gestor los esfuerzos se centrarían en la dimensión humana con el fin de liberar al máximo el talento disponible. Si existe visión compartida, aunque avanzar en lo humano no es tarea fácil, con esfuerzo y persistencia siempre se consigue alcanzar la implicación, entendida en los términos explicados más atrás, de un número suficiente de empleados, los cuales estarán interesados por el proyecto y por la contribución que hacen al mismo desde los puestos que ocupan. Con la dimensión técnica, por el contrario, por mucho esfuerzo y recursos que se dediquen nunca se puede garantizar que la anticipación llegue a ser una realidad.

En definitiva, consideramos que la ruta ideal para conseguir una innovación que suponga una anticipación en base al talento es empezar dotando a la empresa de los sistemas adecuados a la vez que se avanza en la delegación y cuando ésta funcione adecuadamente es el momento de centrar los esfuerzos en la implicación.

En efecto, en gran medida, el diseño e implantación de sistemas corresponde a personal técnico, de manera que, para llevar a cabo cambios significativos en esta dimensión, suele ser suficiente que participe un número reducido de personas. Por esta razón, es relativamente fácil avanzar en la profesionalización de la dimensión técnica, sobre todo cuando se parte de niveles bajos. El benchmarking ayuda a avanzar con mayor seguridad en la profesionalización técnica que en la humana. De esta forma se prepara el camino para centrarse luego en la dimensión humana, en la que el cambio es, sobre todo, el resultado de un proceso de aprendizaje. Obviamente, en la medida en que éste se apoye en sistemas adecuados aumenta las probabilidades de éxito.

Superada esa fase inicial, cuando la empresa ya cuenta con los sistemas adecuados para apoyar la gestión, el cambio hará énfasis en el desarrollo de la dimensión humana hasta llegar al estilo DPI, pasando por el estilo Director-Gestor. 
Una vez que la organización ha alcanzado el estilo DPI, significa que ya se está poniendo en funcionamiento un alto porcentaje del talento existente en la misma $y$, en consecuencia, aumentan las probabilidades de afrontar con éxito un ritmo de innovación que permitirá avanzar con garantía hacia el liderazgo a nivel mundial o, lo que es lo mismo, entrar en el grupo de empresas excelentes.

La ruta ideal es la adecuada para desarrollar ventajas competitivas basadas en el conocimiento y, por lo tanto, para hacerlas más sostenibles que, como hemos repetido, esto ocurre más fácilmente cuando es el resultado de un proceso de aprendizaje.

De acuerdo con estas ideas, partiendo de los estilos de dirección resumidos en la matriz T-H y de la que hemos llamado ruta ideal hacia el estilo Director-Líder, distinguimos cuatro tipos básicos de cambio estratégico, tal como muestra la Figura 3.8.

Figura 3.8. Modelos básicos de tipos de cambio.

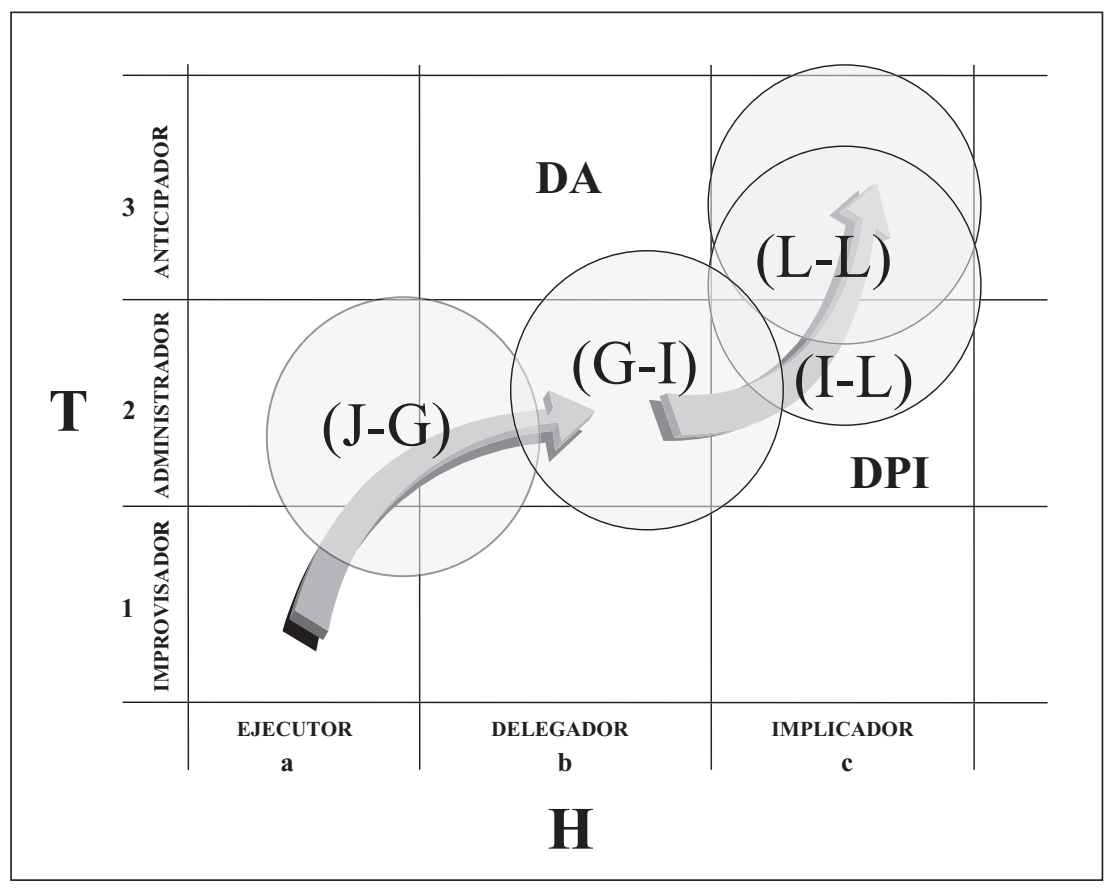

1. Cambio de estilo jefe a estilo gestor (J-G). Por los objetivos que pretende le llamaremos Profesionalización.

2. Cambio de estilo gestor a estilo implicador (G-I). Supone llegar a asumir el nuevo concepto de empresa como coalición de intereses. Por esta razón, lo llamaremos Renovación.

3. Cambio de estilo implicador a estilo líder (I-L). En gran medida requiere la redefinición del sector, de ahí que lo denominemos Reinvención. 
4. Cambio en el estilo líder (L-L). Lo llamaremos Revolución, por suponer una re-reinvención de las reglas de juego.

La mayor parte de las empresas de carácter familiar no llegan a la tercera generación porque durante la vida del líder emprendedor no han llevado a cabo una verdadera profesionalización-renovación que transformara la visión de ese líder en un proyecto compartido capaz de funcionar como una organización inteligente. En algunos casos, sin embargo, los líderes emprendedores si son capaces de llevar a cabo procesos de transformación, primero profesionalizando la empresa y luego dotándola de un talento organizativo que garantiza su competitividad sin la presencia del líder fundador.

\section{El ¿qué? del cambio: Un modelo explícito para los procesos de profesionalización y de renovación de la empresa}

\subsection{Los modelos explícitos como herramienta para determinar el con- tenido del cambio}

Después de ver la necesidad del cambio y las distintas modalidades del mismo, ahora vamos a analizar como dar respuesta a dos cuestiones clave desde el punto de vista práctico: ¿Qué aspectos concretos de la empresa hay que cambiar en cada caso? y ¿cómo llevarlo a cabo?

Para dar respuesta a estas dos preguntas nos apoyaremos en la teoría de sistemas $\mathrm{y}$, en concreto, en los modelos, por constituir una herramienta útil para analizar algo que, como el tema que nos ocupa, encierra cierta complejidad. En general, un modelo es algún tipo de expresión simplificada, que sirva para representar las relaciones entre el objetivo a conseguir y lo que pueden considerarse causas del mismo.

Las relaciones causa-efecto que explican el comportamiento del tema a estudiar, pueden estar reflejados de una forma explícita, o permanecer en el mundo del subconsciente. Dicho de otra forma, cabe distinguir dos tipos de modelos: explícitos y mentales. En ambos casos, nos referimos a modelos conceptuales, no físicos, para explicar algún tema empresarial y tanto los explícitos como los mentales, son de suma importancia para la moderna dirección.

Los modelos explícitos constituyen una herramienta muy importante para ayudarnos a definir el contenido del cambio (¿qué cambiar?) en las organizaciones y también la metodología y el proceso que nos permitirá ponerlo en práctica (¿cómo hacerlo?).

La elaboración de un modelo explícito responde, como hemos dicho, a un proceso racional. Para su desarrollo seguiremos las siguientes fases:

1. Definir claramente el objetivo que se busca con el modelo (o, mejor, con el sistema que representa el modelo).

2. Identificar qué partes o componentes (factores, aspectos, o subsistemas en general) son relevantes para explicar el objetivo. 
3. Desplegar, en niveles sucesivos las partes o componentes identificados en cada nivel (los factores, aspectos, etc.), hasta alcanzar el grado de detalle suficiente para la aplicación que se pretende.

Relacionando estas tres fases con los principios de la TGS tendríamos:

a) La fijación del objetivo, supone aplicar el principio de finalidad, según el cual las partes o componentes del tema objeto de estudio (sistema en general) se caracterizan por buscar un objetivo común, que prevalece sobre los objetivos particulares de las partes.

b) Para identificar las partes relevantes, se aplicarán los principios de especialización, totalidad y causa-efecto de la TGS. Aplicar el principio de especialización conlleva a identificar qué partes (subsistemas: factores aspectos, fases, etc.). explican el objetivo. Definir qué partes constituyen el todo siempre es algo subjetivo, que depende de la finalidad que se busca. La totalidad significa que las partes (factores, aspectos) considerados delimitan adecuadamente el objetivo; sin que nada relevante quede fuera. Para poder comprender que esto es así, se empezará considerando partes muy globales, para que en total no haya un número superior a cuatro o cinco. Si hay más, es difícil comprender si abarcan todo lo que hay que considerar o no. Por último, el principio de causalidad, permitirá comprender la relación los aspectos entre sí y con el objetivo.

Una vez que tenemos identificado lo que constituyen las causas para el objetivo buscado, nos preguntaremos ¿Está claro conceptualmente el significado de cada una de estas causas? ¿Están definidas de forma que ninguna de ellas puede considerarse incluida en otras de las identificadas? ¿Resulta muy difícil encontrar algo que no está incluido en las causas ya definidas y que sea suficientemente importante para explicar el objetivo? Si las respuestas son afirmativas, todavía queda una pregunta: ¿Las causas identificadas están definidas con el detalle suficiente para que ya resulte relativamente fácil diseñar acciones de mejora? Cuando se trata de temas con cierta complejidad lo más probable es que cuatro o cinco causas en total reflejen conceptos muy globales, de modo que no resultan operativos para poder definir acciones concretas de mejora de las mismas. Por eso es necesario proceder al despliegue.

c) Para el despliegue, además de los principios citados para la fase anterior, se aplicará básicamente el de jerarquía. Una vez que se han identificado los subsistemas que explican el sistema a $\mathrm{N}_{1}$ (nivel uno), se continuará haciendo lo mismo con cada uno de los subsistemas, análisis a $\mathrm{N}_{2}, \mathrm{~N}_{3}$, etc., hasta llegar a un grado de detalle suficiente.

\subsection{Contenido del cambio (el ¿qué?): El Trípode del cambio estratégico}

\subsubsection{La mejora de la competitividad como objetivo del cambio estratégico}

Hemos dicho que para muchas empresas el principal objetivo de la dirección estrategica es definir e implantar el cambio para que la empresa sea competitiva en 
el futuro. Por lo tanto, está claro que el objetivo del cambio estratégico es la mejora de la competitividad de la empresa. Pero, ¿qué es la competitividad?

Parece evidente que el término competitividad se asocia al de competencia ${ }^{14}$, y significa la capacidad de una persona, empresa, región, país, etc. para actuar ante la rivalidad suscitada al relacionarse con otra persona, empresa, región o país para conseguir algo que se ofrezca en forma limitada y que es de común interés. En este sentido, los agentes que rivalizan entre sí son competidores y la competitividad representa tanto la capacidad para rivalizar como un indicador de la posición relativa de un agente frente a sus competidores y su aptitud para mantenerla y mejorarla de forma sostenida. Cuando hablamos de la competitividad de una empresa, siempre está presente la idea de globalidad (la competitividad depende de la empresa en su conjunto) y la de largo plazo (las causas que determinan la competitividad tienen efectos a largo plazo).

Desde mediados de los 80 son muchos los autores que se han esforzado por desarrollar conceptos y modelos que permitan a las empresas y demás instituciones analizar, medir y mejorar su competitividad. Si pensamos en una empresa concreta, su competitividad hay que relacionarla con la de sus competidores, no sólo reales sino también potenciales.

4.2.2. Identificación de los grandes grupos de factores que causan la competitividad: El "Trípode del cambio estratégico"

Una vez aclarado lo que se entiende por mejorar la competitividad, las preguntas a realizar serían: ¿De qué depende la mejora de la competitividad? ¿Sobre qué podemos actuar para mejorar la competitividad de nuestra empresa?

Los diferentes factores que pueden ser causa de la competitividad podemos agruparlos formando lo que llamaremos componentes de la competitividad de la empresa $^{15}$. Uno de esos componentes estaría formado por los factores extrínsecos, o sea, sería el entorno. Serían los factores donde la empresa encuentra tanto amenazas como oportunidades.

Más difícil es decidir en cuántos componentes agruparemos los factores intrínsecos. En todo caso, empezaremos haciendo grandes agrupaciones, de modo que un máximo de cuatro o cinco comprendan todos los factores relevantes para explicar la competitividad. Luego, ya conseguiremos el detalle necesario mediante el despliegue.

La empresa puede ser vista, como hemos dicho, como una combinación de personas y tecnologías para desarrollar una determinada actividad. Las personas y las tecnologías son los recursos con que cuenta la empresa. Por lo tanto,

14 Ahora utilizamos la palabra competencia para referirnos a las empresas que ofrecer productos sustitutivos del nuestro. Se trata de unos de los componentes del entorno específico.

15 Teniendo en cuenta que, como hemos dicho, la estrategia de la empresa es el camino que ésta sigue para ser competitiva, es indistinto hablar de componentes de la competitividad que de componentes de la estrategia. 
podemos iniciar la reflexión, identificando dos grandes componentes intrínsecos: recursos y actividad.

Hagámonos ahora las preguntas que sugeríamos en el comentario anterior. ¿Está claro conceptualmente el significado de cada uno de estos componentes como causas de la competitividad? ¿Están definidos de forma que ninguno de ellos puede considerarse incluida en los otros? ¿Resulta muy difícil encontrar algo que no está incluido y que sea suficientemente importante para explicar el objetivo? Profundicemos en estas cuestiones aplicándolas a los grupos de factores sugeridos.

El término actividad es confuso. Puede referirse a los procesos que realiza la empresa y también al negocio que desarrolla. Se trata de conceptos muy distintos que interesa separar. En vez de actividad haremos dos componentes intrínsecos: los procesos y el negocio. En cuanto al otro componente, los recursos, también es un concepto excesivamente amplio. Prestaremos especial atención a los recursos intangibles relacionados con los valores, actitudes y comportamientos que, en conjunto definen la cultura de la empresa. Pensando en el peso que tiene el cambio de cultura en los procesos de profesionalización y de renovación de las empresas, le daremos vida propia, considerando el resto de los recursos como el soporte de la empresa.

En definitiva, para mejorar su competitividad la empresa deberá analizar el entorno (identificar las amenazas y las oportunidades) y realizar los procesos que propicien que en cada momento cuente con la cultura y el soporte adecuados para poder desarrollar el negocio deseado, aprovechando las oportunidades y afrontando las amenazas en mejores condiciones que sus competidores. Por lo tanto, para explicar y mejorar el comportamiento competitivo de la empresa, el modelo explícito que utilizaremos será:

$$
\mathbf{K}=\mathbf{f}(\mathbf{E}, \mathbf{C}, \mathbf{N}, \mathbf{S}, \mathbf{P})
$$

Donde:

$$
\begin{aligned}
& \mathbf{K}=\text { Competitividad } \\
& \mathbf{E}=\text { Entorno } \\
& \mathbf{C}=\text { Cultura }
\end{aligned}
$$

$$
\begin{aligned}
& \mathbf{N}=\text { Negocio } \\
& \mathbf{S}=\text { Soporte } \\
& \mathbf{P}=\text { Procesos }
\end{aligned}
$$

Este modelo relaciona la competitividad con los factores que son causa de la misma, agrupados en cinco grandes componentes. Será la base para la dirección del cambio estratégico de la empresa, tanto desde el punto de vista estático -contenido-, como dinámico -implantación-.

Partiendo del modelo anterior, puede afirmarse que el cambio estratégico consistirá, precisamente, en buscar las respuestas a las cinco preguntas clave siguientes:

1) ¿Cuáles son/serán las oportunidades y amenazas ante las que se encuentra/encontrará la empresas? (Entorno).

2) ¿Con qué valores, actitudes y comportamientos cuenta/contará la empresa? (Cultura). 
3) ¿Qué actividad desarrollamos/desarrollaremos, dónde la llevamos/llevaremos a acabo y a quién elegimos/elegiremos para ello? (Negocio).

4) ¿Con qué otros recursos y capacidades ${ }^{16}$ contamos/contaremos? (Soporte).

5) ¿Cómo actuamos/actuaremos para que al utilizar nuestros recursos y capacidades consigamos ser más competitivos? (Procesos).

Las cinco preguntas clave sobre la competitividad las hemos formulado haciendo referencia al presente y al futuro. Las respuestas referidas al presente explican el comportamiento competitivo actual de la empresa (diagnóstico estratégico, tanto externo como interno). Referidas al futuro, indicarán cuál sería el comportamiento competitivo si las respuestas sobre el comportamiento futuro del entorno (hipótesis sobre cuáles serán las amenazas y oportunidades) y a las preguntas clave sobre los componentes internos (diseño de la estrategia intencional) se cumpliesen. De antemano sabemos que ésto no se cumplirá totalmente, por lo que el comportamiento competitivo de la empresa en el futuro se verá influido, como hemos dichos más atrás, por la estrategia emergente, resultado del aprendizaje de la organización.

De una forma gráfica, representaremos el modelo en lo que llamamos el trípode del cambio estratégico, según muestra la Figura 3.9.

Figura 3.9. El trípode del cambio estratégico.

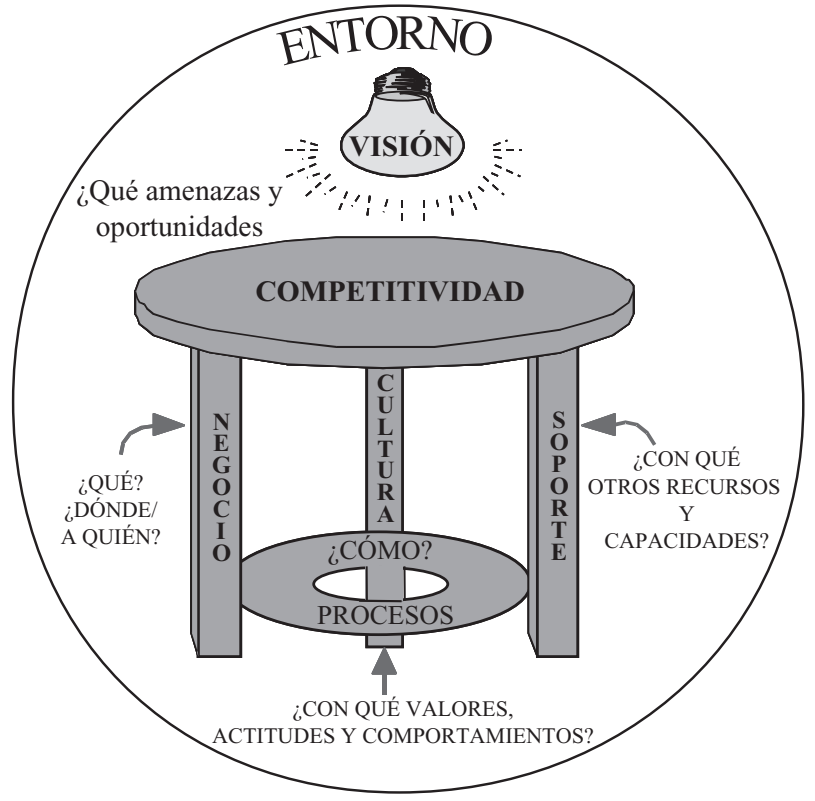

${ }^{16}$ El papel de los recursos y capacidades en la estrategia de la empresa puede verse en AMIT, R. y SCHOMAKER, P (1993). Ambos términos, equivalen a recursos en sentido amplio, o competencias de la empresa. Todo aquello con que cuenta para llevar a cabo su estrategia y avanzar hacia la visión. No cabe duda que la cultura es una competencia empresarial, en los términos en que las definimos. De ahí que en el soporte incluyamos los otros recursos y capacidades de la empresa. 
Como puede observarse, los objetivos de competitividad de la empresa descansan en tres patas que representan la cultura (valores y actitudes seguidas por las personas que forman la empresa), el negocio (actividad que desarrolla la empresa) y el soporte (otros recursos y con que cuenta).

El trípode se caerá y los objetivos de competitividad se irán al suelo, si las tres patas del trípode no guardan cierto equilibrio. Pero, además, las tres patas no son independientes. Están unidas dinámicamente, lo que representamos mediante una pieza que refleja los procesos que de forma continua realiza la empresa. El trípode está dentro de un entorno determinado, que es necesario conocer, distinguiendo el general, que afecta por igual a todas las empresas y el especifico para cada tipo de actividad. Como el entorno cambia constantemente, la empresa deberá mantenerse actualizada de ahí que uno de los procesos más importantes sea el propio cambio estratégico.

El conjunto de preguntas clave forma un sistema global, de manera que el éxito empresarial supone dar una respuesta adecuada a todas ellas a la vez, en el marco creado por la visión o proyecto de empresa. El modelo del trípode, tal como ha sido planteado, sirve para definir el contenido del cambio estratégico, cualquiera que sea la situación de partida de la empresa. Sin embargo, cuando se trata de la profesionalización o de la renovación, es cuando el modelo es de mayor utilidad. En estos casos para definir el contenido del cambio y asignar prioridades es necesario rastrear todos los factores contenidos en el trípode. Por el contrario, en los procesos de reinvención y revolución los temas a cambiar en cada momento no resultan de un proceso de búsqueda racional hecha a propósito, sino que habitualmente son consecuencia del funcionamiento normal de la empresa, donde la innovación forma parte de los procesos habituales.

\section{El cómo del cambio: Los mapas del cambio estratégico}

Una vez visto como los modelos explícitos constituyen una herramienta importante para definir el contenido del cambio estratégico y estudiado el modelo del trípode del cambio, en el presente epígrafe profundizaremos en cómo aplicarlo en la práctica.

\subsection{La estructura organizativa para el cambio estratégico: Los equipos de mejora y la espiral de aprendizaje}

Es frecuente asociar la idea de equipo a la de eficacia, de modo que cuando surge algún tema complejo en la empresa, enseguida se piensa en crear un equipo para resolverlo. Esto es un error, no se pueden ver a los equipos como panacea. Muchos temas se tratan mejor de forma individual que en equipo.

Dado nuestro objetivo, es especialmente útil diferenciar los equipos de acuerdo con su finalidad. En la empresa hay, normalmente, equipos de dirección 
que funcionan de forma permanente. Así, cada vez es más frecuente que exista un comité de dirección que se reúne periódicamente para tomar cierto tipo de decisiones y para hacer el seguimiento de los objetivos a nivel de empresa. Sin embargo, también es cada vez más habitual que cuando se abordan proyectos de cambio para un tema determinado se creen equipos de mejora para ese fin concreto. Del mismo modo, para llevar a cabo un proyecto de cambio estratégico lo más habitual es seguir una metodología basada en equipos de mejora.

Estos equipos de mejora creados con motivo de un proyecto de cambio estratégico ofrecen las siguientes características:

- Cubren todos los niveles jerárquicos.

- Se trata de equipos "ad hoc", se crean para fines concretos.

- Son temporales, desapareciendo una vez que cumplen los objetivos establecidos.

- Tienen cierto grado de formalización.

En proyectos estratégicos, el número de equipos de mejora a crear, las funciones que desempeñarán, el grado de formalización y metodología de trabajo, dependerán del tipo de cambio de que se trate.

Para el cambio estratégico de los tipos J-G, profesionalización, y G-I, renovación, en una empresa de tipo medio, consideramos adecuado crear tres tipos de equipos:

El $E D E$ (equipo de desarrollo estratégico), integrado por directivos del primer nivel. Su función es realizar el análisis, prediseño y diseño de la estrategia, hasta contar con un plan director del cambio ${ }^{17}$.

Los EDOs (equipos de desarrollo operativo), que se encargarán de elaborar los distintos programas estratégicos a que de lugar el plan director. Estará formados por directivos de los niveles intermedio y superior.

Los EIs (equipos de implantación). Formados por personal del nivel medio y operativo, con el fin de definir los planes de acción y de ponerlos en práctica.

Los equipos de mejora formarán la estructura horizontal de la empresa, de carácter temporal, que se solapa con la estructura vertical, permanente, que es la responsable de la dirección y gestión. En el caso de una empresa de tipo medio organizada por funciones, podemos representar gráficamente la estructura resultante, según muestra la Figura 3.10.

17 Como veremos más adelante, en el proceso estratégico suelen considerarse distintas fases. Una de ellas es el diseño de la estrategia, que se resume en lo que llamamos Plan Director del cambio. Abarca toda la empresa y constituye la arquitectura estratégica en el marco definido por la visión del tipo de empresa que se quiere ser. Está formado por un conjunto de programas estratégicos, los cuales serán elaborados con el detalle suficiente para servir de marco para la implantación. 


\section{Figura 3.10. Estructura vertical y estructura horizontal.}

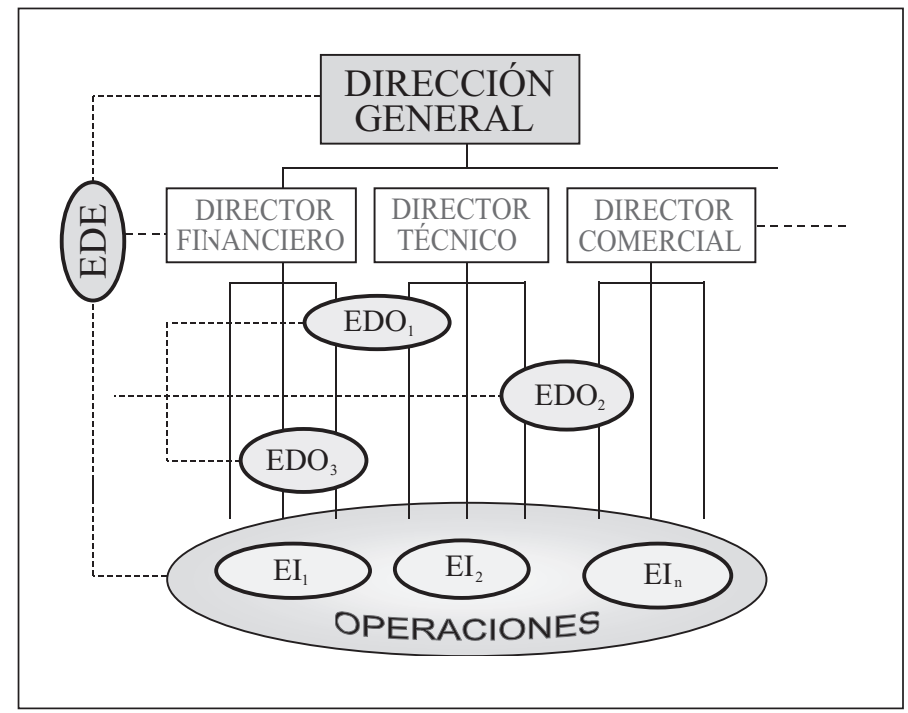

El objetivo de la estructura horizontal es facilitar el aprendizaje organizativo y desarrollar el proceso que lleve a la innovación en todos los niveles y ámbitos de la empresa. Por lo tanto, no tiene mucho sentido crearla con personal específico para la misma y con carácter permanente, dotando a la organización de una especie de nuevos analistas para generar conocimiento. El conocimiento interno está, básicamente, en el personal de línea y, por lo tanto, será el que deba formar la estructura horizontal, no permanente. Por esta razón, el número de equipos de mejora que pueden funcionar simultáneamente en la empresa viene muy condicionado por el tamaño de la misma.

La alta dirección se implicará directamente en el proyecto, pero deberá haber un responsable directo con dedicación total al mismo. Habitualmente, en las empresas del tipo que estamos comentando, no existe la persona adecuada en competencias y disponibilidad para asumir esta responsabilidad, por lo que es necesario incorporarla. Tampoco suele haber en la empresa la persona adecuada para dirigir técnicamente el proyecto. Lo más frecuente es que esa tarea la asuma una consultora externa.

La clave para conseguir que los equipos funcionen de forma eficaz, según hemos dicho repetidas veces, es que exista total confianza entre sus miembros y que éstos tengan las competencias adecuadas. En efecto ¿cómo sería posible compartir conocimiento si no hay confianza entre los que participan? y ¿cómo se puede crear conocimiento si no se comparte conocimiento, experiencias, know-how, etc.?

Los EIs constituyen un medio muy importante para aumentar el grado de implicación de los empleados del nivel operativo. Por la técnica de trabajo seguida, 
realización de workshops $^{18}$, se aumenta la autoestima del personal. Los empleados de base descubren que son capaces de hacer algo más que un trabajo rutinario.

Como veremos con detalle en el siguiente epígrafe, la herramienta básica del aprendizaje organizativo durante el proceso de cambio son los mapas del cambio estratégico, que pueden referirse a las personas, a los equipos y también a la organización. Constituyen una herramienta poderosa para ordenar todo el proceso de cambio, estimulando el funcionamiento de la espiral de aprendizaje personaequipo-organización como muestra la Figura 3.11.

Figura 3.11. Espiral de aprendizaje persona-equipo-organización.

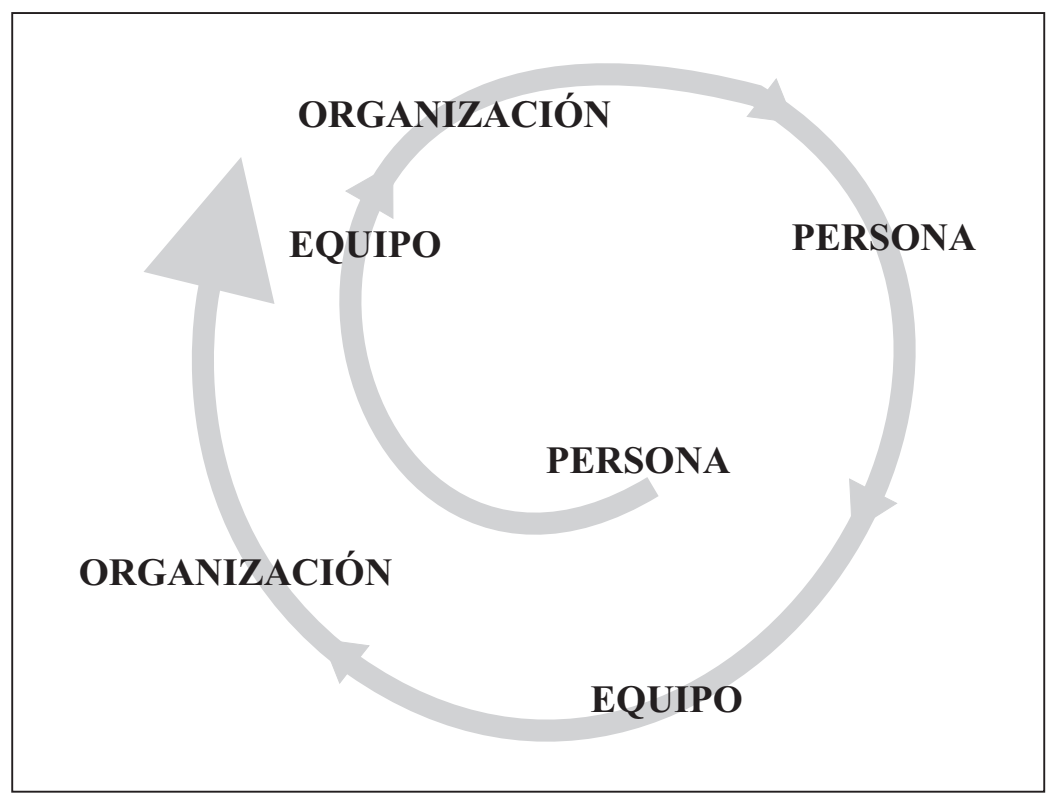

\subsection{Hacia la empresa inteligente: El concepto de mejorable y su papel en la mejora sistemática}

Cada vez se utiliza más el término de empresa inteligente. Utilizamos como sinónimos las expresiones empresa inteligente y organización que aprende. "Una organización aprende cuando traduce las enseñanzas obtenidas de su pasado en normas que orientan su conducta” (Barbara Levit y James G. March, Organizational Learning, American Review of Sociology, 1988). De igual

18 Las reuniones de los equipos de mejora, a todos los niveles, funcionan como wokshops: cada reunión tiene unos objetivos prácticos muy concretos y definidos y se apoyan en una metodología que garantiza que todos los participantes hacen aportaciones y que se avanza sistemáticamente hacia los objetivos. Sin embargo, frecuentemente al hablar de workshops nos referimos a las reuniones de los niveles más operativos, ya que se asocia más a la idea de taller de trabajo: se aprende en el propio "taller", con una metodología totalmente inductiva y experimental. 
modo, "el aprendizaje de empresa se produce mediante el intercambio de ideas, conocimiento y modelos mentales... basándose en el conocimiento y experiencia anterior, es decir en la memoria..." (Ray Stata, Organizational Learning: The Key to management Innovation", Sloan Management Review, 1989). Realmente, para poder hablar de empresa inteligente no basta con qué aprenda. En efecto, tal como dice P. Senge (2000), "todas las empresas aprenden, en el sentido de que se adaptan a medida que el mundo cambia a su alrededor, pero algunas son más rápidas y eficientes aprendiendo. La clave está en ver el aprendizaje como inseparable del trabajo cotidiano."

Asociamos la idea de empresa inteligente, a la de aprender de forma más o menos espontánea. ¿Cómo avanzar hacia este tipo de empresa?

Un concepto fundamental para comprender la empresa inteligente es el de mejora sistemática, para lo cual se que requiere, a su vez, el concepto de mejorable. Veamos en que consiste y cómo se aplica.

En el campo de la dirección ha sido habitual hablar de "Análisis y solución de problemas", lo que ha propiciado el desarrollo de una cultura de reacción ante los acontecimientos y no de anticipación a los mismos. Cuando por alguna razón algo deja de funcionar, la reacción es lógica: poner un parche para que siga funcionando hasta que los técnicos que "saben" de eso decidan cambiar la tecnología y/o procesos. Esta forma de pensar, parte de la idea que el conocimiento válido para las decisiones sólo lo poseen los técnicos, de modo que los empleados que están en contacto directo con las máquinas, procesos, clientes y, general, con la operativa del día a día, tienen poco que aportar para hacer que la situación mejore. El aprendizaje es muy pobre y, en todo caso, de "bucle único"19, utilizando la terminología de C. Argiris (1991).

Frente a este enfoque, de tipo taylorista, en los últimos años se ha generalizado el enfoque de la mejora continua, de origen japonés, basado en el "Análisis y mejora de situaciones", que refleja la idea de que nada es perfecto y todo es perfectible, por lo que, cualquier aspecto que tratemos, es necesario mejorarlo continuamente. En este caso, ya se considera que los empleados que están en la operativa poseen conocimiento de utilidad a la hora de decidir mejoras. Por lo tanto, es importante contar con ellos para decidir e implantar cambios relacionados con los procesos que realizan normalmente.

19 Chris Argiris, profesor de Harvard Business School, es uno de los autores más reconocidos del mundo sobre comportamiento organizacional y, en concreto, sobre el aprendizaje. Ha acuñado las expresiones de "aprendizaje de bucle sencillo" y de "bucle doble". Un termostato actúa como aprendizaje de "bucle sencillo": si se alcanza cierta temperatura, 20 grados por ejemplo, se dispara. Un termostato que pudiera preguntar "¿Por qué me han fijado a 20 grados?" y luego pudiera explorar si otra temperatura podría o no lograr más económicamente el objetivo de calentar la habitación estaría realizando un aprendizaje de "bucle doble". 
Aún así, cuando el entorno experimenta cambios intensos y de forma permanente, la mejora continua no garantiza la competitividad de la empresa a largo plazo. Actualmente, el avance tecnológico provoca rupturas que exigen que las empresas tengan que hacer cambios radicales, poniendo al día sus equipos y sus procesos. En los últimos años, como consecuencia de las llamadas TICs (Tecnologías de Información y Comunicación), estos cambios han sido espectaculares por lo que la mejora continua o incremental no fue suficiente para adecuarse a la nueva situación.

De hecho, los dos tipos de mejora citados no son incompatibles. Al contrario, ambos son complementarios, de modo que las empresas deben definir e implantar sistemas para propiciar la evolución hacia una cultura organizativa que provoque una combinación espontánea del conocimiento de los empleados y el de los técnicos para introducir mejoras incrementales y radicales. A este enfoque lo llamamos mejora sistemática y constituye, la base de la metodología para el funcionamiento de la DPI. Se basa en lo que hemos llamado aprendizaje de "doble bucle": está claro el fin, ser más competitivo, pero el camino se cuestiona constantemente.

Es obvio que las empresas que tienen éxito de forma sostenida no se limitan a resolver problemas, sino que, y sobre todo, se anticipan a las situaciones desfavorables cambiando, con cierta frecuencia, algunas cosas cuando todavía funcionan bien. Pues bien, utilizamos el término mejorable para explicar qué tipos de cambios deben abordarse, con independencia de que sean problemas o no.

En este sentido, un mejorable es la identificación de cualquier aspecto de la empresa en el que es posible introducir mejoras, unida al compromiso de definir e implantar el plan correspondiente. En la definición se ha destacado:

a) La existencia de un mejorable supone tomar conciencia de una situación en la que es posible introducir mejoras. Una situación con un importante potencial de mejora, sólo tiene repercusiones prácticas cuando se toma conciencia de esa situación.

b) Además, exige la asunción de un compromiso para definir e implantar el plan que haga realidad esas mejoras. La identificación sin compromiso tampoco tiene efectos prácticos. En consecuencia, para poder hablar de mejorables, la identificación del posible aspecto a mejorar corresponderá a personas o equipos con capacidad de decisión suficiente.

La Tabla 3.1. presenta los diferentes tipos de mejorables que se utilizan en el modelo de aprendizaje que proponemos, atendiendo al objetivo o finalidad perseguida:

Hay mejorables cuya finalidad es resolver problemas actuales, algo no deseado que está ocurriendo. Pero también los hay cuya finalidad no es resolver problemas, sino compensar desventajas, reales o potenciales, con respecto a los competidores. Hemos incluido también mejorables cuyo objetivo es mantener o crear ventajas frente a los competidores. 
Tabla 3.1. Tipos de mejorables.

\begin{tabular}{|c|c|c|}
\hline FINALIDAD & CARACTERÍSTICAS & TIPO \\
\hline \multirow{4}{*}{$\begin{array}{l}\text { SOLUCIÓN } \\
\text { DE } \\
\text { PROBLEMAS }\end{array}$} & Conocidos por los clientes. & $\mathbf{M}_{1}$ \\
\hline & $\begin{array}{l}\text { Conocidos por nosotros pero desconocidos por los } \\
\text { clientes. }\end{array}$ & $\mathbf{M}_{2}$ \\
\hline & Desconocidos por nosotros y por los clientes. & $\mathbf{M}_{3}$ \\
\hline & $\begin{array}{l}\text { Asociados a desventajas con respecto a los competi- } \\
\text { dores. }\end{array}$ & $\mathbf{M}_{4}$ \\
\hline $\begin{array}{l}\text { COMPENSAR } \\
\text { VENTAJAS DE LOS } \\
\text { COMPETIDORES }\end{array}$ & $\begin{array}{l}\text { Compensar ventajas asociadas a competencias de los } \\
\text { líderes. }\end{array}$ & $\mathbf{M}_{5}$ \\
\hline $\begin{array}{l}\text { MANTENER } \\
\text { VENTAJAS }\end{array}$ & $\begin{array}{l}\text { Mantener ventajas asociadas a competencias de la em- } \\
\text { presa. }\end{array}$ & $\mathbf{M}_{6}$ \\
\hline $\begin{array}{l}\text { CREAR } \\
\text { VENTAJAS }\end{array}$ & Nuevos diferenciales con respecto a los competidores. & $\mathbf{M}_{7}$ \\
\hline
\end{tabular}

Dentro de los mejorables asociados a la solución de problemas, los de tipo $\mathrm{M}_{4}$ aparecen como problemas, no porque la empresa haga algo mal ante los ojos de los clientes, sino porque éstos descubren que los competidores lo hacen mejor. Mención especial merecen los mejorables $\mathrm{M}_{3}$ ya que al referirse a problemas desconocidos no pueden explicitarse acciones concretas para afrontar su resolución. Las acciones asociadas a este tipo de mejorables pueden llevar a la afloración de problemas reales que ya existen, pero también pueden anticiparse de forma genérica a problemas en potencia.

La frontera que separa unos mejorables de otros es borrosa, especialmente los $\mathrm{M}_{4}$ de los $\mathrm{M}_{5}$. A medida que los competidores innovan más deprisa que la empresa es cuando aparecen los $\mathrm{M}_{4}$. Se trata de algo que fue ventaja competitiva para algunos competidores pero, aunque la empresa ha quedado rezagada, la imitación se ha generalizado. Dejan de ser ventajas para unos y pasan a ser problemas para otros. Los $\mathrm{M}_{5}$, por el contrario, corresponden a ventajas competitivas de las empresas claramente líderes del mercado.

Partiendo del concepto de mejorable, podemos definir la mejora sistemática como un proceso de identificación de mejorables y de la subsiguiente definición e implantación de mejoras tal como muestra la Figura 3.12.

Cuando la mejora sistemática está incardinada en la vida normal de la empresa, el proceso se produce cuasi-automáticamente, tanto a nivel de personas como de equipos, dando lugar a la empresa inteligente. 
Figura 3.12. De los mejorables a las acciones de mejora.

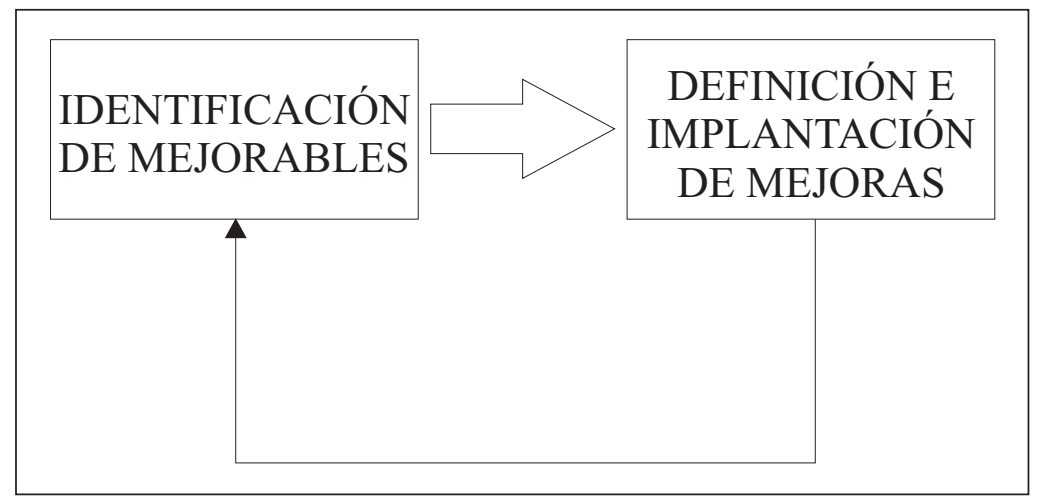

\subsection{Los mapas del cambio estratégico}

Tal y como hemos definido el cambio estratégico, deberá ser llevado a cabo como consecuencia de un proceso que combina futurización con planificación, liderazgo con gestión. El éxito de un cambio global en las organizaciones exige que el líder número uno tenga clara la visión de a dónde desea llegar con el cambio, de tal forma que esa visión debidamente declarada y comunicada constituya la guía que oriente todo el proceso.

Lo mismo que la brújula, la visión orienta hacia donde se quiere ir, pero no señala el camino concreto que debe seguirse. Un símil nos ayudará a comprender esta idea. Si para llegar a un determinado lugar, debemos cruzar una montaña con muchos obstáculos y nos guiamos únicamente por la brújula podemos encontrarnos, cuando menos lo esperemos, ante un precipicio que haga imposible el camino hacia la meta. Para llegar al destino deseado hace falta un mapa del territorio que ponga de manifiesto los obstáculos que dificultan el camino y también los lugares por donde hay posibilidades de avanzar, de acuerdo con los recursos de que disponemos o que podemos llegar a disponer. En definitiva, la combinación de la brújula y el mapa nos permitirá avanzar con seguridad hacia la meta deseada.

Si aplicamos este símil al cambio estratégico, la visión nos proporciona la herramienta de guía del cambio, o sea será nuestra brújula para orientar la estrategia, pero no para definirla. Para esto necesitamos el mapa. Aunque la idea de mapa es ampliamente utilizada en dirección, todavía se utiliza de formas muy distintas.

El concepto de mapa es de uso creciente en Dirección, sin embargo no todos los autores le dan el mismo significado. C. Argiris en Organizational Learning (1999) habla de los Mapas para la acción, como instrumentos para representar los comportamientos que utilizan las personas para diseñar y realizar sus acciones. T.H Davenport y L. L. Prusak en Working Knowledge: How Organizations Manage They Know (1998) afirman que el objetivo principal de un Mapa de 
Conocimiento es mostrar a los miembros de la organización a dónde deben dirigirse cuando necesitan conocimiento especializado.

R. S. Kaplan y D.P. Norton en su libro The Strategy Focused Organization (2001) desarrollan el concepto de Mapa estratégico de un Cuadro de Mando Integral, y lo aplican para describir el proceso de transformación de los activos intangibles en resultados tangibles con respecto al consumidor y a las finanzas, proporcionando a los directivos un marco que les permite describir y gestionar la estrategia en una economía del conocimiento. Más recientemente, estos mismos autores han profundizado en esta herramienta en su libro Strategy Maps (2004).

El mapa del cambio estratégico resume de forma ordenada el conocimiento relevante para decidir el camino concreto del cambio que se desea llevar a cabo. Formalmente, el mapa estratégico que proponemos lo presentamos como una matriz de siete columnas, interrelacionadas entre sí, tal y como muestra la Figura 3.13., que refleja un modelo de hoja de trabajo para la elaboración de los mapas del cambio estratégico.

Figura 3.13. Hoja de trabajo para realizar el mapa estratégico

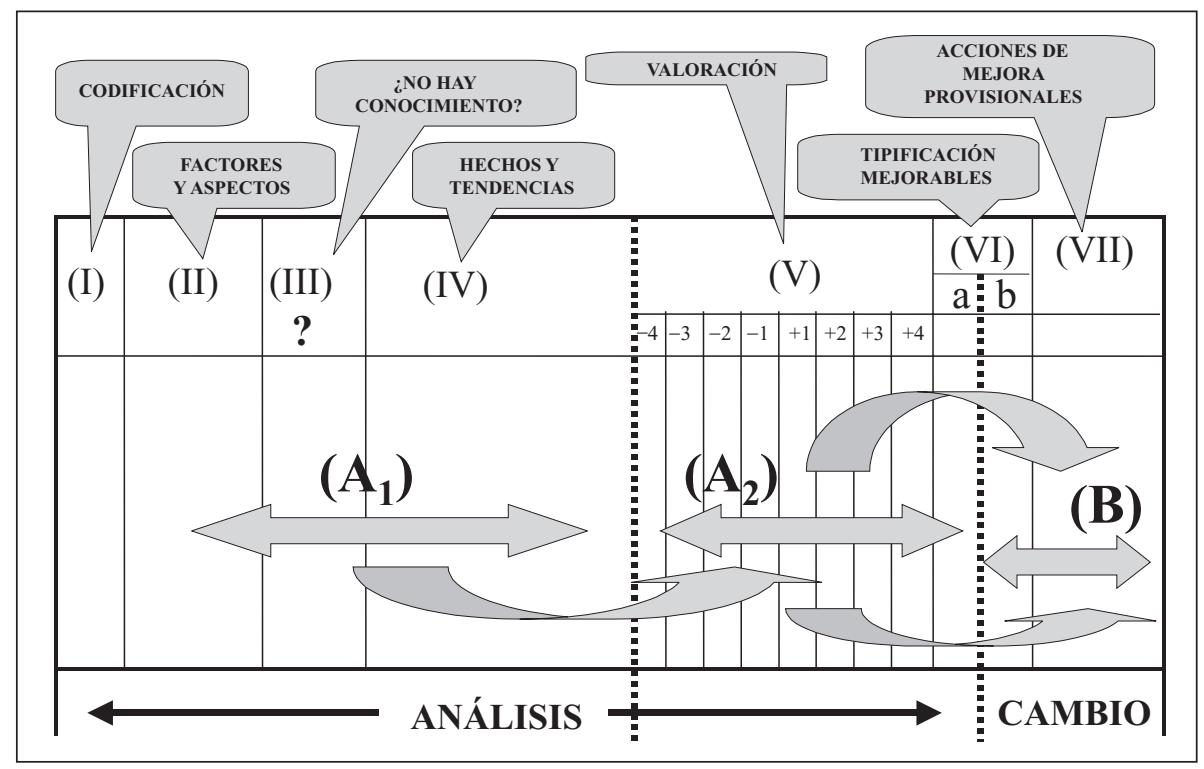

Las columnas I) y III) son meramente instrumentales.

I) Codificación, de cara a facilitar el tratamiento del conocimiento generado durante el proceso. Si bien pueden elaborarse los mapas estratégicos del cambio sin emplear sistemas informáticos, lo lógico es apoyarse en ellos para el tratamiento de toda la información y conocimiento que se produce durante el proceso. 
III) Carencia de conocimiento. Si el miembro del EDE que está haciendo el mapa individual no dispone de conocimiento para describir y valorar cómo en un determinado aspecto la situación de la empresa y/o entorno afecta a la competitividad no debe cumplimentar esa fila del mapa. Cuando en un aspecto concreto coinciden todos los miembros del EDE en este desconocimiento, se ponen de manifiesto lagunas de conocimiento sobre aspectos potencialmente relevantes $y$, en consecuencia, la necesidad de hacer algo al respecto: estudios, encuestas, etc. Por lo tanto, aunque decimos que se trata de una columna meramente instrumental, tiene un papel importante.

Todas las columnas del mapa están íntimamente interrelacionadas. Sin embargo, podemos considerar dos bloques, según se relacionen con el análisis de la situación actual o con el cambio. Profundicemos en cada uno de estos bloques.

a) El bloque (A) comprende, además de la I) y III) que ya hemos comentado, las columnas II), IV), V) y VIa), que recogen el conocimiento sobre la situación actual. A su vez, hemos considerado el subbloque (A) formado por las columnas II) y IV) que muestran el conocimiento para identificar las relaciones causa efecto en la estrategia actual y el subbloque ( $\left.\mathrm{A}_{2}\right)$ que comprende las columnas (V) y (VIa) para reflejar la medida de cómo los factores y aspectos, de acuerdo con los hechos y tendencias considerados, inciden en la competitividad de la empresa.

b) EI bloque (B) está formado por las columnas VIb) y VII) donde se recoge el conocimiento sobre las acciones de cambio que se decide emprender.

Veamos, aunque sea brevemente, el tipo de conocimiento contenido en cada una de las columnas del mapa del cambio estratégico. Tomaremos como base para la explicación la Figura 3.14, que muestra una visión global de la interrelación entre los concepto que recoge el mapa estratégico.

5.3.1. El contenido del mapa del cambio estratégico: Conocimiento sobre el análisis de la situación actual

En la columna II) del mapa figura el check list de conceptos sobre los que los miembros de los equipos deben reflexionar para establecer relaciones causaefecto y valorar su incidencia en la competitividad de la empresa. Definen el marco potencial en el que se actuará para el diseño e implantación de acciones de cambio.

Para identificar de forma adecuada los factores, aspectos y subaspectos que son relevantes para describir la estrategia actual de la empresa (análisis) y la que se decidirá para avanzar hacia la visión (diseño), habrá que reflexionar sobre todo lo que potencialmente puede serlo. Por esta razón, se ha insistido tanto en el papel de los modelos explícitos, como herramienta que garantice que la relación de 
aspectos y subaspectos incluidos en las hojas de trabajo constituya un check list adecuado para orientar el trabajo del EDE.

Lo ideal es que figure todo lo relevante y no más: Que esté todo lo importante pero que no figure nada que no lo sea, ya que sólo sería un "ruido" para el proceso. Sin embargo, para seleccionar bien lo que es realmente relevante deberá aplicarse una técnica que permita un filtrado a partir de todo lo que potencialmente puede $\operatorname{serlo}^{20}$.

\section{Figura 3.14. Las acciones de mejora en el contexto del mapa del cambio estratégico.}

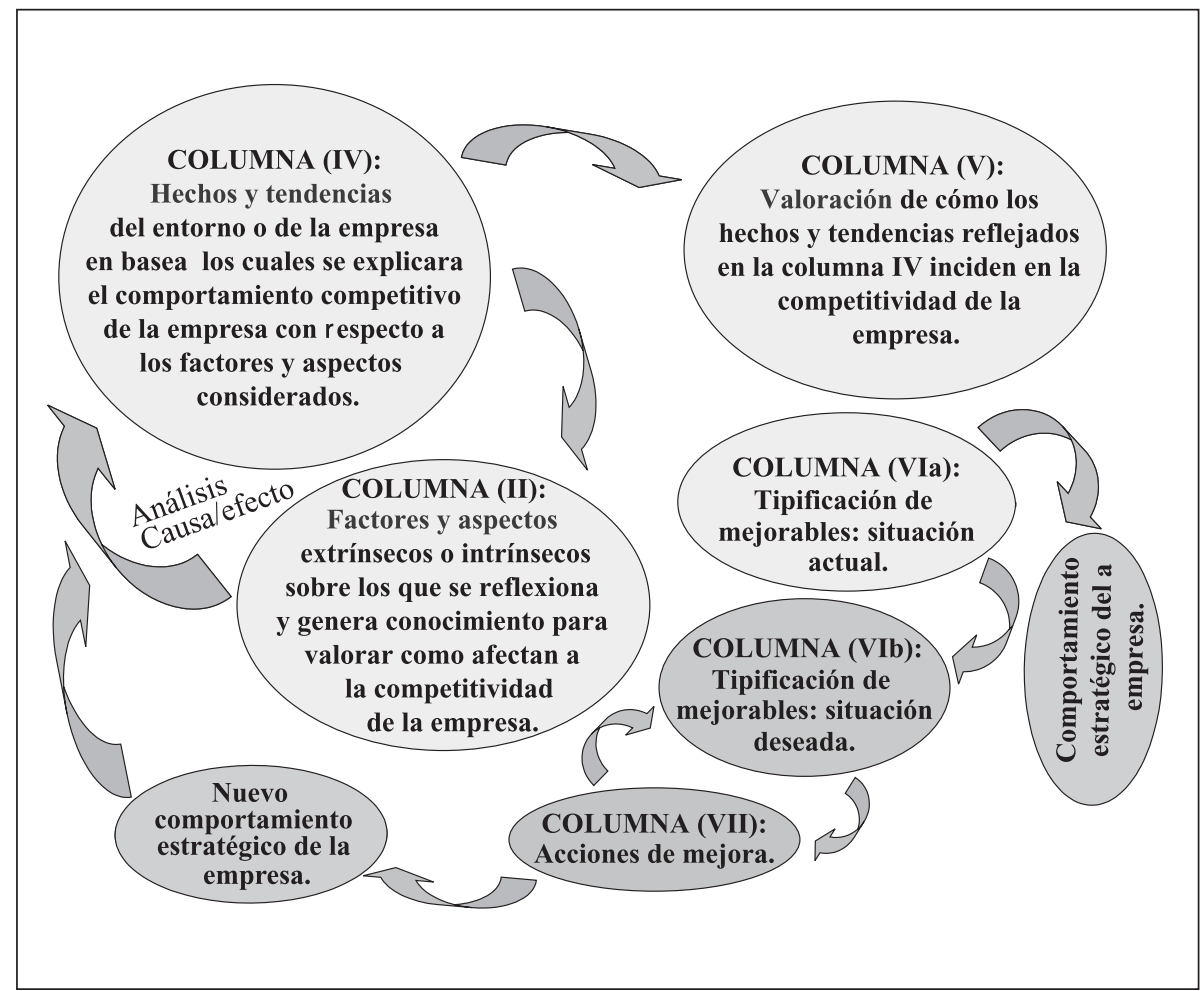

En la columna IV) se resume el conocimiento que sirve de base para valorar el comportamiento competitivo de la empresa en relación a los factores, aspectos y subaspectos que figuran en la columna II). Se trata de algo que ha ocurrido o que, de forma generalmente asumida, se espera que ocurra y que se relaciona con los aspectos a valorar. Es importante resaltar que se trata de hechos y tendencias basados en conocimiento y no de opiniones.

20 Tomar como base un modelo explícito elaborado al efecto, como es el trípode del cambio, que hemos presentado más atrás, conduce a un Check list adecuado del que partir para aplicar la técnica de filtrado $\mathrm{MP}^{2}$ (Muchos-Pocos-Priorización). 
En la columna V) se refleja la valoración de la incidencia en la competitividad de la empresa de los aspectos que figuran en cada renglón de la columna II) del mapa. La valoración la hace cada participante, si se trata de los mapas personales o el equipo si se trata del mapa del EDE, en función de los hechos y tendencias que figuran en la columna IV), basándose en criterios lo más objetivos posible y siempre los mismos para todos los mapas.

La columna VI) recoge el conocimiento sobre los mejorables que el EDE considera durante el proceso de cambio estratégico. Se incluyen dos subcolumnas, la VIa) para reflejar las situaciones tal como están actualmente y la VIb) que recoge conocimiento sobre el cambio (cuál es la situación que se desea alcanzar con las acciones de mejora que se pondrán en práctica).

\subsubsection{El contenido del mapa del cambio estratégico: Conocimiento sobre las acciones de mejora}

Como muestra la Figura 3.15., en la columna VII) de los mapas del cambio se resume la aplicación a la definición de Acciones de mejora del conocimiento que figura en las columnas de análisis. La columna VIb) también es de diseño ya que recoge conocimiento sobre la finalidad (tipo de mejorable) que el EDE considera que se debe alcanzar con el diseño e implantación de las acciones que figuran en la columna VII) del mapa. En definitiva, el conocimiento que se recoge en las columnas del mapa referidas al análisis será tanto más pertinente cuanto más contribuya a cumplimentar de forma eficaz las columnas VII) y VIb), o lo que es lo mismo, a decidir las acciones de mejora.

Dada la importancia práctica de los mapas del cambio, presentamos un ejemplo para aclarar su funcionamiento global. Supongamos que una empresa con un estilo entre D-J y D-G, más próximo a este último, está afrontando un proceso de transformación. Ha culminado la profesionalización y en estos momento inicia la fase que puede encuadrarse en lo que llamamos renovación. En una de las hojas de trabajo para hacer los mapas del cambio figura como aspecto el siguiente: Retención del talento.

Los miembros de los equipos que elaboran los mapas deberán reflexionar sobre este aspecto como factor de competitividad para valorar, en función de hechos y tendencias concretas, si afecta de forma positiva o negativa a la competitividad de la empresa y, además, en qué medida. Es decir, deberán hacer el diagnostico de la empresa con respecto a la retención del talento. Luego, en función del diagnóstico realizado y del rumbo que desea emprender la empresa propondrán las acciones de cambio que se consideran adecuadas para avanzar en la dirección deseada. La Figura 3.15. resume el proceso de razonamiento para cumplimentar el renglón del mapa correspondiente al referido aspecto y el resultado obtenido. 


\section{Figura 3.15. Un ejemplo de cómo reflexionar a partir de un aspecto concreto.}

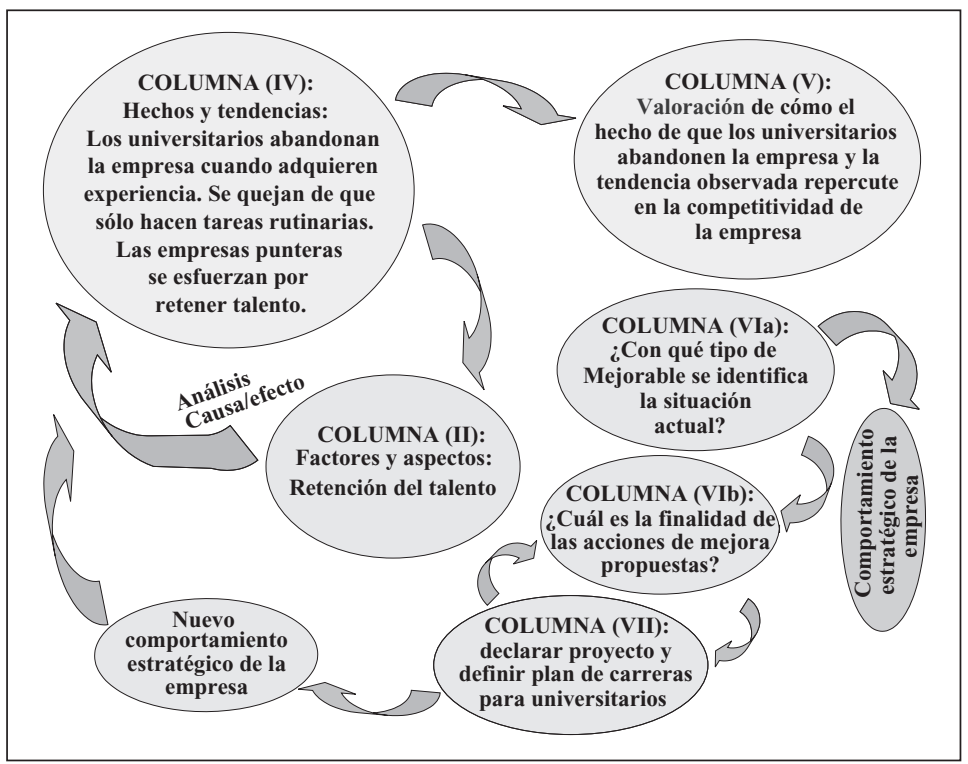

Para cubrir la columna IV) los miembros del EDE que están haciendo su mapa del cambio personal deberán hacerse múltiples preguntas sobre qué ocurre en su empresa con la retención del talento. ¿Permanece en la empresa el talento existente? ¿Qué hechos concretos explican lo que ocurre? ¿Cuáles son las tendencias claras que se observan en el entorno en general y sobre todo en las empresas que tomamos como referencia?

Para responder a estas preguntas y otras similares que se hagan, deberán basarse en conocimiento referido a hechos y tendencias concretas. Muchas veces ese conocimiento será fruto de experiencias vividas y que hasta ahora permanecía como conocimiento tácito que la metodología seguida ayuda a explicitar. Una vez que se han explicitado hechos concretos relacionados con la retención del talento, es cuando debemos cumplimentar la columna V). ¿Cómo incide la forma en que la empresa retiene el talento, en su competitividad? ${ }^{21}$

Lo que ocurre en la empresa en torno a la retención del talento, tal y como ha sido recogido en las columnas anteriores del mapa se identifica con una situación en términos de mejorable que se indicará en la columna VIa). En el caso que exponemos pudiera ocurrir, por ejemplo, que los clientes se quejan de que cuando los técnicos jóvenes de la empresa empiezan a conocer su problemática y pueden ayudarles a resolverla son sustituidos por otros sin experiencia y, por lo tanto, ya no les pueden ayudar. En este caso, se trataría de un $\mathrm{M}_{2}$.

21 Para la valoración es importante basarse en criterios claros, sencillos y objetivos. Hacerlo así, facilita el funcionamiento de los equipos de mejora y propicia el aprendizaje. 
El conocimiento recogido en las columnas explicadas hasta aquí responde al análisis de la situación actual, y refleja el comportamiento estratégico de la empresa con respecto al aspecto tratado: la retención del talento. Las columnas VIb) y VII) recogen las acciones de mejora que, según el autor o autores de los mapas, deberán llevarse a cabo. Son las columnas de diseño.

En VIb) se indicará, lo que el miembro del EDE que hace el mapa, o en su caso el propio EDE, considera como objetivo marco a alcanzar con las mejoras recogidas en la columna VII). Si en nuestro caso lo que se quiere es que en este aspecto pasemos desapercibidos, que el cliente no perciba ni como problema ni como ventaja la forma en que lo hacemos, con la acción de cambio trataríamos de resolver el problema tal como está definido, poniendo $\mathrm{M}$ en VIb). Si queremos resolverlo tomando como referencia lo que hacen los mejores pondríamos $\mathrm{M}_{3}$.

\section{El proceso de implantación de la DPI}

\subsection{El modelo del cambio estratégico en seis etapas}

El proceso lo planteamos en las seis etapas o fases que muestra la Figura 3.16. Veamos una breve explicación de cada una de las fases.

Figura 3.16. El proceso estratégico en seis etapas: contenidos y aspectos formales.

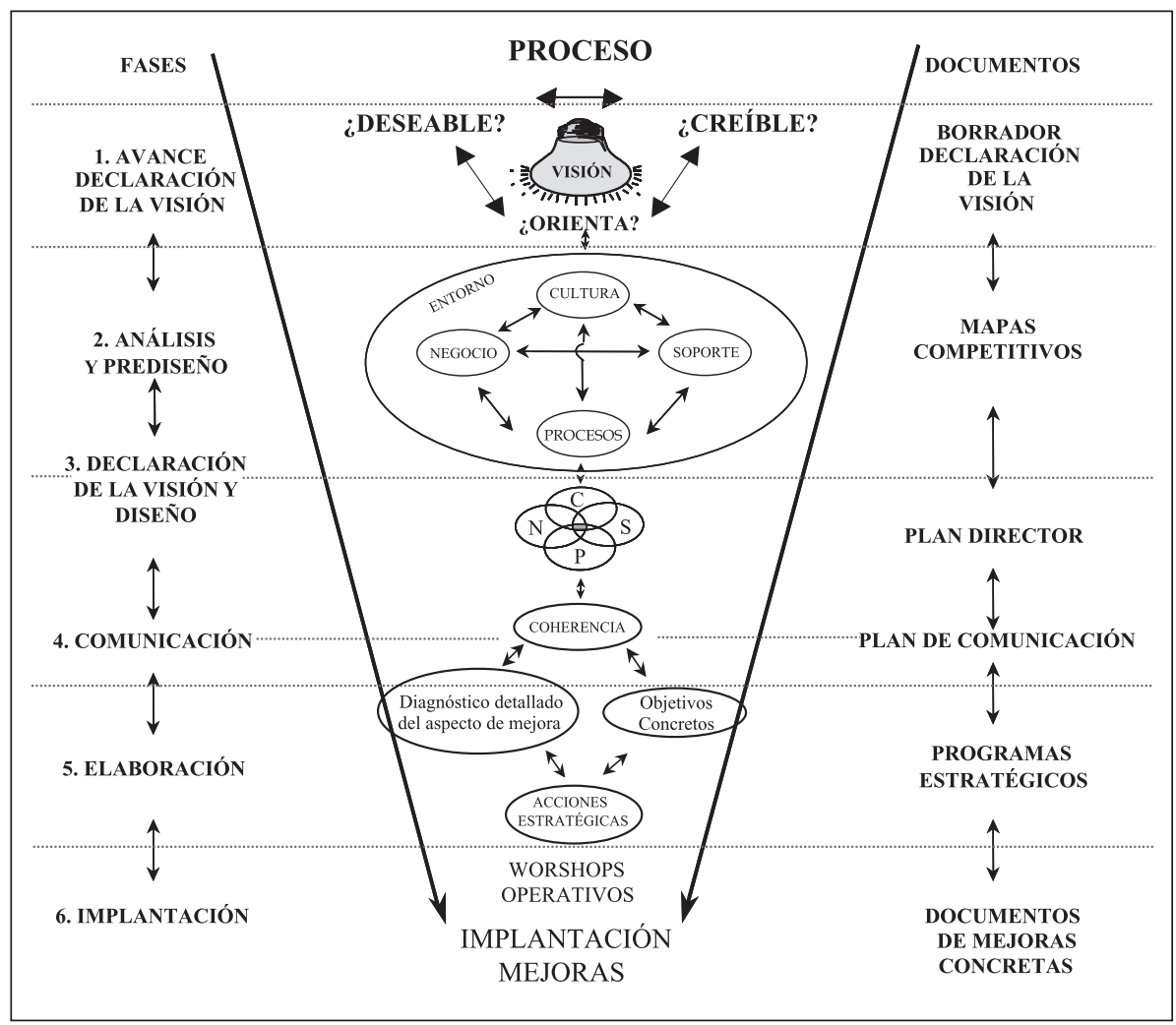




\subsubsection{Fase 1. Avance de la declaración de la visión}

A lo largo del presente trabajo ha estado en mente la idea de que el proceso de implicación sólo tiene sentido si los empleados conocen el proyecto del que se quiere que formen parte. Cuando ese proyecto no existe, no se puede implantar la DPI, tal como la hemos definido. Igualmente, se ha comentado que, con frecuencia, en las empresas hay un líder o líderes que tiene/tienen esa visión, aunque no esté explicitada. En esos casos, sí se puede implantar la DPI y el primer trabajo a abordar será preparar un borrador de declaración de visión, que sirva de base para comunicar el proyecto de cambio a los que participarán directamente en el mismo desde el primer momento.

El resultado de esta fase será el borrador de la Declaración de la Visión Compartida por el líder y sus colaboradores que forman parte del EDE. Este borrador deberá ser sencillo, pero en todo caso ha de transmitir un imagen de cambio deseable (en principio por todos aquellos que se quiere que hagan de motores del cambio), factible (no motiva lo que se considera inviable) y además, y es muy importante, ha de constituir el marco para encuadrar la siguiente fase.

\subsubsection{Fase 2. Análisis y prediseño}

Tiene como objetivo identificar las amenazas y oportunidades del entorno, así como las fortalezas y las debilidades de la empresa (análisis). Además, se avanzan ideas para mejorar la empresa (prediseño). El resultado de esta fase se resume en los mapas del análisis y prediseño del cambio estratégico.

El concepto de mapa del cambio estratégico, tal como lo hemos explicado sirve tanto para la fase del análisis y prediseño como del diseño. Durante el análisis, se consideran por separado los distintos componentes del trípode, según muestra la Figura 3.17.

\section{Figura 3.17. Analisis por separado de los componentes de la estrategia.}

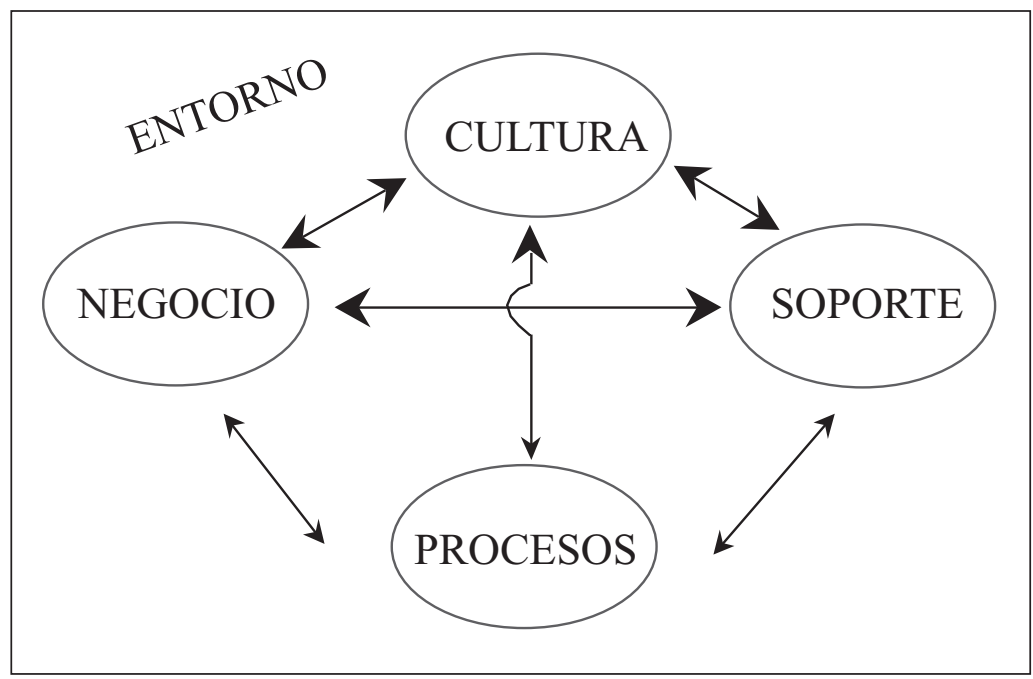


Por esta razón las acciones de mejora que van surgiendo tendrán carácter provisional. Luego al hacer la síntesis con el diseño, podrán modificarse

\subsubsection{Fase 3. Declaración de la visión y diseño}

Una vez llevado a cabo el análisis y prediseño como un proceso de aprendizaje, ya se ha adquirido suficiente conocimiento para tener claro si se sigue con el proceso o si todavía hay que preparar más el terreno. Si se decide seguir, es el momento de hacer la declaración definitiva de la visión y para diseñar la estrategia para avanzar hacia dicha visión.

La síntesis del diseño se materializa en lo que llamamos plan director de la estrategia de la empresa. Formalmente, consta de una serie de programas estratégicos que deberán ser desarrollados posteriormente de cara a avanzar hacia la implantación.

Del análisis de las propuestas que hacen los autores más conocidos sobre visión y, de forma muy especial, de nuestra propia experiencia, consideramos como características necesarias para una buena declaración de visión:

1. Constituir la imagen de un futuro deseado.

2. Suponer un reto creíble.

3. Orientar la estrategia.

4. Fácilmente comunicable.

Una vez que contamos con la visión y disponemos de los mapas estratégicos surgidos del análisis y prediseño, ya es el momento de realizar el diseño. En la fase de análisis, se identifican las oportunidades y amenazas ante las que se encuentra y encontrará la empresa, y se proponen acciones de mejora aisladas para cada uno de los aspectos analizados (negocio, soporte, cultura y procesos). Esas acciones aisladas para cada aspecto estratégico tienen poco sentido práctico. Los cuatro componentes de la estrategia están interrelacionados, por lo que las acciones definitivas han de tener en cuenta esa realidad. En consecuencia, en el diseno, hay que definir acciones de mejora teniendo en cuenta tales interrelaciones, según indica la Figura 3.18.

Las acciones de mejora debidamente integradas se agruparán formando los programas estratégicos de la empresa. En esencia, en el proceso de las seis etapas que seguimos, el diseño consiste en:

- Definir con suficiente detalle acciones de mejora, teniendo en cuenta la globalidad de la empresa, y agruparlas de forma coherente de cara a su implantación. Cada una de esos grupos de acciones constituirá un Programa Estratégico.

- Priorizar los programas estratégicos, para establecer por cuáles debe empezarse la implantación. Normalmente, las empresas, sobre todo las de estilo 
próximo al D-J, no tienen Recursos Humanos ni tiempo para hacer todo a la vez, de ahí la necesidad de priorizar los programas estratégicos.

El conjunto de los programas estratégicos constituyen el Plan Director. Es el resultado de los trabajos del EDE y resume la estrategia intencional de la empresa.

Figura 3.18. Del análisis al diseño.

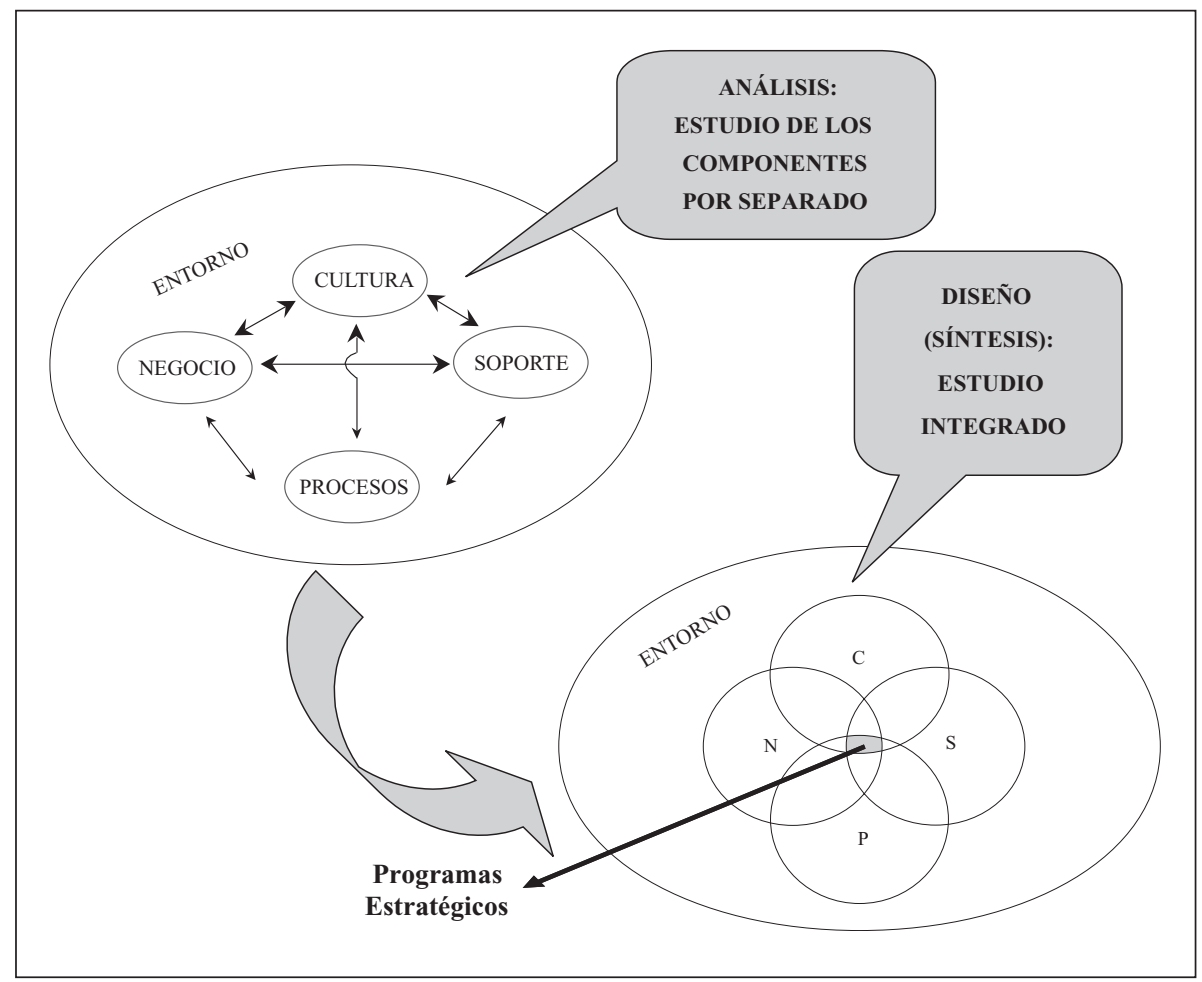

\subsubsection{Fase 4. Comunicación}

Una vez que se cuenta con la declaración de la visión y con el diseño estratégico como proyecto de cambio, resumido en el plan director, se preparará un plan de comunicación del proyecto a toda la organización, como inicio del proceso de implicación del equipo humano.

\subsubsection{Fase 5. Elaboración}

En esta fase se crean nuevos equipos de trabajo, los EDOs, para que profundicen en la elaboración de la estrategia, mediante el desarrollo de los diferentes programas estratégicos, pensando ya en la implantación de la misma. La elaboración supone, por lo tanto, un paso más en la concreción del proyecto de cambio pensando ya en la puesta en práctica. 
La Figura 3.19. muestra las diferencias más importantes entre el diseño, del que resulta el plan director, y la elaboración, que genera los programas estratégicos.

Figura 3.19. Del diseño a la elaboración.

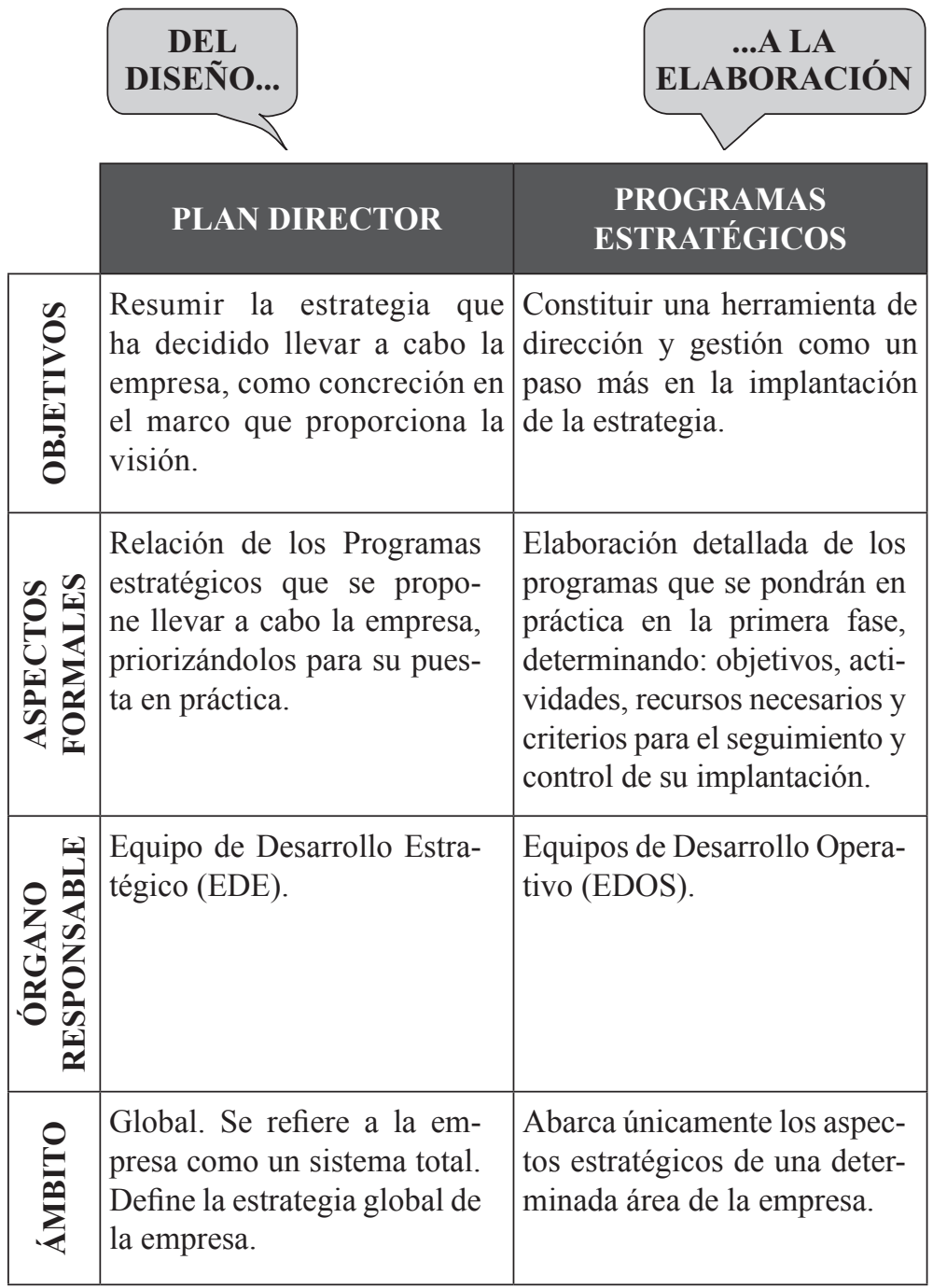

El conjunto de los programas estratégicos constituyen el Plan Director. Es el resultado de los trabajos del EDE y resume la estrategia intencional de la empresa.

\subsubsection{Fase 6. Implantación}

Las acciones de mejora consideradas como necesarias en los programas, ahora deberán ser definidas con suficiente detalle en planes de acción que se incorporarán al Plan Operativo de la Empresa para ser implantadas. 


\subsection{Cómo la metodología propuesta garantiza el funcionamiento} de la espiral personas-equipos-organización durante el proceso de implantación del cambio

De acuerdo con la metodología planteada para llevar a cabo el proceso de implantación del cambio se garantiza el funcionamiento de la espiral de aprendizaje persona-equipo-organización a que nos hemos referido anteriormente. Durante el proceso se utilizará conocimiento de todo tipo:

1. Conocimiento externo, relacionado con competidores, proveedores, clientes, coyuntura, situación política, etc.

2. Conocimiento Interno: CTP (Conocimiento Tácito personal); CEP (Conocimiento Explícito personal); $C E O$ (Conocimiento Explícito Organizativo), y CTO (Conocimiento Tácito Organizativo).

El conocimiento externo es básico para evitar la endogamia y para aprovechar las experiencias de otros, sobre todo cuando se trata de procesos de profesionalización y de renovación. El conocimiento interno es clave sobre todo por los efectos positivos que tiene para la implicación y, además, porque en algunos casos, sobre todo de profesionalización, suele ser la base del funcionamiento actual de la empresa y que interesa aprovechar. La Figura 3.20 muestra como funciona la espiral de aprendizaje en el proceso de de análisis, decisión e implantación del cambio.

\section{Figura 3.20. Funcionamiento de la espiral de aprendizaje personas-equipos-organización.}

\begin{tabular}{|c|c|c|}
\hline $\begin{array}{l}\text { Conocimiento } \\
\text { Externo }\end{array}$ & $\begin{array}{l}\text { CEO: } \\
\text { Se obtiene al trabajar en } \\
\text { equipo en base a las } \\
\text { aportaciones } \\
\text { individuales según los } \\
\text { mapas estratégicos. } \\
\text { CEP: } \\
\text { Se crea a través de la } \\
\text { reflexión individual, } \\
\text { dando lugar a los mapas } \\
\text { estratégicos individuales. }\end{array}$ & $\begin{array}{l}\text { CTO: } \\
\text { Supone la consolidación } \\
\text { de las mejoras, cuando } \\
\text { tras su implantación se } \\
\text { crean nuevos valores, } \\
\text { actitudes y } \\
\text { comportamientos } \\
\text { compartidos. } \\
\text { CTP: } \\
\text { Es el input inicial. }\end{array}$ \\
\hline
\end{tabular}




\subsubsection{Iniciación del proceso: Partir del CTP}

$\mathrm{El}$ análisis y prediseño se empieza con los mapas estratégicos individuales. La idea de partida es contar con el CTP de cada uno de los miembros del EDE. Esto es básico sobre todo en los procesos de profesionalización, ya que las empresas con estilo de dirección próximo al D-J utilizan, sobre todo, CTP, que es necesario explicitar como punto de partida para poder compartirlo.

\subsubsection{Creación de conocimiento explícito personal}

Ahora, se pasará de CTP a CEP, como vía para compartirlo más fácilmente a través de un cauce racional. Para facilitar la tarea, se propiciará la reflexión sobre cada aspecto concreto que figura en la columna II) de las hojas de trabajo de los mapas: factores y aspectos. Cada miembro del equipo tendrá que hacer un esfuerzo para relacionar sus experiencias, muchas de ellas aparentemente olvidadas, con los diferentes aspectos contemplados en el modelo. Deberá relacionar hechos concretos con los resultados que, de acuerdo con su experiencia, han ocurrido. Esto permite crear CEP que, obviamente, aunque se refiera a un mismo aspecto, habitualmente será diferente para cada una de las personas que forman el equipo, ya que al tener distintas experiencias valoran las cosas de diferente forma.

Los modelos explícitos contribuyen de forma importante a que esta transformación de conocimiento tácito, del hemisferio derecho, en conocimiento explícito, del hemisferio izquierdo se haga de forma eficaz, de cara a ser compartido posteriormente. Supone centrarse en cada momento en un aspecto concreto de la situación a mejorar. Esto es lo que se hace al actuar por filas cuando se hace el mapa estratégico.

En esta fase de la espiral, resulta de sumo interés el conocimiento externo proporcionado por los analistas y/o consultores. Este conocimiento se refiere sobre todo a la metodología, para hacer más eficaz el proceso de explicitación del CTP aportado por las personas que participan en el proceso de mejora y también a conocimiento sobre las mejores prácticas relacionadas con los temas tratados.

\subsubsection{Creación de conocimiento explícito organizativo}

Ahora, también es interesante el conocimiento externo proporcionados por analistas y consultores, sobre todo cuando se trata de empresas que no tienen suficiente experiencia en la reflexión en equipo. Además de su función como facilitadores de los debates que surjan a partir de las aportaciones individuales, aplicando el método socrático, su experiencia y conocimientos de las mejores prácticas son muy importantes para la creación de CEO. Se inicia con CEO referido al análisis prediseño y se continúa el proceso (diseño-elaboración) hasta disponer de los planes de acción que serán implantados.

\subsubsection{Creación de conocimiento tácito organizativo}

Como consecuencia del proceso de decisión, una parte del CEO se traduce en sistemas, manuales de procedimiento, etc., que serán utilizados por las personas que 
forman la organización. Lo que empieza a ser utilizado por ser una exigencia de la empresa, acabarán deseándolo los empleados, ya que, consciente y/o inconscientemente, habrán comprobado que es lo adecuado. De esta forma se avanza en la dirección de modelos mentales compartidos, que definirán la nueva cultura de la empresa. Así, se inicia el camino hacia la empresa inteligente, lo que se alcanzará cuando, en lo esencial, la espiral de aprendizaje funcione automáticamente, ya que el aprendizaje se ha incorporado a los valores de la empresa.

La primera vuelta de la espiral de aprendizaje sitúa a la empresa en una mejor posición en la ruta hacia la excelencia. En esta nueva situación, los empleados llevan a cabo su trabajo en un ambiente más profesionalizado y renovado en función del tipo de empresa que se quiere ser en el futuro. En consecuencia, la segunda vuelta de la espiral se inicia con un mayor radio, lo que indica que se utiliza más talento personal y organizativo. El proceso se repetirá indefinidamente.

A medida que la empresa avanza en la ruta ideal hacia el estilo D-L, la formalización del proceso de aprendizaje pierde importancia con respecto al aprendizaje informal. A la estructura horizontal formal para propiciar el aprendizaje y desarrollo estratégico se suma una estructura informal. Los modelos explícitos pierden importancia a la vez que los mentales la ganan como forma de liberar el talento de las personas y potenciar los procesos de reinvención y revolución en la empresa.

En definitiva, la metodología propuesta garantiza que la empresa avance hacia el éxito poniendo en juego el talento organizativo, hasta alcanzar el estilo DL, que le permitirá reinventar continuamente su sector y poner en práctica nuevas estrategias de forma eficaz con la implicación mayoritaria de su personal. Y esto lo hacen año tras año, con independencia de los líderes que en cada momento estén al frente (O'Tool, 2000).

James O'Toole (2002), profesor de investigaciones del Centro para la eficiencia organizativa de la Universidad de California del Sur, inició en 1999, al frente de un equipo, una investigación para el Foro Económico Mundial con el fin de crear una base de datos sobre el liderazgo. En sus conclusiones destacan que "muchas compañias rentables consideran que la capacidad directiva no es un rasgo exclusivamente individual, sino también institucional. Sorprendentemente descubrimos que algunas compañías con un historial de éxito continuado no presentan apenas atención al desarrollo del liderazgo tradicional, es decir, individual..., sino que es el resultado de una responsabilidad compartida, como un coro bien conjuntado de distintas voces".

Es lo que ocurre en empresas como Hewlett Packard, ABB, Motorola, 3M, etc. Ocupaban el liderazgo durante la vigencia de la economía industrial y han hecho los cambios necesarios para mantenerlo en el nuevo siglo. Ese liderazgo institucional que las caracteriza, hace que el cambio estratégico sea algo normal y continuo, de modo que en este momento ya tienen un estilo de dirección adecuado para competir en la Sociedad del Conocimiento ${ }^{22}$.

22 Sin poder hablar de un momento concreto de cuando estas empresa tipo D-L han hecho los cambios en su organización para adecuarse a los nuevos tiempos, puede afirmarse que el proceso se inicia a principios de los noventa. 


\section{Bibliografía}

- ALBRECHT, K. (1996): La misión de la empresa. Ediciones Piadós Ibérica, Barcelona.

- AMIT, R. y SCHOMAKER, P. (1993): "Strategic Assets and Organizational Rents". Strategic Management Journal, vol. 14.

- ARGYRIS, C. (1991): “Un enfoque clave para el aprendizaje de los directivos”. Harvard Deusto Business Review, cuarto trimestre 1991.

- DAVENPORT, T. H. y PRUSAK, L. (2001): Conocimiento en acción. Pearson Education, Buenos Aires.

- GRATTON, L. (2001): Estrategias de Capital humano. Pearson Educación. Madrid.

- KAPLAN, R. S. y NORTON, D. P. (2001): Como utilizar el Cuadro de Mando Integral. Ediciones Gestión 2000, Barcelona.

- KAPLAN, R. S. y NORTON, D. P. (2004): Mapas estratégicos. Ediciones Gestión 2000, Barcelona.

- LEVITT, B. y MARCH, J. G. (1988): Organizational Learning, en COHEN, M. D. y SPOULL, L. S. (eds.): Organizational learning. Sage Pub, California.

- MINTZBER, H. y WATERS, J. (1985): "Of strategies, Deliberate and emergent”. Strategic Management Journal, julio-septiembre.

- O’TOOLE, J. (2002): "La capacidad directiva de la organización” en BENNIS, W.; SPREITZER, G. y CUMMINGS, T.: El Futuro del Liderazgo. Ediciones Deusto: Bilbao.

- RUBINSTEIN, M. F. y FINSTENBERG, I. R. (2001): La organización pensante. Oxford University Press: México, D.F.

- SENGE, P. (2000): La Danza del cambio. Ediciones Gestión 2000: Barcelona.

- STATA, R. (1989): "Organizational Learning: The Key to management Innovation". Sloan Management Review.

- TISSEN, R., ANDRIESSEN, D. y DEPREZ, F. L. (1998): Value-Based Knowledge Management. Addison Wesley Longman, Nederland BV. 

4

La adopción de la perspectiva de los recursos (RBV) como enfoque dominante en la Economía de la Empresa

Vicente A. López López Profesor Titular de Organización de Empresas Universidad de Santiago de Compostela 



\section{Introducción}

La creciente importancia de la Sociedad de la Información, el conocimiento y sus diversas manifestaciones, justifica el creciente interés que los investigadores están prestando al análisis de las implicaciones competitivas de "lo intangible". Las empresas rivalizan en entornos muy dinámicos, discontinuos e impredecibles, lo que provoca que las ventajas competitivas del pasado en poco se parezcan a las del presente y en casi nada a las del futuro.

En este escenario, las organizaciones descubren que el enfoque competitivo "habitual" de producto-mercado es, en la mayoría de las ocasiones, de alcance reducido y las empresas comienzan a reconocer como generadores de ventajas competitivas, sus recursos y la capacidad organizativa para crearlos, desarrollarlos y utilizarlos eficientemente (Barney, 1991). El papel ejercido por los intangibles como factor competitivo difícil de crear e imitar, no es una idea "reciente"; investigadores como Itami (1987), Aaker (1989) y Hall (1992) destacaron, con anterioridad, la importancia de los factores intangibles como generadores de ventajas competitivas perdurables.

La naturaleza evolutiva de este proceso, propaga la importancia de algunos recursos, como el aprendizaje organizativo, para así poder reaccionar como organización de una forma eficiente, rápida y, al mismo tiempo flexible, a los retos en los que se encuentran inmersas las empresas en este siglo.

\section{De los recursos, capacidades y competencias}

Desde fechas relativamente recientes, el estudio de la competitividad y los orígenes del éxito organizativo, se ha venido desplazando desde las propuestas de Porter, influenciado por los industrialistas y el paradigma estructura-conductaresultados, hacia enfoques que subrayan el papel ejercido por los recursos de la empresa, como los verdaderos dinamizadores de las ventajas competitivas sostenibles (Grant, 1991). Los orígenes de la perspectiva de los recursos podemos ubicarlos en las aportaciones de Penrose (1962), para quien la empresa puede ser considerada como una colección única y organizada de recursos, orientación ésta notablemente diferente de la conceptualización neoclásica de la empresa que identificaba a ésta con una función de producción.

Además de Penrose, existe un amplio consenso en considerar a Wernerfelt (1984) como otro los principales impulsores del enfoque RBV. Adicionalmente, las aportaciones de Barney (1991) y Grant (1991) introdujeron una definición de recursos, desarrollaron esquemas conceptuales en los que se integraba a los recursos en la formulación-implementación estratégica y formularon una serie de condiciones a cumplir por los recursos para poder asignarles la denominación de estratégicos. En el Gráfico 4.1. se sintetiza las aportaciones principales a la orientación RBV.

A la hora de contrastar empíricamente el marco conceptual del enfoque de los recursos, la década de los noventa ha sido notablemente prolífica. Entre 
otros, es de destacar las aportaciones de Hall (1992), Henderson y Cockburn (1994), Miller y Shamsie (1996), Powell (1996), Maijoor y Witteloostuijn (1996) y Mehra (1996).

Tabla 4.1. Contribuciones a la perspectiva de los recursos.

\begin{tabular}{|c|c|c|}
\hline Año & Autores & Aportación \\
\hline 1958 & Penrose & $\begin{array}{l}\text { Los recursos de la empresa determinan su creci- } \\
\text { miento. }\end{array}$ \\
\hline 1984 & Wernerfelt & $\begin{array}{l}\text { Recursos controlados por la empresa: fuente de efi- } \\
\text { ciencia y ventaja competitiva. }\end{array}$ \\
\hline $\begin{array}{l}1986 \\
1991\end{array}$ & Barney & $\begin{array}{l}\text { Definición de recursos, relación con la ventaja com- } \\
\text { petitiva y análisis de los mecanismos que facilitan } \\
\text { la inmovilidad de los recursos. }\end{array}$ \\
\hline 1987 & Rumelt & $\begin{array}{l}\text { Importancia de los recursos en el desarrollo de la } \\
\text { estrategia. }\end{array}$ \\
\hline 1989 & Dierickx y Cool & $\begin{array}{l}\text { Los activos estratégicos son desarrollados interna- } \\
\text { mente, no se adquieren y se necesita un tiempo con- } \\
\text { siderable para su desarrollo. }\end{array}$ \\
\hline 1990 & Schoemaker & $\begin{array}{l}\text { Análisis de los factores que determinan el carácter } \\
\text { estratégico de los recursos. }\end{array}$ \\
\hline 1990 & Prahalad y Hamel & Recursos críticos: habilidades y tecnología. \\
\hline 1990 & Peteraf & $\begin{array}{l}\text { Identifica cuatro características fundamentales en } \\
\text { los recursos. }\end{array}$ \\
\hline 1991 & Grant & $\begin{array}{l}\text { Relación entre recursos, capacidades, ventaja com- } \\
\text { petitiva y estrategia. }\end{array}$ \\
\hline 1991 & Connor & $\begin{array}{l}\text { Estudio de los recursos que perduran en la empresa } \\
\text { y que son difíciles de imitar. }\end{array}$ \\
\hline 1993 & Amit y Schoemaker & Análisis de los procesos de desarrollo de recursos. \\
\hline 1994 & Kay & $\begin{array}{l}\text { Recursos estratégicos: habilidad innovadora, repu- } \\
\text { tación y red de relaciones. }\end{array}$ \\
\hline 1997 & $\begin{array}{l}\text { Teece, Pisano y } \\
\text { Shuen }\end{array}$ & Estudian la naturaleza cambiante de los recursos. \\
\hline
\end{tabular}

Fuente: Adaptado de Lynch, 2000. 


\section{La adopción del enfoque RBV como perspectiva dominante en la Economía de la Empresa}

Con el propósito de determinar el peso de la Teoría de los Recursos entre los investigadores, se procedió a realizar una revisión de los artículos divulgados en las principales publicaciones españolas en el ámbito de la Economía de la Empresa. Adicionalmente, se consultó la base de datos Teseo para tener referencia de las principales tesis doctorales elaboradas. Las revistas incluidas en este estudio se detallan en Tabla 4.2.

Tabla 4.2. Trabajos según fuente: 1992-2003.

\begin{tabular}{|l|c|}
\hline \multicolumn{1}{|c|}{ Fuente } & Artículos \\
\hline Cuadernos de Dirección y Economía de la Empresa. & 5 \\
\hline Cuadernos Aragoneses de Economía. & 4 \\
\hline Teseo. & 12 \\
\hline Boletín de Estudios Económicos. & 3 \\
\hline Revista Asturiana de Economía. & 2 \\
\hline Revista Europea de Dirección y Economía de la Empresa. & 12 \\
\hline Revista Española de Financiación y Contabilidad. & 1 \\
\hline Economía Industrial. & 4 \\
\hline Información Comercial Española. & 2 \\
\hline Papeles de Economía. & 3 \\
\hline Otros. & 10 \\
\hline
\end{tabular}

El relativamente amplio número de publicaciones generadas en España en torno al enfoque de los recursos, tal y como se puede observar en la Tabla 4.3. y en el Gráfico 4.1., no hace más que constatar la enorme influencia generada por esta perspectiva, tanto a nivel teórico como empírico, en el ámbito de la economía de la empresa. 
Tabla 4.3. Investigaciones RBV desglosadas por año de publicación.

\begin{tabular}{|c|c|c|}
\hline Año & Teórico & Empírico \\
\hline 1992 & Fernández (1992). & \\
\hline 1993 & Fernández (1993). & \\
\hline 1995 & Fernández (1995). & \\
\hline 1996 & $\begin{array}{l}\text { Fernández et al. (1996a). } \\
\text { López (1996). } \\
\text { Salas (1996). } \\
\text { Fernández y Suárez (1996). }\end{array}$ & $\begin{array}{l}\text { Montes (1996). } \\
\text { Fernández et al. (1996b). } \\
\text { De la Fuente y Suárez (1996). }\end{array}$ \\
\hline 1997 & $\begin{array}{l}\text { Fernández et al. (1997). } \\
\text { Camelo (1997). }\end{array}$ & Galán y Vecino (1997). \\
\hline 1998 & $\begin{array}{l}\text { Fernández et al. (1998). } \\
\text { Bueno (1998). } \\
\text { Durán (1998). } \\
\text { Medina (1998). }\end{array}$ & $\begin{array}{l}\text { Vicente (1998). } \\
\text { Tejedor y Aguirre (1998). } \\
\text { Sabater y Piñera (1998). }\end{array}$ \\
\hline 1999 & $\begin{array}{l}\text { López y Madrid (1999). } \\
\text { Suárez (1999). } \\
\text { Cuervo (1999). } \\
\text { Cañibano et al. (1999). }\end{array}$ & $\begin{array}{l}\text { Chiva y Camisón (1999). } \\
\text { Gómez (1999). } \\
\text { Camisón y Guía (1999). } \\
\text { Ordiz (1999). }\end{array}$ \\
\hline 2000 & $\begin{array}{l}\text { Morcillo et al. }(2000) . \\
\text { Claver et al. }(2000) . \\
\text { Vicente (2000b). } \\
\text { De Saá y García (2000). }\end{array}$ & $\begin{array}{l}\text { Camelo et al. (2000). } \\
\text { Carmona et al. }(2000) . \\
\text { Salmador (2000). } \\
\text { García y Santos (2000). } \\
\text { Claver, Molina y Quer. (2000). } \\
\text { Valenzuela (2000). } \\
\text { Vicente (2000a). }\end{array}$ \\
\hline 2001 & $\begin{array}{l}\text { Bruque y Vargas (2001). } \\
\text { Gutiérrez (2001). } \\
\text { Navas y Ortiz (2001). } \\
\text { Suárez y Vicente (2001). } \\
\text { Sánchez (2001). } \\
\text { Morcillo et al. (2001). }\end{array}$ & $\begin{array}{l}\text { Bruque (2001). } \\
\text { Castro (2001). } \\
\text { De Saá y García (2001). } \\
\text { López (2001). } \\
\text { Ordóñez (2001). } \\
\text { Pérez (2001). }\end{array}$ \\
\hline 2002 & & $\begin{array}{l}\text { Fernández (2002). } \\
\text { Bayo-Moriones y Merino-Díaz } \\
(2002) . \\
\text { Palacios (2002). } \\
\text { Sanz y Sabater (2002). }\end{array}$ \\
\hline 2003 & & $\begin{array}{l}\text { Bastida (2003). } \\
\text { Escrig (2003). }\end{array}$ \\
\hline
\end{tabular}




\section{Gráfico 4.1. EI RBV en España: trabajos teóricos versus investigaciones empíricas (1992-2003).}

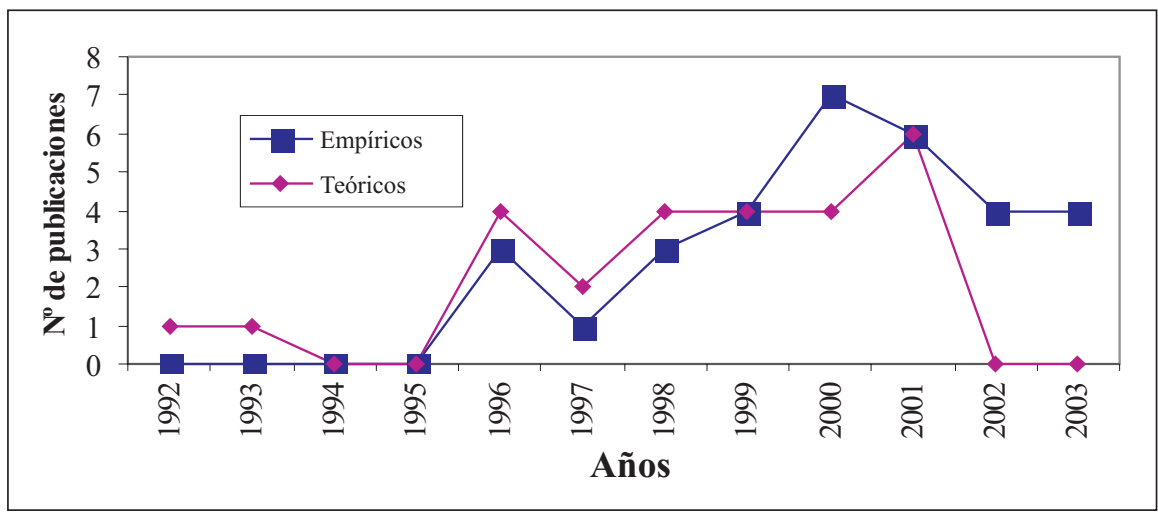

Uno de los primeros estudios que abordan la influencia de la perspectiva de los recursos entre los académicos españoles es el desarrollado por Gutiérrez (2001). En éste, se profundiza sobre la etiquetación de algunas teorías de la dirección de empresas (como puede ser el caso de la perspectiva RBV) como "simples modas académicas" que se emplean para la transmisión de los conocimientos. Igualmente, se comprueba el retraso de las publicaciones españolas frente al inicio de la difusión del enfoque de los recursos en el ámbito internacional (Gutiérrez, 2001; págs. 28-29). Este patrón de comportamiento no es atribuible exclusivamente a la perspectiva RBV, dado que también se manifiesta en la mayor parte de los temas objeto de investigación en el ámbito de la Economía de la Empresa en España.

El punto de referencia de la aparición de la perspectiva RBV en nuestro país, quizás tengamos que situarlo en el trabajo de Fernández (1992). A pesar de que en este estudio, el propósito fundamental es el análisis de la competitividad de la empresa española, no es menos cierto que es el nacimiento de una serie de investigaciones (Fernández, 1993; Salas, 1993; Fernández, 1995) que comienzan a debatir la importancia relativa del paradigma estructura-conducta-resultados como armazón conceptual capaz de explicar la variabilidad de rendimiento entre nuestras empresas. Los principales trabajos desarrollados en España desde el enfoque de los recursos se compendian en el Tabla 4.4.

Hasta 1996 no aparece el primer trabajo empírico (Montes, 1996) en el que se estudia la importancia del efecto industria versus efecto empresa, como factores explicativos de la variable dependiente rendimiento. Con posterioridad, en la investigación llevada a cabo por Galán y Vecino (1997), con una metodología muy similar al estudio anterior, se replica el experimento en una muestra ${ }^{1}$ configurada

1 Montes (1996) utiliza una muestra de 81 empresas ( 8 sectores de actividad) que cotizan en bolsa. Con posterioridad, Galán y Vecino (1997) utilizan una muestra de 1642 empresas andaluzas pertenecientes a 162 sectores (CNAE74). 
por empresas de un perfil sustancialmente diferente al utilizado por Montes (1996). El estudio de Claver, Molina y Quer (2000) utiliza igualmente modelos lineales generales (análisis de componentes de la varianza) en una muestra de 544 empresas alicantinas pertenecientes a 92 sectores de actividad. En los tres trabajos anteriormente señalados, las conclusiones principales son bastante similares: una mayor importancia de los aspectos internos de la empresa como factor explicativo del rendimiento organizativo. Adicionalmente, García y Santos (2000) continúan con la línea de investigación utilizada en los tres trabajos anteriores, estudiando la complementariedad de los efectos sector y empresa en una muestra de cajas de ahorros españolas. En sus conclusiones, estos investigadores afirman que a pesar del mayor peso de las condiciones idiosincrásicas de la empresa sobre el rendimiento organizativo, existe complementariedad entre el efecto empresa y el efecto industria dependiendo del intervalo de tiempo que se considere.

Tabla 4.4. Trabajos RBV agrupados por bloques temáticos.

\begin{tabular}{|c|c|c|c|c|}
\hline $\begin{array}{l}\text { Competitividad, } \\
\text { marco teórico, } \\
\text { validación teórico- } \\
\text { empírica y recursos } \\
\text { estratégicos }\end{array}$ & $\begin{array}{c}\text { Relación } \\
\text { con otras } \\
\text { perspectivas }\end{array}$ & $\begin{array}{l}\text { Recursos } \\
\text { humanos y otros } \\
\text { recursos } \\
\text { complementarios }\end{array}$ & Diversificación & $\begin{array}{c}\text { Internacionalización, } \\
\text { producción y } \\
\text { otros }\end{array}$ \\
\hline \multicolumn{5}{|c|}{ TEÓRICOS } \\
\hline $\begin{array}{l}\text { Fernández (1992). } \\
\text { Fernández (1993). } \\
\text { Fernández (1995). } \\
\text { López (1996). } \\
\text { Salas (1996). } \\
\text { Fernández y } \\
\text { Suárez (1996). } \\
\text { Fernández et al. } \\
\text { (1996a). } \\
\text { Fernández et al. } \\
\text { (1997). } \\
\text { Fernández et al. } \\
\text { (1998). }\end{array}$ & $\begin{array}{l}\text { Bueno } \\
(1998) . \\
\text { Medina } \\
(1998) . \\
\text { Cuervo } \\
(1999) . \\
\text { Morcillo et } \\
\text { al. (2000). } \\
\text { Morcillo et } \\
\text { al. (2001). }\end{array}$ & $\begin{array}{l}\text { De Saá y García } \\
(2000) \text {. }\end{array}$ & $\begin{array}{l}\text { Camelo (1997). } \\
\text { Suárez (1999). } \\
\text { Sánchez (2001). } \\
\text { Suárez y } \\
\text { Vicente (2001). }\end{array}$ & Durán (1998). \\
\hline $\begin{array}{l}\text { Cañibano et al. } \\
\text { (1999). } \\
\text { López y Madrid } \\
\text { (1999). } \\
\text { Vicente (2000b). } \\
\text { Bruque y Vargas } \\
\text { (2001). } \\
\text { Navas y Ortiz } \\
\text { (2001). } \\
\text { Gutiérrez (2001). }\end{array}$ & & & & \\
\hline
\end{tabular}


Tabla 4.4. Trabajos RBV agrupados por bloques temáticos. (Cont.)

\begin{tabular}{|c|c|c|c|c|}
\hline $\begin{array}{l}\text { Competitividad, } \\
\text { marco teórico, } \\
\text { validación teórico- } \\
\text { empírica y recursos } \\
\text { estratégicos }\end{array}$ & $\begin{array}{c}\text { Relación } \\
\text { con otras } \\
\text { perspectivas }\end{array}$ & $\begin{array}{c}\text { Recursos } \\
\text { humanos y otros } \\
\text { recursos } \\
\text { complementarios }\end{array}$ & Diversificación & $\begin{array}{c}\text { Internacionalización, } \\
\text { producción y } \\
\text { otros }\end{array}$ \\
\hline \multicolumn{5}{|c|}{ EMPÍRICOS } \\
\hline $\begin{array}{l}\text { Montes (1996). } \\
\text { Galán y Vecino } \\
\text { (1997). } \\
\text { Fernández et al. } \\
\text { (1996b). } \\
\text { Vicente (1998). } \\
\text { Camisón y Guía } \\
\text { (1999). } \\
\text { Sabater y Piñera } \\
\text { (1998). } \\
\text { Camelo et al. } \\
\text { (2000). } \\
\text { Claver et al. } \\
\text { (2000). } \\
\text { García y Santos } \\
\text { (2000). } \\
\text { Claver, Molina y } \\
\text { Quer. (2000). } \\
\text { Vicente (2000a). } \\
\text { Salmador (2000). } \\
\text { López (2001). }\end{array}$ & $\begin{array}{l}\text { Tejedor y } \\
\text { Aguirre } \\
\text { (1998). } \\
\text { Chiva y } \\
\text { Camisón } \\
\text { (1999). } \\
\text { Castro } \\
\text { (2001). } \\
\text { Ordóñez } \\
\text { (2001). } \\
\text { Pérez } \\
\text { (2001). } \\
\text { Palacios } \\
\text { (2002). } \\
\text { Escrig } \\
\text { (2003). }\end{array}$ & $\begin{array}{l}\text { Bruque (2001). } \\
\text { Ordiz (1999). } \\
\text { Carmona et al. } \\
(2000) \text {. } \\
\text { De Saá y García } \\
\text { (2001). } \\
\text { Bayo-Moriones } \\
\text { y Merino-Díaz } \\
\text { (2002). } \\
\text { Sanz y Sabater } \\
(2002) \text {. }\end{array}$ & $\begin{array}{l}\text { Forcadell } \\
\text { (2003). }\end{array}$ & $\begin{array}{l}\text { De la Fuente y } \\
\text { Suárez (1996). } \\
\text { Gómez (1999). } \\
\text { Valenzuela (2000). } \\
\text { Fernández (2002). } \\
\text { Bastida (2003). } \\
\text { Urgal (2003). }\end{array}$ \\
\hline
\end{tabular}

Otro grupo de autores, se preocupó de analizar el armazón conceptual del enfoque, comparándolo con otras perspectivas. Fernández y Suárez (1996) realizaron la primera síntesis conceptual de la perspectiva y una recopilación de las principales aportaciones teóricas y empíricas vinculadas al enfoque RBV, trabajo que, posteriormente, es complementado por Fernández et al. (1997), Cuervo (1999) y por Morcillo et al. (2001), que analizan la relación de la perspectiva RBV con diferentes orientaciones de pensamiento estratégico, en especial con las escuelas descriptivas sugeridas por Mintzberg. Los problemas asociados a la validación teórico-empírica de los postulados del enfoque de los recursos son abordados por Vicente (2000a, 2000b) y por Bruque y Vargas (2001).

En la investigación de Medina (1998) se analizan las similitudes y diferencias entre el enfoque de los recursos, la perspectiva del aprendizaje y la gestión del conocimiento. La relación gestión del conocimiento y Capital Intelectual, desde una punto de vista teórico, ha sido abordada por Bueno (1998) y por Navas y Ortiz (2001). Estos dos trabajos son complementados con diferentes estudios empíricos como los de Tejedor y Aguirre (1998), analizando la capacidad de aprendizaje de 
la empresa española en una muestra de 222 organizaciones; Salmador (2000), trabajo en el que se estudia la relación entre creación de conocimiento y el proceso estratégico en la banca por Internet en España; Castro (2001), evaluando las fusiones y adquisiciones del sector farmacéutico español como un medio para la renovación de las capacidades y el conocimiento en la empresa; López (2001), contrastando, en una muestra de empresas gallegas, la influencia que las percepciones directivas sobre un grupo de recursos intangibles (reputación de la empresa, reputación del producto, Capital Humano y cultura organizativa) pueden ejercer sobre el rendimiento empresarial; Pérez (2001), que contrasta, en 195 empresas españolas de más de 200 trabajadores, las relaciones causales entre aprendizaje organizativo, variables organizativas internas, implementación de prácticas de gestión del conocimiento y rendimiento organizativo; Palacios (2002), evaluando, en las industrias biotecnológicas y de telecomunicaciones, la relación entre gestión del conocimiento, generación de competencias y resultado de la organización; Escrig (2003), que estudia, en una muestra de 231 empresas industriales y de servicios, la interdependencia de la dirección de calidad, el desarrollo de competencias distintivas y su influencia sobre el rendimiento organizativo.

Como consecuencia del desarrollo de la perspectiva de los recursos, principalmente en la década de los noventa, los Recursos Humanos empiezan a ser considerados como recursos estratégicos, es decir, con capacidad para generar ventajas competitivas y por lo tanto influir en los resultados organizativos (Lado y Wilson, 1994). El trabajo de Saá y García (2000), en línea con esta corriente, evalúa el potencial estratégico de los Recursos Humanos y su capacidad de influir en la competitividad empresarial. Entre las investigaciones de Recursos Humanos con una orientación empírica destacamos las de Ordiz (1999), en el que se estudia el papel desempeñado por la gestión de los Recursos Humanos (actuando individualmente) en el desarrollo de ventajas competitivas o, si por el contrario es una variable que tiene capacidad de influencia si se considera de forma conjunta con otras variables estratégicas; Carmona, Céspedes y Jérez (2000) analizan el rol ejercido por la función de Recursos Humanos en el desarrollo de capacidades estratégicas, además de estudiar la interacción con otros recursos complementarios como las Tecnologías de la Información; el trabajo de Bruque (2000) contrasta las relaciones entre los recursos intangibles humanos y su complementariedad con otro recurso estratégico, las Tecnologías de la Información, en el sector de la distribución farmacéutica en España; De Saá y García (2001) evalúan, en el sector de las cajas de ahorros españolas, si las decisiones de gestión de Recursos Humanos, siempre y cuando estén integradas en un sistema de Recursos Humanos, poseen capacidad de influir en el rendimiento empresarial y en el desarrollo de capacidades organizativas; la investigación de Sanz y Sabater (2002), contrasta, en el sector de maquinaria y componentes de automoción, si la utilización de prácticas de Recursos Humanos denominadas universalistas influyen de forma positiva en el rendimiento organizativo, además de estudiar si su efecto es mayor cuando se implementan de forma conjunta constituyendo un sistema homogéneo; Bayo-Moriones y Merino-Díaz (2002) estudian en qué medida 
la adopción, por parte de la empresa, de prácticas de Recursos Humanos denominadas de alto rendimiento influye en el rendimiento operativo de las organizaciones, contrastando, además, su efecto contingente con la estrategia seguida por la empresa, en el sector de la industria manufacturera española.

La perspectiva de los recursos también ha mostrado poder explicativo en las decisiones de diversificación de mercados (Farjoum, 1994) o, igualmente, en las estrategias de internacionalización de la empresa (Collis, 1991). El trabajo de Camelo (1997) analiza la diversificación interna, evaluando las motivaciones de las empresas que adoptan esta opción estratégica y concretando los factores que permiten a la organización implementarla con ciertas garantías de éxito. Posteriormente, Suárez (1999) y Suárez y Vicente (2001) complementan el estudio teórico de la estrategia de diversificación y, el trabajo de Sánchez (2001) profundiza en la relación entre diversificación y la creación de valor en la empresa. De la Fuente y Suárez (1996) publican uno de los primeros estudios empíricos españoles sobre la estrategia de internacionalización del sector bancario y la estructura de recursos más apropiada para la implantación en mercados internacionales. Durán (1998) contempla la internacionalización de los capitales propios de la empresa como una fuente generadora de recursos y capacidades. Tomando como referencia la base de datos de empresas exportadoras del Instituto de Comercio Exterior, Valenzuela (2000) propone y contrasta un modelo teórico, en el que el grado de internacionalización de las organizaciones españolas es desarrollado como consecuencia del acopio de recursos que potencian la creación de capacidades exportadoras. También, bajo el enfoque de los recursos se ha considerado a la capacidad directiva internacional como un activo estratégico de primer orden y ha pasado a constituir una de las escasas fuentes verosímiles de ventajas competitivas sostenibles. Siguiendo esta línea de investigación, Bastida (2003) contrasta en una muestra de directivos expatriados de organizaciones con domicilio social en la Comunidad Autónoma Gallega, aquellos factores que, al menos de forma parcial, contribuyen a facilitar el ajuste del expatriado y, en consecuencia, su rendimiento.

\section{Conclusiones}

En una primera aproximación a las publicaciones anteriormente señaladas, se observa que, tanto en el ámbito teórico como empírico, los investigadores españoles en el ámbito de la Economía de la Empresa tampoco han sido ajenos a las elevadas expectativas generadas, fundamentalmente en las publicaciones anglosajonas, por la teoría de los recursos y las capacidades de la firma. Una prueba fehaciente de esta afirmación, es que la revisión bibliográfica desarrollada en este trabajo identificó un total de 59 investigaciones, 27 teóricas y 32 empíricas, en un período relativamente corto de tiempo (aproximadamente 10 años) ${ }^{2}$.

2 A pesar de haber considerado en revisión la bibliográfica el intervalo de tiempo 1992-2003, algunos de los trabajos que podrían aparecer referenciados en el 2003, todavía no tenemos constancia de su aparición debido a que algunas revistas a pesar de ser publicaciones del 2003, no aparecen editadas "físicamente" hasta el año siguiente. Por lo tanto, la revisión de trabajos tendrá que ser completada en el 2004. 
El estudio del efecto empresa versus efecto sector, es el origen de los trabajos empíricos en España, el cual reproduce fielmente el patrón seguido en las publicaciones anglosajonas, con la salvedad de un retardo de cinco años, si se toma como punto de referencia el trabajo pionero de Richard Rumelt en 1991.

La diversidad de temas analizados por los investigadores españoles, utilizando este enfoque teórico es igualmente amplia si lo comparamos, por ejemplo, con la revisión bibliográfica de publicaciones en inglés efectuada por Fernández y Suárez (1996), entre otros: fuentes de ventajas competitivas, síntesis conceptual de la perspectiva, efecto empresa-sector-país, validación teórica del enfoque, relación con otras perspectivas (fundamentalmente con el conocimiento y el aprendizaje), diversificación, Recursos Humanos, internacionalización y expatriación de directivos, etc.

\section{Bibliografía}

- AAKER, D. A. (1989): "Managing assets and skills. The key to a sustainable competitive advantage". California Management Review, vol. 31, n. 2, págs. 91-106.

- AMIT, R.; SCHOEMAKER,P. J.H.(1993): "Strategic assets and organizational rent”. Strategic Management Journal, vol. 14, pp. 33-46.

- BARNEY, J. B. (1991): "Firm resources and sustained competitive advantage". Journal of Management, vol. 17, nº 1, págs. 99-120.

- BASTIDA, M. (2003): Asignaciones internacionales. Causas y consecuencias del ajuste del expatriado. Tesis doctoral no publicada. Universidad de Santiago de Compostela.

- BAYO-MORIONES, A.; MERINO-DÍAZ, J. (2002): "Human Resource Management, Strategy and Operational Performance in the Spanish Manufacturing Industry”.M@n@gement, vol. 5,no 3, págs. 175-199.

- BRUQUE, S. J. (2001): Ventaja competitiva, Tecnologías de la Información y factores humanos y de gestión. Jaén: Servicio de publicaciones de la Universidad de Jaén.

- BRUQUE, S. J.; VARGAS, A. (2001): "El problema de la validación empírica de la Teoría de los Recursos y Capacidades. Síntesis y propuesta metodológica". En Publicación homenaje al Prof. Dr. Manuel Ortigueira Bouzada. Editorial@Tres, Sevilla.

- BUENO, E. (1998): "El capital intangible como clave estratégica en la competencia actual”, Boletín de Estudios Económicos, vol. LIII, n 164, págs. 207-229.

- CAMElO, C. M.; MARTÍN, F.; VALLE, R. (2000): “Capacidades intangibles y orientación estratégica en las empresas españolas". Revista Asturiana de Economía, nº 19, págs. 181-203. 
- CAMELO, M. C. (1997): La estrategia de diversificación interna desde la teoría basada en el conocimiento de las empresas. Tesis doctoral no publicada. Universidad de Cádiz.

- CAMISÓN, C.; GUÍA, J. (1999): "Relaciones verticales y resultados: estudio empírico de la eficiencia comparativa de la integración vertical versus descentralización productiva". Revista Europea de Dirección y Economía de la Empresa, vol. 8, $\mathrm{n}^{\circ}$ 2, págs. 101-126.

- CAÑIBANO, L.; GARCÍA-AYUSO, M.; SÁNCHEZ, P. (1999): "La relevancia de los intangibles para la valoración y la gestión de empresas: revisión de la literatura". Revista Española de Financiación y Contabilidad, nº 100, págs. 17-88.

- CARMONA, E.; CÉSPEDES, J. J.; JÉREZ, P. (2000): “El papel de los Recursos Humanos en el desarrollo de capacidades estratégicas. Una evidencia empírica". Revista Europea de Dirección y Economía de la Empresa, vol. 9, $\mathrm{n}^{\circ}$ 2, págs. 117-130.

- CASTRO, M.C. (2001): Transferencia de conocimiento en fusiones y adquisiciones de empresas. Tesis doctoral no publicada. Universidad de Santiago de Compostela.

- CHIVA, R.; CAMISÓN, C. (1999): "Estilos de aprendizaje, valores organizativos y competitividad en el sector cerámico: un estudio de casos". Revista Europea de Dirección y Economía de la Empresa, vol. 8, nº 1, págs. 41-62.

- CLAVER, E.; LlOPIS, J.; MOLINA, H.; CONCA, F.; MOLINA, J. (2000): "La tecnología como factor de competitividad: un análisis a través de la teoría de recursos y capacidades". Boletín de Estudios Económicos, vol. LV, n $\mathrm{n}^{\mathrm{o}}$ 169, Abril, págs. 119-138.

- CLAVER, E.; MOLINA, J.; QUER, D. (2000): "Incidencia comparada del efecto empresa y el efecto sector en la rentabilidad económica. Aplicación a una muestra de empresas de Alicante 1994-1998”. Economía Industrial, ${ }^{\circ}$ 334, IV, págs. 143- 152.

- CUERVO, A. (1999): "La dirección estratégica de la empresa. Reflexiones desde la Economía de la Empresa". Papeles de Economía Española, $\mathrm{n}^{\circ}$ 78-79, págs. 34-55.

- DE LA FUENTE, J.; SUÁREZ, I. (1996): "Estructura de recursos e internacionalización de la empresa bancaria española". Revista Asturiana de Economía, $\mathrm{n}^{\mathrm{o}}$ 5, págs. 93-114.

- DE SAÁ, P.; GARCÍA, J. M. (2000): "El valor de los Recursos Humanos según la visión de la empresa basada en los recursos". Revista Europea de Dirección y Economía de la Empresa, vol. 9, nº 2, págs. 95-114.

- DE SAÁ, P.; GARCÍA, J. (2001): "El sistema de Recursos Humanos y el desarrollo de capacidades organizativas: una aplicación empírica en el sector de las cajas de ahorros españolas". Cuadernos de Economía y Dirección de la Empresa, $\mathrm{n}^{\circ}$ 8, enero-abril, págs. 109-136. 
- DURÁN, J. (1998): "La internacionalización de los capitales propios de la empresa como fuente de recursos y capacidades". Cuadernos de Economía y Dirección de la Empresa, $\mathrm{n}^{\mathrm{o}}$ 1, enero-junio, págs. 5-29.

- ESCRIG, A. B. (2003): "Un análisis empírico de las relaciones entre la dirección de la calidad las competencias distintivas y distintos tipos de resultados". Estudios Financieros, $n^{\circ} 244$, págs. 111-184.

- FARJOUM, M. (1994): "Beyond Industry Boundaries: Human Expertise, Diversification and Resource-Related Industry Groups". Organization Science, vol 5, nº 2, págs. 185-199.

- FERNÁNDEZ, E.; MONTES, J.; VÁZQUEZ, C. (1996a): "Efecto industria y conducta empresarial". Revista Europea de Dirección y Economía de la Empresa, vol. $5, \mathrm{n}^{\circ} 2$, págs. 149-158.

- FERNÁNDEZ, E.; MONTES, J.; VÁZQUEZ, C. (1996b): "Factores de competitividad en la pequeña y mediana empresa: inversión en activos intangibles, tamaño y límite al crecimiento". Economía Industrial, no 310, IV, págs. 141-148.

- FERNÁNDEZ, E.; MONTES, J.; VÁZQUEZ, C. (1997): "La teoría de la ventaja competitiva basada en los recursos: síntesis y estructura conceptual". Revista Europea de Dirección y Economía de la Empresa, vol. 6, nº 3, págs. 11-32.

- FERNÁNDEZ, E.; MONTES, J.; VÁZQUEZ, C. (1998): "Los recursos intangibles como factores de competitividad de la empresa". Cepade, Septiembre, págs. 83-98.

- FERNÁNDEZ, P. (2002): Aspectos de comunicación asociados al rendimiento de los procesos de desarrollo de nuevos productos. Tesis doctoral no publicada. Universidad de Santiago de Compostela.

- FERNÁNDEZ, Z. (1992): "Algunas reflexiones sobre la competitividad empresarial y sus causas”. Información Comercial Española, nº 705, págs. 139-152.

- FERNÁNDEZ, Z. (1993): "La organización interna como ventaja competitiva para la empresa”. Papeles de Economía, no 56, págs. 178-193.

- FERNÁNDEZ, Z. (1995): "Las bases internas de la competitividad de la empresa". Revista Europea de Dirección y Economía de la Empresa, vol. 4, nº 2, págs. 11-20.

- FERNÁNDEZ, Z; SUÁREZ, I. (1996): "La estrategia de la empresa desde una perspectiva basada en los recursos". Revista Europea de Dirección y Economía de la Empresa, vol. 5, n 3, págs. 73-92.

- GALÁN, J. L.; VECINO, J. (1997): "Las fuentes de rentabilidad de las empresas". Revista Europea de Dirección y Economía de la Empresa, vol. 6, n 1, págs. 21-36.

- GARCÍA, M. T.; SANTOS, M. V. (2000): "Análisis de la complementariedad de los efectos sector y empresa. Evidencia empírica para las cajas de ahorro en España". Investigaciones Europeas de Dirección y Economía de la Empresa, vol. $6, \mathrm{n}^{\circ} 1$, págs. 101-116. 
- GÓMEZ, M. (1999): "Teoría de los recursos y estrategia de marketing: aplicación al sector bancario español". Cepade, vol. 21, enero, págs. 83-93.

- GRANT, R. M. (1991): "The resource-based theory of competitive advantage". California Management Review, Spring, págs. 114-135.

- GUTIÉRREZ, I. (2001): "Modas de investigación en dirección de empresas: pioneros y seguidores". Cuadernos Aragoneses de Economía, vol. 11, nº 1, págs. 15-34.

- HALL, R. (1992): “The strategic analysis of intangible resources". Strategic Management Journal, vol. 13, págs. 135-144.

- ITAMI, H. (1987): Mobilizing invisible assets. Harvard University Press, Boston.

- LADO, A.; WILSON, M. (1994): "Human resource systems and sustained competitive advantage: a contingency-based perspective". Academy of Management Review, vol. 19, nº 4, págs. 699-727.

- LÓPEZ, J. (1996): "Los recursos intangibles en la competitividad de la empresa. Un análisis desde la teoría de los recursos". Economía Industrial, n 307, I, págs. 25-35.

- LÓPEZ, V. A. (2001): El potencial estratégico: recursos e intangibilidades. Tesis doctoral no publicada. Universidad de Santiago de Compostela.

- LÓPEZ, J. A.; MADRID, M. F. (1999): "El desarrollo de la dotación de recursos y capacidades de la empresa”. ESIC MARKET, n 102, págs. 78-96.

- LYNCH, R. (2000): Corporate Strategy. Prentice-Hall, Essex (England).

- MEDINA, D. R. (1998): "Una visión integral de la empresa basada en los recursos, el conocimiento y el aprendizaje". Investigaciones Europeas de Dirección y Economía de la Empresa, vol. 4, nº 2, págs. 77-90.

- MONTES, J. M. (1996): Importancia relativa y significación de los factores empresariales de competitividad. Tesis doctoral no publicada. Universidad de Oviedo.

- MORCILLO, P.; RODRÍGUEZ, J.; CASANI, F.; RODRÍGUEZ, J. (2000): “El valor de los conocimientos y del aprendizaje como fuente de ventajas competitivas básicas distintivas”. Dirección y Organización, n 24, págs. 12-20.

- MORCILlO, P.; RODRÍGUEZ, J. M.; CASANI, F.; RODRÍGUEZ, J. (2001): "La teoría de recursos y capacidades: un cruce de caminos". Cuadernos Aragoneses de Economía, vol. 11, nº 1, págs. 49-65.

- NAVAS, J. E.; ORTIZ DE URBINA, M. (2001): "Gestión del conocimiento y Capital Intelectual: algunos aspectos conceptuales". Cuadernos Aragoneses de Economía, vol. 11, n 1 1, págs. 35-48.

- ORDIZ, M. (1999): Gestión estratégica de los Recursos Humanos en la empresa española; un enfoque basdo en la teoría de recursos y capacidades. Tesis doctoral no publicada. Universidad de Oviedo. 
- ORDÓÑEZ, P. (2001): Capital intelectual, gestión del conocimiento y sistemas de gestión de Recursos Humanos: influencia sobre los resultados organizativos. Tesis doctoral no publicada. Universidad de Oviedo.

- PALACIOS, D. (2002): La creación de competencias distintivas dinámicas mediante la gestión del conocimiento y su efecto sobre el desempeño. Análisis empírico en las industrias de biotecnología y telecomunicaciones. Tesis doctoral no publicada. Universidad Jaume I de Castellón.

- PENROSE, E. T. (1962): Teoría del crecimiento de la empresa. Madrid: Aguilar.

- PÉREZ, S. (2001): El aprendizaje organizativo como factor de competitividad en la empresa española. Implicaciones para la gestión del conocimiento. Tesis doctoral no publicada. Universidad de Oviedo.

- PETERAF, M. A. (1993): "Cornestones of competitive advantage: a resource based view”. Strategic Management Journal, no 14, págs. 179-192.

- PORTER, M. (1985): Competitive Advantage: Creating and Sustaining Superior Performance. Free Press. New York.

- RUMELT, R. P. (1991): "How much does industry matter?". Strategic Management Journal, vol. 12, págs. 167-185.

- SABATER, R.; PIÑERA, J. (1998): "Las capacidades empresariales: medición y características. Una evidencia empírica". Acede VIII, Las Palmas, http://www.fcee.ulpgc.es/Acede98/acede/posters/poster02.htm.

- SALAS, V. (1996): "Economía y gestión de los activos intangibles". Economía Industrial, $\mathrm{n}^{\circ}$ 307, I, págs. 17-24.

- SALAS, V. (2000): "La cultura en las organizaciones". Cuadernos de Economía y Dirección de la Empresa, nº 7, septiembre-diciembre, págs. 341-364.

- SALMADOR, M. P. (2000): El proceso de formación de la estrategia de la banca por Internet en España: enfoques de creación del conocimiento y dimensiones de la complejidad. Tesis doctoral no publicada. Universidad Autónoma de Madrid.

- SÁNCHEZ, L. (2001): "Diversificación y creación de valor desde una perspectiva de recursos". Revista Europea de Dirección y Economía de la Empre$s a$, vol. 10, $\mathrm{n}^{\mathrm{o}} 3$, págs. 41-56.

- SANZ, R.; SABATER, R. (2002): "Enfoque universalista de Recursos Humanos. Estudio empírico de sus efectos sobre los resultados de la empresa". Revista Europea de Dirección y Economía de la Empresa, vol. 11, nº 1, págs.163-182.

- SUÁREZ, I. (1999): "El análisis del crecimiento de la empresa desde la dirección estratégica”. Papeles de Economía Española, no 78-79, págs. 78-100.

- SUÁREZ, I.; y VICENTE, J. D. (2001): "Decisiones de diversificación y reestructuración: reflexiones desde el enfoque de recursos". Cuadernos Aragoneses de Economía, vol. 11, nº 1, págs. 67-89. 
- TAMPOE, M. A. (1994): "Exploiting the core competences of your organization”. Long Range Planning, vol. 27, August, págs. 66-77.

- TEJEDOR, B.; AGUIRRE, A. (1998): "Proyecto Logos: investigación relativa a la capacidad de aprender de las empresas españolas”. Boletín de Estudios Económicos, vol. LIII, no 164, págs. 231-249.

- URGAL, B. (2003): Análisis Estratégico de las Decisiones de Producción desde la Perspectiva de la Teoría de los Recursos. Una Aplicación en el Sector del Metal en España. Tesis doctoral no publicada. Universidad de Vigo.

- VALENZUELA, A. (2000): "Modelo de capacidades para la internacionalización de la empresa exportadora española”. Cuadernos de Economía y Dirección de la Empresa, nº 5, enero-abril, págs. 91-109.

- VICENTE, J. (2000a): "Implicaciones financieras de la estrategia basada en recursos: especificidad, opacidad y estructura de capital". Cuadernos de Economía y Dirección de la Empresa, n 5, enero-abril, págs. 67-90.

- VICENTE, J. D. (2000b): "Hacia una teoría de la estrategia basada en recursos: implicaciones contrastables de una propuesta teórica". Revista Europea de Dirección y Economía de la Empresa, vol. 9, nº 2, págs. 19-40.

- WERNEFELT, B. (1984): "A resource-based view of the firm". Strategic Management Journal, vol. 5, págs. 171-180. 



\title{
5
}

\section{Una apuesta por la creación de Capital Intelectual: La Escuela de Negocios Caixanova}

\author{
Eduardo García Erquiaga
}

Director de la Escuela de Negocios Caixanova 



\section{Introducción}

En el año 1987 se inicia en Vigo un proyecto destinado a apoyar la competitividad de nuestras empresas a través de la formación. Caixanova (entonces Caixavigo) decide crear una Escuela de Negocios en Galicia, y lo hace con una misión: contribuir a la mejora de la competitividad de las empresas gallegas a través de la formación de sus directivos.

El inicio de esta aventura entonces pudo ser interpretado por algunos como un proyecto puntual destinado a acercar la mastermanía de los años 80 a los universitarios gallegos. Sin embargo, esta iniciativa era mucho más que apuntarse a una moda, ya que se trataba del primer paso de un proyecto de largo alcance realmente comprometido con el desarrollo económico y empresarial de Galicia. La puesta en marcha de la Escuela de Negocios no era una idea más (de mayor o menor relevancia o interés social). Se trataba de redoblar una apuesta, de profundizar en la filosofía que desde Caixanova había hecho de la formación el eje conductor de su Obra Social.

\section{Los antecedentes}

En efecto, desde sus comienzos en la Dirección General de la entidad, Julio Fernández Gayoso ha sido siempre un convencido del poder de la formación para cambiar Galicia. Antes del inicio de las actividades de la Escuela de Negocios y bajo su dirección, Caixavigo había desarrollado múltiples actividades en el campo formativo, abarcando muy distintos niveles y siempre con el objetivo puesto en lograr mejores empresas y una ciudadanía mejor formada.

La creación del Colegio Hogar San Roque fue, sin duda, un elemento esencial para formar profesionales y técnicos, y ha sido y sigue siendo clave para dotar de mano de obra cualificada a nuestras empresas y muy especialmente a lo que hoy son los clusters del sector naval o de la automoción, estratégicos para el desarrollo económico de Galicia.

A esa apuesta por la formación profesional le siguió la creación de lo que hoy es la Universidad de Vigo. La puesta en marcha del Colegio Universitario de Vigo (CUVI) posibilitó el nacimiento de la Universidad y con ella un escenario formativo de primer nivel para los ciudadanos del sur de Galicia. Y fue posible gracias a un esfuerzo titánico por parte de Caixanova, cuya obra social cargaba con el coste del profesorado y personal de todo el proyecto. Muchos años después podemos afirmar que la Universidad de Vigo existe hoy en día gracias a aquella apuesta.

En este marco y con estos antecedentes en la primavera del 87 se anuncia el arranque del proyecto, un proyecto que antes de la creación de la Escuela de $\mathrm{Ne}$ gocios Caixanova ya se había iniciado desde la propia Caja a través de su Servicio de Asesoramiento y Desarrollo Empresarial (SADE) que desarrollaba cursos específicos para gerentes y empresarios vigueses. Y es que a la vocación por la formación de la entonces Caixavigo hay que añadir su decidida orientación a la 
empresa. De hecho la caja viguesa siempre apostó por un modelo implicado con el desarrollo local y la apuesta por el apoyo a la empresa, lo que se plasmaba en un ratio de financiación a las empresas muy superior al de la media de las cajas españolas, cuyos créditos se destinaban fundamentalmente a los particulares. Se puede hablar de un modelo de entidad financiera muy volcada en lo social y en el apoyo al desarrollo, lejos de la tentación que supone un modelo volcado en el interbancario y la rentabilidad a corto plazo.

La creación de la Escuela de Negocios marca una apuesta por el desarrollo del Capital Intelectual en Galicia, y pone en marcha un mecanismo de gran valor para la creación, gestión y difusión del conocimiento. Hoy en día parece que todos los males empresariales se resuelven con la gestión del conocimiento y la creación de Capital Intelectual, y sin embargo su empleo masivo está devaluando estos conceptos y cada vez más se utilizan como un mero elemento de marketing institucional. Por ello, más allá de estas consideraciones, debemos preguntarnos cuál es el impacto real de aportaciones concretas a la mejora del Capital Intelectual y la creación y difusión de conocimiento en el campo de la dirección. Debemos valorar cuál es la incidencia real de iniciativas como la creación de una escuela de negocios en el desarrollo de nuestras empresas. Para ello acudiremos a algunos de los estudios más relevantes sobre competitividad empresarial.

\section{Capital Intelectual y desarrollo empresarial}

¿De qué depende la competitividad de una empresa?, ¿de la tecnología?, ¿del dinero?, ¿de la información?, ¿de los recursos?, ¿de las estructuras? La búsqueda de los factores clave del éxito empresarial es la búsqueda de la piedra filosofal en la que se empeñan todos los gurús con éxito desigual. ¿Es la mejor empresa la que cuenta con más dinero?, ¿la mejor universidad la que tiene más y mejores edificios?, ¿el mejor equipo el que cuenta con los jugadores más cotizados? Los recursos, la tecnología o la financiación son aspectos importantes para explicar el éxito empresarial. Pero un proyecto que quiera contribuir al desarrollo empresarial debe orientarse a los factores básicos que, como veremos, van más allá de estas cuestiones.

Para entender la influencia que puede llegar a tener un proyecto ambicioso de formación de directivos en el desarrollo económico es interesante observar las más recientes investigaciones que a nivel mundial se están desarrollando sobre la competitividad empresarial. Al hilo de esta cuestión conviene citar dos trabajos que nos hacen ver la importancia de contar con buenos líderes para lograr empresas competitivas.

What really works es un reciente estudio desarrollado en Harvard (Joyce, Noria y Roberson, 2004) que aporta claves de interés sobre esos factores de éxito y, lo que es más importante, nos permite detectar con mayor claridad qué es lo que no funciona, aquellas técnicas y estrategias que, pese a las modas y al marketing, no tienen una incidencia real en la competitividad de nuestras organizaciones. 
Este amplio trabajo de investigación ha observado cientos de empresas americanas durante un período de diez años, y se ha basado en un riguroso análisis estadístico. Abarcando múltiples áreas y variables, sus autores han analizado las relaciones entre los recursos y métodos de gestión de estas empresas y los resultados que obtuvieron durante una década.

De este modo este proyecto de investigación, además de detectar los factores clave de la competitividad, destapa esas prácticas que no funcionan, que no marcan la diferencia. Y en este apartado encontraremos muchas de las fórmulas mágicas en uso.

En efecto, no marca la diferencia poseer un fantástico sistema de información, ni la cantidad monetaria invertida en tecnología, ni los programas de gestión del cambio, ni el empleo de las técnicas suply-chain management, ni el corporate governance, ni el fichaje de directivos "galácticos".

El impacto en los resultados de todos estos elementos ha sido rigurosamente analizado por Joyce, Noria y Roberson y los resultados han sido concluyentes: no explican la competitividad de las empresas ganadoras. No guardan relación con sus mejores resultados durante el largo período de diez años en los que se centra la investigación.

Más allá de las modas en el management se impone la prudencia y el sentido común, y parece obvio que el buen ejercicio del liderazgo tiene mucho más que ver con los resultados empresariales que el dinero, la tecnología o los programas de gestión de cambio. Ilustra esta realidad una anécdota un tanto peculiar. Sucedió en el Vaticano. Cuando el Papa Juan XXIII asumió el pontificado, en una de las muchas entrevistas que concedió a un joven periodista le preguntó: “¿Santidad, cuántas personas trabajan en el Vaticano?" a lo que el pontífice, con fina ironía, respondió: "Aproximadamente la mitad."

Las aportaciones de este amplio trabajo nos reconcilian con la prudencia y el sentido común más allá de las modas y nos hacen ver la importancia de un liderazgo efectivo y de la capacitación de los directivos como factor de éxito empresarial. Estos son los principales factores de competitividad (los que funcionan para el logro de buenos resultados sostenidos en el tiempo):

- Una estrategia clara y enfocada al cliente.

- El énfasis en la acción.

- Una cultura orientada a los resultados.

- La construcción de una organización sencilla.

A estos factores el trabajo de Joyce, Noria y Roberson añade dos consideraciones con una gran trascendencia para entender la importancia y el enfoque de la formación directiva.

- Según el estudio queda demostrado que el 15\% de la varianza de los resultados empresariales se explica por el liderazgo comprometido con la dirección. 
- Destaca como factor vital la capacidad para conservar a los buenos empleados y promover a aquellos que atesoran el talento.

En definitiva, la más reciente y completa de las investigaciones sobre el éxito empresarial y sus factores determinantes nos muestra con claridad que, más allá de modas, inversiones y modernas recetas de gestión los resultados vienen de la mano de la calidad directiva. Dependen, esencialmente, de lograr que "todos trabajen en el Vaticano", y de lograr que las cosas se hagan.

Este estudio de 2004 nos hace ver la importancia de las variables "soft". Antepone la formación de las personas a contar con recursos y tecnología en el desarrollo empresarial. Un equipo orientado al rendimiento, una organización sencilla y bien construida, una estrategia orientada al cliente son todas variables que dependen de la calidad directiva, de las competencias de los directivos, de las personas de la organización.

Cuatro años antes, en el 2000, un conocido investigador canadiense (Julien, P. A., 2000) puso de relieve la importancia de saber ejercer el liderazgo para explicar el desarrollo de las organizaciones, y lo hacía analizando el mundo mucho más cercano a nosotros de la pequeña y mediana empresa.

El éxito empresarial tiene mucho que ver con la capacidad de gestionar el desarrollo de la pequeña empresa, con la capacidad para gestionar y organizar el crecimiento. Por eso resulta de especial interés para el empresario y el directivo gallego los resultados obtenidos por Pierre-André Julien.

En su trabajo ${ }^{1}$ identifica los factores que determinan el éxito en la gestión del crecimiento de estas empresas. Se evaluaron cientos de variables que podían ser las claves para el éxito o fracaso de ese crecimiento acelerado. Se profundizó en la tecnología, la financiación, las operaciones, el marketing, la I+D.

¿La clave? La delegación. De entre ese gran cúmulo de factores destaca uno de modo especial: la capacidad de delegar, de "hacer hacer", que es el verdadero motor de la dirección de la empresa. Las mejores máquinas, el mejor equipo técnico, los mejores estudios de mercado, todo eso que podemos comprar en el mercado con dinero, pasa a un discreto segundo plano. Lo esencial es ser capaz de distinguir cuándo debo hacerlo yo y cuándo debo dejarlo en manos de mis colaboradores.

Los empresarios y directivos gallegos tenemos grandes virtudes: flexibilidad, entrega, tesón y una enorme capacidad de trabajo. Todas estas cualidades pueden resultar inútiles si nos aferramos al paradigma del "mais vale facelo que mandalo" que llevamos en nuestros genes.

El directivo que no delega limita el crecimiento de su empresa, condicionándolo a su propio saber hacer y a su capacidad personal. El que da el paso hacia la delegación invertirá mucho tiempo y energías en capacitar a su equipo.

1 Se trata del informe "La PME à forte croissance" dirigido por Pierre-André Julien, director del GREPME en Canadá y colaborador de la Escuela de Negocios Caixanova. 
Al principio es una tarea ardua, porque la primera vez se cumple el "mais vale facelo que mandalo", pero a la larga el esfuerzo de formación interna que supone la delegación multiplica las capacidades de los colaboradores y posibilita el crecimiento equilibrado de la empresa.

Desengañémonos, la mejor inversión es aprender a dirigir. A decidir, a organizar, a motivar, a delegar. A tratar personas y sacar de ellas el máximo rendimiento. No es fácil porque, a diferencia de las máquinas, nuestros colaboradores no tienen manual de instrucciones ni especificaciones técnicas. Requiere determinación, constancia y seguir el adecuado proceso de entrenamiento. Y mucha paciencia. No en vano a Moisés le costó mucho menos sacar a los israelitas de Egipto que sacar Egipto de la cabeza de los israelistas.

Hoy los trabajos más prestigiosos inciden en la importancia de la formación de los empresarios y directivos, y confirman lo acertado de la apuesta de Caixanova en 1987. Como vemos la mejor inversión es aprender a dirigir, y la mejor apuesta por el desarrollo económico, social y empresarial es crear una escuela de negocios con vocación de servicio a nuestra comunidad.

\section{La puesta en marcha del proyecto}

En esos años la Escuela amplia su cartera de productos y, sobre todo, va conformando un equipo de profesionales en su claustro que combina conocimiento de la empresa y orientación académica, y lo que no es menos importante, va nutriendo una red de colaboradores que permite contar con los mejores de España y combinar su aportación con el conocimiento de la realidad local de los profesores gallegos. En estos años el crecimiento de la actividad es exponencial y conforma las diferentes áreas de actividad que expondremos en detalle a continuación.

\section{Una escuela pionera en la formación de directivos}

La Escuela ha sido el primer centro de estas características en Galicia y desde entonces ha conseguido una sólida implantación como líder en la formación de empresarios y directivos. Cada año pasan por sus aulas más de 2.500 alumnos, y en estos momentos cerca de 30.000 directivos que desarrollan su labor en Galicia han pasado por alguno de los cursos de formación que se organizan a lo largo de todo el Eje Atlántico.

Esta misión muy concreta se ha volcado no sólo en la realización de cursos de directivos, tanto actuales como futuros, sino en el desarrollo de una importante línea de trabajo volcada en la investigación aplicada para proporcionar información útil para la toma de decisiones empresariales. Asimismo se ha desarrollado una importante labor de proximidad con el entorno empresarial a través de los servicios prestados a las empresas que buscan llevar a la práctica todo los conocimientos a través de modelos de trabajo de formación-acción. 
Se trata, como decíamos anteriormente, de trabajar en el desarrollo del Capital Intelectual, para con ello mejorar los modelos de gestión empresarial a través del conocimiento y de las personas.

Actualmente la Escuela de Negocios Caixanova desarrolla sus actividades en todo el ámbito gallego y en el norte de Portugal (Vigo, A Coruña, Ourense, Pontevedra, Ferrol, Lugo, Oporto), desde 1999 la Escuela une a su sede de Vigo una sede permanente en Ourense, en al año 2002 fue necesario ampliar las instalaciones en A Coruña y en 2004 se ha puesto en marcha una sede permanente en Lugo. De esta manera se ha conseguido una mayor presencia y conexión con el empresariado de toda la Comunidad Gallega y hacer extensiva a Portugal la experiencia docente desarrollada en España, contribuyendo de esta manera a incrementar los lazos entre dos regiones íntimamente conectadas por vínculos muy profundos como son Galicia y el Norte de Portugal.

\section{Las distintas áreas de actividad}

La actividad académica de la Escuela de Negocios Caixanova se desarrolla en tres grandes áreas de trabajo concretas: la formación de postgrado, la formación de grado y la formación para directivos.

\subsection{La formación de Postgrado}

En Octubre de 1987, la Escuela pone en marcha en Galicia, concretamente en su sede de Vigo, el primer MBA a tiempo completo en el cual participaron 30 alumnos procedentes de distintas carreras Universitarias. En 1990 se incorpora el Executive-MBA, un programa de formación en dirección general de empresas dirigido a Licenciados Universitarios, con una experiencia profesional superior a 3 años en puestos de responsabilidad. El ánimo de extender su actividad a todo el ámbito territorial de Galicia y ante la demanda de los profesionales de la zona norte se implanta un modelo en el Executive MBA que ha permitido que desde 1995 se imparta alternativamente cada año en las sedes de Vigo y A Coruña. Desde entonces ya han pasado 17 promociones por el MBA y 13 por el Executive MBA.

En septiembre de 2003 se ha dado un paso hacia delante en la expansión de la Escuela de Negocios Caixanova al poner en marcha simultáneamente la XVI promoción del MBA full time simultáneamente en Vigo y A Coruña, consiguiendo de esta manera dos grupos de jóvenes de alto potencial que en el futuro se configurarán como los líderes y directivos de las empresas de nuestra región, contribuyendo con ello de manera indirecta al desarrollo de nuestro tejido industrial y la mejora competitiva de las empresas.

Pero en este mundo volcado al mercado global, la Escuela de Negocios Caixanova afrontó en el año 2002 un paso adelante en el proceso de internacionalización de la actividad de la Escuela, ya que en el ánimo de convertirse en un centro de referencia en la formación de directivos en la eurorregión denominada 
Eje Atlántico, se pone en marcha en la ciudad portuguesa de Oporto la primera promoción del International Executive MBA. El año 2004 ha supuesto la consolidación de la actividad en Oporto con la puesta en marcha de la II promoción de este programa.

La actividad en los cursos de postgrado ve aumentada su presencia en la cartera de productos de la Escuela de Negocios, cuando a los masters en dirección general se les unen los masters de especialización. Así en 1994 se implanta un modelo que intenta acercar una formación de prestigio y muy especializada a los diferentes profesionales ya implantados en la empresa o aquellos que deseasen desarrollar su carrera profesional en un ámbito concreto de la empresa. De esta manera se ponen en marcha el Máster en Dirección Comercial y Marketing, el Máster en Dirección de Recursos Humanos y el Máster en Tributación y Sistema Fiscal. Estos cursos especializados han resultado ser todo un éxito lo cual ha animado a la Escuela a ampliar su oferta, enfocando su actividad hacía temas tan importantes como el comercio internacional, el asesoramiento jurídico, etc. Así nacen el Máster en Dirección y gestión de Negocios Internacionales, que quiere formar a profesionales que puedan afrontar con éxito los procesos de internacionalización de las empresas, y que se imparte hace cinco años y el Máster de Asesoría Jurídica que se encuentra en su cuarta edición.

En los dos últimos años la actividad de postgrado ha ido creciendo por dos vías de especialización muy concretas: la formación de profesionales para desarrollar sus labores de gestión en el tercer sector y la formación volcada a sectores concretos de gran peso en la economía gallega. Así en 2001 se pone en marcha el Máster en Dirección y gestión de Entidades no lucrativas en colaboración con la oficina autonómica de la Cruz Roja Española y en 2003 se han puesto en marcha dos programas dentro del área del Agribusiness, el Máster en Dirección de Empresas Agroalimentarias en colaboración con Coren (una de las empresas más importantes del sector, que en su actividad en Galicia genera directamente el $5 \%$ del PIB de Galicia) y el Máster en Innovación, Tecnología de la Producción y de la Gestión Acuícola en colaboración con el Clúster de la Acuicultura de Galicia, y el Máster en Asesoría financiera y de gestión de patrimonios, orientado a formar profesionales para el sector financiero. A estos programas hay que añadir muy recientemente el Máster en Dirección y Gestión de la Promoción Inmobiliaria que la Escuela de Negocios Caixanova realiza conjuntamente con APROIN (La Asociación de Promotores de Pontevedra).

\subsection{Formación de grado: $E l B B A$}

Continuando con su permanente política de innovación y ampliación de su oferta de programas, en 1994 la Escuela asumió uno de sus retos más relevantes: la puesta en marcha del Bachelor in Business Administration (BBA) una carrera Universitaria en Dirección y Administración de Empresas, cuyo titulo está oficialmente homologado por la Universidad de Gales, y que ha contribuído a consolidar una 
vez más la imagen pionera de la Escuela en el campo de la formación empresarial. Los alumnos que una vez finalizada su carrera universitaria en la Escuela lo han solicitado ante el Ministerio de Educación, han convalidado oficialmente en España su título al de Licenciado en Administración y Dirección de Empresas.

Se trata de una carrera universitaria de cuatro años de duración, en la que se trabaja para formar un jovén de alto potencial, familiarizado con los modelos de gestión empresarial, con un aprendizaje volcado a la experiencia real y con un especial énfasis en el desarrollo de sus habilidades directivas e informáticas; cuando finaliza sus estudios el perfil del alumno responde a un jóvenes con una formación práctica, basada en experiencias reales, con gran capacidad de trabajo y de integración en equipos, con un alto nivel de inglés.

\subsection{Formación de directivos}

El área de formación de directivos ha sido una pieza clave para materializar la conexión de la Escuela de Negocios Caixanova con el tejido empresarial de Galicia. Desde 1994 se han desarrollado multitud de iniciativas de formación, si bien otro importante evento lo constituyó el lanzamiento por el IGAPE (Instituto Gallego de Promoción Económica, organismo dependiente de la Consellería de Economía de la Xunta de Galicia), del plan PIMEGA (Plan Integral de Mejora de la Empresa Gallega), en cuya puesta en marcha la Escuela ha tenido una activa participación, formando a lo largo de tres años a más de 2000 pequeños empresarios, a través de cursos de formación impartidos en las más importantes ciudades de Galicia. Basados en un modelo de formación-acción se trataba que los directivos de la propia empresa asumieran un papel activo en el proceso de mejora de la organización a través de la formación y la tutoría.

En su preocupación por promover y desarrollar el espíritu emprendedor y por favorecer la creación de empresas, como motor del desarrollo económico, la Escuela ha colaborado con el IGAPE en el programa LANZA, tanto en su diseño como puesta en marcha, impartiendo cursos de formación con un enfoque muy práctico dirigidos a jóvenes emprendedores que partiendo de su idea de negocio debían elaborar su plan de empresa, contando para ello con el apoyo de un equipo de profesores-tutores que realizaban una labor de asesoramiento. Gracias a ello, y dado que por el programa Lanza han pasado más de 450 alumnos, la Escuela ha participado activamente en el desarrollo de proyectos de creación de empresa, impulsando así su misión de ayudar al desarrollo económico de Galicia.

La colaboración con instituciones empresariales ha marcado el crecimiento del área de formación de directivos; estos acuerdos han permitido el desarrollo del Programa en Dirección y Gestión de Empresas, programa que ha sido diseñado específicamente para aquellos profesionales que, partiendo de su experiencia actual quieren afrontar los retos del futuro desde una visión gerencial de la empresa y con una preparación adecuada que impulse sus respectivas carreras profesionales. Dado el éxito de esta oferta para directivos y profesionales del mundo de la empresa ha tenido en sus ediciones en Vigo desde hace más de cinco años, actualmente este mismo programa se imparte simultáneamente en Ferrol y próximamente en Lugo 
en colaboración con sus respectivas Cámaras de Comercio y también en Orense en colaboración con la Confederación de Empresarios de Orense.

Recientemente se ha materializado un acuerdo con la Confederación de Empresarios de A Coruña, que ha permitido la puesta en marcha de una iniciativa conjunta bajo la denominación del Centro de Desarrollo Directivo; este acuerdo permite a la Escuela de Negocios Caixanova aportar su experiencia docente y acercar su oferta formativa de prestigio a los empresarios de A Coruña.

Al año siguiente, en 1999, la Escuela de Negocios Caixanova decide incorporar a su catálogo de productos el PDGE (Programa en Dirección y Gestión de Empresas), un curso de formación de directivos dirigido a personas con experiencia empresarial. Su característica diferencial es su compatibilidad con el desempeño de una función directiva.

En respuesta a la petición expresa de empresas relacionadas con el sector tecnológico, la Escuela de Negocios Caixanova imparte el Programa en Dirección y Gestión de Empresas de las TIC'S, que se ha diseñado para aportar conocimientos de gestión empresarial a profesionales que desarrollan su labor profesional en el campo exclusivamente técnico y que necesitan completar su formación en el mundo de la empresa. También respondiendo a una demanda del mercado la Escuela de Negocios Caixanova ha especializado su oferta formativa, incorporando un Programa para dirección de Empresas Inmobiliarias a petición de la Asociación de Promotores Inmobiliarios de Pontevedra.

En el año 2002 se pone en marcha una nueva línea de cursos especializados de corta duración dirigidos a profesionales del mundo de la empresa que quieran profundizar en su área concreta de actividad. Nacen los Cursos Avanzados, que con una duración aproximada de tres meses, han permitido ampliar la oferta formativa hacia áreas como la gestión de personal, la dirección de ventas, el control de gestión y la dirección de operaciones.

En cuanto a la oferta puntual de seminarios, todos los años se incorporan a la línea de cursos de más corta duración los temas más novedosos para las empresas, tratando en todo momento de aportar al empresariado gallego las últimas novedades en el mundo del management y la dirección.

Otra actividad de referencia la constituye la formación in company, en la que se realizan cursos específicos, diseñados a la medida de las necesidades concretas de las empresas, siendo relevante el trabajo realizado para sectores como el mejillonero, el pesquero o el pizarrero, todos ellos de especial relevancia en la creación de riqueza de la economía gallega.

A toda esta amplia actividad para los directivos gallegos debemos sumar una iniciativa que ha gozado de gran éxito en los últimos años: la puesta en marcha del Programa de Alta Dirección, al que asisten los principales empresarios y directivos gallegos en sendas ediciones en Vigo y A Coruña. Se trata de cubrir las necesidades formativas al máximo nivel, conscientes de la importancia que tiene la actualización y la reflexión de la dirección general para la competitividad de las empresas. 


\subsection{La Escuela para las Administraciones Públicas}

Ya en 1998, comienza la colaboración con diversos centros hospitalarios de la Comunidad Autónoma, para la formación del personal hospitalario, convenios que continúan hoy vigentes, y que se han materializado en multitud de programas a medida por el que han pasado un número muy importante de alumnos. En el año 2002 se firma un acuerdo con la FEGAS (Organismo dependiente de la Consellería de Sanidade de la Xunta de Galicia), que ha permitido la realización del Programa en Dirección y Gestión de Servicios Sanitarios.

Esta colaboración con las instituciones públicas se ha concretado con la puesta en marcha de la Escuela para las Administraciones Públicas, una línea de negocio de la propia Escuela de Negocios y que quiere acercar a la Función pública el modelo de aprendizaje y gestión que desde sus aulas se transmite a las empresas. Su actividad se ha concretado en la realización del Programa en Dirección y Gestión de Entidades Públicas, dirigido a funcionarios con responsabilidades directivas. Además recientemente se ha puesto en marcha el Máster en Gestión y dirección de Administraciones Públicas, para formar jóvenes que quieran desarrollar su carrera profesional en la función pública.

\subsection{La actividad investigadora}

Además de la amplia actividad académica anteriormente descrita, la Escuela de Negocios Caixavigo ha venido desarrollando a lo largo de estos años proyectos y estudios de investigación aplicada de gran transcendencia que han convertido a la Escuela en un centro de referencia en el ámbito español en el campo de la pequeña y mediana empresa.

Entre ellos se pueden destacar la publicación en 1996 del Informe Estratégico de la Empresa Gallega que ha sido publicado también en Portugal, el Informe Económico-financiero de la empresa gallega y el monográfico sobre Competitividad de las PYMES encargado por la revista Alta Dirección. Otro proyecto de notable importancia ha sido la activa participación de la Escuela en la creación de la Base de Datos Ardan de la Zona Franca de Vigo que constituye una de las mayores bases de datos existentes en la actualidad sobre el tejido industrial español y portugués.

Estos estudios han constituido el pilar fundamental para llevar a cabo ambiciosos planes de diagnóstico y formación sectorial tales como los realizados para el sector pesquero, mejillonero, pizarra. Ligada a esta formación sectorial, la Escuela ha elaborado varios trabajos de investigación aplicada como el Diagnóstico Estratégico del Sector Mejillonero, o la definición de un sistema de garantías crediticias para el sector pesquero español.

Los estudios más recientes abarcan desde un estudio sobre la contribución del sector mejillonero al desarrollo local de Galicia, el diagnostico y plan estratégico del sector turístico en el Baixo Miño y Ferrolterra, el Diagnostico estratégico del polígono industrial de San Cibrao das Viñas en Orense, el plan de fomento de la actividad emprendedora en la mancomunidad de municipios del 
área intermunicipal de Vigo y más recientemente el plan estratégico de la denominación de origen Rias Baixas.

En estos momentos se están desarrollando diferentes proyectos que buscan tener una mayor conexión con nuestra realidad empresarial, e identificar el proceso de creación empresarial. Estos proyectos se concretan en la elaboración de los casos referentes de empresas gallegas de éxito y en la creación del Observatorio denominado "Atalaya del emprendedor", que trata de identificar las motivos de éxito y fracaso de las empresas de nueva creación. Recientemente la Escuela de Negocios Caixanova se ha integrado como entidad de apoyo de las empresas del Foro Neotec (creado por el Ministerio de Innovación) en su proceso de captación de capital riesgo para empresas de tecnología. Y en la actualidad, siguiendo la senda de los trabajos del vino o del mejillón, la Escuela de Negocios Caixanova está desarrollando el Plan Estratégico de las Actividades Náuticas de Galicia, el libro azul de las actividades náuticas en Galicia.

\subsection{El proceso de internacionalización}

En noviembre de 2001 y en colaboración con la Consellería de Emigración y la Agencia Española de Cooperación Internacional, se realizó el Programa de Formación-Acción Honduras 2002, que supuso la realización de dos actividades de formación en Tegucigalpa (Honduras). El programa incluía dos iniciativas de formación, una dirigida a empresarios y directivos, el Programa de mejora de la Competitivivad de las empresas (que se desarrolló en dos módulos, uno de modelos y herramientas para la mejora de la dirección y metodología para el diagnóstico global de la empresa y otro sobre el diseño de un plan director); la segunda iba dirigida a los emprendedores hondureños, en base al cual un total de 24 alumnos realizaron el Programa de capacitación de emprendedores, que ha finalizado el mes pasado con la presentación pública de los proyectos que habían desarrollado una vez finalizado el programa y que fueron tutelados desde España.

En un mundo en un cambio constante y rápido, sin precedentes en la historia, que paradójicamente se está haciendo cada vez más pequeño, no tendría sentido un modelo de Escuela volcada a su medio local. La apertura a un entorno global y más competitivos es la base de las Relaciones Internacionales que la Escuela mantiene con instituciones de gran prestigio, como la Universidad de Gales en el Reino Unido (que otorga el titulo oficial de la carrera universitaria que imparte la Escuela), la Universidad de Georgetown en Washintown, la Universidad de Berkeley en California y la Universidad de Millersville en Pennsylvania, en base al los cuales, alumnos de diferentes programas de la Escuela pueden realizar programas y ampliar su formación en cursos de estas prestigiosas universidades americanas.

La Escuela de Negocios Caixanova es miembro de la EFMD (European Foundation of Management Development), institución europea con base en Bruselas, que trata de promover y fijar los standards y valores de calidad, está reconocido como un centro de excelencia para el desarrollo y la formación de directivos en Europa. 
Estos avances en el área internacional han llevado a la escuela a desarrollar un programa pionero en Galicia de la mano de la Consellería de Emigración: el programa de formación de gestores internacionales. Se trata de lograr una red de expertos en Relaciones Internacionales en cada uno de los países vinculados a Galicia. Se seleccionan 20 jóvenes gallegos o descendientes de gallegos para que se formen de modo intensivo en negocios y empresa española de modo que vuelvan a sus países de origen para convertirse en red de las empresas gallegas en el exterior. Se trata de un modo más de contribuir a la mejora de la competitividad de las empresas gallegas a través de la formación.

\section{Los rasgos de una estrategia marcada por el compromiso}

Hasta aquí hemos narrado el proceso de puesta en marcha y consolidación de una iniciativa vinculada al desarrollo del Capital Humano en Galicia. Hemos relatado los hechos y los acontecimientos que la han hecho posible. Pero, probablemente, sería difícil entender en toda su dimensión la Escuela de Caixanova si no dedicamos los últimos párrafos a exponer las líneas directrices del proyecto, los ejes que definen el por qué del modelo de escuela por el que se ha optado. Lo hacemos a continuación.

\subsection{Escuelas de Negocios y Negocios de Escuela}

Una escuela de negocios que quiera cumplir su misión de contribuir al desarrollo del tejido empresarial de Galicia tiene que asumir que sólo vale el modelo de Escuela de Negocios, y que es imprescindible huir de la tentación de un modelo alternativo imposible de compatibilizar con la máxima calidad en un mercado estrecho como es el gallego. Gracias a pertenecer a la Obra Social de una Caja comprometida como Caixanova es posible desarrollar programas internacionales, con un claustro de primer nivel y que desarrolle metodologías y equipos de trabajo pensando en crear y difundir conocimiento sobre la empresa gallega en Galicia.

No es casualidad que las dos únicas instituciones que cuentan con los mejores másters fuera de Madrid y Barcelona sean dos instituciones de marcado carácter social. Deusto en el País Vasco y Caixanova en Galicia. Y no es casualidad el desarrollo empresarial y la cultura directiva en el País Vasco, tras decenios de funcionamiento de la Universidad de Deusto. Tampoco lo es, no lo duden, el despertar empresarial de Galicia y el éxito de muchas de sus empresas y sectores. Está, sin lugar a dudas, vinculado a la difusión de un modelo de profesionalización directiva del que está siendo un motor la Escuela de Negocios Caixanova.

\subsection{Formación para la acción: Un centro de entrenamiento de directivos}

Una cosa es saber y otra es hacer. Somos lo que somos por imitación, y por eso es tan importante elegir bien. Por eso es necesario distinguir entre un sexto de 
carrera y un MBA. Al hablar de formación es imprescindible tener muy claro que una cosa es saber y otra bien distinta es hacer, que una cosa es el conocimiento y otra bien distinta la acción. Se trata de adquirir las habilidades necesarias para hacer las cosas adecuadamente, para trascender la ciencia e internarse en los frondosos bosques de la prudencia.

Tal vez usted conozca a ese experto que lo sabe todo sobre el matrimonio: es catedrático de psicología, experto en las relaciones de pareja, máster en derecho matrimonial... Ese caballero se casó hace seis meses. Ayer se ha divorciado. Una cosa es la ciencia y otra la prudencia: una cosa el saber y otra bien distinta el hacer. La formación de todo directivo comienza por adquirir habilidades para la acción, y ello exige ser selectivos para escoger, de todo el vasto campo científico, aquellos conocimientos que nos permitirán construir un directivo orientado a la acción, con habilidades para hacer, para negociar, para exponer, para escuchar.

Sólo será realista una estrategia formativa que piense en el entrenamiento directivo, en el desarrollo de competencias y, por lo tanto, que no convierta el conocimiento en fin en si mismo, sino que trabaje por el logro de competencias directivas: el método del caso, el role playing, la formación fuera del aula, los proyectos y simulaciones son la clave para aprender haciendo. La clase magistral es, desde esta perspectiva, un elemento más.

\subsection{Una formación para cada etapa en la vida de un directivo}

Los tiempos han cambiado y ya no sirve eso de formarse una vez para toda la vida. En la vieja economía, en las sociedades industriales, la vida de cualquier persona se dividía en tres grandes etapas. Vivíamos una primera etapa, los primeros veinte años de vida, de formación, de captación de información y cultura para poder actuar y desenvolverse en la vida. Tras esa etapa de intensiva captación de conocimientos e información, se iniciaba una segunda, más larga, dedicada al ejercicio profesional y al trabajo: el logro y "ganarse la vida y progresar" son los dos aspectos que configuran el norte en esta segunda etapa. Tras ella, tarde o temprano, llegaba la tercera etapa: la de la añoranza, la del recuerdo "de los buenos tiempos", la de pasar a la retaguardia y ceder el protagonismo a las nuevas generaciones.

Bien entrado el siglo XXI ya no estamos en esa sociedad industrial y vivimos en la nueva Sociedad de la Información. El viejo concepto del trabajador manual ha cedido el protagonismo a los trabajadores del conocimiento. El empleo para toda la vida y el empleado "dependiente" de una compañía que lo afiliaba ha pasado a la historia. El nuevo entorno nos exige mantener la empleabilidad durante toda una vida.

Si esto es así para la gran mayoría de la población, formada por trabajadores del conocimiento, lo es en mayor medida para los directivos. Un directivo es el máximo exponente del trabajador del conocimiento y, por ello, la formación es a la vida del directivo lo que el albergue al peregrino. Debemos asumir la necesidad 
de gestionar con inteligencia nuestra carrera profesional añadiendo elementos que aporten valor para las compañías a las que servimos.

El desarrollo de programas y de metodologías empleado en la Escuela de Negocios Caixanova asume esta filosofía de la formación de directivos y reconoce tres grandes etapas (y por lo tanto tres tipos de actividades formativas):

1. “Del saber al hacer”. La época del MBA y los masters para jóvenes con escasa experiencia. Se trata de lograr gestionar cosas y gobernarse a uno mismo. Se trata de adquirir hábitos directivos saludables, de avanzar en el logro de las competencias directivas básicas y convertir en hechos las ideas, objetivos y proyectos.

2. "Del hacer al hacer hacer". La época del Executive $M B A$ y otros programas para directivos. Lo más difícil en la carrera profesional es pasar de ser un buen gestor a un buen director, de "hacerlo" a "lograr que otros lo hagan”. La metodología debe estar orientada a avanzar en la delegación, la comunicación, la gestión de conflictos... Mucho más que ciencia, sobre todo el ejercicio de la prudencia.

3. "Del hacer hacer al liderazgo estrategico, al dejar hacer". La étapa del Programa de Alta Dirección y otros programas para la gerencia de la empresa. Se trata de ir más allá de la pedagogía, moverse en el mundo de la "androgogía". Se trata de profundizar en el liderazgo, el coaching, la estrategia... Saber conciliar el proyecto de largo alcance con el cuidado de los detalles.

Entendiendo la formación como un largo camino con diferentes etapas y protagonistas se puede diseñar una cartera de programas que pueda, ofrecer el método adecuado para cada caso. El café para todos ha sido la causa del fracaso de muchas escuelas de formación de directivos. En Galicia no queremos caer en ese error.

\subsection{Una estrategia "glocalizada": La mejor escuela de negocios del mundo para Galicia}

Se trata de combinar lo más avanzado en el conocimiento sobre la empresa a nivel internacional con el dominio de la realidad local. La composición de un claustro con 300 profesionales de diferentes lugares posibilita acercar lo último en management, y los acuerdos de colaboración con Georgetown, Gales o Berkeley permiten un enfoque internacional aprovechando al máximo la globalización. Pero a su vez esa estrategia global se funde con el máximo compromiso a nivel local y el profundo conocimiento de la realidad empresarial de la eurorregión.

De este modo se puede desarrollar y difundir conocimiento al máximo nivel sobre los problemas y retos de nuestras empresas. Hay muchas escuelas de negocio en el mundo, pero la mejor de ellas difícilmente podrá competir con la Escuela de Negocios Caixanova en el diseño de un plan para la mejora de la competitividad del mejillón en Galicia, o para definir el plan director de las 
bodegas de vino de nuestro entorno, o para desarrollar formación para los emprendedores del rural en Galicia... Se trata de hacer realidad, mediante la "glocalización", el lema que inspira a la escuela: ser la mejor escuela de negocios del mundo para Galicia.

\subsection{Las clases son la consecuencia}

A lo largo del último curso académico se han impartido cerca de 14.000 horas de formación. Sin embargo una escuela de negocios que se limite a formar directivos no cumpliría su función social de dinamización empresarial. En la Escuela de Negocios Caixanova creemos que las clases que impartimos son la consecuencia, son la última fase de un proceso de creación y difusión de conocimiento sobre la realidad de nuestras empresas.

Es la última etapa. Primero hacemos con empresarios e instituciones, después sistematizamos y ordenamos ese conocimiento en forma de publicaciones, casos, informes, etc., y finalmente difundimos ese conocimiento de modo que sea útil en el proceso de aprendizaje de nuestros alumnos. Sólo así haremos valer la diferencia que supone el roce permanente y la integración de la actividad de la Escuela y sus alumnos con el tejido empresarial.

\subsection{Orientación al valor: Integración con las empresas e instituciones}

¿Cuáles son los parámetros que definen la calidad en un proyecto formativo de postgrado? Podríamos citar muchos (innovación en los métodos, aplicabilidad práctica, claustro docente, actualización en los contenidos...). Pero si no queremos desviarnos del valor para el cliente debemos poner en primer plano las posibilidades de integración de los alumnos en las empresas a través de prácticas y las posibilidades reales de promoción en las empresas de nuestro entorno. Este ha sido siempre un elemento clave en la estrategia de la escuela. El primer directivo de un importante grupo empresarial de nuestro entorno comentaba recientemente:

"Más de treinta de los directivos de primer nivel proceden de la Escuela de Negocios Caixanova. Antes trataba de encontrarlos a través de head hunters en Madrid y Barcelona y encontraba grandes dificultades para que se integrasen en el entorno de Galicia. Desde que confío en los directivos formados en Caixanova he resuelto el problema".

Sólo si se profundiza en ese valor para el cliente (para las empresas y los jóvenes que acuden a las aulas) podremos cerrar el círculo que lleva al desarrollo empresarial.

\subsection{Un modelo comprometido: Mucho más que acercar formación de primer nivel a Galicia, crear conocimiento desde y para Galicia}

Si observamos la estrategia seguida por muchas instituciones en diferentes puntos de España cuando han abordado la formación de directivos o de postgrado veremos que han tratado de "acercar" la formación impartida por instituciones de 
Madrid o Barcelona “a provincias". De este modo muchas entidades financieras, fundaciones o asociaciones empresariales se han convertido en distribuidoras de formación de escuelas nacionales o internacionales desarrollando programas concretos.

La apuesta de Caixanova trasciende este enfoque. Por supuesto que se ha acercado a cada ciudad de Galicia formación de primer nivel, contando con más de trescientos ponentes, pero lo que se ha creado es un claustro con más de cincuenta profesionales de Galicia que consultan empresas gallegas, que crean casos de nuestras empresas, que forman directivos y generan un know how que no es posible crear y difundir en Galicia sin esta apuesta.

Una cosa es la implicación y otra bien distinta el compromiso. El compromiso requiere asumir una estructura de recursos y personas, entender la apuesta como algo permanente en beneficio del conocimiento empresarial para nuestro entorno. Sirva el ejemplo del desayuno. Para comerse un buen desayuno de huevos con bacon es preciso el concurso de la gallina y de un pata negra. Pero el grado de vinculación de la gallina y del pata negra es bien distinto. La gallina estaba implicada y el cerdo pata negra estaba comprometido. Sirva esta anécdota para comprender el significado de esta estrategia comprometida en pro del Capital Humano.

\subsection{La apuesta por el Capital Humano: "Todos somos tripulación"}

Frank Maguire, importante ejecutivo de Federal Express nos explicaba hace tan sólo un año las claves del éxito de su empresa, y lo hacía a través de un símil náutico. Asegura que su empresa debe su éxito a que "todos somos tripulación: no hay pasajeros". Este factor en el que Maguire hace descansar el éxito de su compañía es un factor esencial para explicar el éxito de la Escuela de Negocios Caixanova. A él me gustaría añadir, para terminar, un rasgo que resulta esencial para dirigir y hacer avanzar cualquier organización de nuestro entorno. Lo saben muy bien las muchas PYMEs que hoy avanzan y compiten en mercados nacionales e internacionales desde Galicia: el énfasis en la acción.

David Starr-Jordan decía que "la sabiduría consistía en saber qué es lo que hay que hacer, la habilidad en saber cómo hacerlo y la virtud consiste en hacerlo". Contar con la información, poseer la tecnología o disponer del dinero ayuda, pero contar con una estrategia y hacerla efectiva por parte de todos es la clave.

Todos estos rasgos reflejan una filosofía, un modo de entender el cambio en la sociedad y en la empresa. Nada mejor para reflejarlo que mencionar un viejo proverbio chino:

Si tus planes son a un año, planta arroz.

Si tus planes son a varios años, planta un árbol.

Si tus planes son a un siglo, forma personas. 


\section{ANEXO 1. \\ Principales hitos en la historia de la Escuela de Negocios Caixanova}

Desde la creación de la Escuela de Negocios cabe destacar los siguientes hitos:

1987 - Se inicia el MBA (Máster in Business Administration), curso de postgrado con dedicación exclusiva.

1988 - Se crea el curso Top Management destinado a formar a Directores Generales de empresas gallegas.

1989 - Se implantan con carácter permanente los Cursos de Alta Dirección.

1990 - Introducción del Executive MBA (Programa MBA para directivos con experiencia) con dedicación parcial como programa de nivel equivalente al MBA para postgraduados con dedicación exclusiva.

1991 - Introducción de los Cursos Superiores de Especialización con un año de duración.

- Se crean las Divisiones de Investigación y Servicios a Empresas.

1992 - Incorporación del título DBA (Diploma in Business Administration), concebido como primer curso del MBA (se desdobla el MBA en dos cursos, ler curso o DBA para licenciados universitarios en general y $2^{\circ}$ curso o MBA para alumnos con título DBA, licenciados en Ciencias Empresariales o Ingenieros Industriales (rama de organización), homologado por la Universidad de Gales.

- Se crea la Asociación de Antiguos Alumnos.

1993 - Firma del convenio con IGAPE para la impartición del programa PIMEGA. Programa integral de mejora de la empresa gallega.

- Se inauguran las nuevas instalaciones de la Escuela de Negocios en Vigo.

1994 - Introducción del programa LANZA (formación de emprendedores) en colaboración con IGAPE.

- Incorporación del título BBA, Bachelor in Business Administration, título de la Universidad de Gales impartido por la Escuela de Negocios Caixanova.

- Se incorpora a la cartera de productos el Máster en Tributación y Sistema Fiscal.

1995 - Comienza el Máster en Dirección Comercial y Marketing y el Máster en Dirección de Recursos Humanos.

- Se inicia la impartición en A Coruña del programa Executive MBA.

- Se firma un convenio de colaboración con el Consejo General del Poder Judicial y la Xunta de Galicia para la formación continuada de Jueces y Magistrados. 
1996 - Introducción en A Coruña de los Cursos Superiores de Dirección.

- Se inicia el Máster en Tributación y Sistema Fiscal en Orense.

- Publicación del Número monográfico de la revista Alta Dirección sobre la COMPETITIVIDAD de las PYMES, cuya realización se encarga anualmente a las más prestigiosas Escuelas de Negocios de ámbito nacional.

- Publicación del "Informe Estratégico de la Empresa Gallega", encargado por la Zona Franca de Vigo, en el que se estudia la situación actual de la PYME gallega en cuanto al entorno, el negocio, la cultura, el soporte y los resultados.

- Participación en el Plan de Mejora de la Competitividad del Sector Mejillonero Gallego. Realizando acciones de formación, tutorización y diagnóstico.

1997 - Celebración $10^{\circ}$ Aniversario Creación Escuela de Negocios Caixanova.

- Firma del Convenio con el Fondo de Formación para colaborar en los programas de formación.

- Firma del Convenio con la Fundación Laboral de la Construcción para realizar acciones de formación con sus asociados.

- Se inicia el Máster en Dirección Comercial y Marketing en A Coruña.

1998 - Convenio de colaboración con el Servicio Galego de Saude para la formación en gestión hospitalaria del personal directivo de sus centros.

- Finaliza la primera promoción del Bachelor in Business Administration título de la Universidad de Gales, autorizado a impartirse en Galicia por la Xunta.

- Firma del Convenio con la Cámara de Comercio de Vigo para la creación de un "Programa de Dirección General de Empresas" dirigido a Directivos de empresa que teniendo una gran experiencia no posean titulación universitaria.

- Colaboración con la Mancomunidad del área intermunicipal de Vigo dentro de la iniciativa comunitaria (ADAPT) a través del proyecto PEGASO. Las líneas de actuación se basan en un Estudio y Diagnóstico de la situación actual de los Sistemas de Información empresariales proponiendo acciones de mejora y desarrollandos servicios de valor añadido.

- Creación de la web de la Escuela en la dirección http://www. enegocioscaixanova.edu.

- Traducción al portugués del Informe Estratégico de la Empresa Gallega elaborado por la Escuela en 1996. 
- Firma de un convenio de colaboración con el FROM para el estudio y el diseño de un sistema de financiación mediante aval para el sector pesquero a nivel nacional.

- Programa de ayuda a Caja España en la puesta en marcha de una titulación de grado superior en administración y finanzas.

1999 - Introducción del título PDGE (Programa de Dirección y Gestión de Empresas) para directivos con al menos dos años de experiencia. Dicho programa surge del convenio de colaboración firmado entre Caixavigo y las Cámaras de Comercio.

- Introducción del título Máster en Dirección y Gestión de Negocios Internacionales.

- Convenio de colaboración con Zona Franca de Vigo, Mancomunidad Intermunicipal de Vigo, Caixavigo a través de la Escuela, y Grupo R (Grupo Callego del Cable) para prestar servicios de alto valor añadido dentro de la Iniciativa de la Secretaría General de Comunicación denominada PISTA.

- Firma de un Convenio con la Xunta de Galicia y con la asociación de Ingenieros de Telecomunicaciones de Galicia para la realización de un Observatorio de la aplicación de las Tecnologías de la información en Galicia.

2000 - La Escuela de Negocios, abre una delegación permanente en Ourense.

- Se diseña el primer Máster en Asesoría Jurídica de Empresas, a celebrar en Ourense.

2001 - La Escuela de Negocios Caixanova, inaugura unas nuevas y modernas instalaciones en la ciudad de A Coruña.

- Se llega a un acuerdo con la Cruz Roja, para la colaboración académica en el I Máster en organizaciones no lucrativas, a impartir en A Coruña.

- Firma de un convenio de colaboración con la Fundación R para la puesta en marcha del primer Programa en Dirección de Empresas del Sector de las Telecomunicaciones, a celebrar en A Coruña.

- Acuerdo de colaboración con la Asociación de Empresarios del Polígono del Tambre (Santiago de Compostela) para impulsar el "Curso Avanzado en Dirección de Ventas", dirigido a directivos con experiencia en la función.

- Se desarrolla un ambiciosa planificación de seminarios para directivos, que abarca todos los temas de actualidad.

- Se firma un acuerdo de colaboración con SAPROGAL para desarrollar un ambicioso programa de formación a empleados, clientes y proveedores. 
2002 - Inauguración nuevas instalaciones en A Coruña.

- Presentación Escuela de Negocios en Oporto.

- Programa en Dirección de Empresas acuícolas con el clúster acuicultura.

- Homologación oficial de los títulos BBA de la $2^{\circ}$ y $3^{\mathrm{a}}$ promoción por los de Licenciado en Administración y Dirección de Empresas.

- Puesta en marcha de Programa Agropecuario en colaboración con Saprogal para España y Portugal.

- Publicación de los primeros libros de la colección de la Escuela de Negocios Caixanova.

- Diagnóstico y Diseño del Plan Estratégico del Polígono de San Cibrao de Viñas (Orense).

- Diagnóstico Estratégico: Denominación de Origen Rías Baixas.

- Diagnóstico Estratégico: Sector turístico en Valmiñor y Ferrolterra.

- Programa Superior en Gestión de Patrimonios.

- Curso Avanzado de e-business en colaboración con la Fundación R y la Consellería de Industria.

2003 - Firma del convenio de colaboración con la Confederación de Empresarios de A Coruña, para la puesta en marcha del Centro de Desarrollo Directivo una iniciativa conjunta de ambas instituciones para facilitar la actividad docente dirigida a empresarios y directivos en la ciudad de A Coruña.

- Impartición del programa de formación in-company para el equipo directivo de Saprogal procedente de toda España.

- Ampliación de la cartera de Cursos Avanzados para directivos. Se ponen en marcha en Vigo el C.A. de Dirección de Operaciones y el C.A. de Control de Gestión. El C.A. de Ventas se imparte en A Coruña.

- Firma del convenio de colaboración con la Asociación de Promotores Inmobiliarios de Pontevedra: se ponen en marcha el Programa en Dirección y Gestión de Empresas Inmobiliarias.

- Presentación del Proyecto de Investigación elaborado para la Denominación de Origen de los Vinos Rias Baixas sobre el diagnostico y diseño de I Plan Estratégico del Sector.

- Firma del Convenio de Colaboración con la Universidad de Berkeley.

- Primera promoción del International Business Programme de la Universidad de Georgetown. Firma del convenio de colaboración.

- Publicación de los números tres, cuatro y cinco de la colección de la Escuela de Negocios Caixanova. 
- Presentación pública del proyecto de diagnostico y diseño estratégico del Polígono Industrial de San Cibrao das Viñas en Ourense.

- Realización del seminario de la sucesión de la empresa familiar en el novedoso formato de obra de teatro.

- Se pone en marcha en A Coruña el MBA a tiempo completo, impartiéndose la XVI promoción de este programa simultáneamente en las ciudades de Vigo y Coruña.

2004 - Firma del convenio de colaboración con Consellería de Deporte para le ejecución del Plan Estratégico de las Actividades Náuticas de Galicia.

- Puesta en Marcha del Programa de Alta Dirección.

- Convenio con la Universidad americana de Millersville para intercambio de estudiantes en los programas de Negocios Internacionales.

- El grupo Recoletos (Expansión) sitúa el MBA entre los diez mejores de España de entre más de 30 programas. Sólo Galicia (Caixanova) y el País Vasco (Deusto) cuentan con un programa entre los diez mejores fuera de Madrid y Barcelona.

- El grupo Vocento premia a la Escuela de Negocios Caixanova como la mejor Obra Social Educativa de España.

- Se presenta la nueva sede de Ourense (en el Centro Social) y la nueva sede en Lugo.

- El remodelado Pazo de San Roque se convierte en sede de los Programas para la Alta Dirección en Vigo. 



\section{ANEXO 2. \\ Información general de la Escuela de Negocios Caixanova}

\section{DATOS DE INTERÉS}

Profesores Totales: 280 .

Profesores Visitantes: 240.

Profesores Propios: 40.

Sexo Alumnos: 40\% Mujeres, 60\% Hombres.

Biblioteca: 13000 ejemplares.

Localidades con Sede: Vigo, Ourense, A Coruña y Oporto.

$\mathrm{N}^{\mathrm{o}}$ Alumnos/a: 2500 (cada año).

$\mathrm{N}^{\mathrm{o}}$ Medio de alumnos por promoción: 25 .

Estatuto Jurídico: Obra Social Caixanova.

\section{DESGLOSE DE LA ACTIVIDAD}

Porcentaje de horas lectivas por tipo de alumno:

Directivos y profesionales: $50 \%$.

Estudiantes de Postgrado: $30 \%$.

Estudiantes de grado: $20 \%$.

Distribución Número de Alumnos:

$\%$ Alumnos con experiencia: $89 \%$.

$\%$ Alumnos sin experiencia: $11 \%$.

\% Alumnos Extranjeros: 3\% (México, Venezuela, Colombia, Portugal, Inglaterra).

\section{SERVICIOS GENERALES}

- Bolsa de Trabajo (accesible por Internet para Antiguos Alumnos: www.directivos-online.com).

- Biblioteca.

- Acceso a Bases de Datos Empresariales e Internet.

- Aulas de Informática para desarrollo de proyectos (acceso a Internet).

- Asociación de Antiguos Alumnos (1200 Asociados de Galicia y Norte de Portugal).

- Seminarios y Conferencias de Actualización. 


\section{METODOLOGÍA DE ENSEÑANZA PROGRAMAS MÁSTER}

Sesiones de Integración:

La primera semana de los programas se dedica por entero a la potenciación del conocimiento entre los asistentes para garantizar una atmósfera de confianza e integración de todos los componentes de la promoción.

\section{Clases Participativas:}

En la Escuela el alumno abandona el papel de oyente y se incorpora activamente en el desarrollo de las clases a través de intervenciones personales, exposiciones y debates en grupo.

Resolución de Casos Prácticos:

El alumno pone en práctica los conocimientos que va adquiriendo en las distintas áreas a través de la resolución de casos que reflejan situaciones reales vividas por empresas. Los casos se resuelven en equipo y permiten desarrollar la capacidad de análisis y la agilidad para tomar decisiones.

\section{Trabajo en Equipo:}

Mediante la participación en equipos de trabajo el alumno enriquece sus conocimientos con las aportaciones de los demás integrantes del grupo, desarrolla su habilidad comunicativa y su capacidad de persuasión.

\section{Visitas y Conferencias:}

La experiencia adquirida mediante visitas y conferencias de personalidades del mundo empresarial acercan al alumno a la realidad del tejido económico dónde desarrollará su carrera profesional.

\section{Documentación:}

El estudio de los contenidos está reforzado por una extensa documentación que permite que el alumno se concentre adecuadamente durante las sesiones sin necesidad de tomar apuntes.

Proyectos:

La realización de un proyecto al final de los programas constituye un pilar clave para poner en práctica los conocimientos adquiridos.

\section{Outdoor Training:}

Se trata de fomentar competencias como la gestión de conflictos, la comunicación, la superación de retos o la convivencia a través de actividades al aire libre, fuera del aula, como la extinción de incendios, la simulación de accidentes o la práctica de actividades deportivas o de contacto con la naturaleza.

Simulación Empresarial:

En casi todos los programas de postgrado se lleva a cabo un Juego Informático que simula una situación competitiva en un mercado real para ejercitarse en la toma de decisiones. 


\section{Seguimiento:}

El limitado tamaño de cada promoción hace que el trato personalizado y el seguimiento de la evolución del alumno sean dos constantes a lo largo del curso.

\section{ASOCIACIÓN DE ANTIGUOS ALUMNOS}

La Asociación de Antiguos Alumnos fue creada a principios de 1992 con el objeto de promover el desarrollo de actividades para la formación integral y permanente de empresarios y directivos de empresa. Cada tres meses, se publica una revista con una tirada de 7.500 ejemplares y anualmente el Libro de Asociados (www.enegocioscaixanova.edu/aaa). 



\section{Análisis de experiencias concretas}

Antonio Grandío Dopico

Catedrático de Economía Aplicada

Universidad de A Coruña 



\section{A modo de prólogo}

Este capítulo no va a hacer referencia a lo que hoy está tan de moda en el mundo de los mercados financieros, particularmente en la Bolsa, en relación con el gobierno corporativo. Me ha parecido mucho más interesante hablar de experiencias personales que tienen mucho que ver con una gran parte de mi vida profesional. Para llegar a esta conclusión ,tomé las referencias que se detallan a continuación.

En primer lugar, revisé un viejo libro, titulado Mundos lonxanos e próximos, que tuve el honor que me prologase el Presidente Fraga, en donde allá por el año 95 escribí lo siguiente: "Hay que potenciar el Wetware". Paul Krugman, Profesor de la Universidad de Stanford, con motivo de un seminario organizado por la revista Expansión el 23 de Febrero de 1995, lanzó el guante al resto de los participantes en el encuentro y dijo: "la ventaja competitiva en el mundo moderno no está unida a los recursos materiales; sino que depende de los intelectuales y, en particular, de la creatividad".

El "wetware" puede definirse como las cosas que la gente sabe, pero que no puede transferir a los ordenadores. Es la auténtica ventaja competitiva.

Creo que lo anterior suena mucho a lo que hoy está de moda en todos los foros, es decir, innovación, desarrollo e investigación.

Además, recordé experiencias que, debo confesar, han sido una gran parte de mi libro de cabecera. Las empresas a las que se va a hacer referencia, como ejemplo de buen gobierno, son las siguientes: Banco Pastor, Constructora San José y Supermercados Claudio. No significa lo anterior que, en Galicia, no pudiésemos -con la perspectiva de hoy- poner ejemplos iguales o mejores. La razón de no hablar de Inditex, Azkar, Fadesa, Caixa Galicia y alguna otra es, entre otras, porque desconozco como se ha gestado el proceso interno que las ha transformado en empresas admiradas, por sus datos fundamentales y por su buen gobierno.

Con esta reflexión quiero lanzar un primer mensaje: todos sabemos que las nuevas tecnologías permiten acceder a todo tipo de información. El verdadero proceso de creación de valor y de buen gobierno es seleccionar y aplicar los conocimientos que son diferenciales. Por decirlo en lenguaje más sencillo: todo el mundo habla de Inditex y de Fadesa pero sólo sus directivos han sabido hacerlo.

\section{Gobierno de la empresa}

En un brillante artículo (El País 12/09/2004) Josehp E. Stiglitz resumía el concepto de responsabilidad de un jefe:

"Aun cuando un jefe ejecutivo no puede saberlo todo, sigue siendo el responsable máximo de lo que ocurre en la empresa que dirige. El o ella escoge a sus subordinados, y es su responsabilidad plantear las cuestiones difíciles sobre que está ocurriendo bajo su vigilancia. más importante es su responsabilidad de crear un clima que fomente o desaliente cierto tipo de actividades. Dicho sencillamente, tiene que tener la responsabilidad de ser un verdadero líder". 
Como todo el mundo sabe, los líderes, a los que la sociedad actual afortunadamente reconoce sus méritos, tienen una misión muy difícil: dirigir.

Mi amigo Enrique Sáez, flamante presidente de la Fundación Juana de Vega y, hasta hace muy poco, Director General del Banco Pastor, lo resumía en la revista ECO (1995) en tres sencillas reglas, fáciles de enunciar y muy difíciles de implementar. Dirigir, en la opinión de Enrique, exige lo siguiente:

- Dejar claro lo que se espera de cada uno. Uno de los problemas más frecuentes, sobre todo en las empresas de dimensión media o grande, es que las personas, empezando por todos o algunos de los directivos, no tienen muchas veces conciencia precisa de lo que se espera de ellas. Cuando esto ocurre, la ambigüedad se resuelve por cada uno como puede, por lo que sería una milagro que el conjunto alcanzara sus objetivos de forma satisfactoria.

- Controlar. Palabra mágica en toda organización. Es más que el resultado de leer muchos números y sacar consecuencias. Los números son importantes, tanto los que se derivan de la contabilidad -general y de costescomo los que recogen evoluciones de las distintas variables, que permiten analizar el posicionamiento de la empresa en el mercado. Pero controlar es un proceso continuo de retroalimentación sobre el nivel de compresión, aceptación y efectividad de las directrices. Exige hablar y escuchar a diferentes personas, crear circuitos de información informal y abrir el abanico de perspectivas, para evitar una visión limitada de la situación o de los problemas de la empresa. Todo esto lleva tiempo y muchas veces es incómodo, pero resulta imprescindible para lograr una organización eficaz y flexible.

- Colocar a cada uno en el lugar adecuado. Lo más difícil de dirigir es valorar a las personas y conseguir que den lo mejor de sí en su trabajo. Se trata de saber elegir a los mejores para las tareas de más responsabilidad, independientemente de su edad, sexo, raza o cualquier otra consideración. Acertar en esta tarea es decisivo para el éxito.

Creo oportuno, ahora, introducir, de manera resumida, los cambios que se han producido en nuestro sistema de gobierno de la empresa y en los Consejos de Administración. Santiago Eguidazu, con el que tengo el honor de colaborar en un proyecto, de la mano de la Corporación Caixa Galicia, que, espero, redunde en satisfacciones para los gallegos y propicie la integración laboral de jóvenes, explica con precisión los determinantes del cambio:

- Transformación de la estructura de la propiedad, por fuerzas que operan tanto desde el lado de la oferta como de la demanda (OPV'S en Bolsa de empresas públicas, proceso de desconcentración de la propiedad con la salida a bolsa de empresas familiares y, desde el lado de la demanda, la cada vez mayor presencia de inversores institucionales y fondos de capital-riesgo). 
- Abandono por la Banca y Cajas de Ahorro del modelo tradicional de inversión en empresas y evolución hacia uno nuevo en donde la presencia bancaria en la industria y servicios tenderá a concentrarse en menos y más grandes empresas (nucleopolio). Hay muchos y buenos ejemplos.

- La tercera fuerza que alienta el cambio en nuestro sistema de gobierno es la globalización y la integración de España en la zona euro.

Eguidazu concluye, en un magnífico libro titulado Creación de valor y gobierno de la empresa en España (1999) que, "en este proceso cada uno desempeñará su papel, pero hay tres instituciones que tendrán la gran responsabilidad: autoridades que deben contribuir a que los mercados funcionen; la de los inversores institucionales, que deben presionar a los equipos directivos de las empresas para tener consejos independientes, eliminar medidas de defensa y establecer sistemas de remuneración que alineen sus intereses con los del accionista; y la de las grandes empresas que deben realizar un "efecto demostración" sobre el resto a través de la adopción de un sistema de gobierno moderno y eficiente".

Es recomendable, a este respecto, la lectura de la Memoria de Responsabilidad Social Corporativa del Grupo Santander. Es bueno, también, seguir los pasos de José $\mathrm{M}^{\mathrm{a}}$ Castellanos ${ }^{1}$ y los datos de Inditex. La decisión de financiar, junto a otras grandes empresas españolas, las investigaciones de Valentín Fuster en el nuevo Centro de Investigaciones Cardiovasculares, honra a quien lo hace y les prestigia a todos. Por encima de todo, genera tranquilidad.

Por razones de espacio y del título de este capítulo, no voy a extenderme más en realizar consideraciones sobre las grandes empresas, cuya información - por lo demás- la tenéis en los informes anuales y en la Comisión Nacional del Mercado de Valores. D. Blas Calzada, presente en este acto, ha sido el motor de la puesta en escena de esta magnífica información.

Quiero, en este momento, efectuar una reflexión sobre la necesidad del buen gobierno en las empresas de menor dimensión que, como todos sabéis, son claves para el desarrollo presente y futuro de Galicia. El buen gobierno es fundamental para superar las etapas en el ciclo de adecuación entre estructura y estrategia en la empresa familiar. Miguel Angel Gallo, ilustre profesor del IESE, que ha sido el gran innovador en todos estos estudios, diferencia las siguientes etapas:

- Periodo fundacional.

- Periodo inicial de sucesión.

- Periodo de desarrollo adecuado de la empresa.

- Periodo de retroceso.

- Periodo de crisis estructural.

Sin entrar en mucho detalle en los puntos anteriores, es obvio que los directivos y los propietarios, con sentido de futuro, dan soluciones diferenciales, que son las que marcan la distancia entre el éxito y el fracaso empresarial, de las etapas que define el profesor Gallo.

$\overline{1}$ Hasta hace días vicepresidente y consejero delegado de Inditex. 
No quiero finalizar este apartado sin enumerar las características que, según Spencer Stuart, deben reunir los consejeros independientes:

- Tener prestigio profesional comparable al de la compañía.

- No haber tenido relación profesional o comercial con la compañía durante los últimos años.

- No tener relación familiar, de amistad o de recepción de donaciones con ejecutivos o accionistas significativos.

- No ser miembro del consejo de administración de una compañía donde lo es también uno de los consejeros ejecutivos de la incumbente (consejeros cruzados).

- El nombramiento debe ser realizado a propuesta de la comisión de nombramientos, tras seguir un proceso de selección.

- Debe existir un límite de reelección como consejero independiente de la compañia.

- No debe representar a un accionista significativo.

- Debe tener disponibilidad razonable de tiempo para dedicar al consejo (acorde con la retribución a recibir).

- Cualquier otro criterio que pueda tener el propio consejo.

Respeto a la remuneración a percibir:

- Que para el consejero no signifique una parte sustancial de sus ingresos totales (que sea moderada).

- No debe recibir remuneración adicional, aparte de sus emolumentos como consejero, ni participar en beneficios extrasalariales propios de empleados (seguros médicos, planes de pensiones).

Muchas de las empresas gallegas, que hoy lideran el ranking de rentabilidad y buen gobierno aplican todas, o gran parte, de los enunciados que he mencionado en este epígrafe.

\section{Ejemplo de estrategias bien concebidas}

Galicia tiene, en el momento actual, empresas muy importantes y líderes empresariales que han roto, en palabras afortunadas de José Luis Méndez, la frontera del lacón y del grelo. En epígrafes anteriores mencioné la prudencia, que no siempre he tenido yo, de no hablar de memoria, sin el preceptivo contraste de datos de las empresas y de los empresarios. Por la razón anterior, voy a hacer referencia a tres situaciones, que conozco de cerca, porque o bien he sido empleado o bien he sido consejero. Antes de comenzar la enumeración, a la que he hecho referencia en el punto anterior, quiero rendir mi particular tributo de admiración a los 200 líderes que han hecho posible una Galicia más moderna, de los que no voy a narrar nada porque el profesor González Laxe, el profesor Cabanelas Omil y un servidor, con el apoyo de jóvenes becarios, hemos relatado en el libro Líderes empresariales gallegos. 
Los casos a los que he hecho referencia en la introducción son los siguientes:

\section{- Banco Pastor}

Esta empresa centenaria, con una historia preciosa que todos deberían conocer, recibe en los últimos treinta años el impulso de la más fiel y leal albacea testamentaria que ha tenido Galicia hasta el momento actual. Es ilustrativo, entre cientos de documentos que guardo como oro en paño, de su forma de hacer y de pensar las palabras que pronunció, en 1990, cuando el Instituto de Empresa y la Fundación Ortega y Gasset le otorgaron el V Premio Juan Lladó. En una tarde-noche calurosa de Madrid, Doña Carmela Arias, Condesa de Fenosa, dijo lo siguiente:

"Muchas gracias al Instituto de Empresa y a la Fundación Ortega y Gasset y a todos los componentes del Jurado por pensar que éramos merecedores de este importante premio.

Digo éramos, porque sé, porque tengo la certeza, que al otorgarme esta distinción pensabais en él, en Pedro Barrié de La Maza, que también supo promover simultáneamente empresa y cultura y que como Juan Lladó, fue su viva preocupación.

Mi única tarea -y la de la Fundación que me honro en presidir- es, seguir su camino, seguir sus huellas. Esas huellas que tan profundamente dejó grabadas a su paso por su tierra. Galicia, ese rincón de España, -ese, para él y para mí maravilloso rincón de España- a quién entregó junto con su trabajo, su talento, su esperanza, todo cuánto poseía y por eso creó la Fundación que lleva su nombre".

Sobran comentarios, pero Doña Carmela es mucho más:

- Una prueba de su coherencia personal es la decisión que tomó, el 11 de Diciembre de 1981, al donar la práctica totalidad de su fortuna, excepto las casas de su familia, al patrimonio de la Fundación.

- Fiel reflejo de su capacidad de mando es la labor desarrollada, desde 1971, al frente de Banco Pastor y de la Fundación. No hay que olvidar la profunda transformación que impulsó ni, tampoco, que fue la abanderada de las mujeres ejecutivas en nuestra sociedad.

- Es síntoma inequívoco de su generosidad la decisión de realizar una ampliación de capital, en 1973, con renuncia a los derechos de suscripción, por 300 millones de pesetas, destinada a los empleados de Banco Pastor. Poco después, con la salida a Bolsa del mencionado banco, el personal logró importantes plusvalías (en la proporción de 1 a 9). Como se puede comprobar, la historia tiene una génesis y la primera vez que esto se hace en Galicia lo hizo Doña Carmela. En definitiva, el Banco Pastor y su Presidenta ha dado oportunidades a quien no las tenía y eso una sociedad justa tiene que agradecerlo. Yo también lo agradezco. 
- Finalment,e es exacto reflejo de su capacidad de trasmitir enseñanzas la carrera que impulsó para un gestor ejemplar, José María Arias, que tiene todas las virtudes que posee su padre, Don Joaquín y que le fue transfiriendo Doña Carmela. De lo que afirmo son ejemplos ilustrativos las calificaciones de las agencias de rating, los resultados del Banco Pastor y la cotización en Bolsa.

\section{- Supermercados Claudio}

El mundo de la distribución en Galicia, no puede entenderse sin la aportación de los hermanos San Martín. El malogrado Claudio, cuya vida segó - en su mejor momento - un comando criminal, Miguel Angel hoy al frente de numerosas iniciativas empresariales, y el equilibro personal y religioso de José Antonio, sacerdote salesiano. Supermercados Claudio estaba considerado, por los expertos, como la joya de corona de las empresas de la distribución en España. Prueba inequívoca de lo que afirmo es el valor en venta de la empresa a un grupo gallego.

Pero, hay algo más:

- Claudio y Miguel Angel propiciaron, junto con otros empresarios, un proceso de renovación comercial sin precedentes. Superco, en Cuatro Caminos fue su primer buque insignia. Hoy hay muchos más y, en el futuro, habrá más bajo la presidencia de otro empresario excepcional José Souto que sigue la labor desarrollada por Miguel.

- Claudio fue decisivo, con la ayuda en el puente de mando ejecutivo de José Luis Méndez abuelo, como él gusta ser llamado, en la creación del líder del mundo financiero gallego: Caixa Galicia.

- Desde la perspectiva empresarial la familia San Martín tiene otros atributos:

- Exquisito trato con los trabajadores.

- Innovación permanente, de los que son ejemplo los MegaClaudio pioneros en Galicia, hoy mimetizados por muchos.

- Desde la perspectiva del buen gobierno de una empresa, con la ayuda inestimable del profesor Luis Rivas, pusieron en marcha el primer protocolo en una empresa gallega. Quiero afirmar que, con su permiso, en el libro del Presidente Laxe, Cabanelas y mío, su índice está enunciado íntegramente.

- Escuela de directivos y clima laboral perfecto.

\section{- Grupo San José}

No me cuesta trabajo afirmar, sin rubor, que mi larga relación con Jacinto Rey y Manuel Estévez, con el que sigo compartiendo sueños, así como su generosidad, me permitieron tomar la decisión de reconsiderar mi trabajo profesional y alejarme ocho años del mundo financiero. 
He de reconocer que esa casa, en los últimos 80 y primeros 90 , fue un auténtico laboratorio de experiencias y cosas bien hechas. Fue, igualmente, un trampolín de acceso para muchos, a un mundo financiero que hoy comandan los nucleopolios.

Hace ya años, un día de cine, yo dejé de ser consejero de la holding. Desde hace seis años, no estoy al tanto del día a día. Lo que sí puedo afirmar es que en diez años constructivos, en viajes en barco, en consejos excelentes, descubrí algunas de las claves que hicieron posible el éxito de esta empresa. Estas claves son, a mi entender, las siguientes:

- Generosidad con la familia de los fundadores.

- Incorporación, como accionistas, de personas del mundo de la emigración que dieron solidez financiera al proyecto.

- La decisión de constituir Udra y diversificar.

- Un método de remuneración pionero, en aquellos momentos, en Galicia: Sueldo, Incentivos y Dividendos.

- La regionalización, mimética del Banco Popular, de sus actividades.

- La proactividad en la consecución de nuevas metas, de la que es un ejemplo la Universidad de A Coruña.

- La eficacia en la ejecución de obras.

- La vinculación con nuevos espacios geográficos (Argentina, Méjico, Estados Unidos, et.)

Creo que los ejemplos son suficientemente ilustrativos de algo que se llama Buen Gobierno. Me dicen amigos de Harvard, de la London, del Insead, que hoy existen en Galicia otros ejemplos. Estoy absolutamente de acuerdo. Inditex, Fadesa, Azkar y otros muchos, cuya cocina desconozco, estoy seguro que no van a la zaga de lo que yo he mencionado.

\section{Un posible método de análisis y alguna consideración final}

Creo obligado concluir, porque a estas alturas algunos se preguntarán por la forma de analizar el buen gobierno, con unas consideraciones del profesor Cabanelas Omil, excelente amigo y mejor profesional. Existen seis pruebas críticas, sistematiza Cabanelas, que miden los resultados en las empresas:

- La prueba del mercado.

- La prueba de la innovación.

- La prueba de la productividad.

- La prueba de la liquidez.

- La prueba de la rentabilidad.

- La prueba de creación de valor.

Podemos convenir todos, sin exagerar, que la clave del buen gobierno se deriva del resultado de estas pruebas. 






